\title{
Die Muschelvergiftung als biologisches Problem auf Grund der neueren diesbezüglichen Ursachenforschung.
}

\author{
Von Ladislaus v. Haranghy, Klausenburg (Ungarn). ${ }^{1}$ ) \\ Mit 41 Abbildungen in Text.
}

Aus der Biolog. Anstalt auf Helgoland und der Zweigstation des Kgl. Uingar. Staatlichen Hygienischen Institutes zu Baja (Ungarn).

\section{Inhalt.}

A. Frühere Untersuchungen.

1. Miesmuschelvergiftungen . . . . . . . . . . . . . . . . . . . . . . . . . . . 280

2. Durch Austern und andere Muscheln verursachte Vergiftungen. . . . . . . . . . . . . 281

3. Vorkommen des Muschelgiftes in Krebsen und Seesternen . . . . . . . . . . . . . . . 281

4. Chemische Eigenschaften und toxikologische Wirkung des Muschelgiftes . . . . . . . . . . . . . . 282

5. Hypothesen über die Muschelvergiftung . . . . . . . . . . . . . . . . . . . . . . . 285

B. Eigene Beobachtungen über Muscheln der Deutschen Bucht.

1. Allgemeine Bemerhungen über den Fundort der giftigen Muscheln . . . . . . . . . . . 292

2. Untersuchungen über Giftwirkung der gesammelten Muscheln . . . . . . . . . . . . . . . . . . . . . 29

3. Untersuchungen der Giftwirkung des Carcinus und Asterias . . . . . . . . . . . . . . . . . 30 s

4. Äußere Eigenschaften der gesammelten Muscheln . . . . . . . . . . . . . . . . . 309

5. Erscheinungen an der Innenfläche der Muschelschalen . . . .. . . . . . . . . . . . . . . 316

6. Eigenschaften und histologisches Bild der Weichteile . . . . . . . . . . . . . . . . . . . 318

7. Deutung der äußeren Eigenschaften . . . . . . . . . . . . . . . . . . . . . . . 321

8. Deutung der Erscheinungen an der Innenfläche der Muschelschalen . . . . . . . . . . . 325

C. Versuche über die Sedimentation von Muscheln.

1. Bedeutung der Versuche in Rahmen des Problems . . . . . . . . . . . . . . . . . 328

2. Die Methodil . . . . . . . . . . . . . . . . . . . . . . . . . . . . . . 338

3. Die Ergebnisse von Versuchen mit Normaltieren . . . . . . . . . . . . . . . . . . . 330

4. Die Ergebnisse von Versuchen mit mangelhaft entwickelten Tieren . . . . . . . . . . . . . . . . . . 339

D. Versuche zum Hervorrufen des Giftigwerdens der Muscheln . . . . . . . . . . . . . . . 343

E. Beziehungen zwischen dem Giftigwerden der Muscheln und den Verhältnissen des Lebensraumes 347

Zusammenfassung . . . . . . . . . . . . . . . . . . . . . . . . . . . . . . . . . 350

Schriftenverzeichnis . . . . . . . . . . . . . . . . . . . . . . . . . . . . 351

\section{A. Frühere Untersuchungen.}

Es ist seit langem bekannt, dass der Genuß von Muscheln mitunter schädliche Folgen nach sich ziehen kann und besonders die Miesmuschel schwere Vergiftungen auszulösen vermag. Aber man konnte über die Muschelvergiftung lange Zeit kein klares

1) Diese Arbeit wurde mit Unterstützung des im Rahmen des dentsch-ungarischen Kulturabkommens erworbenen Humboldt-Stjpendiums durchgeführt. Die Untersuchnngen wurden durch die weitgehende Unterstïtzung und die wertrollen Ratschläge von Prof. Dr. A. HAGMEIER, dem Direktor der Biologischen Anstalt auf Helgoland und von Dr. H. HertuING, Kustos für Zoologie, ermöglicht. Die hydrologischen Daten wurden mir durch das Marschenbauamt Heide, Forschungsabteilung Büsum, gütigst zur Verfügung gestellt. Die au den Austern erfolgten Untersuchungen sind der liebenswürdigen Mithilfe Dr. B. HAvingA's, die Miesmuscheluntersuchungen ron Varna dem Entgegenkommen von Dr. H. CASPERS zu verdanken. Beim Durchsehen des Textes sind mir Dr. J. Henschel und Frl. Dr. A. STIER freundlicherweise behilflich gewesen. Den hier genannten Forschern. sowie auch allen Mitgliederu der Biolog Anstalt auf Helgoland, dje mir in jeder Hinsicht weitgehende Hilfe geleistet haben, spreche ich an dieser Stelle meinen innigsten Dank aus. 
Bild gewinnen, weil anfangs die durch faulende oder infizierte Muscheln verursachten Lebensmittelvergiftungen und die nach Verzehrung von frischen Muscheln auftretenden Erkrankungen ohne Untersehied unter dem Begriff der Muschelvergiftung zusammengefaßt wurden. Heute werden die als Folge des Genusses von Muscheln auftretenden Übel sowohl in Bezug auf die auslösende Ursache, als betreffs des Ablaufs der Krankheit in drei, von einander vollkommen getrennte Gruppen eingeteilt, nämlich 1. in die durch den Genuß von Muscheln hervorgerufenen Überempfindlichkeitszustände, 2. in die Lebensmittelvergiftungen, bzw. Infektionskrankheiten, welche durch faulende oder infizierte Muscheln verursacht wurden, schließlich 3 . in die nach Genuß von frischen Muscheln entstandenen paralytischen Muschelvergiftungen. Die nach Genuß von Muscheln auftretenden Überempfindlichkeitszustände, die Besprechung der Lebensmittel- und Infektionskrankheiten, fallen nicht in den Rahmen dieser Abhandlung, wir werden uns hier nur mit den paralytischen Muschelvergiftungen befassen.

\section{Miesmuschelvergiftungen.}

Die ersten Beschreibungen der Miesmuschelvergiftung stammen noch aus dem XVIII. Jahrhundert. HARLEM erwälint im Jahre 1762, DE Costa 1778 die paralytische Muschelvergiftung und das im Jahre 1787 veröffentlichte polizeiärztliche Handbuch von FrAN Kgibt Verhaltungsmaßregeln zur Vermeidung oder Vergiftungen an. Eine genauere Beschreibung der Vergiftungen geben erst D. BURRows und ForBES SyLVIUS, die auch richtig feststellen, daß die giftigen Muscheln gekocht nicht unschädlich werden und daß die Vergiftung auch von ganz frischen Muscheln herrühren kann. Nachdem aber mehrere Autoren als Krankheitsbild der Vergiftung die durch faulende oder infizierte Muscheln hervorgerufenen Erkrankungen beschrieben hatten, wurde die Möglichkeit einer durch frische Muscheln hervorgerufenen Vergiftung nicht bakteriellen Ursprunges bezweifelt. Im Jahre 1885 wurden aber in Wilhelmshaven derartige Muschelvergiftungen beobachtet, die mit Gewißheit bestätigten, daß in gewissen Fällen auch frische Muscheln als selbstïndiges Krankheitsbild bestehende, rasch ablaufende schwere Vergiftungen hervorrufen können. Es wurde nämlich am 17. Oktober am erwähnten Orte aus einem abgeschlossenen Teil des Kriegshafens ein kleines Schiff herausgezogen und mehrere haben von den am Schiffsboden anhaftenden Miesmuscheln in gekochtem Zustand gegessen. Im Laufe der Nacht erkrankten 19 Personen u. zw. 4 tödlich, 10 schwer und 5 leichter. Bei jenen. die viele Muscheln gegessen haben, zeigten sich sofort nach der Mahlzeit schwere Vergiftungssymptome. Die weniger von den Muscheln genossen haben erkrankten erst nach Stunden. Die Vergiftung nahm mit Trockenheitsempfindungen in der Kehle ihren Anfang, bald meldeten sich stechende, brennende Gefühle an den Gliedmaßen, welche von Frostschütteln abgelöst wurden, worauf eine Lähmung der Glieder eintrat. Die Lübmung wurde durch Scbwitzen, Beklommenheitsgefühle und Sprachstörungen begleitet; der Tod erfolgte in den einzelnen Fällen nach ${ }^{3}-5$ Stunden, bei vollem Bewußtsein, unter Atembeschwerden. Die Vergiftungserscheinungen und die Giftmuscheln wurden von SchmidTMANN, WolfF, SALKowskY, VIRchow, Brieger, Lohmeyer, Schneider, Martens, Schulze, Möbius, Kobeit und anderen untersucht.

Man stellte fest, daß die giftigen Muscheln ausschließlich in dem durch Schleusen abgeschlossenen Teil des Wilhelmshavener Hafens zu finden waren. Dieser Teil des Hafens bildete ein stehendes Wasser, frisches Wasser gelangte nur dann in die Bucht, wenn den Kriegsschiffen die Schleusen geöffnet wurden. Das Wasser der Bucht war jedoch vor Verunreinigungen geschützt und die Marinemannschaft durfte nur die Aborte am Ufer benutzen. Die Untersuchungen zeigten, daß bereits der Genuß von 5-6 Miesmuscheln schwere Vergiftungssymptome auslöste. Bei Mäusen erfolgte einige Minuten nach subcutaner Injizierung entsprechender Menge Muschelextraktes die Läbmung der Hinterbeine, bald breitete sich die Lähmung weiter aus und das Tier starb bei vollkommener I ähmung unter großen Atembeschwerden binnen einigen Minuten ab.

Die Vergiftungen von Wilhelmshaven haben daher den Beweis erbracht, daß die Lähmungsform der Muschelvergiftungen ein selbständiges Krankheitsbild darstellt, welches von den Erkrankungen durch faulende und infizierte Muscheln und von den Überempfindlichkeitszuständen gegenüber Muscheln völlig abgesondert zu behandeln ist. Solche Vergiftungen sind wohl sehr selten, aber es sind den Wilhelmshavener Vergiftungen ähnliche massenhafte Vergiftungen auch seither beobachtet worden.

Schon am 30. September 1888 sind in Wilhelmshaven 3 neue Vergiftungsfälle vorgekommen und einer der Vergifteten ist bereits nach 6 Stunden gestorben. Im selben Jahre wurden noch in Liverpool Vergiftungen beobachtet. Im Jahre $1890 \mathrm{ah}$ in Dublin eine Familie (die Mutter, 5 Kinder und die Dienstmagd) Miesmuscheln und 20 Minuten nach der Mahlzeit traten schon die Vergiftungserscheinungen auf. Von der Familie blieben ein einziges Kind und die I)ienstmagd am Leben. Im Jahre 1901 "starb in Christiania ein Matrose an Muschelvergiftung und später sammelte eine 7 Personen zählende Familie an derselben Stelle Muscheln nach deren Genuß 6 Familienmitglieder erkrankten und eine Person starb unter schweren Vergiftungssymptomen. Die Vergiftungen hat THESEN sehr eingehend untersucht und festgestellt, daß auch hier im Innern des abgeschlossenen Hafens die giftigen Muscheln zu finden waren, jedoch die aus dem freien Meer gefangenen sich als ungiftig erwiesen haben. Die Zahl der Vergiftungen ist in Anbetracht des sehr bedeutenden Muschelgenusses verhältnismäBig wirklich gering. DoDGSoN (1928) bält das Vorkommen der paralytischen Vergiftungen in 8-10 Fällen fïr bewiesen. Die von DoDGson aufgezählten gruppenweisen Muschelvergiftungen sind in Wilhelmshaven, Oslo, Dublin, Tralee (Irland), Liverpool, Hartlepool, Leith (England) 
vorgekommen und es ist auffallend, daß die Vergiftungen auf die nördliche Hälfte Europas fallen, wogegen in den Mittelmeerländern trotz des bedeutenden Muschelgenusses paralytische Muschelvergiftungen anscheinend nur ausnahmsweise vorkommen. In letzter Zeit wurden aus Amerika nicht zu bezweifelnde Muschelvergiftungen beschrieben. Nach MEYER sind 1927 in Kalifornien viele Vergiftungen vorgekommen, von welchen 6 Fälle mit dem Tod endeten.

Im Jahre 1938 sind laut bezüglicher Mitteilung von Prof. G. GILson in Brügge charakteristische Muschelvergiftungen vorgekommen, von welchen in 4 Fällen der Tod eintrat. Durch die Miesmuschel verursachte paralytische Vergiftungen sind daher auch in der jüngsten Vergangenheit beobachtet worden und es ist erklärlich, daß in den Ländern, wo der Genuß der Miesmuschel allgemein verbreitet ist, die Ursache der Giftigkeit der Muscheln ein vielfach besprochenes und den Gegenstand zahlreicher Untersuchungen bildendes Problem geworden ist, wie unmittelbar nach den Vergiftungen von Wilhelmshaven.

\section{Durch Austern und andere Muscheln verursachte Vergiftungen.}

$\mathrm{Ob}$ die paralytische Muschelvergiftung auch nach Verzehrung von Austern vorkommt, darüber besitzen wir -- zumindest Europa betreffend - keine derartig verläßliche Angaben, wie über die Muschelvergiftungen von Wilhelmshaven.

Eine nach Genuf von Austern eingetretene Muschelvergiftung wird bereits vom Jahre 1821 erwähnt, doch stammt die erste genaue Beschreibung von Brosch vom Jahre 1896. Laut dieser hatte ein Offizier im Jahre 1895 in Wien angeblich verdorbene Austern gegessen und war am folgenden Tag unter schweren Vergiftungserscheinungen gestorben. Das Krankheitsbilid der Vergiftungen wich jedoch von jenen der lähmenden Muschelvergiftung in vielen Beziehungen $a b$ und erinnerte vielmehr an den Botulismus. Unter den weiteren Angaben ist es gleich schwer zu entscheiden, wieweit die Fälle der paralytischen Muschelvergiftung vorliegen und wieweit sie als gewöhnliche Lebensmittelvergiftung infolge des Genusses von faulenden Muscheln aufzufassen seien. Das ist der Grund, weshalb in ihren diesbezüglichen Arbeiten THESEN (1901) und BUCHHOLZ (1912) überhaupt nicht als bewiesen annehmen wollen, daß nach Genuß von gekochten oder gebratenen Austern lähmende Muschelvergiftungen jemals beobachtet worden sind.

Gemäß meinen in Neapel vorgenommenen Untersuchungen enthielten die aus der Bucht von Mergellina stammenden Exemplare von Ostrea plicata Giftspuren und so kann die theoretische Möglichkeit nicht ausgeschlossen werden, daß nach dem Genuß von Austern auch in Europa die paralytische Muschelvergiftung vorkommen kann. Es scheint aber die Möglichkeit der paralytischen Austernvergiftung in Europa recht gering zu sein, wahrscheinlich aus dem Grunde, da auf den Austernbänken die für die Giftbildung günstigen Umstände nicht zur Geltung kommen; unter den die Giftentwicklung fördernden Verhältnissen, z. B.: in abgeschlossenen Häfen mit stagnierendem Wasser, reichen die Bedingungen für das Gedeihen der Austern nicht aus.

Der Volksglaube hält einzelne Muscheln, so z. B. laut HaAs die Art Anomia ephippium von vornherein für giftig. Die sich mit der Biologie der Muscheln befassenden Fachwerke zählen ebenfalls außer der Miesmuschel und Auster mehrere Muschelarten auf, nach deren Genub angeblich Vergiftungen auftraten. Als solche werden die Genera Venus, Cardium, Donax, Arca noë usw. erwähnt.' Die von mir in Helgoland untersuchten Exemplare von Anomia ephippium enthielten nicht einmal Spuren des Giftes und an den aus der Bucht von Mergellina stammenden Venus-Exemplaren war das Gift auch in der geringsten Menge nicht nachweisbar, obwohl zu gleicher Zeit Mytilus minimus und Ostrea plicata Giftspuren aufwiesen. Genauere Beschreibungen über die durch Venus, Cardium und die übrigen erwähnten Muscheln angeblich hervorgerufenen Vergiftungen liegen uns nicht vor und es ist sehr schwer zu entscheiden, wieweit die allgemeine Bezeichnung Vergiftung einem einfachen, durch Muscheleiweiß ausgelösten Überempfindlichkeitszustand oder einer gewöhnlichen Lebensmittelvergiftung, eventuell einer durch die Muschel vermittelten Infektionskrankheit entspricht. Daher kann das Vorkommen von durch die erwähnten Muscheln verursachten paralytischen Vergiftungen - zumindest in Europa vorderhand nur als eine theoretische Möglichkeit angesehen werden und jedenfalls wird neben den Miesmuschelvergiftungen die praktische Bedeutung der durch die übrigen Muscheln hervorgerufenen paralytischen Vergiftungen als verschwindend gering zu betrachten, bzw. einzelne Muscheln betreffend auch zu bezweifeln sein, ob sie überhaupt imstande sind, paralytische Muschelvergiftungen hervorzurufen.

\section{Vorkommen des Muschelgiftes in Krebsen und Seesternen.}

Im Gegensatz zu den obigen ist von drei, im System von den Muscheln weit entfernt stehenden Tieren mit Gewißheit bewiesen worden, daß sie unter gewissen Umständen Muschelgift enthalten können und zwar sind diese der Seestern Asterias rubens, der Krebs 
Emerita analoga und die Garnelen. Überdies kann das paralytisch wirkende Muschelgift laut meinen Helgoländer. Untersuchungen ausnahmsweise auch in einer vierten Tierart, in Carcinus maenas vorkommen. Von obigen Tieren wird über die für den menschlichen Genußs ausschließlich in Betracht kommenden Garnelen von WolfF in seiner Arbeit über die Muschelvergiftungen bemerkt, daß diese Tiere in Deutschland, Holland und Frankreich mitunter Nassenvergiftungen verursachten. Die durch die rasch faulenden, schwer zu konservierenden Garnelen bewirkten Lebensmittelvergiftungen sind wohl bekannt, aber die paralytischen Muschelvergiftungen stehen mit diesen Erkrankungen in gar keinem Zusammenhang. Genaue klinische Beschreibungen über paralytische Garnelenvergiftungen sind mir nicht bekannt und obwohl auf Grund des Gesagten die Möglichkeit der paraIytischen Garneelenvergiftung nicht ausgeschlossen erscheint, muß dieses Krankheitsbild als eine grofe Seltenheit betrachtet werden und dasselbe ist mit Bestimmtheit bis heute nicht nacllgewiesen worden. Unter diesem Gesichtspunkt ist jener Feststellung von WoLFF Beachtung zu schenken. daß sich die Giftwirkung der Garneelen sogar im abgeschlossenen Hafenteil von Wilhelmshaven bedeutend geringer als die jener Nuscheln erwies, demgemäß hätte nur die Verzehrung einer verhältnismäßjig großen Menge der in dem abgeschlossenen Hafenteil gefischten Garnelen die Vergiftung auszulösen vermocht. Überdies ist die Giftwirkung auch bei den Garnelen keine ständige Erscheinung. In Aquarien mit reinem Wasser haben auch die Wilhelmshavener stark giftigen Muscheln nach einer bestimmten Zeit ihre Giftwirkung eingebüßt, und so ist es erklärlich, daß die nicht an bestimmte Orte gebundenen und nur in größeren Wassergebieten und in großen Massen gefischten Garnelen tatsächlich nur unter ganz besonderen Ausnahmebedingungen klinisch erkennbare, paralytische Vergiftungen bewirken können.

\section{Chemische Eigenschaften und toxikologische Wirkung des Muschelgiftes.}

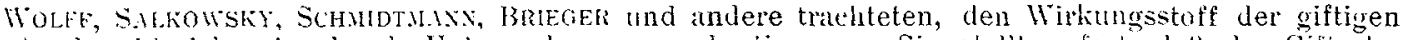
Yustheln durh zahheiche eingehende Untersuchungen zu bestimmen. Sie stellten fest, dais das Gift das stundenlange fochen in simerem Medium rertrïgrt, jedoch im alkallischen Nedium rasch zerstört wird. Deshaib rät S.lLkowsky, die zum allgemeinen Verbrauch bestimmten Muscheln mit Sola zu kochen und das siedewasser wegzugieß̧en. Die sauere Lösung kann ohne ihre Wirlisamkeit zu verlieren bis zum Trocknen eingedampft und der liest während der bauer ron 7 Minuten auf $110^{\circ}$ erhitzt werden. Das Gift geht nicht in den Wasserdunst über. Es ist in Aether und Alkohol lüslich und kann rom Vuschelkörper mit wenig Salzsilure enthaltendem Alkohol oder Wasser gut extrahiert werden. SALkowsky hat zur Bereitung des wässerigen und des alkoholischen Extraktes getrennte Verfahren bekanntgemacht und festgestellt, daß unter den vier Lon ihm hergestellten Extraliten der unmittelbar bereitete alkoholische Extrakt der wirksamste sei.

Im Zusammenhang mit den Osloer Vergiftungen beschreibt THEseN nach BRIEGER ein gut anwendbares und auch von mir durchweg benütztes Verfahren zur Herstellung ron Wuschelgiftextrakten. Sein Verfahren ist das folgende: der aus der Muschelschale abgetrennte und abgewogene Weichkörper wird auf 1-2 Minuten in siedendes Wasser geworfen. Man verreibt die erstarrten Weichteile (am zweckmäßigsten mit chemisch reinem Quarzsand) und nimmt eine Verdünnung mit der zehnfachen Menge destillierten Wassers ror, wobei einige ccm verdünnte Salzsäure beigegeben werden (nach meinen Versuchen ist die Verdünnung von ${ }^{1}, 11 \mathrm{n}$ Salzsäure in einem Verhältnis von $2-5^{\prime \prime}$ "zweckmäßig, je nachdem die Flüssigkeit mit Lackmuspapier kontrolliert, sich ausgesprochen sauer verhält). Drei Stunden lang hält man die Lösung in einem mit Watte verschlossenen Kolben in siedendem Wasserbad, filtriert sie darauf durch Watte und dampft sie danach im Wasserbad auf ihr ursprüngliches Volumen ein. Dann wird die dünne, sirupartige Flüssigkeit mit doppelter Menge 96": igen Alkohols verdünnt. Nach Zugabe von Alkohol ergibt sich zumeist ein reichlicher Niederschlag, zu dessen Ausscheidung die Flüssigkeit 30 Minuten lang in einem hohen Meßkolben stehen gelassen und dann filtriert wird (oft ist das Zentrifugieren zweckmäßiger). Aus der vollkommen rein filtrierten Flüssigkeit wird der Alkohol im Wasserbad verdunstet und der Rest mit destilliertem Wasser derart verdünnt, daß das Gewicht der Lösung 1': des Weichteilgewichtes der Muschel entspricht. Sollte die Lösung nach der Verdünnung trübe geworden sein, so filtriert man dieselbe wiederholt oder man zentrifugiert sie sorgfältig, wobei die Reaktion auf Säure eingestellt wird. Bemerkt sei, daß es zweckmäßig ist, die Reaktion während des ganzen Vorganges zu kontrollieren, nachdem in der bereits erwähnten Weise das Alkalischwerden der Reaktion die Zerstörung des Giftes mit sich bringt. Da die Bakterien das Gift rasch zersetzen, muß der Extrakt vor der Verwahrung mit 1-2 Tropfen Chloroform konserviert werden und es ist zweckmäßig, denselben in geschmolzenen Röhrchen zu verwahren. In sauerem Medium kann das Gift mit Chloroform konserviert an kühlem Orte auch ein Jahr lang aufbewahrt werden und die Wirkungskraft bleibt unverändert. Salkowsky stellte fest, daß der alkoholische Extrakt der giftigen 
Muscheln von dunkel goldgelber Farbe sei, dagegen ist der Extrakt der ungiftigen Muscheln blaßgelb. Mit einigen Tropfen Salpetersäure erwärmt, gibt der Extrakt der Giftmuschel eine grasgrüne Reaktion. Die Reaktion wird insbesondere dann augenscheinlich, wenn einer trüben alkoholischen Lösung soviel absoluter Alkohol beigegeben wird, bis die Lösung sich vollkommen klärt. Die Probe scheint jedoch an größere Giftmengen oder an einem dauernd bestehenden Zustand des Tieres, eventuell an irgend einen pathologischen Vorgang in der Leber gebunden zu sein (WoLfF, Schmintarans), da sich die Reaktion nicht immer positiv zeigt und Tiere, die für kurze Zeit in ein die Giftentwicklung förderndes Milieu gebracht wurden und giftig geworden sind, diese Farbreaktion nicht aufweisen. So fehlte dies nach der Beschreibung von LiNower bei den in der geschlossenen Bucht von Wilhelmshaven in kurzer Zeit giftig gemachten Tieren, aber auch ich selbst habe diese Beobachtung bei den in der Bucht von Mergellina lebenden Giftspuren aufweisenden Muschein nicht wahrgenommen. Ferner fehlte sie bei Mytilus minimus, welche ich in Neapel und Helgoland nachträglich schwer giftig gemacht hatte. Dagegen zeigte sich die Reaktion sehr stark bei den von der Süderpiep-Tonne stammenden giftigen Muscheln und meine Aufmerksamkeit wurde auf die Giftigkeit derselben in erster Linie gerade durch die sehr auffallende Salpetersäure-Probe gelenkt.

Eine genaue chemische Bestimmung des Giftstoffes selbst ist noch bis heute nicht erfolgt. BRIEGER gedachte das Muschelgift mit dem von ihm Mytilotoxin benannten Stoff zu identifizieren, die späteren Forscher konnten aber seine Annahme nicht bestätigen. MFY FR und Méler halten für wahrscheinlich, daß das Gift eine Quarternärammoniumbase sei. Mehrere Daten lassen darauf schlieben, daß das Gift Histamin oder eine demselben verwandte chemische Verbindung darstellt. Von diesem Gesichtspunkt aus sind insbesondere jene jüngst vorgenommenen Untersuchungen von Interesse, welche in der Deutung des amaphylaktischen Schocks die Histamintheorie in den Vordergrund rücken und annehmen, dat. das Histamin jener Stoff sei, welcher den anaphylaktischen Schock auslöst. Bekanntlich führten zur Begründung der Lehre der Anaphylaxie - eines der wichtigsten Probleme der Immunitätslehre - jene Versuche von RICHET, die er mit giftigen Extrakten von Mytillas edulis und Actinien ausführte. Nach seinen Untersuchungen ist in den giftigen Exemplaren von Mytiluss edulis ein dem Actinien-Gifte ähnlicher Stoff vorhanden, den er Mytilocongestin benannte. Die Einspritzung der Substanz macht das Tier überempfindlich, die wiederholte Injizierung löst den Schock aus. Die Besprechung der Bedeutung von RicheT's Versuchen, die zur Aufstellung des Begriffes der Anaphylaxie führten, erstreckt sich weit über den Rahmen dieser Arbeit, umso mehr, da, wie ich später zeigen werde, in RICHET's Versuchen die Giftwirkung und die richtigen Erscheinungen der Anaphylaxie sich in komplizierter Weise verwickelten, zumal das Muscheleiweiß eine starke anaphylaktische Wirkung besitzt und in dem durch RICHET beschriebenen Schock möglicherweise sowohl die anaphylaktischen als auch die toxischen Erscheinungen zur Geltung kommen und das Verhältnis des Mytilocongestin zum Muschelgift mit Gewißheit noch heute nicht klargelegt ist. Es sei jedoch wiederholt betont, daß die modernen chemischen Forschungen betreffs der Substanz des Muschelgiftes und die auf Basis der grundlegenden Versuche von RICHET begonnenen Anaphylaxie-Untersuchungen neuerdings nach weiten Wegen in der Histamintheorie zusammentrafen und nach meinen Untersuchungen in Neapel stellen RICHET's Versuche auch heute noch sozusagen das einzige Verfahren zum Nachweis von Spuren des Muschelgiftes dar.

In reinem Zustande wurde das Muschelgift in Jahre 1935 von MüLLER hergestellt. Er, ferner KEllaway, Prinzinetal, Sommer und Leake stellten fest, daß das Gift ein zentral und peripherisch wirkendes Neurotoxin darstellt. Die zentrale Wirkung des Giftes berïhrt hauptsächlich die respiratorischen und cardiorascularen Zentren und große Dosen des Giftes verursachen infolge Einwirkung auf das Atmungszentrum den fast sofortigen Tod. Das Gift lähmt peripherisch die motorischen und sensorischen Nervenendapparate. Die Curare-Wirkung kommt vor allem an den Nervenendigungen, schwächer an den Nervengeflechten und noch schwächer an den Muskeln selbst zur Geltung. Durch das Gift wird die Herztätigkeit bei Kaninchen, Hunden, Fröschen vorerst gefördert, dann gehemmt. Das reine Gift wird rom Magen-Darmkanal langsam resorbiert und durch die Nieren ausgeschieden. Tiere zeigen sich gegen dieses Gift in verschiedenem Grade empfindlich. Kaninchen und Mäuse weisen große Empfindlichkeit auf, Frösche sterben aber erst ab, wenn ihnen ungefähr das 15-fache der Kaninchen-Dosis verabreicht wird. Als Letaldosis wird im allgemeinen eine Menge betrachtet, welche die intraperitoneal injizierte Maus von $20 \mathrm{~g}$ Körpergewicht in $10-20$ Minuten tötet. Von dem alkoholischen Extrakt der Wilhelmshavener Muscheln hat eine Menge von $1.2 \mathrm{ccm}$ (mit $1.125 \mathrm{~g}$ Muschelkörpergehalt) ein $900 \mathrm{~g}$ schweres Kaninchen getötet. THESEN, der mit dem wässerigen Extrakt der aus Oslo stammenden Muscheln arbeitete, fand, daß $0.01-0.02 \mathrm{ccm}$ wässerige Stammlösung (mit $0.001-0.002 \mathrm{mg}$ organischem Gehalt) die Maus, $0.5 \mathrm{ccm}$ Stammlösung (mit 0.04-0.05 mg organischem Stoffgehalt) die Ratte und $3.5 \mathrm{ccm}$ Stammlösung (mit $0.10-0.30 \mathrm{mg}$ organischem Stoffgehalt) das Kaninchen tötete. Nach den neuen Angaben von Prinzmeral, SomMER, LEAKE beträgt die Letaldosis des isolierten Giftes bei Mäusen je nach Reinheit der Präparate $0.02-1 \mathrm{mg}$. 
Das Bild der Vergiftung durch den nach ThEsEn's Verfahren hergestellten Muschelextrakt beobachtete ich an Mäusén mit $20 \mathrm{~g}$ Körpergewicht wie folgt: Nach Einspritzung doppelter, dreifacher Menge der Letaldosis verendete das Tier unter heftigen Atembeschwerden in Begleitung von 1-2 Zuckungen in ein - anderthalb Minuten. Wurde die Letaldosis injiziert, so verhielt sich das Tier nach einigen Minuten unruhig, sträubte die Haare (Abb. 1. Fig. links oben), nach weiteren 1-2 Minuten erlahmten die Hinterbeine, bald schleppte sich das Tier unruhig mit wurmartiger Bewegung weiter, wobei die lahmen Beine ausgestreckt blieben (Abb 1. Fig. rechts oben). Bald konnte das Tier den Kopf nicht aufrecht halten, derselbe sinkt ihm zur Seite. Gleichzeitig wurden auch die Vorderbeine lahm, das Tier ist nicht imstande sich aufzurichten, sondern streckt sich flach hin (Abb. 1. Fig. links unten). Das Atmen wird allmählich anstrengender und schwieriger.

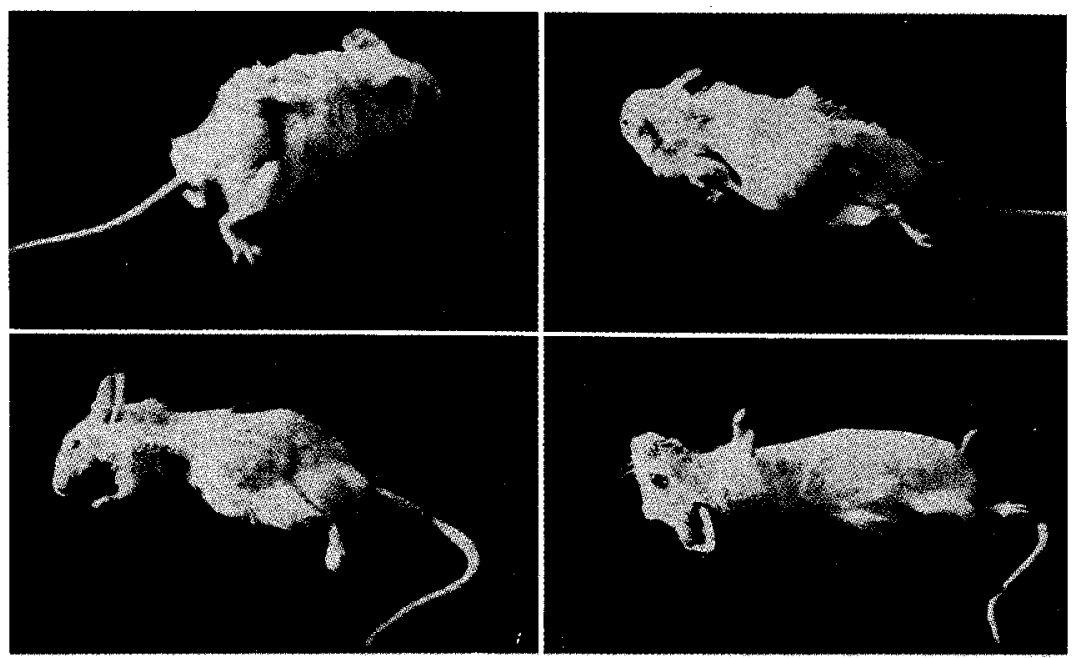

Abb. 1. Mit dem Extrakt giftiger Muscheln geimpfte weiße Maus in verschiedenen Stadien der Vergiftung.
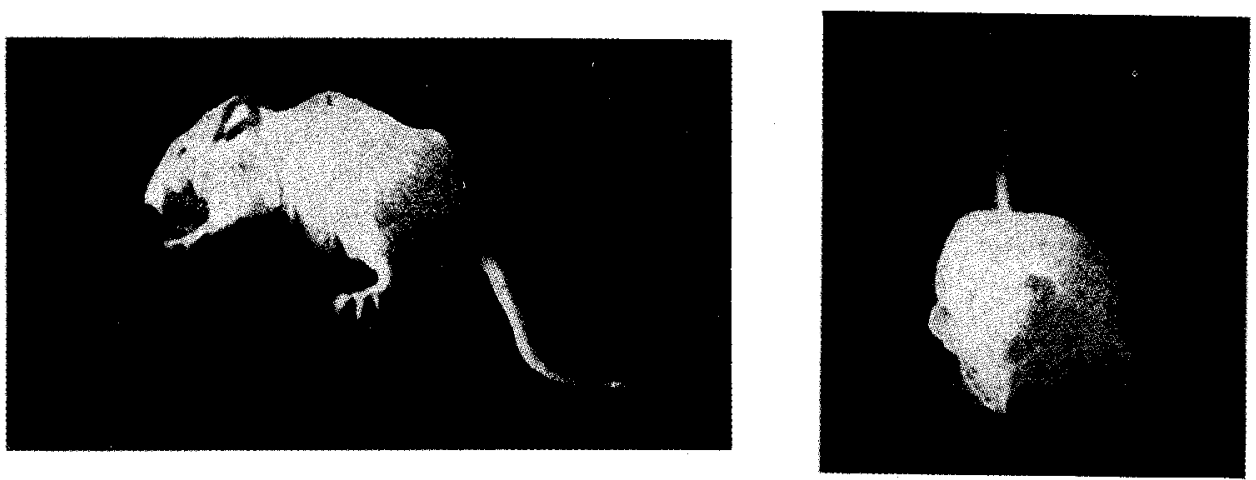

Abb. 2. Halbseitige Lähmung bei einer weißen Maus nach überwundener Muschelvergiftung.

Es kommt vor, daß das Versuchstier unterdessen zappelnde Bewegungen ausführt (sich umherschleudert) und sich oft auf den Rücken wendet (Abb. 1. Fig. rechts unten), jedoch gehören richtige klonische Krämpfe zu den Seltenheiten. Schließlich bleiben die Bewegungen ganz aus und nur das heftige, starke Atemholen gilt noch als Lebenszeichen. Binnen 1-2 Minuten hören auch die Atembewegungen meistens auf, die Herztätigkeit bleibt aber in der Regel noch 1-2 Minuten lang bestehen. Speichelrinnen kommt wäbrend der Vergiftung nicht vor, aber die Entleerung der Blase erfolgt fast in jedem Falle. Die ganze Vergiftung führt in der Regel in 10-20 Minuten zum Tode. Das bewegungslos auf dem Rücken liegende, heftig atmende Tier kann auch nach stundenlanger Bewußtlosigkeit ausnahmsweise zu sich kommen. Diese Erscheinung kann besonders nach geringerer Giftmenge 
oder nach Verabreichung eines weniger wirksamen Giftextraktes, oder bei Tieren vorkommen, die mit giftigen Muscheln gefüttert worden sind. Solche Tiere können auch wieder gesund werden, oft bleiben aber Lähmungen von peripherischem oder zentralen Charakter zurück und in letzterem Falle gehen die Tiere infolge Krankheitskomplikationen in 2-4 Wochen ein. Abb. 2. zeigt einen solchen haemiplegischen Zustand 21 Tage nach der Vergiftung. Das Tier konnte, wie besonders am unteren Bild sichtbar, sich nicht aufrichten, sondern schlich, auf die Seite gewendet, weiter. Bei Ratten und Kaninchen ist das Vergiftungsbild im Wesentlichen identisch, es zeigt nur insoweit eine Abweichung, als beim Kaninchen dem Verenden eine oft stundenlang währende Bewußtlosigkeit vorangeht. Von Ratten werden verhältnismäßig viele Tiere geheilt und ich habe weder bei Kaninchen noch bei Ratten den Eintritt einer dauernden Lähmung nach der Vergiftung jemals beobachtet.

\section{Hypothesen über die Muschelvergiftung.}

Zur Erklärung der Giftwirkung der Muscheln entwickelten sich im Laufe der Zeit verschiedene Ansichten, die bis heute noch nicht zur Übereinstimmung gelangten. Die ersten Autoren schrieben das Gift den in der Muschel lebenden kleinen Krebsen oder den an der Muschel anhaftenden Seesternen bzw. gar den Eiern der Seesterne zu. Die ersten genauen biologischen Forschungen haben diese Behauptungen naturgemäß bald widerlegt.

Die Untersuchungen im Zusammenhang mit den Wilhelmshavener Vergiftungsfällen zeigten, daß die Giftwirkung der Muscheln eine periodische Entwicklung sei. Die stärkste Giftwirkung wiesen die Muscheln von Oktober bis Dezember auf, dagegen hat sich die Giftwirkung in den Monaten Januar-Februar wesentlich vermindert. Gelegentlich der Vergiftungen von Oslo fand THEsEn die Muscheln Ende Mai und Mitte Juni giftig, dagegen waren vom 22. Juni bis 16 . September an denselben Stellen. kaum oder überhaupt keine giftigen Muscheln zu finden. Nach MEYER kommen in Kalifornien vom Dezember bis März giftige Muscheln überhaupt nicht vor. Daher ist in der Giftwirkung der Muscheln eine gewisse Periodizität zu beobachten und so lag die Annahme nicht fern, daß das Gift ähnlich dem Fischgift Fugu ein Produkt der Geschlechtsdrüsen sei. Der Gedanke ist fast ebenso alt wie die Forschungen über die Muschelvergiftung. Die Vermehrung der Austern geht im Mittelländischen Meer und an den Küsten von Frankreich zu Beginn des Frühjahrs vor sich und das Schwärmen der in der Mantelhöhle befindlichen Larven erfolgt vom Mai bis Ende Juni. Der Volksglaube hielt die Austern mit Eiern für giftig und im XVIII. Jahrhundert meinte man, daß ein großer Teil der Muttertiere nach dem Ausschwärmen der Larven erkrankt. FRANK beschreibt auch im Jahre 1787 die Eigenartigkeiten der im Sommer auffindbaren kranken Tiere und bemerkt, daß diese von bläulicher Farbe und ungewöhnlich locker und weich seien. Dieser Glaube hatte die französischen Behörden bewogen, im Jahre 1732 eine Verfügung zu treffen, wonach in Paris vom Mai bis September Muscheln zu verkaufen verboten sei. Kurz darauf wurden in Spanien ähnliche Vorkehrungen getroffen und allmählich bürgerte sich auch hier die Ansicht ein, daß Austern nur in den

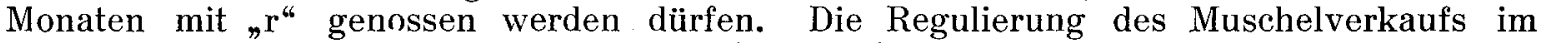
Sommer war ohne Zweifel eine zweckmäßige Maßnahme, weil die Gefahr der Fäulnis, die Gefahr von Lebensmittelvergiftungen und Typhusinfektionen im Sommer am größten ist. Der Grundgedanke der Maß3regel jedoch, daß die Muschelvergiftung mit der Funktion der Geschlechtsdrüsen, mit der Fortpflanzung der Muscheln im Zusammenhang stünde, erscheint mehr und mehr unwahrscheinlich. Es genügt zu bemerken, daß in Wilhelmshaven die Muscheln von Oktober bis Dezember, also nicht während der Fortpflanzungszeit, am giftigsten geworden sind. WoLFF hat außerdem festgestellt, daß zur gleichen Zeit ein großer Teil der giftigen Tiere einen unentwickelten Eierstock, bzw. Hoden besaß und die Giftwirkung an die Leber gebunden war, zumal die Geschlechtsdrüsen kein Gift enthielten. F. WHEDON's eingehende Untersuchungen zeigten, daß zwischen der Giftwirkung und der Fortpflanzung der Mytilus californianus gar kein Zusammenhang besteht. Nach meinen Beobachtungen in Neapel waren die Giftspuren in der Bucht von Mergellina an den jungen, geschlechtlich ganz unreifen Mytilus minimus-Exemplaren (Abb. 21. Fig. 4. u. 5.) geradeso nachweisbar, wie an den geschlechtsreifen Tieren. Bei den später zu behandelnden Muscheln von der Süderpiep-Tonne war die Giftwirkung der jungen, geschlechtlich vollkommen unreifen, ganz winzigen (Abb. 8. Reihe rechts) Muscheln jener der größten geschlechtsreifen Exemplare ähnlich, d. h. man kann behaupten, daß die Entfaltung der Giftwirkung von der Geschlechtsfunktion unabhängig und das Muschelgift nicht das Produkt der Geschlechtsdrüsen ist. 
Im Zusammenhang mit den in Irland in Tralee beobachteten Vergiftungen kam Cruxpe auf den Gedanken, daß die giftige Muschel einer selbstaindigen Art entspricht und benaunte sie Mytilus venenosus. im Anschluß an die Wilhelusharener Yergiftungen fand diese Ausicht in LOHMEYER einen necien Anhänger. Er glaubte nümlich an den Giftmuscheln von Wilhelmshaven besondere morphologische Merkmale entdeckt zu haben und schlols daraus auf eine neue Art oder zumindest eine neue Varietait, Mytilas eulis var. striatus, wie er sie nannte. Er tindet, daß „die durchscheinende, leichtere, zerbrechlichere, mit glatter, glïnzeuder hornartiger Oberhaut bedeckte Schale und die auffillige Streifung resp. Zeichnung und Farbung und breite Gestalt der jüngeren Tiere die für Abart die hamptsüchlichsten und charakteristischen Merkmale sind". Auß3erdem beschrieb er auch Unterschiede in der Färbung des Weichkörpers. Die giftigen Muscheln besitzen nach ihm gelb-orangerote Färbung, während die ungiftigen von mehr ralmingelbein oder blassem Farbton sind. Auch andere Forscher vertreten ähnliche Ansichten. Poul sonderte ohne Rüchsicht auf ihre Giftiglieit die mehr blaßgelbe Schalen besitzeuden Miesmuscheln unter dem Namen Mytilus flavus, jene mit gestreifter Schale als Mytilus sagittatus von Mytilus edulis schon von vornherein ab. KoBELT findet eine gewisse Verwandtschaft im Aussehen der Wilhemshavener Giftmuschelu mit einer an den atlantischen Küsten von England lebenden Mytilusrasse, die dort als Mytilus pellucidus PENadNT beschrieben ist. Er macht darauf aufmerksam, dab nach Aussagen englischer Schiffskapitäne auch diese Varietät wegen Verdacht der Giftigkeit von der Bevölkerung nicht gegessen wird. Andererseits macht er auch darauf aufmerksam, daß die charakteristische breitere Form der Giftmuscheln an eine im Mittelmeer heimische Muschelform erinnert und hält es, wie übrigens auch LOHNEYER, für möglich, daß die Giftmuscheln durch Kriegsschiffe ach Wilhelmshaven eingeschleppt worden sind.

SchmidiMAN, einer der ersten Beschreiber der Vergiftungen, gibt ebenfalls an daß die Schale der Giftmuscheln dümer, zerbrechlicher und ron lichterer Farbe ist als jene der ungiftigen Muscheln. Nach LINDNER sind die Wilhelmshavener Giftmuscheln flach, auffallend leicht, die Schale papierdïnn, durchsichtig, gestreift und ihre Oberfläche glïnzend und äußerst zerbrechlich. Dazu bemerkt LiNDNER noch, dab die giftigen Tiere einen unangenehmen Fäulnisgeruch haben.

Die Beschreibung dieser morphologischen Abweichung giftiger Tiere veranlaßte viele Autoren zu weiteren Nachforschungen. Diese Untersuchungen haben im allgemeinen LOHMEYER's Ansicht, daß die Giftmuscheln als selbständige Varietät oder gar Art aufzufassen seien, verworfen. Martens, Möbius, Schnerder, Schulze haben sogar überhaupt keinen morphologischen Unterschied zwischen den giftigen und ungiftigen Muschein gelten lassen. Möbius lenkte die Aufmerksamkeit auf Grund seiner Beobachtungen in der Nordsee, Ostsee und im Mittelmeer dahin, „daß die Miesmuschel ein im hohen Grade euryhalines und eurythermes Tier ist, d. h. große Schwankungen im Salzgehalte und in der Temperatur des Wassers verträgt und sich daher sehr verschiedenen Lebensumständen durch Abänderung der Form, Größe, Dicke und Farbe seiner Schale anpaßt". Nach ihm sind „die lichten Strahlen der Schalen ein Zeichen ihres jugendlichen Alters" und die Farbe "des Mantels hängt von der Geschlechtstätigkeit ab. So besteht für ihn zwischen diesen Merkmalen und der Giftwirkung der Muscheln überhaupt kein Zusammenhang.

Den richtigen Zusammenhang aber zwischen den morphologischen Merkmalen und der Giftigkeit der Muschein erkannte bereits, wie gerade in dieser Arbeit gezeigt werden kann, VIRCHOw. Er faßte seine Meinung in Bezug auf die morphologischen Eigenschaften der Giftmuscheln zuerst darin zusammen, daß, obwohl „die Anlage für die Streifung unzweifelhaft bei allen Muscheln vorhanden ist", wenn die giftigen und ungiftigen Muscheln nebeneinander liegen, ,die giftigen in Masse einen anderen Anblick gewähren " Später schrieb er über dieselbe Frage folgendes: „Die giftigen Miesmuscheln zeigen sehr häufig gewisse Veräıderungen, welche eine geringere Energie der Bildungsvorgänge anzeigen. Sie sind weniger pigmentiert, die Schalen sind weniger stark, sie entwickeln sich nicht in der vollen Gestalt und Größe, sie werden mehr breit, sie scheinen ein langsameres Wachstum zu haben, also kurz gesagt, sie haben etwas Atrophisches an sich." Dann haben WolfF, Vikchow und SchmidtMann zeigen können, daß giftige Muscheln in Aquarien mit reinem Wasser nach einiger Zeit ihre Giftwirkung verlieren, wogegen ungiftige Tiere, im Dock von Wilhelmshaven untergebracht, nach einer gewissen Zeit giftig werden. Daran scheiterte natürlich die Auffassung über das Vorhandensein einer selbständigen giftigen Muschelart vollständig. Es blieb aber die Frage offen, wieweit die an den Giftmuscheln wahrnehmbaren Formabweichungen und Wachstumsstörungen mit den Vergiftung bewirkenden Faktoren im Zusammenhang stehen oder inwiefern sie als zufällige, unwesentliche Begleiterscheinungen angesehen werden dürfen. Auf die eingehende Besprechung dieser letzten Frage werden wir noch anläßlich der Behandlung der später zu beschreibenden giftigen Muscheln von der Süderpiep-Tonne zurückkommen.

Nachdem klargelegt wurde, daß die giftigen Muscheln nicht als selbständige Art angesehen werden können, tauchte die Meinung auf, daß die Muscheln die giftigen Stoffe aus dem Meerwasser aufnehmen. Bereits die allerersten Vergiftungen erweckten den Verdacht, daß die Muscheln von jenen Gegenständen, welchen sie anhaften, z. B. vom Kupferbeschlag des Schiffsbodens, von Metalltonnen, metallische Gifte wie Kupfer, Blei usw. in sich aufnehmen. WOLFF und THESEN wiesen jedoch nach, daß für die Entwicklung der Giftwirkung der Umstand, welchen Gegenständen, Schiffsböden, Holzpfählen oder 
Steinen die Muscheln anhaften, keine Rolle spielt, da die Tiere an den erwähnten Stellen gleich giftig sein können. THESEN warf also, wie bereits bemerkt, den Gedanken auf, ob die Giftstoffe nicht vom umgebenden Seewasser in das Innere der giftigen Muscheln gelangen. Daß die Muscheln im Wasser gelöste Gifte Strychnin, Curare, in sich aufnehmen, hat er durch Versuche nachgewiesen und gefunden, daß das Gift aus dem Körper des Tieres später wieder verschwindet. Entweder scheiden daher die Muscheln das Gift aus, oder es wird zu einer unschädlichen Verbindung umgewandelt. Es sei allerdings bemerkt, daß THEsEn's Versuche nicht in jeder Hinsicht als vollwertig anzusehen sind. Er selbst berichtet über seine Versuche folgendes: "Somit ist es mir gelungen nachzuweisen, daß Muscheln in Aquarien nicht allein Curare und Strychnin aufnehmen können, sondern auch paralysierendes Muschelgift und auf diese Weise sehr giftig werden, ohne daß sie selbst irgend ein äußeres Zeichen von Vergiftung darbieten". In seinen Versuchen "rief der Extrakt nach Verlauf von 2 Tagen deutliche Paresen hervor" und die Muscheln wurden nach 5-6 Tagen schwer giftig. Aus dem Versuchsprotokoll geht es aber klar hervor, daß das Wasser des Versuchsaquariums in Füulnis überging und es ist fraglich, ob die Muscheln nicht infolge des faulenden Wassers, der Vermehrung der Bakterien und der schlechten Oxydationsverhältnisse giftig geworden sind, so wie in meinen Versuchen in Neapel. Dabei gelang es nicht im Seewasser an jenen Stellen, wo die giftigen Tiere zu finden waren, das Gift nachzuweisen und WoLfF stellte fest, daß selbst das Wasser des Fundortes der Wilhelmshavener Giftmuscheln 100 literweise eingedampft und sogar in großer Menge auf einmal injiziert bei den Versuchstieren irgend eine Giftwirkung nicht zustande brachte. THESEN weist wohl mit Recht darauf hin, daß dieser Umstand an und für sich gegen die Aufnahme der im Wasser löslichen Giftstoffe noch keinen sicheren Beweis liefert, weil der Nachweis des Giftes aus dem Seewasser infolge der starken Verdünnung recht erschwert sein kann, wogegen die Muscheln in ihrem Körper sehr geringe Mengen des Giftes in bedeutenden Mengen anzuhäufen vermögen. Es ist aber zu beachten, daß das klinische Bild der Muschelvergiftung von den in Betracht kommenden, durch präformierte Gifte, wie Kupfer, Arsen, Blei usw. hervorgerufenen Vergiftungssymptomen ganz abweicht. Dabei wurden bei den chemischen Untersuchungen im Muschelkörper solche Gifte nur in äußerst geringen, verschwindend kleinen Mengen nachgewiesen, so, daß wie z. B. DoDGsoN berechnete, unter Berücksichtigung des Arsengehaltes der Muscheln 435-580 Liter Miesmuscheln verzehrt werden mübten, um eine schwere Arsenvergiftung zu bewirken. Daher dürfte es unwahrscheinlich sein, daß die giftigen Muscheln gelöste, präformierte Gifte vom Seewasser in sich aufnehmen und die Entwicklung der Giftwirkung ist wohl in anderen Ursachen zu suchen. Bemerkt sei, daß die Fischer im Gegensatz zu Obigem die Giftwirkung der Muscheln an vielen Orten auch heute noch dem Umstand zuschreiben, daß die Muscheln am Kupferbeschlag des Schiffsbodens oder an mit Minium frisch angestrichenen Tonnen anhaften. Von den Helgoländer und Schleswig-Holsteiner Fischern habe ich auch selbst oft gehört, daß es gefährlich sei, die von den Tonnen abgetrennten Miesmuscheln zu essen, da unter denselben verhältnismäßig viele giftig seien und die Giftwirkung davon herrühre, daß die Tiere von der Tonnenoberfläche metallische Gifte in sich aufnehmen. Daß unter den der Tonne anhaftenden mangelhaft entwickelten Tieren tatsächlich giftige vorkommen können, haben die von Tonne $F$ aus Süder-Piep stammenden Giftmuscheln mit Bestimmtheit bewiesen und bestätigen damit gewiß die Richtigkeit der alten Erfahrung der Fischerleute. Aber diese Untersuchungen wiesen auch nach, dab die Giftwirkung der an der Tonne befindlichen Muscheln nicht mit der Metallsubstanz der Tonne in Verbindung gebracht werden kann, sondern die Ursache des Giftigwerdens im Organismus der Muschel selbst zu suchen ist.

Im Anschluß an die Wilhelmshavener Vergiftungen lag auch die Erwägung jener Möglichkeit auf der Hand, daß das Muschelgift ein Fäulnisgift sei, welches vom stark verunreinigten Wasser in das Innere der Muschel gelangt, eventuell sich in dem Muschelkörper selbst bildet. Durch Lindner's Beobachtung, der anläßlich der im Jahre 1888 beobachteten Wilhelmshavener Vergiftungen an den Giftmuscheln einen unangenehmen Fäulnisgeruch wahrnehmen konnte, wurde diese Vermutung noch gestützt. WOLFF und VIRCHOW wiesen aber mit Gewißheit nach, daß das Muschelgift kein Fäulnisgift sei und später stellten THESEN und andere auch das zweifellos fest, daß frische Giftmuscheln Anzeichen der Fäulnis nicht aufweisen. Da es aber sehr auffallend war, daß die Giftmuscheln von Wilhelmshaven ausschließlich im Dock mit stagnierendem Wasser lebten, wo auch die Verunreinigung sehr bedeutend war und das Wasser Schwefelwasserstoff enthielt, sprach WOLFF von der Möglichkeit, „daß das Gift unter Mitwirkung von Bakterien gebildet wird“. VIRCHOw versuchte auch die in Betracht kommenden Bakterien zu isolieren, aber 
diese Untersuchungen waren nicht von Erfolg begleitet. Später beschrieb LEwiN eine Bakterienart, welche seiner Ansicht nach durch Erkrankung der Muschel die Giftbildung auslösen dürfte, er suchte aber die unmittelbare Ursache der Giftbildung bereits in der Erkrankung der Muschel. Demgegenüber gelangte Ivo Bandi im Jahre 1912 zur Feststellung, daß die Muscheln Bakterien in sich aufnehmen und verdauen und einerseits das durch die Bakterien ausgeschiedene Gift, andererseits die vom aufgelösten Bakterienkörper frei gewordenen Stoffe bei Verzehrung der Muschel giftig wirken und daß „nicht nur Fälle von Infektionen, sondern auch die Vergiftungserscheinungen, welche nach dem Genuß roher und frischer Mollusken auftreten, ausschließlich bakteriellen Ursprungs seien". Aber das Muschelgift ist sowohl in Bezug auf die toxikologische Wirkung, als auch auf seine außerordentliche Widerstandsfähigkeit von den Bakteriengiften im wesentlichen verschieden. Außerdem ging die Giftwirkung der Muscheln nicht parallel mit der Verunreinigung des Wassers, z. B. in Oslo, wo die Verunreinigung der geschlossenen Bucht im Juli und August am größten war und die Zahl der Bakterien am meisten anstieg, ist die Giftwirkung der Muscheln um diese Zeit gesunken. Überdies haben meine Untersuchungen in Neapel auch bewiesen, daß ,die Verdauung der Bakterien nur dann in bedeutendem Ausmaße erfolgt, wenn die Muschel unter günstigen oder nicht übermäßig schlechten Oxydationsbedingungen lebt und beträchtliche Mengen von anderen Nahrungsstoffen ihr nicht zur Verfügung stehen". Dies bedeutet, daß auf Grund des Besprochenen das Muschelgift nicht einfach als Giftstoff der das Wasser verunreinigenden Bakterien aufgefaßt werden darf und daß in der Entwicklung der Giftbildung außer den Bakterien auch andere Faktoren eine Rolle spielen werden.

In jüngster Zeit gaben insbesondere amerikanische Forscher der Ansicht Ausdruck, daß das Muschelgift von den durch die Muschel aufgenommenen giftigen Planktonten, hauptsächlich vom Gonyaulax herrührt. Das Herstammen des Muschelgiftes von giftigen Planktonten hat eigentlich zuerst LINDNER noch im Jahre 1888 anläßlich des Vergiftungsfalles II. von Wilhelmshaven behauptet. Er bemerkt, daß „bei vielen Giftmuscheln der ganze Mantel besonders an der Innenfläche der Schalen mit Myriaden von eingekapselten Infusorien, Amöben und Gregarinen ähnlichen Formen besetzt war, unter denen sich auch coccidienartige Mikroben befanden“. Später schreibt er über Rhizopoden und Sporozoen und gelangt zur Feststellung, daß die Zerbrechlichkeit und die Streifung der Muschelschalen als eine „durch niederste tierische Parasiten hervorgerufene Atrophie anzusehen

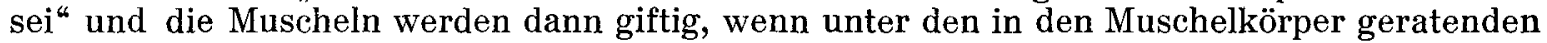
Mikroorganismen sich giftbildende Organismen befinden. Seiner Aussage nach waren an den Fundorten der Giftmuscheln zahlreiche "Monaden“, dagegen fand er solche ebendort im offenen Meer nicht. LINDNERs Meinung konnte allgemeine Anerkennung schon deshalb nicht erlangen, da man über die als giftig bezeichneten Planktonten aus seinen Arbeiten kaum mehr erfährt, als daß sie den einzelligen Tieren angehören. Experimentelle Untersuchungen, die seine Behauptung hätten stützen können, führte er nicht aus. So ist seine Auffassung bald in Vergessenheit geraten. Im Jahre 1932 veröffentlichte jedoch SoMMER eine äußerst interessante Beobachtung. Er fand nämlich anläßlich der im Jahre 1932 in Kalifornien vorgekommenen Vergiftungen, daß der im Sande lebende Krebs Emerita analoga, welcher sich mit Planktonorganismen ernährt, zur selben Zeit, als die Miesmuscheln Vergiftungen verursachten, ebenfalls giftig geworden war. Nach seinen Untersuchungen war das Gift auch im Sande nachweisbar.

Daß zugleich mit den Miesmuscheln auch andere Tiere giftig werden können, haben die Untersuchungen von WOLFF schon früher bewiesen. WOLFF zeigte nämlich, daß im selben Hafenteil, wo die giftigen Muscheln lebten, die Seesterne und sogar die Garnelen sich die Giftwirkung aneigneten. Soweit die Giftwirkung der Muscheln abnahm, verringerte sich auch jene der Seesterne. Was die Erklärung der Vergiftungsfähigkeit der Seesterne anbelangt, so nimmt er die Möglichkeit an, daß das Gift von den verzehrten Muscheln in die Seesterne gelangt. Es ist bekannt, daß der Seestern Asterias rubens an vielen Orten ausschließlich auf Muschelnahrung angewiesen und daß das dieser Lebensweise angepaßte Tier der ärgste Verwüster der Muschelbänke ist. Dies scheint WolfF's Annahme in jeder Hinsicht zu stützen. Überdies haben meine später zu erörternden Versuche klargelegt, daß ungiftige Seesterne nach Verzehrung von Giftmuscheln sich stark giftwirkend erweisen. Das bedeutet, daß das Gift der Seesterne von den Muscheln herstammt. HAVINGA, der sich mit der Ernährung der Garnelen befaßte, behauptet, daß die Garnelen mit Vorliebe tierische Nahrung verzehren; im Magen sind hauptsächlich winzige Krebse und Wurmüberreste zu sehen, selten schlucken sie Schlamm, "es werden als Nahrung noch kleine Schnecken und Muscheln erwähnt". Da im Sinne der obigen Angaben die Gar- 
nelen außer Muscheln auch viel anderes verzehren, erklärt es sich, daß ihre Giftwirkung bedeutend geringer ist als die der Muscheln und Seesterne. Dennoch dürfte in Anbetracht des Gesagten die Giftwirkung dieser Tiere ähnlich den Seesternen mit der Verzehrung von Muscheln zu erklären sein und geradeso wird auch meine Beobachtung verständlich, daß die in eine große Masse von Giftmuscheln eingeschlossenen Carcinus-Krebse sich als giftig erwiesen haben. Die Art Emerita analoga ernährt sich jedoch, wie bereits erwähnt, von Planktonorganismen und eine derartige Erklärung der Giftwirkung würde auf Schwierigkeiten stoßen.

Mit der Giftigkeit von einzelnen Planktonten hat man sich schon früher befaßt und besonders im Zusammenhang mit den Peridineen bemerkt, daß, falls sie sich stark vermehren, die Seetiere massenhaft absterben. Nach LindemanN „machen die Peridineen mit den Bacillariaceen die Hauptmasse der Unnahrung des Meeres aus". Wie er sagt, trifft man auf offener See häufig „meilenweite Flecken von gefärbtem Oberflächenwasser, rotes oder gelbes Wasser", dessen "Ursache nicht die schwefelhaltigen Quellen des Grundes sind, wie man das früher annahm, sondern die außergewöhnliche Vermehrung von Peridineen. Es kommt sodann vor, daf die Peridineen (wie z. B. Gonyaulax) in großen Massen absterben ,so, daß ihre Zersetzungsprodukte das Wasser mit Gift anreichern, dann tritt meist ebenfalls ein großes Sterben aller möglichen Meerestiere ein ". Lindemann beobachtete bei Rostock ein durch Heterocapsa und Glenodinium verursachtes massenhaftes Eingehen von Fischen. KoFoId beschrieb im Jahre 1907 in Kalifornien im Golf von San Pedro anläßlich des durch Gonyaulax polyedra verursachten „roten Wassers“ das massenhafte Absterben der verschiedensten Seetiere und bemerkte, daß nicht alle Tiere in gleicher Weise zum Opfer fielen, da nebst mehreren anderen die Strandkrebse wie Hyppa (Emerita) analoga und Cancer antennarius unbeschädigt blieben. Bringt aber LiNDEMANN das Zugrundegehen der Tiere mit den Zersetzungsprodukten der absterbenden Peridineen in Zusammenhang, so vermutet Koford, daß3 Gonyaulax Gift bildet. Eine derartige Vermehrung der Peridineen, daß diese mikroskopischen Planktonten in abgeschlossenen Buchten schon den äußeren Anblick des Wassers ändern, bleibt aller Wahrscheinlichkeit nach auf die Oxydationsverhältnisse nicht ohne Einfluß und eine starke Verschlechterung derselben wird auch für die Peridineen selbst von großem Nachteil sein, so, daß ihrer Vermehrung bald ein Ende bereitet wird. In geschlossenen Buchten wird aber gewiß auch der Nahrungsmangel der weiteren Vermehrung Schranken setzen und es ist vollkommen erklärlich, daß bei Wirkung der obigen zwei Faktoren ein rasches Ansteigen der Anzahl der Peridineen bald durch eine gleichartige Senkung derselben abgelöst wird. Die aùs den in riesigen Massen absterbender Organismen herstammenden Zersetzungsprodukte schädigen die schon durch den Sauerstoffmangel ohnehin schwer leidenden Seetiere empfindlich und das kann ihr massenweises Eingehen verursachen Bei diesen Vorgängen ist es daher ganz überflüssig, an eine besondere Giftabsonderung zu denken und die Erscheinung darf keinesfalls als ein Beweis der Giftwirkung der Peridineen angesehen werden. KoFoID, einer der besten Kenner der Peridineen, beschrieb bei Untersuchung der Dinoflagellaten von SanFrancisco zwei neue Arten, namentlich Gonyaulax catenella und Gonyaulax acatenella. Er und F. Whedon stellten fest, daß in der Nähe von San-Francisco diese Peridineen im Plankton vorherrschen, und daß dieselben im Magen und Darm der giftigen Muscheln und des Krebses Emerita analoga ebenfalls in großer Menge zu finden sind. So dachte man daran, daß sie bei der Entwicklung der Giftigkeit „eine Rolle spielen können“. Anfangs haben sich die Autoren in Bezug auf den Zusammenhang zwischen Anwesenheit von Gonyaulax und der Entfaltung der Giftwirkung mit Vorbehalt geäußert und sprachen nur über Möglichkeit und Wahrscheinlichkeit, später aber, nach fortgesetzten Forschungen, haben sie zusammen mit H. Sommer und K. F. MEYER im Jahre 1936 auf dem Mikrobiologischen Kongreß zu London ihre Untersuchungen dahin gehend zusammengefaßt: „Das Muschelgift ist während des Sommers für wenige Tage in gefährlichen Beträgen vorhanden. Nur wenn Meerwasser, welches eine große Menge von Gonyaulax catenella enthält, an die Tiere verfüttert wurde, nahm deren Giftigkeit zu. Das Gift konnte direkt aus dem Plankton extrahiert werden, ähnliches mag für Europa gelten“. KoFoID und Mitarbeiter erklären daher die Giftwirkung in einer recht einfachen Weise durch die Gegenwart von giftigen Planktonten und es ist eben durch die Einfachheit dieser Auffassung erklärlich, daß dieselbe in den Fachkreisen umso eher verbreitet wurde, als gegen die Richtigkeit der Beobachtungen der von ihren hervorragenden Peridineenforschungen wohl bekannten obigen Autoren kein Einwand erhoben werden kann. An manchen Orten wünschte man diese Auffassung auch in der Praxis in der Weise zu verwerten, daf im Hinblick auf das Leuchtvermögen von Gonyaulax-Arten in den Zeiträumen, wo das charakteristische Leuchten 
des Meeres einsetzte, der Muschelgenuß eingestellt wurde. Sommer hatte schon vorausgehend die Untersuchung der Giftwirkung des an den Kalifornischen Küsten häufigen Krebses Emerita empfohlen, weil die Giftwirkung dieses Tieres jene Periode anzeigt, wo auch die Miesmuscheln giftig werden. Unzweifelhaft haben die Beobachtungen von KoFoID und Mitarbeiter betreffs der Muschelvergiftungen sehr interessante und wertvolle Angaben ans Tageslicht gebracht, bei Übersicht sämtlicher auf die Giftwirkung der Muscheln bezughabender Daten gelangt man jedoch zur Feststellung, daß auch diese Untersuchungen die Frage nicht nach jeder Richtung restlos erklären. Die aus den Beobachtungen der genannten Autoren sich ergebenden Folgerungen stehen mit unseren bisherigen Feststellungen nicht ganz im Einklange. Es ist nämlich schwer anzunehmen, daß es hervorragenden Forschern, wie Möbius, WolfF, Schulze, Virchow, Thesen und anderen nicht aufgefallen wäre, daß3 der Magen und Darm der Muscheln mit Peridineen oder mit anderen einzelligen Lebewesen voll ausgefüllt sei. Handelte es sich um eine derartige Erscheinung, so hat das auch LINDNER gesehen, dessen diesbezügliche ungewisse Beschreibung klar zeigt, daß er den obigen Forschern ähnliche protistologische Kenntnisse nicht besaß. Überdies haben die vorangehend erwähnten Forscher im Wasser des giftigen Hafenteiles, auch falls es in grober Menge eingedampft wurde, Giftstoffe nicht nachweisen können und im Wasser ein massenhaftes Vorhandensein von Peridineen zumindest nicht beschrieben. Ich seibst konnte im Magen der von der Süderpiep-Tonne siammenden Giftmuscheln auch durch mikroskopische Untersuchung Peridineen nicht nachweisen und aus den Giftspuren zeigenden Muschehn von Neapel haben die Peridineen ebenfalls gefehlt. Setzt man außerdem voraus, daß die Giftigkeit der Muscheln durch die mit der Nahrung aufgenommenen Peridineen hervorgerufen wird, deren Gift vom Plankton unmittelbar extrahiert werden kamn, wird auch das schwer zu verstehen sein, weshalb Wolff $2-3$ Wochen, SchmidTManN im Berliner Aquarium 3-4 Monate brauchte, damit die Muscheln im frischen Wasser ihre Giftigkeit verlieren, wozu am offenen Meer (LINDNER's Mitteilung) nur einige Tage nötig sind, und warum es demgegenüber bei WOLFF $2-3$ Wochen dauerte, bei SchIMDTMANN (laut Mitteilung von LiNDNer) nur 24 Stunden, bis die Muscheln in dem Hafen mit gifthaltigem Wasser giftig geworden sind.

Die auß3erordentliche Seltenheit der Muschelvergiftungen in Europa und deren Beschränkung auf das nördliche Wassergebiet kann auch nicht einfach durch die Gegenwart von giftigen Peridineen erklärt werden. Spielen doch z. B. bei den vom Adriatischen Meer unter den Namen "Mare sporco“ oder "Malattia del mare“ beschriebenen Erscheinungen, beim Schleimigwerden des Meeres, wie Struer 1903 und Con 1905 beobachteten, in erster Linie eine aufleuchterde Gonyaulax-Art, nach Beobachtung von GARÁd im Jahre 1905 wieder manchmal Ceratien und Peridineen die Hauptrolle und trotz der außerordentlich großen Vermehrung der Peridineen hat man Vergiftungen am Adriatischen Meer noch niemals verzeichnet, obwohl die Küstenbevölkerung dem Muschelgenuß nicht abgeneigt ist. Nach Bericht von $H$. CAspers sind die Peridineen im Schwarzen Meer in der Nähe von Varna sehr häufig und die Miesmuscheln ein beliebtes Nahrungsmittel. Trotzdem kommen paralytische Muschelvergiftungen nicht vor. Weshalb unter verschiedenen Muschelarten die Giftwirkung eben besonders nach Genuß der Miesmuschel auftritt, kann durch die Gegenwart von giftigen Planktonten gleichfalls nicht in erforderlicher Weise erklärt werden und es sind Salkowsky's, Lohneyer's und meine Beobachtungen ebenso wenig verständlich, daß nämlich unter einer großen Menge von ungiftigen Muscheln auch Giftspuren aufweisende oder wenig giftige Tiere vorkommen. In meinen später zu beschreibenden in Neapel vorgenommenen Untersuchungen, wo die Giftwirkung zunahm, bzw. die Muscheln giftig geworden sind, konnte von der Anwesenheit von giftigen Planktonten keine Rede sein. KoFoID's und seiner Mitarbeiter wertvolle Beobachtungen sind daher spezielle Fälle der Entstehung des Muschelgiftes unter den kalifornischen Verhältnissen, zu deren Erklärung jedoch weitere Untersuchungen erforderlich erscheinen. Die auf Grund dieser Beobachtungen gemachten allgemeinen Feststellungen haben die Aetiologie der Giftwirkung der Muscheln noch nicht bis auf den Grund klargelegt. Die Anschauungen wieder, welche die Theorie von KoForD und seinen Mitarbeitern nicht nur auf die Muschelvergiftungen, sondern auch auf andere ähnliche Erscheinungen auszubreiten suchten, haben nicht einmal mehr die feste biologische Grundlage beibehalten und können im höchsten Grade als hypothetisch bezeichnet werden.

Es genügt von diesem Standpunkt aus darauf hinzuweisen. daß eine Auffassung vertreten wurde, wonach die durch die Aale verzehrten giftigen Planktonten die Haffkrankheit auslösen sollten. Diese Forscher nehmen als Ursache dieser in vielen Hinsichten noch ungeklärten Erkrankung einen angeblichen PeridineenGiftstoff an, welcher über ein vermittelndes Wirtstier in dea menschlichen Organismus gelangte. Nach dieser 
Meinung häufe sich das Gift der Planktontiere in solcher Menge in den Geweben des Aales an, daß das Verzehren des giftigen Fisches diese von der Muschelvergiftung so sebr verschiedene Erkrankung hervorriefe. Zur Annahme des Vorhandenseins eines derartigen präformierten, gegen äußere Einwirkungen widerstandsfähigen, und verschiedene Krankheitsbilder zeigenden überaus starken Giftes, besonders bei den Lebewesen, welche "mit den Bacillariaceen die Hauptmasse der Urnahrung des Meeres ausmachen" besitzen wir heute noch keinen sicheren Anhaltspunkt.

Nachdem es nicht gelungen ist, anläßlich der Wilhelmshavener Vergiftungen im Wasser präformiertes Gift nachzuweisen, dachten mehrere Forscher, daß sich das Gift im Zusammenhang mit Stoffwechselerkrankungen der Muschel bildet, eventuell mit Funktionsstörungen der Leber verbunden ist. WoLFF's eingehenden Untersuchungen gemäß ist das Gift in erster Linie an die Leber gebunden. Im November und Dezember des Jahres 1885 konnte bei den in dem Wilhelmshavener Hafen gefundenen Muscheln das Gift nur in der Leber nachgewiesen werden, dagegen war das Gift bei den Tieren vom Januar und Februar des Jahres 1886 außer in der Leber auch in den anderen Weichteilen nachweisbar, aber auch in diesen Fällen erwies sich die Leber am giftigsten. Durch seine Untersuchungen gelangte WOLFF zur Ansicht, das Gift dürfte sich wahrscheinlich in der Leber bilden, obwohl er die Möglichkeit nicht ausschloß, daß die Leber das Gift nur aufspeichert und daß das Gift „unter Mitwirkung von Bakterien" gebildet wird. Die Untersuchungen von SaLkowskY führten ihn ebenfalls zur Meinung, daß das Muschelgift in der Leber seinen Sitz hat. Nach seinen schon erwähnten Versuchen weicht der alkoholische Extrakt der giftigen Tiere von jenem der normalen in der Farbe ab und gibt mit Salpetersäure in der Hitze eine charakteristische Farbreaktion. Wie bereits zitiert, behauptet VIRCHOw, daß3 die giftigen Tiere „eine geringere Energie der Bildungsvorgänge anzeigen, aIso kurz gesagt sie haben etwas Atrophisches an sich". Er hat daher auch selbst die giftigen Muscheln für mangelhaft entwickelte, kranke Tiere angesehen.

Schumptunn hat die giftigen Muscheln ebenfalls als pathologisch aufgefaßt und von diesen festgestellt, dak ihre Schale dünn, zerbrechlich und blat ist. Die Tiere hatten einen unangenehmen Geruch und die "Leber war tief verändert". Auch andere Forscher haben die auf die Erkrankung hinweisenden Symptome der "giftigen Tiere an den Weichteilen beschrieben und nach einigen ist das Fleisch mehr Iocker, mehr schleimig, andere stellten wieder fest, daf das Fleisch "etwas heller ist und einen Ton ius gelbliche hat". LiNDNER beschreibt den Mantel als auffallend fettreich. Nach der Aussage von melireren Autoren ist "der Gerucl und Geschmack widerlich süßlich, an Fleischbrühe erinnernd und das Kochwasser der giftigen Muschein ist bläulich (das der gesunden gell)lich). LinDNER bezeichnet den Geruch der Tiere als widerlichen Fäuthisgeruch, "ihnlich dem Geruch, wie er nicht selten in der Nïhe der Watten walugenommen wird". Wie bereits erwähnt, haben VIRCHOW und WoLfF festgestellt, daß die in frisches Wasser gesetzten Muscheln ihre Giftwirkung in 2-3 Wochen verlieren. SchmidThiNN hat anlïßłlich der i.J. 1885 vorgekommenen Erkrankungen gefunden, dab bei den im Berliner Aquarium gehaltenen Tieren die Giftwirkung erst nach Verlauf von 3-4 Monaten verschwand, wogegen nach LiNDNER"s Angaben die Muscheln an der offenen See die Vergiftungsfähigkeit schon nach einigen Tagen eingebült haben. 'WoLFF's Untersuchungen zeigten auch, dats bei den 3 Wochen lang im Filtrierpapier gehaltenen Hungertieren die Giftwirkung bedeutend abnahm und sogar die 3-4 fache Josis des Giftextraktes nur einen Teil der Versuchstiere tötete. Wolfr, VIRCHOW' und SchmidTanN haben dagegen auch festgestellt, dak gesunde Muscheln in dem geschlossenen Hafenteil, dem Fundort der Giftmuscheln ron 1885 untergebracht, 2-3 Wochen zum Giftigwerden brauchten, während nach LINDNER Angahen die an den Fundort der Giftmuscheln von 1888 gesctuten Tiere sehon nach 24 Stunden "emineut giftig" geworden sind. Dementsprechend erfolgt die Fintstebung und das Verschwinden des Giftes in Abhängigheit vom Zustand des Tieres oder von äuferen Fabtoren in recht versehiedenen Zeiträumen, was wieder nur dann verstïndlich erscheint, wenn das Gift nicht als aus dem Wasser aufgenommenes Gift angeselıen, sondern als Produkt des tierischen Organismus aufgefaßst wird. Auf Grund der angeführten Tatsachen wird es erklïrlich erscheinen, daß nach den Wilhelmsharener Vergiftungsfällen, wie THESEN sagt: "die alJgemeine Annahme war, daR das Gift als ein pathologisches Stoffwechselprodukt der Muschel aufzufassen sei". In Anbetracht seiner Untersuchungen, die ergaben, daß giftige Tiere keine histologisch faßbaren Verïnderungen aufreisen, und daß die Eigenschaften giftiger und gesunder Tiere sich voneinander nicht unterscheiden, nahm THlsEN gegen obige Ansicht scharf Stellung. Abgesehen von den an der Schale und an den Weichteilen nahrnehmbaren Besonderheiten - auf deren Erörterung wir noch später zurïckkommen, - hat auch THESEN selbst auf eine mit den giftigen Muscheln verbundene eigentümliche, Erscheinung hingewiesen, daß nämlich die Ratten die giftigen Muscheln in irgend einer Weise erkennen und nicht fressen.

Diese von THEsen schon 1902 erwähnte Erscheinung habe ich in Neapel auch selbst beobachtet. Die im Käfig untergebrachten ungiftigen Muscheln wurden von den Ratten rasch aufgefressen. Auch die von den Schalen abgetrennten giftigen Muscheln umgaben die Ratten sofort, ohne jedoch anzubeißen. Daß dieses Verhalten der Ratten mit irgend einem Geruch zusammenhängt, beweisen jene meiner in Neapel ausgeführten Versuche, die zeigten, daß, falls die Nase der Ratten mit Kokain eingerieben, d. h. unempfindlich gemacht wurde, sie auch die Giftmuscheln verzehrten und bei ihnen bald die schweren Symptome der Muschelvergiftung auftraten. Die giftigen Muscheln besitzen daher doch irgend einen besonderen Geruch, nur ist dieser Geruch nicht immer so stark, daß auch wir ihn empfinden können. Interessant ist in dieser Hinsicht auch LINDNER's Beobachtung, daß „der Geruch der giftig gemachten Miesmuschel zwar auch widerlich, jedoch bei weitem 
nicht so penetrant ist, wie bei den ursprünglich giftigen Tieren“. Es scheint also, daß die auf die Giftwirkung hinweisenden Zeichen nur bei Tieren, die länger unter für die Giftigkeit günstigen Verhältnissen leben, zur Geltung kommen. Überdies ist es aus der allgemeinen Pathologie bekannt, daß nicht alle Stoffwechselstörungen in dem äußeren Zustand des Organismus oder in der Änderung der anatomischen Struktur von einzelnen Organen zum Ausdruck kommen und so spricht bei den Muscheln weder das Fehlen von äußerlichen Abweichungen, noch das negative Ergebnis der histologischen Untersuchungen an und für sich gegen die Voraussetzung einer Stoffwechselstörung und schließt das Entstehen eines pathologischen Stoffwechselproduktes nicht aus. Es ist daher begreiflich, daß gegenüber von Thesen's Ansicht die Auffassung der Mehrheit der Wilhelmshavener Forscher von mehreren auch viel später angenommen wurde. Im Anschluß an die kalifornischen Vergiftungen vom Jahre 1927 gelangte MEYER neuerlich zur Feststellung, daß es sich bei den giftigen Muscheln um eine Stoffwechselerkrankung handelt, welche wahrscheinlich zur Bildung eines einer Quarternärammoniumbase entsprechenden pathologischen Stoffes führt, ohne dabei die äußeren Merkmale der Muscheln zu ändern. Meine Untersuchungen im Jahre 1936 in Neapel lassen ebenfalls die Folgerung zu, daß das Entstehen des Muschelgiftes mit dem ungünstigen Gasstoffwechsel und mit der ungünstigen Ernährung im Zusammenhang steht, d.h. es ist schließlich ein Ergebnis der pathologischen Lebenserscheinungen der Muschel. Die Bedingungen der Entstehung des Muschelgiftes wurden aber auch durch diese jüngsten Untersuchungen nicht in jeder Hinsicht geklärt und es blieben insbesondere eben die Beobachtungen von MEYER ungeklärt, der anläBlich der kalifornischen Vergiftungen feststellte, daß die giftigen Muscheln weder unter schlechten Oxydationsverhältnissen lebten, noch in stark verunreinigtem Wasser gewesen sind und trotzdem in einigen Tagen giftig wurden.

\section{B. Eigene Beobachtungen über Muscheln der Deutschen Bucht.}

\section{Allgemeine Bemerkungen über den Fundort der giftigen Muscheln.}

Im Zusammenhang mit den Wilhelmshavener Vergiftungen gelangten die Forscher (CRUMPE und PERMEWANS früheren Beobachtungen entsprechend) zur Feststellung, daß die giftigen Muscheln in abgeschlossenen, stagnierenden Wassergebieten Ieben. Nach Beobachtung von CrumPE lebten die giftigen Muscheln von Tralee in einem schmalen Fjord, welcher von der offenen See durch eine Schleuse abgesondert war. Den Fundort der Wilhelmshavener Muscheln bildete ein geschIossenes Dock, ein langes, schmales Bassin mit zwei Schleusen. WolfF's Untersuchungen zeigten, daß sowohl die Muscheln als auch die Seesterne ,im Hafenbassin“ dort am giftigsten waren „wo die Stagnation am größten, nahezu vollkommen war“. Die Giftwirkung "nimmt etwas ab, je mehr man sich dem Vorhafen nähert, wo der Wasserwechsel beim Öffnen und Schließen "der Schleusen etwas größer ist". WoLFF hebt jedoch in seinen Untersuchungen Iervor, daß Wilhelmshaven kanalisiert ist, und daß alle Kloaken weit außerhalb des Hafens münden. Das Wasser an den giftigen Stellen aber hat er doch stark verunreinigt, sowie schwefelwasserstoffhaltig gefunden“. ScHMIDTMANN unternahm seit $1885 \mathrm{im}$ Wilhelmshavener Dock monatlich Untersuchungen, von welchen LINDNER sagt: ,Gewöhnlich entsprach der Grad der Muschelgiftigkeit im Hafenwasser dem Grade seiner Stagnation. Auffallend war es, da $\beta$ in dem nach Süden gelegenen Handelshafen, in welchem See- und Süßwasser sich mischen, eine giftbildende Wirkung des Wassers auf die Muscheltiere bisher niemals zur Wahrnehmung gekommen war"

Die von THESEN aus Oslo beschriebenen giftigen Muscheln stammten ebenfalls aus einem geschlossenen Hafenteil. THESEN bekam nur aus solchen Hafenteilen Giftmuscheln, deren Wasser stagnierte, doch bestand seiner Feststellung nach zwischen der Verunreinigung und der Giftwirkung kein bestimmter Zusammenhang. Übrigens waren in den von DoDGSON als bestimmt paralytische Muschelvergiftung anerkannten Fällen die Muscheln fast alle aus geschlossenen Häfen stammende, sogenannte Dockmuscheln und so konnte man mit Recht daran denken, daß in der Entstehung der Giftwirkung die Stagnierung des Wassers irgend eine Rolle spielt. Da jedoch zwischen der Stagnierung des Wassers und der Giftwirkung der Muscheln der Zusammenhang nicht immer deutlich erscheint und trotz der fortgeschrittenen Stagniorung des Wassers die Muscheln nicht immer giftig werden, sei mir gestattet, bloß auf meine Untersuchungen in Neapel hinzuweisen. Im Jahre 1936 waren in dem Mergellina benannten Teil des Golfes von Neapel nach meinen Untersuchungen Giftspuren enthaltende Exemplare von Mytilus minimus und Ostrea plicata zu finden. Genannter Golfteil, von seichtem Wasser und durch die dort stationierten Fischerbarken stark verunreinigt, wird nach Osten zu durch einen schmalen Landstreifen begrenzt, nach Norden zu steht aber die Bucht durch ein breites Tor offen. Der den Verunreinigungen ausgesetzte Buchtteil bildet dementsprechend wohl kein offenes Wassergebiet, derselbe steht aber durch einen breiten Eingang mit dem Wasser der großen Bucht in steter Ver- 
bindung und es sind darin trotzdem Giftspuren enthaltende Muscheln zu finden. Dagegen ist die Austernzucht des Lago del Fusaro in der Nähe von Baja bei Neapel durch einen schmalen Landstreifen vom offenen Meer vollständig getrennt. Der Teich ist nur durch schmale Kanäle mit dem Meer verbunden, die darin lebenden Muscheln weisen trotzdem keine Giftwirkung auf. Ein ähnlicher Fall liegt bei den Miesmuscheln und Austern aus Taranto vor. Die berühmte Austern- und Miesmuschelzucht befindet sich im Mare Piccolo. Diese tiefe Bucht steht im ganzen durch zwei schmale Kanäle mit dem offenen Meer in in Verbindung. Im Innern der Bucht sind die Verhältnisse noch ungünstiger, da, während sich am Fusaro-See größere Ansiedlungen nicht befinden, die Stadt Taranto mit ca. 55000 Einwohnern unmittelbar an der Innenseite des Mare Piccolo liegt und hier befindet sich einer der größten Kriegshäfen Italiens. Also der Umstand allein, daß die giftigen Muscheln an abgeschlossenen, mehr oder weniger verunreinigten Stellen leben, die von der Strömung des Wassers abgesperrt sind, erklärt im Sinne des Beschriebenen die Entstehung der Giftwirkung noch nicht.

Anläßlich der kalifornischen Vergiftungsfälle wurde auch der Gedanke aufgeworfen, daß die zu Vergiftungen führende Änderung des Stoffwechsels von Mytilus californianus wenigstens zum Teil vom Trockenliegen bei Ebbe herrührte. Richtig ist aber die Behauptung von H. HEATH, daß dieser Umstand bei Entstehung des Giftes keine Rolle spielen kann, denn es ist ja in Kalifornien das Sammeln und der Genuß der nach Ebbe zuräckgebliebenen sogenannten Ebbemuscheln außerordentlich verbreitet und Vergiftungen kommen doch sehr selten vor. Außerdem haben auch die bereits erwähnten Versuche von WolfF bewiesen, daß bei in Filtrierpapier eingewickelten, trockengehaltenen Hungertieren die Giftwirkung nicht steigt, sondern abnimmt. Das Verständlichmachen des Zusammenhangs zwischen der Stagnierung des Wassers und der Giftwirkung wird nach einzelnen Angaben auch dadurch erschwert, daf die giftigen Muscheln nicht nur in verunreinigten Häfen mit geschlossenem Wasser vorkommen, sondern zusammen mit gesunden Tieren auch dort, wo von einer Stagnierung des Wassers nicht gesprochen werden kann. So bemerkt z. B. SAlkowsky bereits in Anschluß an die Wilhelmshavener Vergiftungen, daß „an einem Ort, wo kein Grund für die Annahme vorhanden war, daß die Muscheln giftig wären, man unter diesen dennoch einzelne gefunden hat, die für Kaninchen tödlichen Alkoholextrakt lieferten, doch waren die letalen Dosen in dem Falle weit gröBer". Zu gleicher Zeit machte WoLFF die Feststellung, daß ein Teil der von der Insel Wangeroog stammenden Muscheln, zwar in geringerem Maße, sich doch als giftig erwies, aber es befanden sich unter diesen Muscheln auch solche, von deren Extrakt auch sehr große Dosen eine Vergiftung nicht auslösten. LOHMEYER hat indessen beobachtet, "daß man auch nicht selten unter den Muscheln, welche sich an Seetonnen oder Strauchwerk angeheftet haben, giftverdächtige Exemplare findet". THESEN bemerkt, mit den Osloer Vergiftungen beschäftigt, ebenfalls, daß auch unter ungiftigen Muscheln einige Exemplare zu finden sind, deren Extrakt zwar nur in bedeutend größeren Dosen, aber doch Giftwirkung auslöst. Und MEYER stellt wieder im Zusammenhang mit den im Jahre 1927 beobachteten kalifornischen Vergiftungen fest, daß die giftigen Muscheln weder in geschlossenen Bassins noch in verunreinigten Häfen lebten und während der Ebbe für längere Zeit nicht trocken lagen und dachte deswegen daran, daß die in wenigen Tagen entstandene Stoffwechselstörung mit der Ernährung oder mit der Geschlechtstätigkeit im Zusammenhang stehen dürfte. Zusammenfassend kann also festgestellt werden, daß die giftigen Muscheln $\mathrm{zwar}$ größtenteils in stagnierenden Gewässern, in verunreinigten Häfen zu finden sind, daß aber auch Daten dafür vorhanden sind, daß in offenen Wassergebieten und unter gesunden Muscheln giftige Muscheln ebenfalls vorkommenkönnen. Vom Standpunkt der Ursachenforschung des Muschelgiftes besitzt eben letztere Feststellung große Bedeutung, da, wenn sich das Vorkommen der Giftmuscheln nicht auf verunreinigte, geschlossene Wassergebiete beschränkt, das Enstehen der Giftwirkung nicht ausschließlich mit diesen Faktoren erklärt werden kann.

Zur Entscheidung der Frage habe ich in der Nähe von Helgoland an der SchleswigHolsteiner Küste die an den an Abb. 3 mit gekreuzten Kreisen bezeichneten Stellen gesammelten Miesmuscheln untersucht und in erster Linie klarzustellen versucht, ob am offenen Wassergebiet unter ungiftigen Muscheln auch giftige vorkommen. Die wichtigeren Angaben über die Fundorte der untersuchten Muscheln, ferner die wesentlichen Eigenschaften der Tiere sind in Tabelle 1 angeführt. Die Daten zeigen, daß die gesammelten Muscheln sowohl in Hinsicht auf Form und Farbe, als auch die Dicke betreffend ein ziemlich wechselreiches Bild boten. Unter durchweg olivgrünen oder olivbraunen Muscheln befanden sich blaßgrüngelbe oder blaßbraune Tiere und die Schale der ganz winzigen 
Exemplare war oft vollkommen farblos. Dabei waren an der Schalenoberfläche von vielen Muscheln ausgesprochene, mehr oder minder breite, meistens radiäre Streifen sichtbar. Überdies erwies sich die Schale einzelner Muscheln als außerordentlich dünn, durchscheinend und zerbrechlich, wogegen die Oberhaut (das Periostrakum) im Gegensatz zu den festschaligen, nicht durchscheinenden Tieren, wo die Oberhaut dünn und matt war, ziemlich glänzend erschien. Es waren aber nicht nur in Farbe und Dicke der Schalen Abweichungen zu vermerken, sondern die Muscheln wichen auch in der Form von einander ab, indem neben der ausgesprochenen länglichen Muschelform auch eine deutlich breite Form in größerer Anzahl vorhanden war. Schließlich konnten auch Abweichungen im Zustand der Innenfläche der Muschelschale in der Farbe und im Entwicklungsgrad des Mantels festgestellt werden.

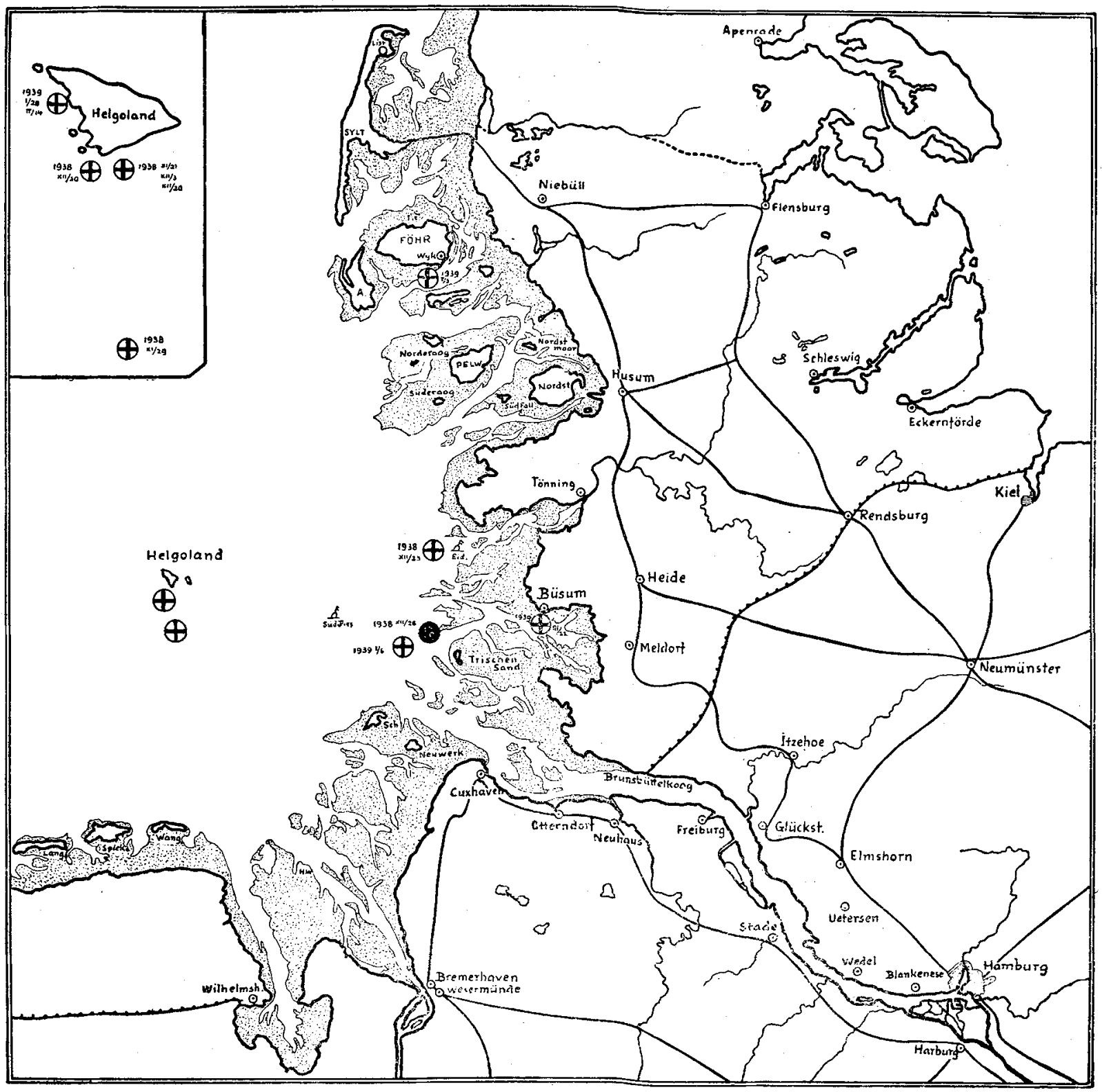

Abb. 3. Karte Schleswig-Holsteins und der Deutschen Bucht. Gekreuzte Kreis e: Fundort der Muscheln mit Angabe des Zeitpunktes des Sammelns. Schwarzer Kreis: Fundort der giftigen Muscheln mit Angabe des Fangtages. (Die dichtpunktierten Teile zeigen das Watt an.) 


\section{Untersuchungen über die Giftwirkung der gesammelten Muscheln.}

Wie schon angeführt, hat man bei den Wilhelmshavener giftigen Muscheln gewisse Formabweichungen im Verhältnis zu normalen Tieren beschrieben und mehrere von diesen Merkmalen waren an den von mir untersuchten Muscheln ebenfalls feststellbar. Es genügt in dieser Hinsicht die Streifung, Durchsichtigkeit, Zerbrechlichkeit und die breite Form der Muscheln zu erwähnen, Eigenschaften, die sich an einzelnen Fundorten außerordentlich charakteristisch zeigten. Den Daten in der Tabelle entsprechend kamen solche Tiere an gewissen Stellen, z. B. längs der Insel Helgoland nur vereinzelt vor, wogegen an anderen Stellen, wo sie einen bedeutenden Teil der Muscheln ausmachten, sich unter ihnen auch Tiere mit anderen Merkmalen befanden, nämlich auch dunkelfarbige Exemplare mit dicker Schale. Die Frage daher, ob die auf Grund der Formabweichung als giftig zu erachtenden Muscheln auch wirklich giftig gewesen sind, kann nur dann richtig entschieden werden, wenn man mit den von verschiedenen Fundorten stammenden Muscheln nicht nur in ihrer Gesamtheit (20-30 Tiere auf einmal) sondern auch mit jedem einzelnen Tier Versuche anstellt und die Tiere zu den Versuchen derart auswählt, daß die Untersuchungen auf die am selben Ort vorkommenden und verschiedene Schalenmerkmale aufweisenden Tiere gleichmäßig erstreckt werden. Da ich bei diesen Forschungen nicht nur größere Giftmengen zu entdecken suchte, sondern bemüht war, womöglich auch Spuren des Giftes nachzuweisen, habe ich zu meinen Untersuchungen nicht nur den Muschelextrakt nach THESEN bereitet, sondern auch RicheT's Versuche ausgeführt.

Die Muschelextrakte stellte ich in der auf Seite 282 dieser Arbeit beschriebenen Weise nach THEseN's Verfahren her und habe ihre Giftwirkung an Mäusen von ungefähr $20 \mathrm{~g}$ Körpergewicht, ferner an etwa $150 \mathrm{~g}$ schweren Ratten und schließlich an etwa $1 \mathrm{~kg}$ schweren Kaninchen ausgeprobt. Vorerst bereitete ich aus einer Gesamtmenge von $100 \mathrm{~g}$ der Weichteile der von verschiedenen Orten stammenden Muscheln Extrakte, dann stellte ich zur Untersuchung der Frage, ob unter den ungiftigen Tieren giftige zu finden seien, aus 10-14 Exemplaren an verschiedenen Fundorten gesammelter Muscheln separat Extrakte her. Da von verschiedenen Fundstellen meistens nur kleinere, oft nur 8-10-12 $\mathrm{g}$ schwere Tiere zur Verfügung standen, war die Menge der aus den einzelnen Tieren hergestellten Extrakte naturgemäß乃 beschränkt und machte $1.5-2 \mathrm{ccm}$, höchstens $3-3.5 \mathrm{ccm}$ aus. Deshalb ging ich bei Bestimmung der Letaldosis des Giftes derart vor, daß, falls $100 \mathrm{~g}$ Gesamtmenge der zu untersuchenden Muschelkörper keine Giftwirkung auslöste, ich vorerst den weißen Mäusen $1 \mathrm{ccm}$ des Extraktes intraperitoneal injizierte. Zeigte sich am Tier binnen 5 Minuten keine Giftwirkung, so spritzte ich nach 5 Mincten wieder $1 \mathrm{ccm}$ ein und wenn auch dann nicht Symptome der Vergiftung auftraten, erhielt das Tier nach weiteren 5 Minuten den Rest auf einmal. Sofern auch nach den darauf folgenden 10 Minuten Zeichen der Vergiftung nicht wahrnehmbar gewesen sind, hielt ich die Muschel für ungiftig. Ging das Versuchstier nach 10-20 Minuten nach der Injektion von $1 \mathrm{ccm}$ des Muschelextraktes ein, so injizierte ich $0.5 \mathrm{ccm}$. Abgesehen von den Muscheln von der Süderpiep-Tonne kam eine geringere Menge Extraktes - u. zw. $0.01 \mathrm{ccm}$ - nur in einem einzigen Falle zur Anwendung, doch hatte diese keine Giftwirkung mehr zur Folge. Bei den Tieren von der Süderpiep-Tonne, wo $100 \mathrm{~g}$ Gesamtmenge der Muscheln schon in Dosen von $0.01-0.02 \mathrm{ccm}$ schwere Vergiftungen auslöste, habe ich die Untersuchung der Giftwirkung mit $0.01 \mathrm{ccm}$ des Extraktes begonnen. In Fällen, wo die injizierte Maus 20 Minuten nach obiger Menge am Leben blieb, habe ich einem zweiten Versuchstier $0.02 \mathrm{ccm}$, falls auch dieses nicht verendete, einem weiteren $0.04 \mathrm{ccm}$ injiziert, dann die Einspritzung von $0.06 \mathrm{ccm}$ versucht. Diese Menge überlebte aber bloß ein einziges Tier, bei welchem auch die Einspritzung von 0.08 , bzw. $0.1 \mathrm{ccm}$ an die Reihe kam. In Fällen, wo $0.01 \mathrm{ccm}$ des Muschelextraktes das rasche Absterben des Tieres herbeiführte, habe ich Versuche auch mit Einspritzung von $0.0 \mathrm{c} 5 \mathrm{ccm}$ des verdünnten Extraktes angestellt, doch tötete diese Menge in 6 solchen Versuchen kein einziges Tier.

Bei Tieren, wo eine Giftwirkung nach Injizierung der zur Verfügung stehenden Gesamtmenge der nach THESEN hergestellten Extrakte nicht eintrat, stellte ich die Überempfindlichkeitsprobe nach RicHET an. In diesen Versuchen ging ich nach RICHET's Prinzip derart vor, das ich die mit der nicht letalen Dosis der Süderpieper Muscheln injizierten Tiere nach Verlauf von 3 Wochen mit einer größeren Menge des Extraktes der zu untersuchenden Muscheln in der Voraussetzung behandelte, daß an den durch das Gift überempfindlich gemachten Versuchstieren, -- falls die zu untersuchende Muschel Giftspuren enthielt, - nach wiederholter Einspritzung das charakteristische Vergiftungsbild zum Vorschein kommen muß. RICHET fand nämlich, wie bereits erwähnt, daß die Tiere nach 
Tabelle 1.

Fundorte, wichtige Eigensehaften der Muscheln

\begin{tabular}{|c|c|c|c|c|c|c|c|c|c|}
\hline \multirow[b]{2}{*}{ Nr. } & \multirow[b]{2}{*}{ Fangtag } & \multirow[b]{2}{*}{$\begin{array}{c}\text { Fundort } \\
\text { der Muscheln }\end{array}$} & \multirow{2}{*}{$\begin{array}{c}\text { Dauer } \\
\text { des Aus- } \\
\text { liegens } \\
\text { der } \\
\text { Tonne }\end{array}$} & \multirow{2}{*}{\begin{tabular}{|c|} 
Tiefe \\
des \\
Was- \\
sers \\
m \\
\end{tabular}} & \multicolumn{2}{|c|}{ Begleitende Arten } & \multicolumn{2}{|c|}{ Größengruppen } & \multirow{2}{*}{$\begin{array}{c}\text { Unter- } \\
\text { suchte } \\
\text { Stück- } \\
\text { zahl }\end{array}$} \\
\hline & & & & & Menge & $\begin{array}{c}\text { untersucht } \\
\text { von }\end{array}$ & $\begin{array}{l}\text { Durch- } \\
\text { schnitts- } \\
\text { Gewicht g }\end{array}$ & $\begin{array}{c}\text { Anteil an } \\
\text { der Gesamt- } \\
\text { menge }\end{array}$ & \\
\hline 1. & $\begin{array}{c}1938 \\
\text { 21. Nov. }\end{array}$ & $\begin{array}{c}\text { Helgoland. } \\
\text { Sehwarze spitze } \\
\text { Tonne, außer- } \\
\text { halb der Lan- } \\
\text { dungsbrücke } \\
\text { ungeführ } 200 \mathrm{~m} \\
\text { weit vom süd- } \\
\text { östlichen Ufer }\end{array}$ & $\begin{array}{c}\text { andert- } \\
\text { halb } \\
\text { Jahre }\end{array}$ & 5 & $\begin{array}{c}\text { Nereis pelagica } \\
\text { L. (vereinzelte } \\
\text { junge Exem- } \\
\text { plare) }\end{array}$ & $\begin{array}{l}\text { K. Meunier } \\
\text { (Helgoland) }\end{array}$ & $\begin{array}{c}24-28 \\
6-12 \\
2-5 \\
\text { erbsengroß } \\
\text { hanfkorn- } \\
\text { groß }\end{array}$ & $\begin{array}{l}1 / 2 \\
1 / 4 \\
1 / 4\end{array}$ & 100 \\
\hline 2. & $\begin{array}{l}1938 \\
\text { 3. Dez. }\end{array}$ & desgl. & desgl. & dies. & dies. & ders. & $\begin{array}{c}24-26 \\
6-8 \\
2-4 \\
\text { erbsengroß } \\
\text { hanfkorn- } \\
\text { groß }\end{array}$ & $\begin{array}{l}1 / 4 \\
1 / 4 \\
1 / 2\end{array}$ & 100 \\
\hline 3. & $\begin{array}{c}1938 \\
20 . \text { Dez. }\end{array}$ & desgl. & desgl. & dies. & dies. & ders. & $\begin{array}{c}25-26 \\
6-7 \\
\text { erbsengroß } \\
\text { hanfkorn- } \\
\text { groß }\end{array}$ & $\begin{array}{l}1 / 10 \\
1 / 10 \\
4 / 5\end{array}$ & 100 \\
\hline 4. & $\begin{array}{c}1938 \\
\text { 30. Dez. }\end{array}$ & $\begin{array}{c}\text { Helgoland. } \\
\text { Hafenklotz im } \\
\text { Marinehafen }\end{array}$ & desgl. & - & $\begin{array}{c}\text { Emplectonema } \\
\text { (sehr zahlreich) } \\
\text { Hyale prevosti } \\
\text { Milne Edwards } \\
\text { (zahlreich) } \\
\text { Sagartia (ver- } \\
\text { einzelte Exem- } \\
\text { plare) }\end{array}$ & $\begin{array}{l}\text { Friedrich } \\
\quad \text { (Kiel) } \\
\text { H. Hertling } \\
\text { (Helgoland) }\end{array}$ & $\begin{array}{c}20-25 \\
8-14 \\
3-4\end{array}$ & $\begin{array}{l}1 / 2 \\
1 / 4 \\
1 / 4\end{array}$ & 200 \\
\hline 5. & $\begin{array}{c}1939 \\
\text { 28. Jan. }\end{array}$ & $\begin{array}{c}\text { Helgoland. } \\
\text { Versuchsteich } \\
\text { der Anstalt an } \\
\text { der Südwest- } \\
\text { küste }\end{array}$ & - & 1,5 & - & $\longrightarrow$ & $\begin{array}{c}25-40 \\
6-8 \\
1-3\end{array}$ & $\begin{array}{c}21 \text { St. } \\
130 \text { St. } \\
\text { ca. } 300 \text { St. }\end{array}$ & 100 \\
\hline 6. & $\begin{array}{c}1939 \\
\text { 14. Febr. }\end{array}$ & desgl. & $\longrightarrow$ & dies. & 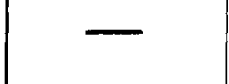 & - & $20-25$ & $58 \mathrm{St}$. & 50 \\
\hline 7. & $\begin{array}{c}1938 \\
\text { 29. Nov. }\end{array}$ & $\begin{array}{l}\text { Helgoland. } \\
\text { Hog-Stean-An- } \\
\text { segelungstonne } \\
\text { ungefär } 2 \text { See- } \\
\text { meilen weit } \\
\text { vom südöst- } \\
\text { lichen Ufer }\end{array}$ & $\begin{array}{l}\text { andert- } \\
\text { halb } \\
\text { Jahre }\end{array}$ & 22 & $\begin{array}{c}\text { Nereis pelagica } \\
\text { L. (vereinzelte } \\
\text { junge Exem- } \\
\text { plare) } \\
\text { Emplectonema } \\
\text { (vereinzelte } \\
\text { Exemplare) }\end{array}$ & $\begin{array}{c}\text { K. Meunier } \\
\text { (Helgoland) } \\
\text { Friedrich } \\
\text { (Kiel) }\end{array}$ & $\begin{array}{c}24-26 \\
8-14 \\
2-4 \\
\text { erbsengroß } \\
\text { hanfkorn- } \\
\text { groß }\end{array}$ & $\begin{array}{l}1 / 8 \\
1 / 8 \\
3 / 4\end{array}$ & 100 \\
\hline 8. & $\begin{array}{c}1939 \\
\text { 3. Jan. }\end{array}$ & $\begin{array}{c}\text { Tonne } 6 \\
\text { Norderaue } \\
\text { (bei Wyk auf } \\
\text { Föhr) }\end{array}$ & $\begin{array}{c}\text { ca. } 9 \mathrm{Mo}- \\
\text { nate }\end{array}$ & 15 & \begin{tabular}{|} 
Carcinus mae- \\
nas (zahlreiche \\
ganz kleine \\
Exemplare) \\
Porcellana lon- \\
gicornis \\
(3 Stück) \\
Balanus (sehr \\
zahlreich)
\end{tabular} & $\begin{array}{l}\text { H. Hertling } \\
\text { (Helgoland) }\end{array}$ & $\begin{array}{c}12-16 \\
8-11 \\
2-6\end{array}$ & $\begin{array}{l}1 / 4 \\
1 / 2 \\
1 / 4\end{array}$ & 200 \\
\hline
\end{tabular}


und verschiedene Angaben über dieselben.

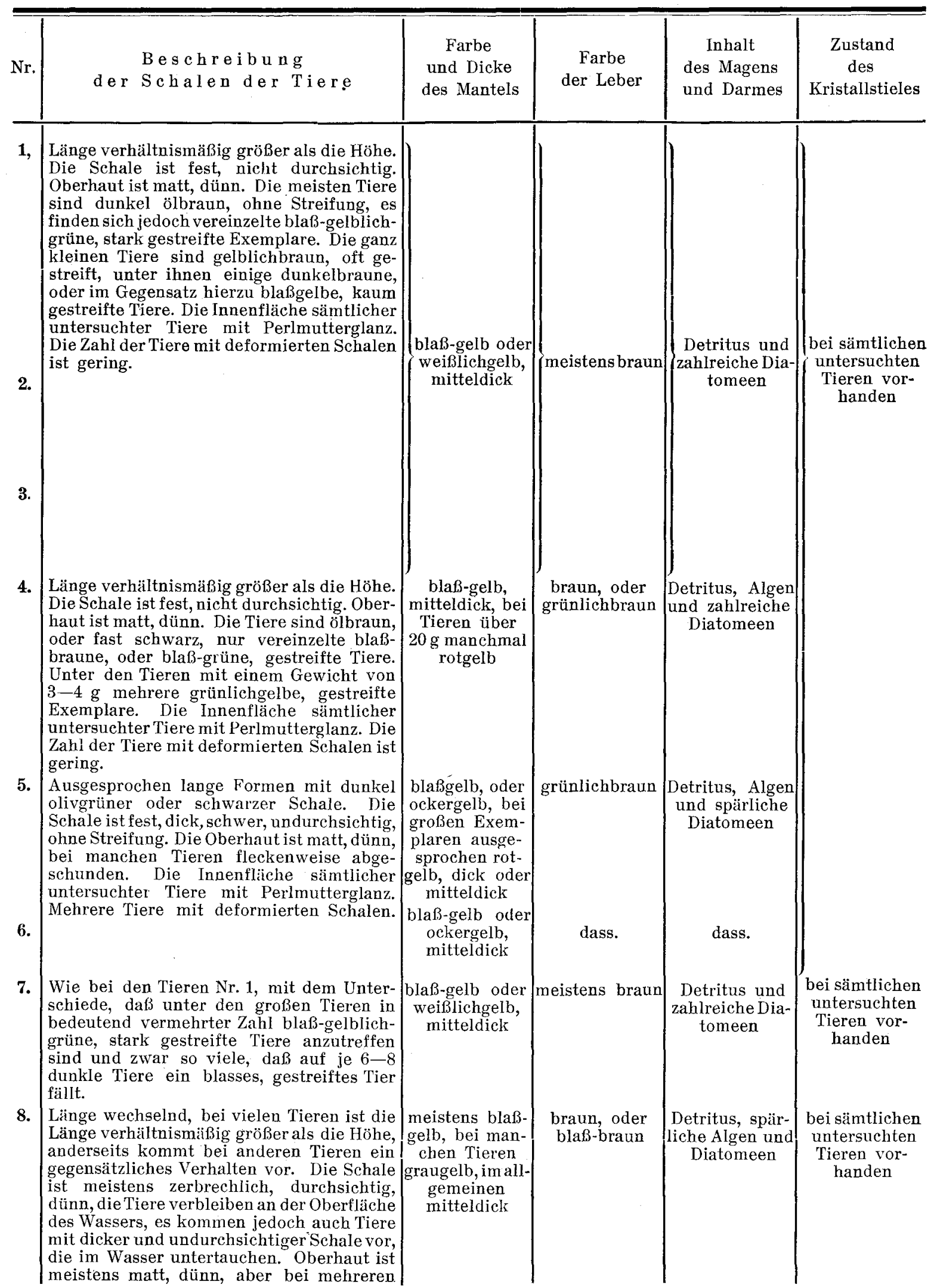


Fortsetzung von Tabelle 1.

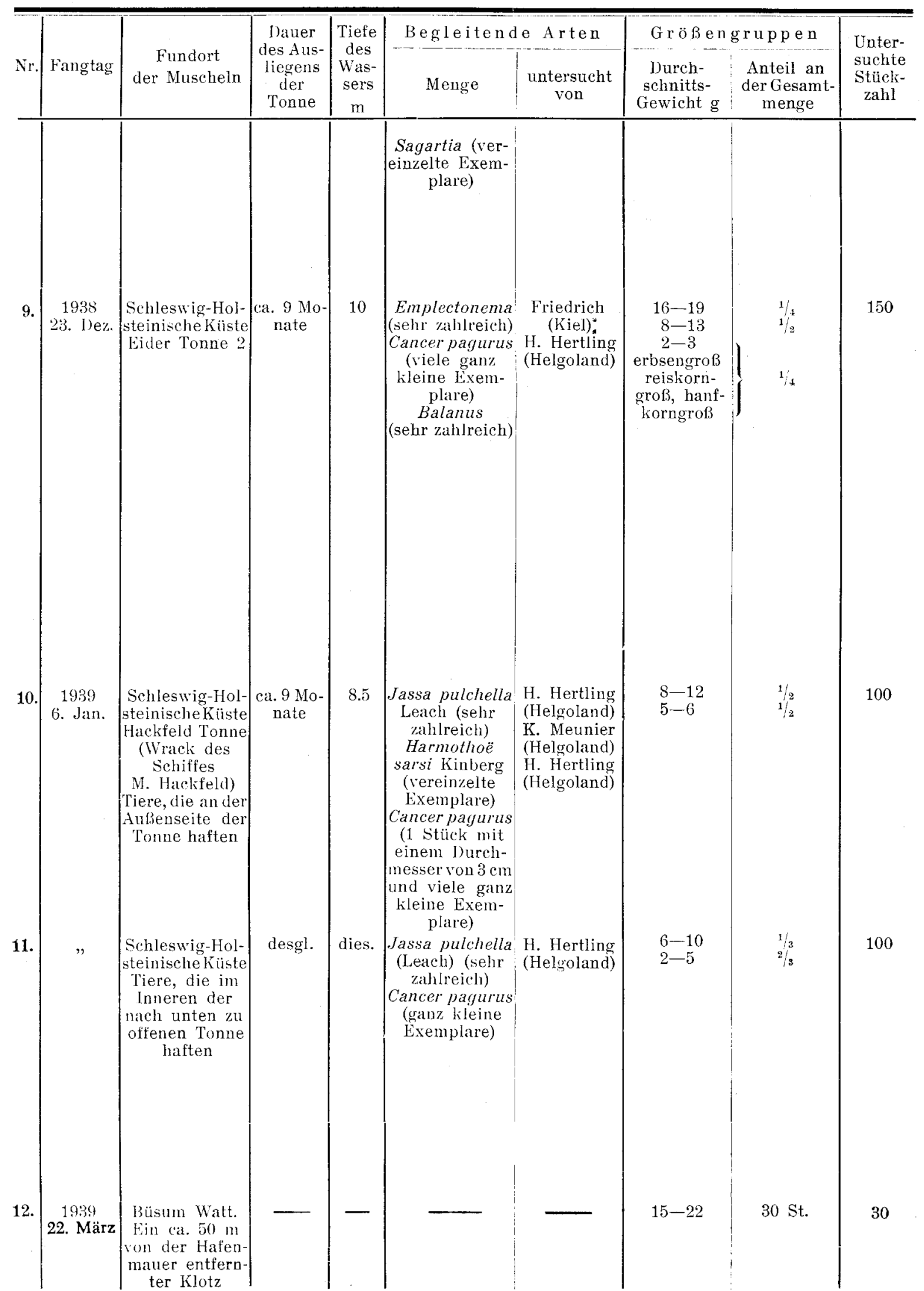




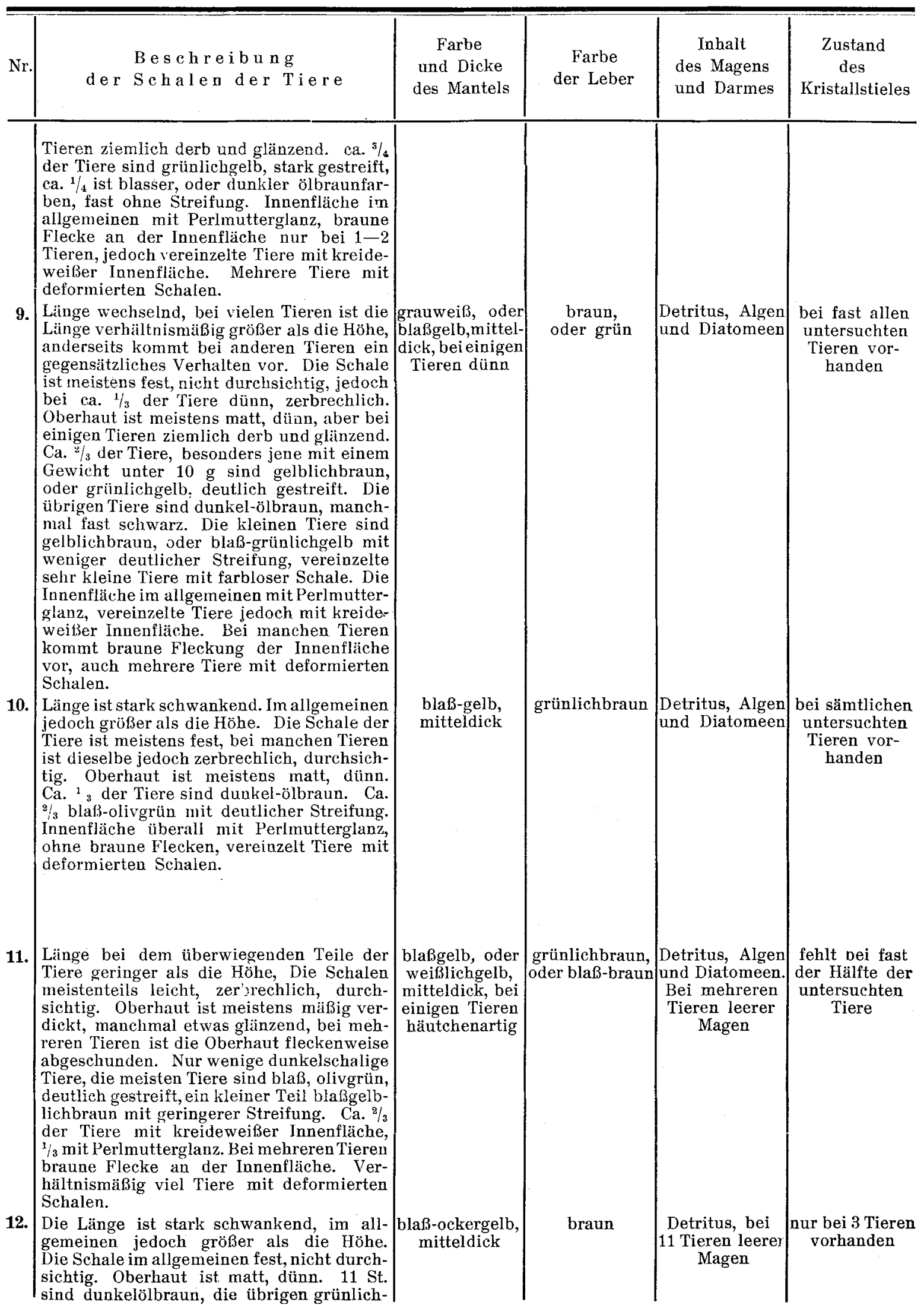


Fortsetzung von Tabelle 1.

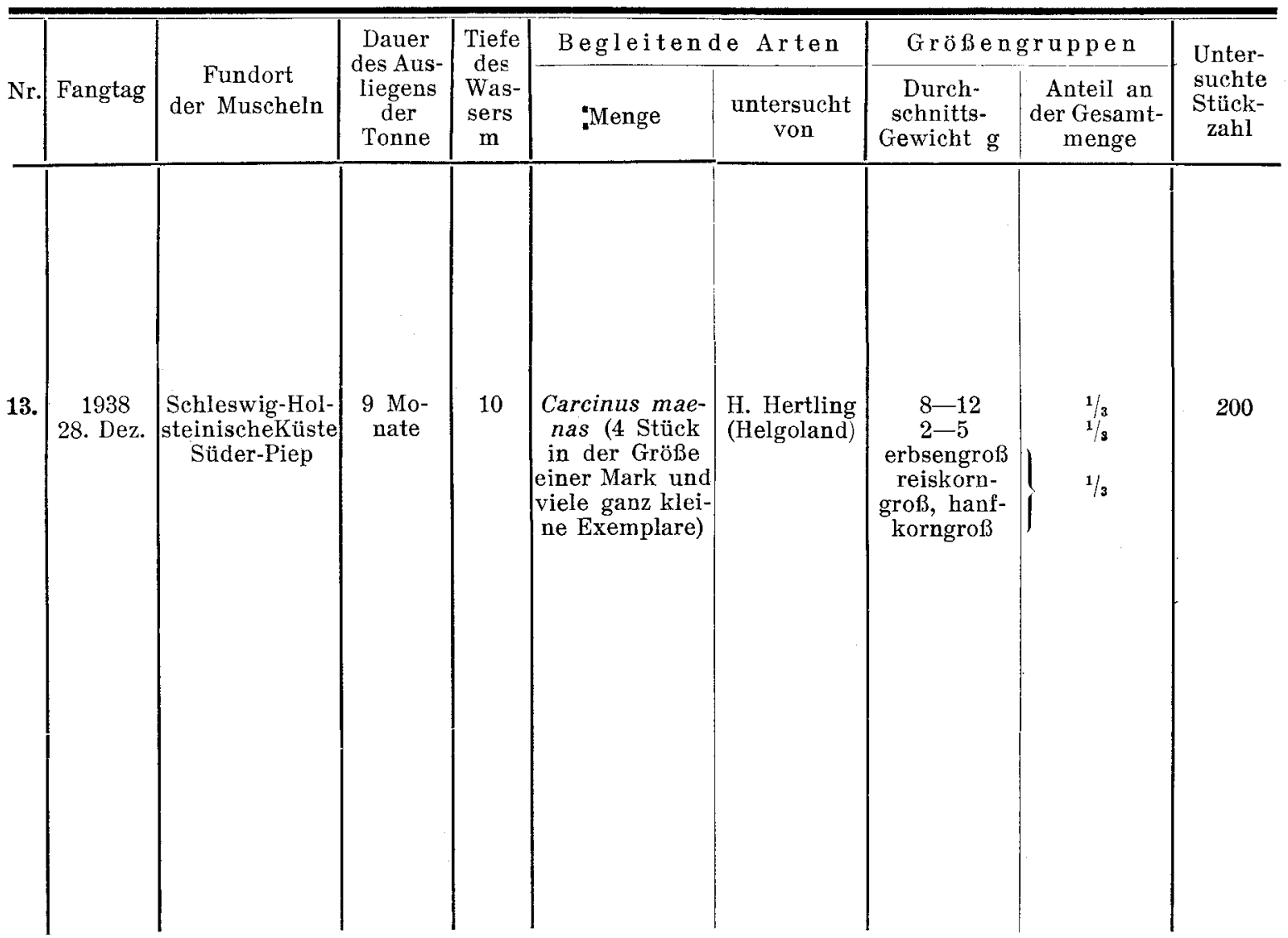

Einspritzung des Giftstoffes der Miesmuschel, von ihm Mytilocongestin benannt, überempfindlich werden, wodurch auch geringe Mengen des Giftes, die sonst pathologische Symptome überhaupt nicht auslösen, schwere Vergiftungen hervorrufen. Das Wesentliche in RicHE''s Versuchen ist bis heute nicht in allen Einzelheiten ins Reine gebracht und die Indentität, bzw. das Verhältnis des Mytilocongestin zum Mytilusgift nicht aufgedeckt. Es wird eben durch den Umstand erschwert in den Versuchen klarzusehen, daß das Congestin einen Organextrakt darstellt, "in welchem die toxische und die ungiftige aber anaphylaktische Wirkung, sei es in einer einzigen chemischen Verbindung (Toxalbumin) oder als Gemisch von mehreren toxischen und nicht toxischen Stoffen, mit einander kombiniert sind". (Preisz). Wie es auch um die theoretische Auslegung von Richer's Versuch stehen mag, haben meine Versuche in Neapel bestätigt, daß Spuren des Mytilusgiftes mit Hilfe dieses Versuchs gut nachweisbar sind. Zuerst führte ich Versuche in Neapel in der Weise aus, daß ich $1 / 3$ der wirksamen Dosis des Extraktes der Giftmuscheln $20 \mathrm{~g}$ schweren Mäusen injizierte und das von der Vergiftung geheilte Tier nach 3 Wochen mit dem Extrakt der zu untersuchenden Muschel behandelte. Wenn die zu untersuchende Muschel Gift enthielt, zeigte das Versuchstier 1-2-3 Minuten nach der zweiten Einspritzung heftige Unruhe, streckte sich nach taumelnder, wurmartiger Bewegung von einigen Minuten mit erlahmten Beinen flach hin und verendete nach 2--3 Minuten unter dauernder schwerer Dispnoë. Bei Mäusen spricht die rasche Entwicklung der Symptome, das Ausbleiben einzelner Erscheinungen, wie z. B. Krämpfe des Tränenrinnens schon an sich gegen die Annahme eines einfachen anaphylaktischen Schocks. Es unterliegt aber keinem Zweifel, daß man in RichET's Versuchen auch mit der anaphylaktischen Wirkung des nicht giftigen Muscheleiweisses zu rechnen hat und so dürften bei Anwendung obiger Methodik betreffs der Bewertung der Versuchsergebnisse gewisse Bedenken berechtigt erscheinen. Nach meinen Versuchen in Neapel löst der aus den Weichteilen der Muscheln ohne Kochen einfach mit Kochsalz hergestellte Extrakt nach wiederholter Einspritzung den typischen, mit starken Tränenfluß und mit Krämpfen begleiteten anaphylaktischen Schock aus und bei den gegen Muscheleiweiss desensibilisierten Tieren kann der durch das Gift hervorgerufene = Überempfindlichkeitszustand auch weiterhin durch das bereits 


\begin{tabular}{|c|c|c|c|c|c|}
\hline Nr. & $\begin{array}{c}\text { Beschreibung } \\
\text { der Schalen der Tiere }\end{array}$ & $\begin{array}{c}\text { Farbe } \\
\text { und Dicke } \\
\text { des Mantels }\end{array}$ & $\begin{array}{c}\text { Farbe } \\
\text { der Leber }\end{array}$ & $\begin{array}{l}\text { Inhalt } \\
\text { des Magens } \\
\text { und Darmes }\end{array}$ & $\begin{array}{c}\text { Zustand } \\
\text { des } \\
\text { Kristallstieles }\end{array}$ \\
\hline 13. & $\begin{array}{l}\text { gelb, mit deutlicher Streifung. Innenfläche } \\
\text { der Schale mit Ausnahme von } 4 \text { Fällen } \\
\text { kreideweiß. (Die in der letzten Stunde der } \\
\text { Ebbe gesammelten Tiere lagen am Trocke- } \\
\text { nen.) Bei } 3 \text { Tieren war auf der Innen- } \\
\text { fläehe eine braune Verfärbung zu beob- } \\
\text { achten. Tiere mit deformierten Schalen } \\
\text { waren nicht zu finden. } \\
\text { Länge ist stark schwankend, im allgemeinen } \\
\text { jedoch wesentlich geringer als die Höhe. } \\
\text { Die Schalen sind sehr dünn, zerbrechlich } \\
\text { und verhältnismäßig sehr durchsichtig. Läßt } \\
\text { man die Tiere auf. den Tisch fallen, so } \\
\text { geben sie einen äßerst hoblen Ton. Die } \\
\text { Tiere verbleiben schwimmend auf der Ober- } \\
\text { fläche des Wassers. Oberhaut derb, glän- } \\
\text { zend, wie lackiert. Der größere Teil der } \\
\text { Tiere ist blaß-gelblichgrün, stark gestreift, } \\
\text { der kleinereTeilgelblichbraun, mitgeringer } \\
\text { Streifung, oder fast streifenlos. Tiere mit } \\
\text { dunkler Schale sind nicht anzutreffen. Die } \\
\text { kleinsten Tiere sind fast sämtlich farblos, } \\
\text { an der Innenfläehe der Schalen ist bei den } \\
\text { meisten Muscheln eine kreideweiße Ver- } \\
\text { färbung zu beobachten bei des Glanzes der } \\
\text { Innenfläche. Bei verhältnismäßig zahlrei- } \\
\text { chen Muscheln rostbraune Flecke und } \\
\text { mancherorts kleine Lücken in der Perl- } \\
\text { mutterschicht. Zahlreiche Tiere mit defor- } \\
\text { mierten Schalen. }\end{array}$ & $\begin{array}{l}\text { meistens grau- } \\
\text { weiß, häutchen- } \\
\text { artig, sehr dünn }\end{array}$ & $\begin{array}{l}\text { blaß-braun, } \\
\text { oder grau }\end{array}$ & $\begin{array}{l}\text { Detritus und } \\
\text { Diatomeen. } \\
\text { Bei 14 Tieren } \\
\text { leerer Magen }\end{array}$ & $\begin{array}{l}\text { fehlt bei fast } \\
\text { allen unter- } \\
\text { suchten Tieren }\end{array}$ \\
\hline
\end{tabular}

angeführte Vergiftungsbild nachgewiesen werden. Das bedeutet, daß der Versuch von RICHET nicht eine einfache, an das Muscheleiweiß gebundene anaphylaktische Wirkung darstellt. Daß in den Versuchen die durch das Gift verursachte Überempfindlichkeits-Reaktion das mittels Muscheleiweiß hervorgerufene anaphylaktische Bild nicht zur Entfaltung kommen läBt, kann einerseits in der Bereitungsweise des Muschelextraktes seine Erklärung finden, wobei das Muscheleiweiß eine bedeutende Umwandlung erleidet, andererseits kann es durch die sogenannte Konkurrenz der Antigene erklärt werden, derzufolge das mehr aktive Antigen die Wirkung des weniger aktiven unterdrückt. Wenn man nämlich zwei, jede für sich separat sensibilisierende Antigene zu gleicher Zeit einspritzt, entwickelt sich die Überempfindlichkeit möglicherweise nur gegen eines derselben und so betrachtet man jenes als mehr aktiv. Mit Rücksicht auf diese Erscheinung habe ich gefunden, daß das in meinen Helgoländer Untersuchungen anfangs angewendete Verfahren einer Modifikation bedarf. Es kann nämlich die Möglichkeit angenommen werden, daß, wenn die Giftspuren in der Muschel zu gering sind, die das Antigen des Muscheleiweiß die spezifische Reaktion des Muschelgiftes unterdrückt und eine einfache anaphylaktische Erscheinung zum Vorschein kommen läßt. Das Muschelgift zeigt gegen Erhitzen eine hochgradige Resistenz und kann im eingetrockneten Zustand auf $110^{\circ}$ während der Dauer von 2 Minuten erhitzt gehalten werden. So scheint der Gedanke nahe zu liegen, daß der anaphylaktogenen Wirkung des Eiweißes durch das Erhitzen auf $110^{\circ}$ vorgebeugt werden kann und die Sensibilisierung mit erhitztem Gift vorzunehmen sei. Aber im Versuch nach RICHET kombiniert sich wie bereits erwähnt, die toxische und die anaphylaktische Wirkung, - sei es in Form einer chem. Verbindung als Toxalbumin oder als Gemisch der toxischen und atoxischen Stoffe. Diesem Umstand soll es zugeschrieben werden, daß es mir mit dem überhitzten Gift nicht gelang, den RicheT'schen Versuch auszuführen, d. h. das zu weit gehende Denaturieren der Muscheleiweiße vereitelte den Versuch. Es soll daher ein Verfahren gefunden werden, mit dessen Hilfe nebst möglichster Beibehaltung des Charakters der an das Gift gebundenen Eiweißstoffe die größere Aktivität des Giftes auch dort gesichert werden kann, wo dessen Aktivität infolge seiner geringen Menge zweifelhaft erscheint. Deshalb wandte ich folgendes 
Verfahren an: Aus den geöffneten Muscheln habe ich den Eingeweidesack nach Entfernung des Fußes, des Byssus und der Kiemen, mit chem. reinem Quarzsand verrieben und den Brei mit einer fünffachen Menge destillierten Wassers verdünnt, welchem ich soviel $1 / 10 \mathrm{n}$ Salzsäure beigab, bis die Reaktion mit Lackmus ausgesprochen sauer wurde. Die Flüssigkeit hielt ich 6 Stunden lang in einem mit Watte verpropften Kolben im Wasserbad auf $56^{\circ}$ and habe die Reaktion bei oftmaligem Schütteln stündlich kontrolliert. Bei Abnahme der Reaktion habe ich die Flüssigkeit erneut mit Salzsäure eingesäuert. Nach 6 Stunden wurde die Flüssigkeit filtriert und 3 Stunden auf Zimmertemperatur gehalten. Während dieser Zeit bildete sich ein Niederschlag. Dann zentrifugierte ich die Flüssigkeit und verschloß sie in einem eingeschmolzenen Glasröhrchen. Vor Gebrauch ließ ich die Flüssigkeit im Proscauer'schen Vacuum-Destillier-Apparat so eindunsten, daß die zum Injizieren verwendete Menge ungefähr $1 / 10$ des Gewichts der Weichteile der Muschel entsprach, dann habe ich die Lösung aus einer Mikrobürette unmittelbar vor der Einspritzung mit $1 / 10$ n Natriumcarbonatlösung neutralisiert. Mit den derart hergestellten Extrakten führte ich die Versuche so aus, daß ich ungefähr $20 \mathrm{~g}$ schweren Mäusen ein drittel der Giftdosis der in vorangehender Weise bereiteten Extrakte der giftigen Muscheln intraperitoneal injizierte und habe dann nach 21 Tagen die Tiere mit subcutaner Injektion des Extraktes von bestimmt ungiftigen Muscheln (aus Helgoland stammende Tiere mit dunkler, dicker Schale) vorerst mit $1 \mathrm{mg}$, nach einer Stunde $3 \mathrm{mg}$, nach zwei Stunden $6 \mathrm{mg}$, nach fünf Stunden $12 \mathrm{mg}$ desensibilisiert. Das somit vorbereitete Tier impfte ich nach Ablauf von 3 Stunden mit der ganzen Menge des Extraktes der zu untersuchenden Muschel intraperitoneal und beobachtete es ständig. Durch obiges Vorgehen suchte ich einerseits die Aenderung des Charakters der ans Gift gebundenen Eiweißstoffe zu umgehen, andererseits im Wege der vor dem Auslösungsversuch vorgenommenen Desensibilisierung, der anaphylaktischen Wirkung des Muscheleiweißes vorzubeugen und habe die Aktivität des Muschelgiftes gesichert. Die Reaktion erachtete ich dann als positiv, wenn das Tier spätestens 4 Minuten nach der Einspritzung beginnend, binnen 3-4 Miıuten unter Lähmung der Gliedmaßen und Atembeschwerden verendete und deutliche Krämpfe oder Tränenrinnen nicht auftraten. Starke Positivität habe ich bei den Versuchen angenommen, wo das Tier bei rasch eintretenden Atembeschwerden und Lähmungen schon binnen 1-2 Minuten einging. Schwach nannte ich die Reaktion falls das Absterben des Tieres erst in 8-10 Minuten erfolgte. Traten in den RicheT'schen Versuchen die typischen Lähmungen und Atembeschwerden auf, so gingen in meinen Versuchen nach 10 Minuten sämtliche Tiere ein. Ueber die Versuche mit den nach ThEsEN's Verfahren hergestellten Extrakten und über die Ergebnisse der RICHET'schen Versuche gibt Tabelle 2 Aufschluß. Darin sind auch die wichtigeren Eigenschaften der giftigen Tiere angeführt und bei den mit THEsEN's Extrakt ausgeführten Versuchen ist auch die Letaldosis vermerkt. Diese Tabelle zeigt, daß längs der Insel Helgoland keine giftigen Muscheln zu finden waren u. zw. weder an den in der Nähe der Ufer verankerten Tonnen, noch am Hafenklotz, auch nicht im geschlossenen Becken des Versuchsteiches; ebenso fehlten die giftigen Muscheln an der ungefähr 2 Seemeilen von der Küste entfernten Hog-Stean Ansegelungstonne. Dagegen konnte man mittels des RichET'schen Versuches von 100 Tieren bei dreien Giftspuren nachweisen uzw. in zwei Tieren, die von der vom Ufer $200 \mathrm{~m}$ entfernten schwarzen Spitz-Tonne stammten und in einem Tier vom Hafenklotz. Die Helgoländer Untersuchungen verwiesen daher auf den Umstand, daß Giftspuren enthaltende Tiere ausnahmsweise auch an Seegebieten vorkommen können, wo von einer Stagnierung des Wassers nicht gesprochen werden kann. Diese Erscheinung wurde durch die Untersuchungen an der Schleswig-Holsteinischen NordseeKüste noch augenscheinlicher. Es zeigte sich, daß in der Norderaue von 40 untersuchten Tieren der Tonne 6 vier Giftspuren aufwiesen und unter den Tieren der Eider Tonne zwei, nicht nur daß in fünf Exemplaren Giftspuren entdeckt wurden, sondern der Extrakt von zweien in einer Dose von $1 \mathrm{ccm}$ schon tödliche Giftwirkung an der $20 \mathrm{~g}$ schweren Maus ausübte. Noch interessanter schien aber die Untersuchung der Tiere, die, an einer das Wrack des Schiffes „Maria Hackfeld" bezeichnenden Blink-Tonne anhafteten. An den äußeren Teilen der Tonne saßen viele Muscheln, es war aber auch eine große Anzahl derselben in der nach unten zu geöffneten Röhre der Tonne zu finden. Unter den außerhalb befindlichen Tieren fand ich von 30 untersuchten Muscheln nur eine giftig, in zweien waren Giftspuren nachweisbar, wogegen von den inwendig anhaftenden Tieren 4 giftig befunden wurden und in 18 Exemplaren die Giftspuren bestimmt nachweisbar waren. Es dürfte der großen Menge von Giftspuren tragenden Tieren zugeschrieben werden, daß der aus 20 solchen Muscheln zugleich hergestellte Extrakt im RichET'schen Versuch ein stark positives Ergebnis herbeiführte. Der nach THEsen hergestellte Extrakt aus der 
gleichen Anzahl ebensolcher Tiere löste dagegen in Dosen von $10 \mathrm{ccm}$ intraperitoneal eingespritzt nur eine kurze Zeit währende Unruhe und beschleunigtes Atmen aus, ohne, daß typische Lähmungen zur Entfaltung gekommen wären. Der Versuch zeigt daher augenscheinlich, daß die Auffindung von eventuell giftigen Muscheln unter ungiftigen nur dann erhofft werden kann, wenn aus den einzelnen Tieren Extrakte bereitet werden, da doch von den Muscheln aus dem Inneren der „Hackfeld“-Tonne, wie gesagt, 4 giftig befunden wurden und der Extrakt von 20 Muscheln in ihrer Gesamtheit dennoch keine bestimmte Giftwirkung zeigte. - Während der aus einer großen Anzahl von obigen Fundorten stammenden Muscheln zugleich hergestellte Extrakt -- abgesehen von der vorher erwähnten recht schwachen Reaktion - so gut wie keine Giftwirkung zustandebrachte, haben die von Tonne "F" im Süder-Piep gesammelten Muscheln sowohl in ihrer Gesamtheit als auch einzeln eine außerordentlich starke Giftwirkung entfaltet. Der nach THESEN aus 20 Muscheln hergestellte Extrakt hat nämlich in einer Dosis von $0.02 \mathrm{ccm}$ der $20 \mathrm{~g}$ schweren Maus injiziert, das Versuchstier in durcnschnittlich 5 Minuten gotötet. Der aus reis- oder hanfkorngroßen, ganz winzigen Muscheln bereitete Extrakt hat in ähnlicher Menge den Tod des Versuchstieres herbeigeführt und dadurch klar gezeigt, daß zwischen geschlechtsunreifen und geschlechtsreifen Tieren in dieser Richtung kein wesentlicher Unterschied besteht. Der Extrakt tötete die $150 \mathrm{~g}$ schwere weiße Ratte intraperitoneal in einer Dosis von $0.8 \mathrm{ccm}$ injiziert in 15 Minuten. Das $1 \mathrm{~kg}$ schwere Kaninchen verendete nach Injizierung der Letaldosis $2.5 \mathrm{ccm}$ schon in 6 Minuten. Die Giftwirkung der frischen Muscheln an den vorher erwähnten Versuchstieren durch Füttern auszuprobieren, war mir leider nicht möglich.

Bei Herstellung von Extrakten einzelner Muscheln von der Süder-Piep-Tonne gelangte ich zum Ergebnis, daß unter 30 Muscheln von 16 die Letaldosis mit dem aus den übrigen Muscheln zugleich hergestellten Extrakt identisch war. Bei 6 Muscheln ist die Giftwirkung stärker, dagegen bei 8 geringer als dies gewesen und die Giftdosis stieg unter den letzteren bei einem Tier auf $0.1 \mathrm{ccm}$ an, was zu bedeuten hat, das betreffs der Giftwirkung auch unter den stark giftigen Muscheln verhältnismäßig große Schwankungen wahrnehmbar sind, aber unter dieser Probe kein einziges ungiftiges Exemplar zu finden war. Meine auf die von verschiedenen Fundorten gesammelten Muscheln bezüglichen Untersuchungen können dahin zusammengefaßt werden, daß an den an offenen Seegebieten liegenden Tonnen sich schwer giftige Muscheln befinden können und einzelne in geringerem Grade giftige Muscheln sogar an solchen Tonnen einmal am Hafenklotz vorkommen können, wo sich sonst die Hauptmasse der Muscheln aus ungiftigen Tieren zusammensetzt. Das Vorkommen von giftigen Muscheln ist daher nicht an Buchten mit abgeschlossenem Wassergebunden und in geringerem Grade giftige oder Giftspuren aufweisende Tiere können sich auch unter ungiftigen Muscheln befinden.

In meinen Untersuchungen konnte auch festgestellt werden, daß im Versuchsteich der Anstalt auf Helgoland, welcher vom offenen Meer durch die Schutzmauer getrennt ist und bei de $m$ der Wasseraustausch nur bei Flut möglich ist, zum Zeitpunkt der Untersuchungen ke ine giftigen Muscheln waren, $d$. h. es hat sich auch hier bestätigt, daß an den von der offenen See abgeschlossenen Stellen die Muscheln auch in der Nordsee nicht unbedingt giftig werden. Die an geschlossenen Wassergebieten lebenden Muscheln betreffend gaben jene Versuche ein interessanteres Ergebnis, die ich an den im Aquarium meines Arbeitsraumes gehaltenen Muscheln anstellte. Ein Teil der am 21. und 29. November und am 3. und 20. Dezember gesammelten Tiere wurde zwecks weiterer Untersuchung in dem breiten, niedrigen Becken mit steter Wasserzuleitung im Laboratorium zurückbehalten. Das Becken war mit Muscheln ständig überfüllt und die früher gebrachten Tiere trachteten an die Oberfläche des Wassers zu gelangen, sodaß schließlich der breite Rand des Beckens mit aus dem Wasser herausragenden, freistehenden Miesmuscheln bedeckt war. Aus diesen, vom Wasser mindestens 1-1 $1 / 2$ Monate hindurch herausstehenden Muscheln bereitete ich Extrakte u. z. aus 20 Tieren im Gesamt und ebenfalls aus je 20 Tieren einzeln und habe sie laut Richet's Versuch auf Giftspuren 'geprüft. Bei allen diesen Untersuchungen war das Gift auch in Spuren nicht nachweisbar und daher haben meine Beobachtungen jene früheren Wahrnehmungen bestätigt, daß das Trockenliegen der Muscheln an und für sich die Giftigkeit nicht hervorruft und so können die bei Ebbe, d. h. der von mir beobachteten Zeit gegenüber nur eine verschwindend kurze Frist freiliegenden Muscheln einzig aus diesem Grunde nicht giftig geworden sein. Darüber, daß die giftigen Muscheln, wie das WOLFF feststellte, längere Zeit trocken gelassen ihre Giftwirkung mehr oder weniger einbüßen, gelang es mir keinerlei Feststellungen zu machen, 
Tabelle 2.

Ergebnisse der Untersuchungen

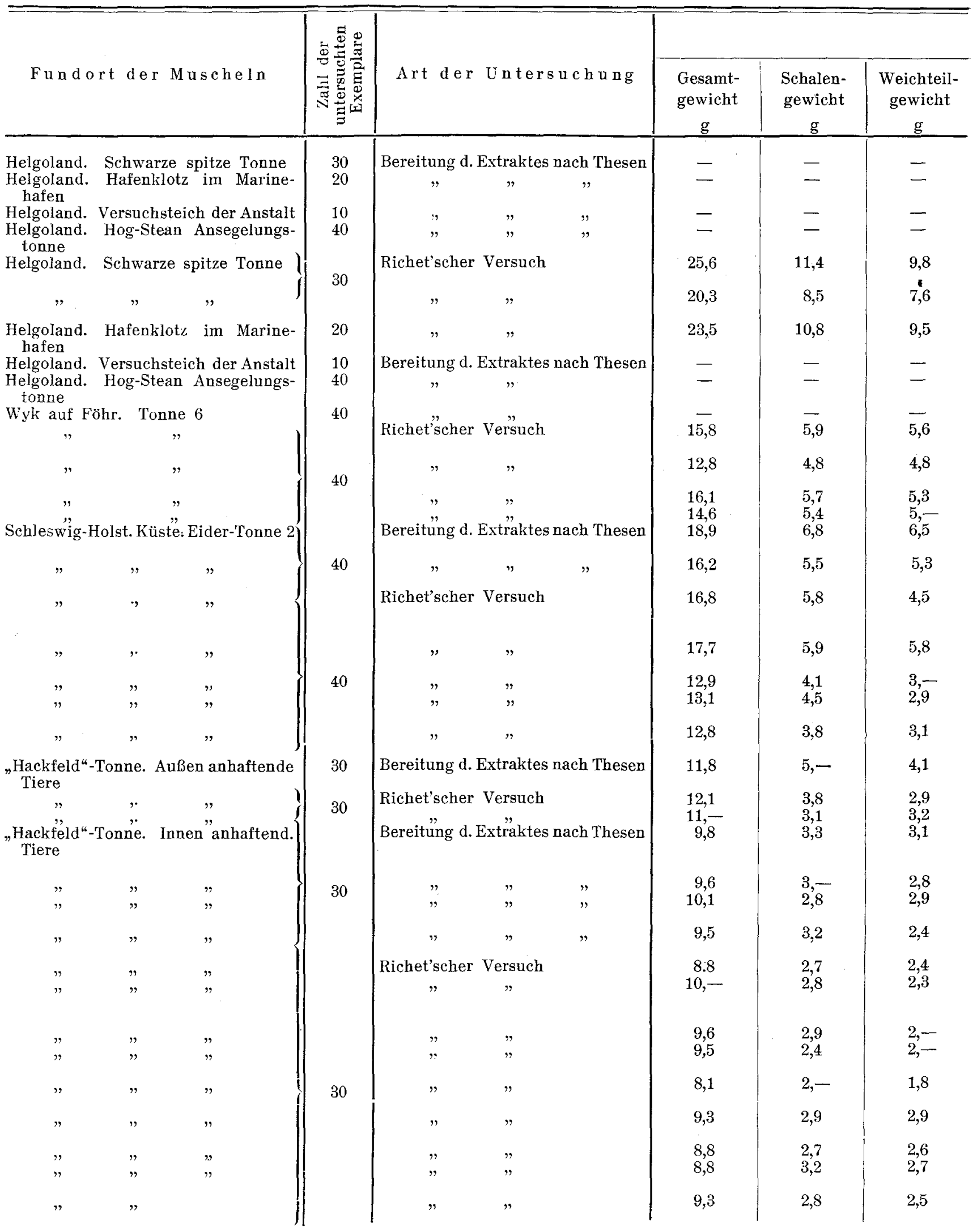


über Giftwirkung der Muscheln.

\begin{tabular}{|c|c|c|c|c|c|c|c|}
\hline \multicolumn{6}{|c|}{ Die Eigenschaften der giftigen Tiere } & \multicolumn{2}{|c|}{$\begin{array}{ll}\text { Ergebnisse } \\
\text { der } & \text { Untersuchungen }\end{array}$} \\
\hline $\begin{array}{l}\text { Länge- } \\
\text { und Höhe- } \\
\text { quotienten }\end{array}$ & $\begin{array}{c}\text { Länge- } \\
\text { und Dicke- } \\
\text { quotienten }\end{array}$ & $\begin{array}{l}\text { Haupteigenschaften } \\
\text { der Muschelschalen }\end{array}$ & $\begin{array}{c}\text { Zustand der } \\
\text { Innenfläche } \\
\text { der Muschel- } \\
\text { schale }\end{array}$ & $\begin{array}{c}\text { Deformation } \\
\text { der Muschel- } \\
\text { schale }\end{array}$ & Kristallstiel & $\begin{array}{l}\text { Tödliche } \\
\text { Dosis des } \\
\text { Muschel- } \\
\text { extraktes } \\
\mathrm{cm}^{3} \\
\end{array}$ & $\mid \begin{array}{c}\text { Ergebnisse } \\
\text { des Richet- } \\
\text { schen Ver- } \\
\text { suches }\end{array}$ \\
\hline - & - & - & - & - & - & - & \\
\hline 一 & - & - & - & - & 一 & - & \\
\hline - & - & - & - & - & - & - & \\
\hline 一 & - & - & - & - & - & - & \\
\hline 1,98 & 2,18 & blaß-grüngelb, gestreift dünn & mit Perl- & fehlt & vorhanden & & positiv \\
\hline 2,02 & 2,30 & ” & $"$ & mäßig & $"$ & & schwach \\
\hline 1,68 & 2,45 & $\begin{array}{l}\text { gelblichbraun, kaum gestreift, } \\
\text { sehr dünn }\end{array}$ & etwas matt & fehlt & $"$ & & $\begin{array}{l}\text { positiv } \\
\text { positiv }\end{array}$ \\
\hline- & - & sell dunt & - & - & - & - & \\
\hline 一 & 一 & - & - & - & - & - & \\
\hline - & - & - & - & - & - & - & \\
\hline 1,88 & 2,18 & $\begin{array}{l}\text { blaß-grüngelb, gestreift, sehr } \\
\text { dünn }\end{array}$ & $\begin{array}{l}\text { mit Perl- } \\
\text { mutterglanz }\end{array}$ & fehit & vorhanden & & positiv \\
\hline 2,08 & 2,72 & $\begin{array}{l}\text { gelblichbraun, gestreift, sehr } \\
\text { dünn }\end{array}$ & $"$ & $"$ & $"$ & & $\begin{array}{r}\text { stark } \\
\text { positiv }\end{array}$ \\
\hline 2,17 & $\begin{array}{l}2,65 \\
2,03\end{array}$ & blaß-grüngelb gestreift, dünn & " & " & $"$ & & positiv \\
\hline $\begin{array}{l}1,73 \\
1,82\end{array}$ & $\begin{array}{l}2,03 \\
2,30\end{array}$ & $\begin{array}{l}\text { blaß-grüngelb, stark" gestreift, } \\
\text { dünn }\end{array}$ & $"$ & $"$ & $"$ & 1 & positiv \\
\hline 1,52 & 1,99 & $\begin{array}{l}\text { gelblichbraun, kaum gestreift, } \\
\text { sehr dünn }\end{array}$ & kreideweiß & stark & $"$ & 1 & \\
\hline 2,21 & 2,93 & blaß-olivgrün, gestreift, dünn & $\begin{array}{l}\text { kreideweiß } \\
\text { mit braunen }\end{array}$ & $\eta$ & " & & positiv \\
\hline 1,88 & 2,10 & $\begin{array}{l}\text { blaßgrüngelb, stark gestreift, } \\
\text { dünn }\end{array}$ & $\begin{array}{l}\text { Flecken } \\
\text { mit Perl- } \\
\text { mutterglanz }\end{array}$ & fehlt & $"$ & & positiv \\
\hline $\begin{array}{l}1,96 \\
2,08\end{array}$ & $\begin{array}{l}2,26 \\
2,25\end{array}$ & $\begin{array}{l}\text { gelblichbraun, gestreift, dünn } \\
\text { gelblichgrün, stark gestreift, } \\
\text { mitteldick }\end{array}$ & $\begin{array}{l}\text { etwas matt } \\
\text { mit Perl- } \\
\text { mutterglanz }\end{array}$ & $\begin{array}{l}\text { mäßig } \\
\text { fehlt }\end{array}$ & $"$ & & $\begin{array}{l}\text { positiv } \\
\text { schwach } \\
\text { positiv }\end{array}$ \\
\hline 1,89 & 2,18 & $\begin{array}{l}\text { blaß̧-grüngelb, stark gestreift, } \\
\text { dünn }\end{array}$ & $"$ & , & $"$ & & positiv \\
\hline 2,10 & 2,20 & $\begin{array}{l}\text { grüngelb, stark gestreift, mittel- } \\
\text { dick }\end{array}$ & $"$ & stark & $"$ & 1 & \\
\hline $\begin{array}{l}1,91 \\
1,93\end{array}$ & $\begin{array}{l}2,17 \\
2,45\end{array}$ & blaß-olivgrün, gestreift, dünn & $"$ & fehlt & " & & $\begin{array}{l}\text { positiv } \\
\text { positiv }\end{array}$ \\
\hline 2,18 & 2,28 & blaß-grüngelb, gestreift, dünn & $\begin{array}{l}\text { kreideweiß } \\
\text { mit braunen }\end{array}$ & $"$ & fehlt & 1 & \\
\hline $\begin{array}{l}2,03 \\
1,68\end{array}$ & $\begin{array}{l}2,65 \\
1,88\end{array}$ & $\begin{array}{l}\text { blaß-ölbraun, kaum "gestreift, } \\
\text { sehr dünn }\end{array}$ & $\begin{array}{c}\text { kreideweiß } \\
, "\end{array}$ & stark & $\dddot{\prime \prime}$ & $\begin{array}{l}1 \\
0,5\end{array}$ & \\
\hline 2,05 & 2,52 & $\begin{array}{l}\text { grüngelb, stark gestreift, sehr } \\
\text { dünn }\end{array}$ & $\begin{array}{l}\text { mit Perl- } \\
\text { mutterglanz }\end{array}$ & $"$ & vorhanden & 1 & \\
\hline 1,88 & 2,17 & blaß-grüngelb, gestreift, dünn & & mäßig & fehlt & & positiv \\
\hline 1,93 & 2,28 & $"$ & $\begin{array}{l}\text { kreideweiß } \\
\text { mit braunen } \\
\text { Flecken }\end{array}$ & fehlt & $"$ & & $\begin{array}{l}\text { schwach } \\
\text { positiv }\end{array}$ \\
\hline $2,-\overline{1,96}$ & $\begin{array}{l}2,39 \\
2,17\end{array}$ & $"$ & kreideweiß & stäk & $\begin{array}{c}\text { vorhanden } \\
\text { fehlt }\end{array}$ & & $\begin{array}{l}\text { positiv } \\
\text { schwach }\end{array}$ \\
\hline 1,9 & 2,26 & $"$ & mit Perl- & mäßig & vorhanden & & $\begin{array}{l}\text { positiv } \\
\text { schwach }\end{array}$ \\
\hline 1,92 & 2,28 & $\begin{array}{l}\text { blaß-grüngelb, stark gestreift, } \\
\text { sehr dünn }\end{array}$ & $\begin{array}{l}\text { mutterglanz } \\
\text { kreideweiß }\end{array}$ & fehlt & fehlt & & $\begin{array}{l}\text { positiv } \\
\text { schwach }\end{array}$ \\
\hline $\begin{array}{l}1,93 \\
1,91\end{array}$ & $\begin{array}{l}2,10 \\
2,28\end{array}$ & blaß-grüngelb, gestreift, dünn & kreideweiß & mäßig & fehlt & & $\begin{array}{l}\text { positiv } \\
\text { stark }\end{array}$ \\
\hline $2,-$ & 2,35 & $"$ & " & fehlt & " & & $\begin{array}{l}\text { positiv } \\
\text { stark } \\
\text { positiv }\end{array}$ \\
\hline
\end{tabular}


Fortsetzung von Tabelle 2.

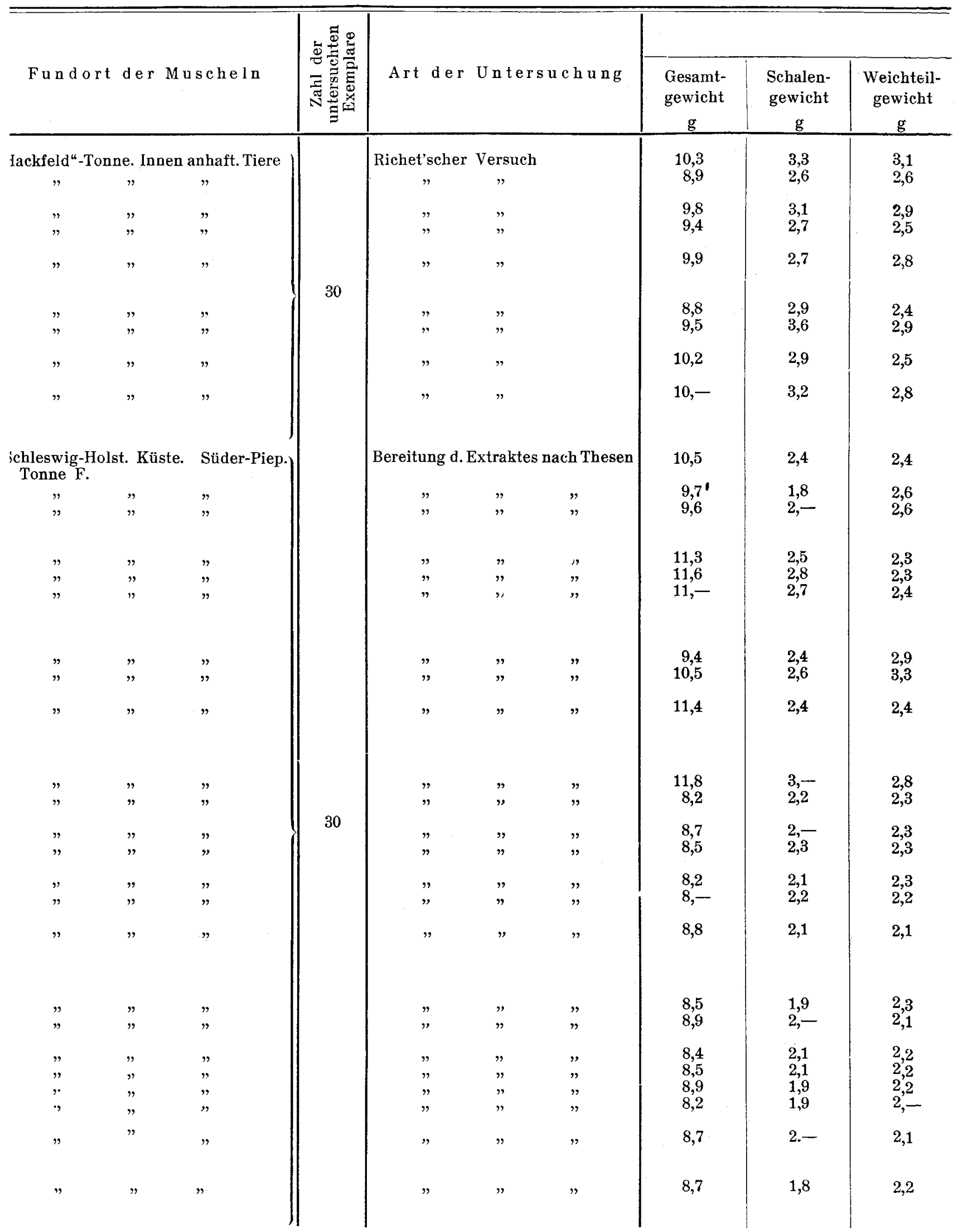




\begin{tabular}{|c|c|c|c|c|c|c|c|}
\hline \multicolumn{6}{|c|}{ Die Eigenschaften der giftigen Tiere } & \multicolumn{2}{|c|}{$\begin{array}{l}\text { Ergebnisse } \\
\text { der Untersuchungen }\end{array}$} \\
\hline $\begin{array}{l}\text { Länge- } \\
\text { und Höhe- } \\
\text { quotienten }\end{array}$ & $\begin{array}{c}\text { Länge- } \\
\text { und Dicke- } \\
\text { quotienten }\end{array}$ & $\begin{array}{l}\text { Haupteigenschaften } \\
\text { der Muschelschalen }\end{array}$ & $\mid \begin{array}{c}\text { Zustand der } \\
\text { lnnenflache } \\
\text { der Muschel- } \\
\text { schale }\end{array}$ & $\begin{array}{l}\text { Deformation } \\
\text { der Muschel- } \\
\text { schale }\end{array}$ & Kristallstiel & $\begin{array}{l}\text { Tödliche } \\
\text { Dosis des } \\
\text { Muschel- } \\
\text { extraktes } \\
\text { en }\end{array}$ & $\begin{array}{c}\text { Ergebnisse } \\
\text { des Richet- } \\
\text { schen Ver- } \\
\text { suches } \\
\end{array}$ \\
\hline $\begin{array}{l}1,93 \\
1,91\end{array}$ & $\begin{array}{l}2,43 \\
2,19\end{array}$ & $\begin{array}{l}\text { blaß-grüngelb, gestreift. dünn } \\
\text { blaß-ölbraun, gestreift, sehr } \\
\text { dünn }\end{array}$ & $\begin{array}{c}\text { kreideweiß } \\
, "\end{array}$ & $\begin{array}{l}\text { fehit } \\
\text { mäßig }\end{array}$ & $\begin{array}{l}\text { vorhanden } \\
\text { fehlt }\end{array}$ & & $\begin{array}{l}\text { schwach } \\
\text { positiv } \\
\text { positiy }\end{array}$ \\
\hline $\begin{array}{l}1,92 \\
1,90\end{array}$ & $\begin{array}{l}2,28 \\
2,35\end{array}$ & $\begin{array}{c}\text { dünn } \\
\text { blaß-grüngelb, gestreift, dünn } \\
",\end{array}$ & $\begin{array}{c}\text { mit PerI- } \\
\text { mutterglanz }\end{array}$ & $\begin{array}{c}\text { stark } \\
\quad "\end{array}$ & vorhanden & & $\begin{array}{l}\text { positiv } \\
\text { stark } \\
\text { positiv }\end{array}$ \\
\hline 1,89 & 2,61 & $\begin{array}{l}\text { blaß-grüngelb, stark gestreift, } \\
\text { sehr dünn }\end{array}$ & $\begin{array}{c}\text { kreideweiß } \\
\text { mit braunen } \\
\text { Flecken }\end{array}$ & mäßig & fehlt & & $\begin{array}{l}\text { positiv } \\
\text { positiv }\end{array}$ \\
\hline $\begin{array}{l}1,94 \\
1,95\end{array}$ & $\begin{array}{l}2,25 \\
2,23\end{array}$ & $\begin{array}{c}\text { blaß-grüngelb, gestreift, dünn } \\
",\end{array}$ & kreideweiß & $\begin{array}{l}\text { fehlt } \\
\text { mäßig }\end{array}$ & $"$ & & $\begin{array}{l}\text { schwach } \\
\text { positiv }\end{array}$ \\
\hline 1,91 & 2,28 & " $\quad "$ & $\begin{array}{c}\text { mit Perl- } \\
\text { mutterglanz }\end{array}$ & stark & $"$ & & $\begin{array}{l}\text { stark } \\
\text { positiv }\end{array}$ \\
\hline 1,89 & 2,33 & $\begin{array}{l}\text { blaf3-ölbraun, stark gestreift, } \\
\text { dünn }\end{array}$ & $\begin{array}{c}\text { mit Perl- } \\
\text { mutterglanz } \\
\text { und braunen } \\
\text { Flecken }\end{array}$ & mäßig & $"$ & & $\begin{array}{c}\text { stark } \\
\text { positiv }\end{array}$ \\
\hline 2,02 & 2,38 & $\begin{array}{l}\text { blaß-grüngelb, stark gestreift, } \\
\text { sehr dünn }\end{array}$ & kreideweis & fehlt & $"$ & 0,02 & \\
\hline $\begin{array}{l}1,73 \\
1,74\end{array}$ & $\begin{array}{l}2,48 \\
2,88\end{array}$ & $" \quad " \quad$ & $\begin{array}{l}\text { kreideweiß } \\
\text { mit braunen } \\
\text { Flecken }\end{array}$ & $\begin{array}{l}\text { mäßig } \\
\text { stark }\end{array}$ & $"$ & $\begin{array}{l}0,02 \\
0,01\end{array}$ & \\
\hline $\begin{array}{l}1,88 \\
1,95\end{array}$ & $\begin{array}{l}2,26 \\
1,99\end{array}$ & $"$ & & mäßig & $"$ & $\begin{array}{l}0,02 \\
0,01\end{array}$ & \\
\hline 2,03 & 2,38 & 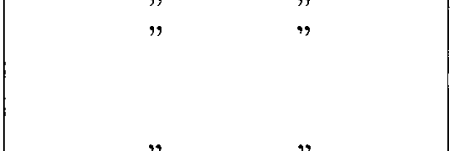 & $\begin{array}{c}\text { mit Perl- } \\
\text { mutterglanz } \\
\text { und braunen } \\
\text { Flecken } \\
\text { kreidewei } 3\end{array}$ & stark & $"$ & 0,02 & \\
\hline 1,93 & 2,23 & $\begin{array}{l}\text { blaß-gelblichbraun, "Kaum ge- } \\
\text { streift, sehr dünn }\end{array}$ & "n & fehlt & $"$ & $\begin{array}{l}0,02 \\
0,04\end{array}$ & \\
\hline 2,06 & 2,56 & " & $\mid \begin{array}{c}\text { kreideweiß mit } \\
\text { braunen } \\
\text { Flecken und } \\
\text { Lücken in der } \\
\text { Perlmutter- } \\
\text { schieht }\end{array}$ & mäßig & " & 0,01 & \\
\hline $\begin{array}{l}2,11 \\
1,93\end{array}$ & $\begin{array}{l}1,88 \\
2,28\end{array}$ & $\begin{array}{l}\text { blaß-grüugelb, stark" gestreift, } \\
\text { sehr dünn }\end{array}$ & kreideweiß & $\begin{array}{l}\text { stark } \\
\text { fehit }\end{array}$ & $"$ & $\begin{array}{l}0,06 \\
0,02\end{array}$ & \\
\hline $\begin{array}{l}1,95 \\
1,99\end{array}$ & 2,40 & $\begin{array}{l}\text { blaß-gelblichbraun, gestreift, } \\
\text { sehr dünn }\end{array}$ & $"$ & stark & $"$ & $\begin{array}{l}0,02 \\
0,01\end{array}$ & \\
\hline $\begin{array}{l}2,17 \\
2,10\end{array}$ & $\begin{array}{l}2,50 \\
2,28\end{array}$ & $\begin{array}{l}\text { blaß-gelblichbraun,fast streifen- } \\
\text { los, sehr dünn }\end{array}$ & $"$ & $\begin{array}{l}\text { mäßig } \\
\text { fehIt }\end{array}$ & $"$ & $\begin{array}{l}0,02 \\
0,02\end{array}$ & \\
\hline 1,74 & 1,98 & $"$ & $\begin{array}{c}\text { kreideweif mit } \\
\text { braunen } \\
\text { Flecken und } \\
\text { Lücken in der } \\
\text { Perlmutters- } \\
\text { schicht }\end{array}$ & $"$ & $"$ & 0,04 & \\
\hline $\begin{array}{l}1,95 \\
1,83\end{array}$ & $\begin{array}{l}2,79 \\
2,18\end{array}$ & $\begin{array}{l}\text { blaß-grüngelb, stark" gestreift. } \\
\text { sehr dünn }\end{array}$ & $"$ & $\begin{array}{l}\text { stark } \\
\text { fehlt }\end{array}$ & $"$ & $\begin{array}{l}0,02 \\
0,02\end{array}$ & \\
\hline $\begin{array}{l}1,81 \\
1,70\end{array}$ & $\begin{array}{l}2,35 \\
2,80\end{array}$ & $" \quad, \quad$, & $\begin{array}{l}\text { etwas matt } \\
\text { kreideweiß }\end{array}$ & stark & $"$ & $\begin{array}{l}0,06 \\
0,04\end{array}$ & \\
\hline 1,92 & 2,35 & $" \quad " \quad "$ & $\eta$ & mäßig & $"$ & 0,02 & \\
\hline 2,06 & 2,73 & $\begin{array}{l}\text { blaß-gelblichbraun, gestreift, } \\
\text { sehr dünn }\end{array}$ & $"$ & stark & ", & 0,01 & \\
\hline 1,78 & 2,60 & $\begin{array}{l}\text { blaß-gelblichbraun,fast streifen- } \\
\text { los, sehr dünn }\end{array}$ & $\begin{array}{l}\text { kreideweiß } \\
\text { mit braunen } \\
\text { Flecken }\end{array}$ & fehlt & $"$ & 0,06 & \\
\hline 1,97 & 1,86 & $\begin{array}{l}\text { blaß gelblichbraun, gestreift, } \\
\text { sebr dünn }\end{array}$ & " r & stark & $"$ & 0,02 & \\
\hline
\end{tabular}


Fortsetzung von Tabelle 2.

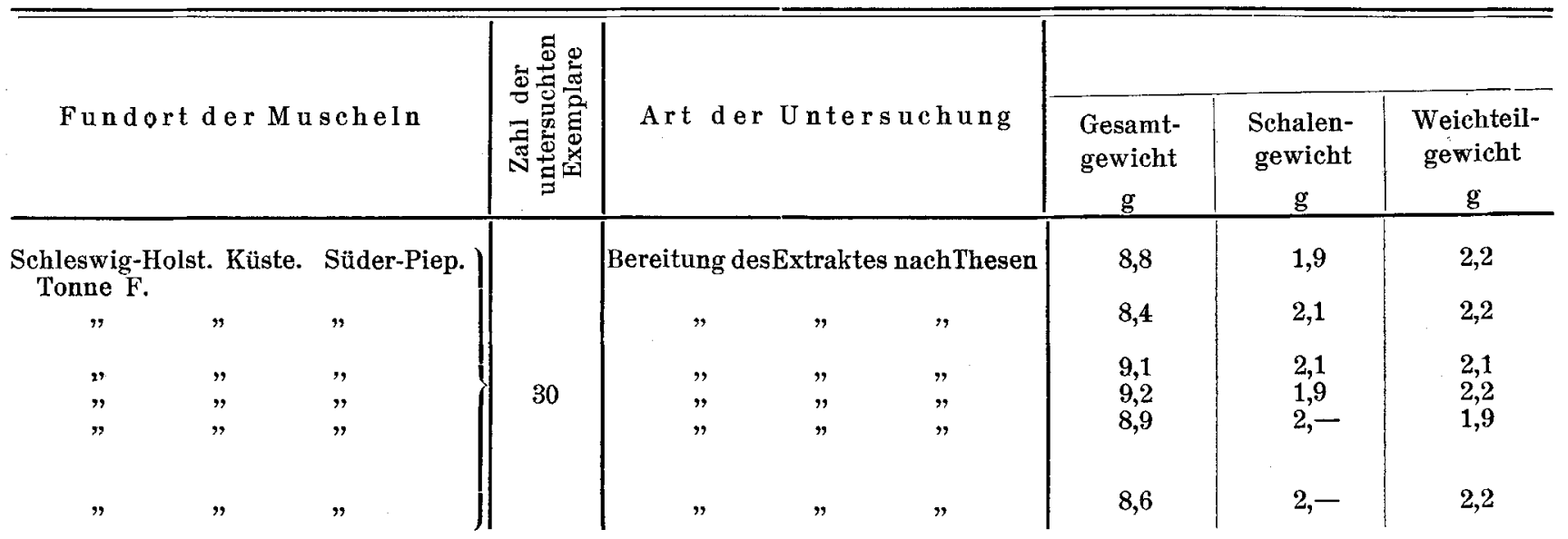

da sämtliche Muscheln von der Süder-Piep-Tonne, die ich in Filtrierpapier eingewickelt trocken legte, in einigen Tagen eingingen.

Bei den giftigen Muscheln von der Süder-Piep-Tonne unterzog ich auch jene Frage einer Prüfung, ob die sich in der Muschelschale befindliche Schalenflüssigkeit giftige Planktonorganismen oder gelöste Giftstoffe enthält. $\mathrm{Zu}$ diesem Zwecke habe ich aus den geöffneten Giftmuscheln die Schalenflüssigkeit gesammelt und insgesamt $200 \mathrm{ccm}$ derselben untersucht. Die Flüssigkeit wurde mit $2 \% 1 / 10$ n Salzsäure angesäuert, 2 Stunden lang im Wasserbad gehalten, dann die auf $10 \mathrm{ccm}$ eingedunstete Flüssigkeit mit $20 \mathrm{ccm}$ Alkohol gemischt, filtriert und nachher auf $3 \mathrm{ccm}$ eingedampft und mit Chloroform konserviert. Schließlich injizierte ich die Gesamtmenge einer $19 \mathrm{~g}$ schweren Maus, fand aber nicht die geringste Spur einer Giftwirkung. Entweder sind daher giftige Stoffe nicht in die Schalenflüssigkeit übergegangen, oder enthielt sie solche Stoffe nicht und folglich war auch dafür kein Anhaltspunkt vorhanden, daß das Gift auf dem Wege der Wasserströmung in den Organismus der Muschel gelangt wäre.

\section{Untersuchungen über Giftwirkung des Carcinus und Asterias.}

Mit den Giftmuscheln von der Süder-Piep-Tonne habe ich auch in der Richtung Untersuchungen vorgenommen, ob nach Verzehrung derselben andere Seetiere giftig werden. Die ersten diesbezüglichen Versuche führte ich an 4 zwischen die Süder-PiepMuscheln eingeschlossenen Carcinus maenas von der Größe einer Silbermark aus. Diese Tiere nahmen in der Mitte der übereinander gehäuften Masse der Muscheln, tief zwischen dieselben eingeschlossen, wie in einem engem Nest Platz. Aus den Tieren stellte ich nach Tötung mit Alkohol und Entfernung des Rückenschildes und der Füße, ähnlich dem durch WOLFF bei den Garnelen angewendeten Verfahren folgende Extrakte her: die Bestandteile der vermahlenen Tiere habe ich mit gleicher Menge 3\% dest. Wasser verdünnt und - täglich öfter geschüttelt -2 Tage lang bei Zimmertemperatur stehen gelassen. Dann hielt ich die Substanz während anderthalb Stunden in einem mit Watte zugestopften Kolben in siedendem Wasserbad, vermengte die filtrierte Flüssigkeit mit Alkohol im Verhältnis $1: 3$ und dampfte sie, noch einmal filtriert, in einer Porzellanschale im Wasserbad auf Sirupdicke ein. Der Rest wurde mit $10 \mathrm{ccm}$ dest. Wasser verrieben und auf Säurereaktion eingestellt, schließlich mit Chloroform konserviert. Die mit dem Extrakt nachträglich geimpfte $20 \mathrm{~g}$ schwere Maus verendete unter charakteristischen Lähmungssymptomen in 8 Minuten. Die Letaldosis des Extraktes betrug $0.08 \mathrm{ccm}$. Ein genauer Vergleich mit dem Muschelextrakt kann in Hinsicht auf die Giftwirkung schon deshalb nicht vorgenommen werden, da das Verhältnis und die Qualität der zur Herstellung benützten Weichteile bei den beiden Tieren sehr verschieden war. Die Giftwirkung der zwischen die Muscheln eingeschlossenen Carcinus-Exemplare kann am einfachsten in der Weise erklärt werden, daß die Krebse die Miesmuscheln gefressen haben. Laut HavinGA dürfte dieser Krebs die kleineren Muscheln fressen und „die Muscheln müssen irgendwie eine Nahrungsquelle für die Krabbe bilden, denn man findet diese überall in großer Zahl wo Muscheln vorkommen." HaAs zählt die Krabben geradewegs zu den Verwüstern der Muschelbänke, es kann daher mit Recht angenommen werden, daß die unter die Muscheln 


\begin{tabular}{|c|c|c|c|c|c|c|c|}
\hline \multicolumn{6}{|c|}{ Die Eigenschaften der giftigen Tiere } & \multicolumn{2}{|c|}{$\begin{array}{ll} & \text { Lrgebnisse } \\
\text { der } & \text { Untersuchungen }\end{array}$} \\
\hline $\begin{array}{l}\text { Länge- } \\
\text { und Höhe- } \\
\text { quotienten }\end{array}$ & $\begin{array}{c}\text { Länge- } \\
\text { und Dicke- } \\
\text { quotienten }\end{array}$ & $\begin{array}{l}\text { Haupteigenschaften } \\
\text { der Muschelschalen }\end{array}$ & \begin{tabular}{|c|} 
Zustand der \\
Innenfläche \\
der Muschel- \\
schale
\end{tabular} & $\begin{array}{c}\text { Deformation } \\
\text { der MuscheI- } \\
\text { schale }\end{array}$ & Kristallstiel & $\begin{array}{l}\text { Tödliche } \\
\text { Dosis des } \\
\text { Muschel- } \\
\text { extraktes } \\
\mathrm{cm}^{2}\end{array}$ & $\begin{array}{l}\text { Ergebnisse } \\
\text { des Richet- } \\
\text { schen Ver- } \\
\text { suches } \\
\end{array}$ \\
\hline 1,94 & 2,93 & $\begin{array}{l}\text { blafi-gelblichbraun, gestreift, } \\
\text { sehr düna }\end{array}$ & kreideweiß & stark & fehlt & 0,02 & \\
\hline 2,11 & 2,28 & $\begin{array}{l}\text { blaß-gelblichgrün, stark ge- } \\
\text { streift, sehr dünn }\end{array}$ & $"$ & mäßig & $"$ & 0,02 & \\
\hline $\begin{array}{l}1,94 \\
1,72\end{array}$ & $\begin{array}{l}2,45 \\
2,85\end{array}$ & ” & $"$ & $\begin{array}{l}\text { fehlt } \\
\text { stark }\end{array}$ & $"$ & $\begin{array}{l}0,1 \\
0,06\end{array}$ & \\
\hline 1,83 & 1,95 & $"$ & $\begin{array}{l}\text { kreideweiß } \\
\text { mit braunen }\end{array}$ & fehlt & $"$ & 0,02 & \\
\hline 1,75 & 2,38 & " & $\begin{array}{c}\text { Flecken } \\
,\end{array}$ & " & , & 0,01 & \\
\hline
\end{tabular}

eingeschlossenen Krebse, welche von anderen Nahrungsquellen auch sonst abgesperrt waren, die Muscheln verzehrten und somit giftig geworden sind.

Daß nach Verzehrung von giftigen Muscheln Seetiere tatsächlich giftig werden können, gelang mir, von den alten Errfahrungen WolfF's ausgehend, an Seesternen nachzuweisen. Zu diesem Zweck habe ich im Aquarium der Muscheln von der Süder-PiepTonne 3 Stück Asterias rubens aus dem Institutsaquarium untergebracht. Diese 3 Tiere haben von den Muscheln einen Tag lang nicht gefressen, deshalb habe ich sie getötet, aus ihnen Extrakte bereitet und vom Institutsaquarium 3 neue Tiere verlangt. Von diesen haben sich zwei bereits im Laufe einer Stunde an je einer größeren Muschel niedergelassen; der dritte griff nach einigen Stunden ebenfalls eine größere Muschel an und nach 24 Stunden fand ich am Grunde des Bassins 11 Stück größtenteils ausgefressene Muschelschalen von ungefähr 8-10 g, wobei zwei Seesterne noch immer an je einer Muschel saßen. Die drei Seesterne habe ich dann auf 24 Stunden in ein keine Muscheln enthaltendes Aquarium mit reinem Wasser untergebracht und aus ihnen Extrakte hergestellt. Bei diesem Verfahren ging ich in der auch von WOLFF benutzten und im wesentlichen bereits vorher beschriebenen Weise vor, indem ich von den geöffneten Tieren sämtliche Weichteile, soweit dies möglich, auskratzte und mit Quarzsand $z u$ einem feinem Brei zerrieb. Dann setzte ich die gleiche Menge von mit $3 \% 1 /{ }_{10} \mathrm{n}$ Salzsäure gemischten dest. Wasser zu und verfuhr im übrigen in der bereits beschriebenen Weise. Ebenso bereitete ich Extrakte aus zwei im Institutsaqarium lebenden Tieren, ferner von jenen drei Tieren, die unter den giftigen Muscheln gewesen waren, jedoch Muscheln nicht gefressen hatten. Der Extrakt jener Seesterne, die Giftmuscheln verzehrt hatten, tötete in 4 Minuten - in einer Dosis von $0.1 \mathrm{ccm}$ unter charakteristischen paralytischen Vergiftungssymptomen - die $20.5 \mathrm{~g}$ schwere Maus, doch zeigten die Extrakte der übrigen zwei Tiergruppen überhaupt keine Giftwirkung. Ein Vergleich der Giftdosis mit jener des Muschelextraktes ist wegen der Verschiedenheit der zur Bereitung benützten Weichteile auch hier nicht möglich. Es kann aber trotzdem festgestellt werden, daß nach Verzehrung der Giftmuscheln die Seesterne auch selbst stark giftig geworden sind, wogegen die vom selben Aquarium stammenden Tiere, die keine Giftmuscheln verzehrten, sich als ungiftig erwiesen. Die Untersuchungen erbrachten daher den Beweis, daß das Gift der unter giftigen MuscheIn lebenden Seesterne, die Giftwirkung zeigten, von der Verzehrung der Muscheln herrührt und es darf als wahrscheinlich angenommen werden, daß die unter die Süder-Piep-Muscheln eingeschlossenen Krebse in ähnlicher Weise giftig geworden sind.

\section{Aeußere Eigenschaften der gesammelten Muscheln.}

Beim Ueberblick über die Eigenschaften der giftig befundenen Tiere fand ich, daß die giftigen Muscheln meistens unter den Tieren mit blasser, gestreifter, dünner Schale anzutreffen waren und zwar nicht nur unter den Muscheln von der Süder-Piep-Tonne, wo alle giftig gewesen sind, sondern auch dort, wo sich giftige unter ungiftigen Tieren befanden. Es wird daher von neuem der Gedanke aufgeworfen, ob nicht zwischen der Vergiftungsfähigkeit und den äußeren Merkmalen irgend ein Zusammenhang besteht. Um das zu beurteilen, suchte ich vor allem die Maße und Gewichte der gesammelten Muscheln 
zu bestimmen und festzustellen, ob zwischen den giftigen und ungiftigen Tieren in dieser Hinsicht irgend eine Abweichung gefunden werden kann. Ich bestimmte an den in Tab. 3 aufgezählten Exemplaren der an verschiedenen Fundorten gesammelten Muscheln das Verhältnis der Länge und Höhe, bzw der Länge und Dicke zu einander, der sogenannte Längen-Höhenquotient, bzw. Längen-Dickenquotient $\left.{ }^{1}\right)$. Ueberdies habe ich einzelne Tiere nach gründlicher Reinigung der Schale auch gewogen und das Gewicht der Schale und der Weichteile einzeln bestimmt. Bei allen diesen Untersuchungen trachtete ich der Möglichkeit nach, die Daten von annähernd gleich schweren Tieren miteinander zu vergleichen und deshalb wurden nur die Ergebnisse der Mittelwerte der Messungen von einer größeren Anzahl ähnlich schwerer Tiere berücksichtigt, wobei ich die verschiedenen Gewichtsgruppen einzeln anführte. Die Ergebnisse der Messungen sind in Tab. 3 und 4 veranschaulicht. Aus den Daten von Tab. 3 geht hervor, daß bei den Helgoländer dunklen Tieren ohne Streifung der Längen-Höhenquotient bei vier Werten über 2,1 ansteigt, bei drei Werten 2,1 nahe stand, jedoch bei den an Helgoländer Tonnen gesammelten Tieren mit gestreifter Schale sich nur um ein weniges über den Wert von 2, 2,03, 2,01 erhob. Wie schon erwähnt, stellen die obigen Resultate Mittelwerte dar, bei deren Bestimmung verhältnismäßig große Schwankungen zu beobachten waren, da sich unter den Tieren Werte von 2,28,2,36 und sogar 2,61 ebenso fanden, wie Werte von 1,98, ja sogar 1,84. Es ist im allgemeinen klar geworden, daß am gesammelten Material aus den obigen Maßen Schlüsse nur dann gezogen werden können, wenn Exemplare in entsprechend reichlicher Menge untersucht werden. Weil aber Helgoländer gestreifte Tiere in den untersuchten Gewichtsgruppen in größerer Anzahl als 20 bzw. 30 Stück nicht zur Verfügung standen, darf der Niedrigkeit des Längen-Höhenquotienten keine übertriebene Bedeutung zugemessen werden. Demgegenüber konnte ich bei den von Wyk-Tonne 6 und Eider-Tonne 2 stammenden Tieren, wo ich an einer größeren Anzahl von Muscheln Messungen vornahm, trotz starker Schwankung der Maßverhältnisse feststellen, daß an diesen Stellen mehr hohe als längliche Exemplare vorkamen. Die Messungen der an der Außenseite der "Hackfeld“-Tonne sitzenden Muscheln führten zu einem ähnlichen Ergebnis, auffallend war jedoch, daß in der nahezu ähnlichen Gewichtsgruppe der inwendig anhaftenden Tiere die Längen-Höhenquotienten ausgesprochen geringer $(1,93$ bzw. 1,92) gewesen sind. Es ist wohl wahr, daß die Anzahl der untersuchten Tiere verhältnismäßig gering (30 bzw. 60) war, aber diese Werte sind dennoch beachtenswert, weil bei den Tieren im Inneren der Tonne der Längen-Höhenquotient im allgemeinen bedeutend weniger Schwankungen zeigte als an den anderen Stellen und ein überwiegender Teil der Tiere schon auf den ersten Blick deutlich höher war. Bci den Tieren von der Süder-Piep-Tonne zeigte der Längen-Höhen-Quotient wohl wieder eine bedeutende Schwankung, doch boten die sich aus je 100 Messungen ergebenden Mittelwerte in jeder Gewichtsgruppe ein derartig einheitliches Bild $(1,92$ bzw. 1,91), daß bei den giftigen Tieren im Verhältnis zu den Helgoländer Muscheln der Längen-Höhenquotient als bedeutend verkürzt angesehen werden muB und die giftigen Tiere im allgemeinen als Tiere ron hoher Form zu bezeichnen sind. Zum Vergleich der Längen-Höhen-Maße nahm ich in Tab. 3 meine in dem Biologischen Institut zu Neapel vorgenommen Messungen auf, ferner die an den durch $\mathrm{H}$. CASPERs aus Varna gesandten 25 verschieden großen Muscheln durchgeführten Bestimmungen. Wie aus der Tabelle ersichtlich, waren die Längen-Höhenquotienten all dieser Muscheln $(1,76-1,90)$ bedeutend niedriger als jene der Helgoländer Tiere und standen jenen der giftigen Süder-Piep-Muscheln näher. Die Form der giftigen und der im Inneren der "Hackfeld"-Tonne sitzenden Muscheln wich daher erheblich von der der normalen Helgoländer Tiere $a b$ und ähnelte mehr den Muscheln aus Neapel und Varna. Neben dem Längen-Höhenquotienten habe ich auch den Längen-Dickenquotienten bestimmt. Doch zeigten diese Messungen sowohl bei den Helgoländer als auch bei den Schleswig-Holsteiner Muscheln eine derart starke und unregelmäBige Schwankung, daß sie sich zum Vergleich der erhaltenen Werte überhaupt nicht eignen. Es ist höchstens soviel auffallend, daß bei den Tieren von der Süder-Piep-Tonne die Mittelwerte in allen drei Gewichtsgruppen auf die flachere Form hinwiesen.

Die Untersuchungen über das Verhältnis zwischen Gewicht der Schale und der Weichteile zeigten gegen die Vorangehenden ein viel einheitlicheres Bild. Die Ergebnisse

1) Als Länge wird der Abstand vom vorderen spitzen zum hinteren stumpfen Ende der Muschelschale bezeichnet, als Höhe der größte Abstand vom ventralen zum dorsalen Schalenrand und als Dicke (Breite) der Muschel der größte Transversaldurchmesser bei geschlossenen Schalenklappen (nach HAGMEIER und KÄxdlBr, 1927 Wiss. Meeresunters. NF. Abt. Helgoland Bd. 16, Abh. 6 u. a.). 
Tabelle 3.

Länge und Höhe sowie Länge- und Dickequotienten der Muscheln nach Fundort und Gewichtsgruppe geordnet.

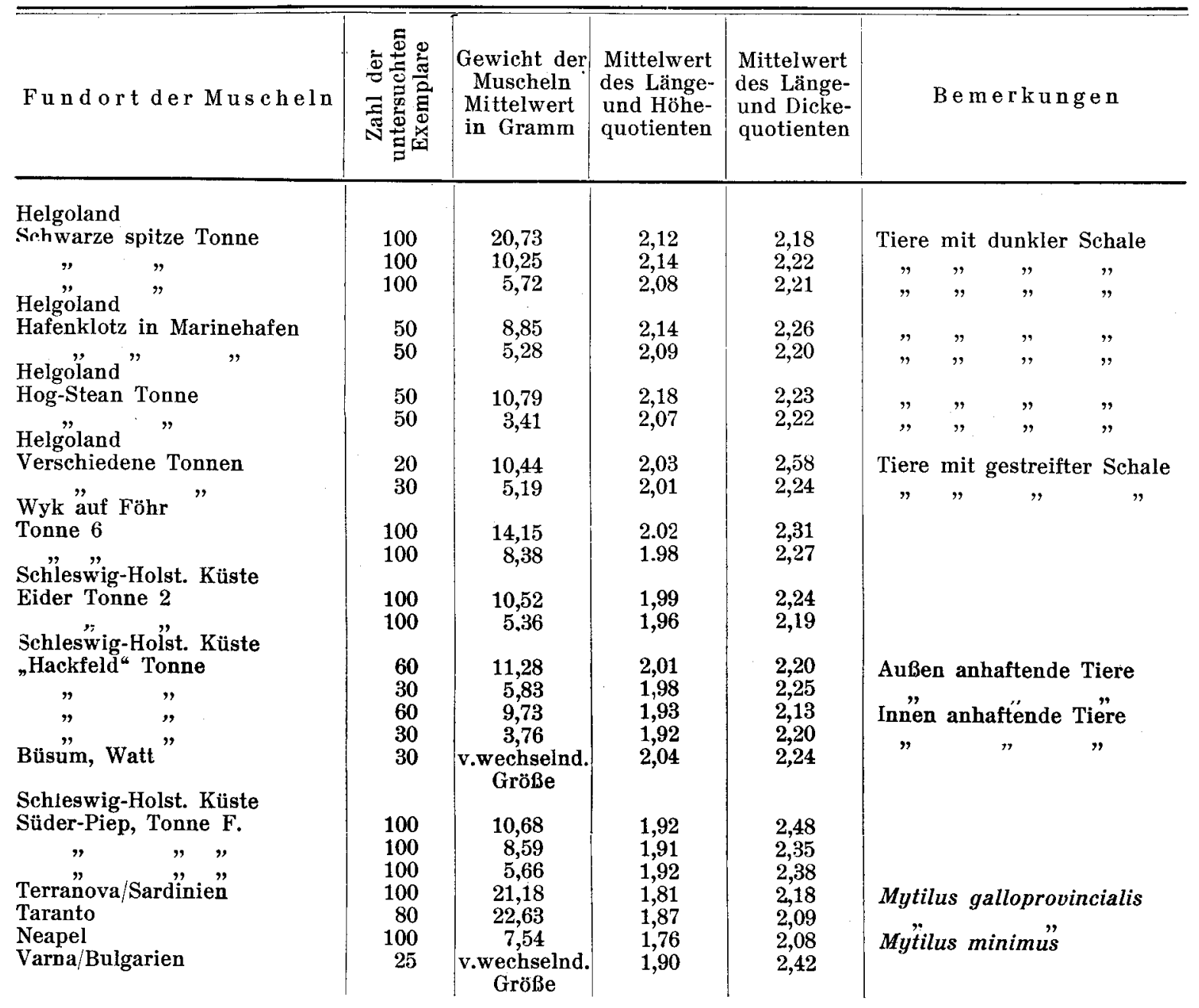

sind in Tab. 4 zusammengefaßt. Dieselbe veranschaulicht die Werte von je 100 gemessenen Tieren jeder einzelnen Gewichtsgruppe der Helgoländer Muscheln mit dunkler Schale, ferner der giftigen Muscheln von der Süder-Piep-Tonne; von je 50 aus jeder einzelnen Gewichtsgruppe der von Tonne 6 aus der Nähe von Wyk auf Föhr stammenden Tiere, von je 20 der.Tiere mit blasser Schale in Kolonne 1 und 2 und von je 30 Tieren in Kolonne 3 und 4, das heißt die Ergebnisse der Messungen an 700 ungiftigen und 400 giftigen Muscheln. Die Angaben der Tabelle lassen die Feststellung zu, da 3 bei den Helgoländer dunklen und lichten Exemplaren als auch bei den aus der Nähe von Wyk a uf Föhr stammenden Tieren das Gewicht der Weichteile geringer ist als das der Schale und besonders bei den dunkelfarbigen Exemplaren ist dieser Unterschied ein recht bedeutender. Demgegenüber ist das Weichteilgewicht bei den Süderpieper Giftmuscheln ausgesprochen größer als das Schalengewicht, das heißt also, daß die Schalen außerordentlich leicht sind. Man könnte daher aus den Daten der Tabelle die falsche Folgerung ziehen, daß der Körper der giftigen Muscheln schwerer sei, als jener der ungiftigen, obwohl, wie bereits in Tab. 1 angeführt, der Mantel der Muscheln, dünn, häutchenartig war. Daß bei den giftigen Tieren tatsächlich nicht nur die Schale sondern auch der Körper leichter war als bei den Muscheln von Helgoland, kommt dann zum Ausdruck, wenn die Gewichtsverhältnisse von Tieren gleicher Größe verglichen werden. Diese Messungen stießen auf gewisse Schwierigkeiten, da die giftigen Muscheln eher zu den höheren, die Helgoländer dagegen 


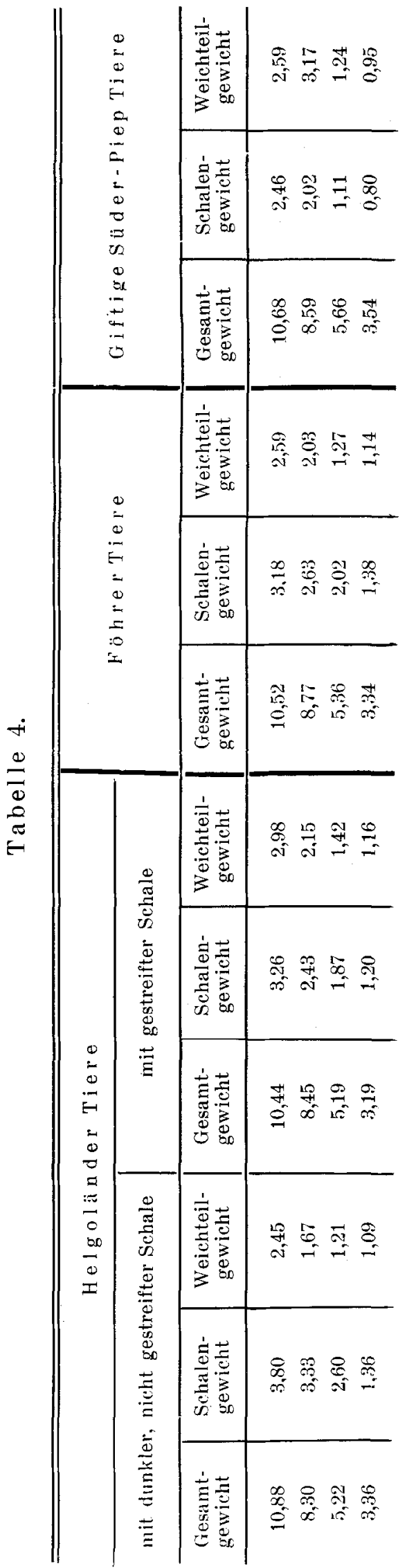

mehr zu den länglichen Tieren gehörten. Es ist daher verständlich, daß es mir nur gelang, 6 Tiere mit ganz ähnlichen Maßverhältnissen zu finden. Die Maße der Schalen dieser Muscheln und die Gewichtsangaben sind in Tab. 5 angegeben. Diese zeigt, daß bei den giftigen Muscheln sowohl das Gewicht der Schale als auch das der Weichteile geringer ist als jenes der normalen Tiere, aber die Gewichtssenkung der Weichteile erscheint von verhältnismäßig geringerem Ausmaß $\mathrm{zu}$ sein, als die der Schale. Daher sind die Zahlenangaben der Tab. 4, nach welchen das Weichteilgewicht der giftigen und nicht-giftigen Tiere ein ähnliches Verhalten aufweisen, ein Scheinergebnis. Einmal ist das Weichteilgewicht giftiger Tiere im Vergleiche zu Tieren von gleichem Umfange, ein geringeres, uud dann vermindert sich - mit Normaltieren verglichen - das Weichteilgewicht in relativ geringerem Grade als das Schalengewicht. Bei den in jeder Hinsicht atrophischen Tieren steht somit die Verminderung des Schalengewichtes im Vordergrund. Das geringe Gewicht der Muschelschalen bei den giftigen Muscheln geht mit der Verdünnung der Schalen einher. Auf die Verdünnung der Schalen weist auch deren verhältnismäßig groß̉e Durchsichtigkeit. Dabei waren die Muschelschalen sehr zerbrechlich. Außerdem blieben die ins Wasser geworfenen Muscheln von der Süder-Piep-Tonne fast ohne Ausnahme an der Wasseroberfläche und die an den Tisch angeschlagenen Muscheln klangen außerordentlich hohl. Das spezifische Gewicht der jungen Miesmuscheln ist auch bei normalen Tieren gering und es ist diesem Umstand zuzuschreiben, daß, falls eine große Menge von Muscheln ins Wasser geworfen wird, oft einzelne Tiere gefunden werden, die an der Oberfläche des Wassers bleiben und es kommt sogar vor, wie z. B. bei den in der Nähe von Wyk gesammelten Muscheln, daß der größte Teil an der Wasseroberfläche schwimmt. Der Umstand aber, daß die Giftmuscheln von der SüderPiep-Tonne fast ohne Ausnahme längere Zeit hindurch an der Oberfläche des Wassers blieben und einzelne sogar halb geöffnet, den Fuß $2-3 \mathrm{~cm}$ lang ausgestreckt, oben schwammen, darf für alle Fälle als eine außerordentliche Erscheinung angesehen werden. Es läßt die Folgerung zu, daß die Schale im Vergleich zum Volumen der Muschel unverhältnismäßig leicht und das Gewicht der Weichteile gering ist.

Außer den erwähnten Merkmaler, zeigten sich bei den Süder-Pieper Muscheln auch in Form und Farbe der Schale solche Abweichungen, die darauf schließen ließen, daß im Aufbau der Schale noch andere Regelwidrigkeiten mitspielten. Von diesem Gesichtspunkt aus ist in erster Linie die bei den Wilhelmshavener Muscheln bereits betonte Eigenschaft, daß die Oberhaut (das Periostrakum) relativ dick und glänzend war, sehr auffallend. Eine ähnliche Erscheinung war bei anderen Muscheln, z. B. bei den aus der Nähe von Wyk, ferner bei von der Eider Tonne 2 stammenden einzelnen 
Tabelle 5 .

Verhalten des Gewichtes von Muscheln mit gleichen Volumen aus Helgoland und von der Süder-Piep-Tonne.

\begin{tabular}{|c|c|c|c|c|c|c|c|c|c|c|c|c|c|}
\hline \multicolumn{7}{|c|}{ Helgoländer Tiere- } & \multicolumn{7}{|c|}{ Giftige Süder-Piep-Tiere } \\
\hline 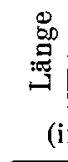 & $\mid \begin{array}{c}0 \\
\substack{0 \\
0 \\
I} \\
\text { in } \mathrm{cm}\end{array}$ & 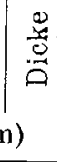 & $\begin{array}{c}\text { Ge- } \\
\text { samtgew. } \\
\text { in } g\end{array}$ & $\begin{array}{c}\text { Schalen- } \\
\text { gew. } \\
\text { in } g\end{array}$ & $\begin{array}{l}\text { Weich- } \\
\text { teilgew. } \\
\text { in g }\end{array}$ & $\begin{array}{c}\mathrm{Be}- \\
\text { merkungen }\end{array}$ & 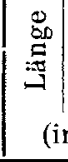 & $\begin{array}{l}\stackrel{0}{0} \\
\mathrm{n} \\
\mathrm{n}\end{array}$ & $\mid \begin{array}{l}0 \\
\stackrel{2}{0} \\
\stackrel{0}{0}\end{array}$ & $\begin{array}{c}\text { Ge- } \\
\text { samtgew. } \\
\text { in } \mathrm{g}\end{array}$ & $\begin{array}{c}\text { Schalen- } \\
\text { gew. } \\
\text { in } g\end{array}$ & $\left\{\begin{array}{c}\text { Weich- } \\
\text { teilgew. } \\
\text { in } g\end{array}\right.$ & $\begin{array}{c}\text { Be- } \\
\text { merkungen }\end{array}$ \\
\hline 5,5 & 2,8 & 2,5 & 10,25 & 3,98 & 2,38 & $\begin{array}{l}\text { Dunkles Tier } \\
\text { ohne Streifg. }\end{array}$ & 5,5 & 2,8 & 2,3 & 8,02 & 1,88 & $2,-$ & $\begin{array}{l}\text { Blasses Tier } \\
\text { mit starker } \\
\text { Streifg. }\end{array}$ \\
\hline 5,6 & 2,6 & 2,3 & 11,08 & 4,18 & 2,85 & dass. & 5,7 & 2,6 & 2,9 & 8,23 & 2,02 & 2.13 & dass. \\
\hline $5,-$ & 2,4 & 2,2 & 8,98 & 3,01 & 2,58 & $\begin{array}{c}\text { Blasses Tier } \\
\text { mit starker } \\
\text { Streifg. }\end{array}$ & $5,-$ & 2,6 & 2,1 & 6,15 & 1,69 & 1,93 & diass. \\
\hline 4,8 & 2,3 & 2,2 & 8,03 & 3,15 & 1,79 & $\begin{array}{l}\text { Dunkles Tier } \\
\text { ohne Streifg. }\end{array}$ & 4,8 & 2,4 & $2,-$ & 4,98 & 1,08 & 1,33 & dass. \\
\hline 4,5 & 2.- & 1,9 & 6,65 & 2,83 & 1,76 & dass. & 4,5 & 2,2 & 1,8 & 4,15 & 0,98 & 1,18 & dass. \\
\hline $4,-$ & 1,8 & 1,8 & $6 ' 17$ & 2,75 & 1,36 & dass. & 4,1 & 1,9 & 1,8 & 3,93 & 0,88 & 0,92 & dass. \\
\hline
\end{tabular}

Tieren zu beobachten. So einheitlich aber, wie bei den Süder-Pieper Tieren ist das sonst nirgends der Fall gewesen. Es verhielt sich auch um die blasse Farbe und Streifung der Muscheln ähnlich, die sich an einzelnen Tieren fast aller Fundorte feststellen ließen, doch zeigten sie sich an den Tieren von der Süder-Piep-Tonne am einheitlichsten. Die Süder-Pieper Muscheln können in dieser Beziehung in zwei Gruppen eingeteilt werden. Einzelne Tiere erschienen, - wie Abb. 4 zeigt, - im Vergleich zu den normalen Helgoländer Tieren (Abb. 4, Fig. 1) von sehr blasser, meistens hell gelblich-brauner Farbe (Abb. 4, Fig. 2-5) und an diesen außerordentlich dünnen, zerbrechlichen, durchscheinenden $\mathrm{Mu}$ schelschalen war eine Streifung meist nur wenig sichtbar, obwohl manchmal unter ihnen auch stärker gestreifte Tiere vorkamen. Die zweite Gruppe der Tiere bildeten jene mit blaß grüngelben Schalen, die im frischen $\mathrm{Zu}-$ stand eine blaß grasgrüne, oder eine dunklere, lebhaft grüne, sehr ausgeprägte Streifung zeigten (Abb. 5 und 6 ). Die Streifen gingen zumeist von der Wirbelspitze aus und verliefen die Schale entlang anfangs in einem schwachen Bogen, später fächerartig ausgebreitet. Es gab aber besonders unter den blaß gelbbraunen Exemplaren auch solche, bei denen die Streifung sich auf Stellen in der Nähe des Schalenrandes beschränkte (Abb. 4, Fig. 5). $\mathrm{Ab}$ und $\mathrm{zu}$ konnte neben den Längsstreifen auch eine mit dem Schalenrand parallel verlaufende konzentrische Streifung beobachtet werden. Während die radiären Streifen aber in der Regel in breiten Gruppen angeordnet waren oder als breite Bänder verliefen, bildeten die konzentrischen Streifen

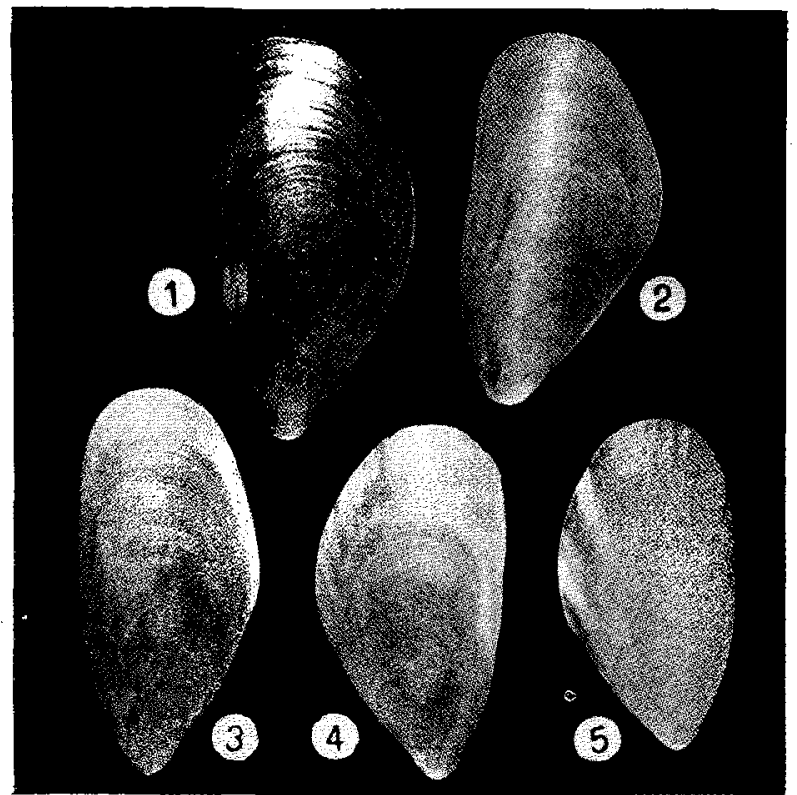

Abb. 4. Blaßbraune, streifenlose (Fig. 2), wenig gestreifte (Fig. 3 u. 4), teilweise gestreifte (Fig. 5) giftige Muscheln von der Süder-Piep-Tonne. Zum Vergleich ein dunkel-ölgrünes Tier aus Helgoland (Fig. 1). $1 \mathrm{~cm}=1,12 \mathrm{~cm}$ in der Natur. 
mehr schmale Linien (Abb. 7 Bild links unten und in der Mitte). Die Streifung war gewöhnlich auch in auffallendem Licht wahrnehmbar, sie zeigte sich aber insbesondere beim Durchleuchten der Muschel, also in durchfallendem Licht, sehr ausgeprägt (Abb. 7). Dabei verliefen die Streifen an der linken und rechten Schalenhälfte niemals symmetrisch und beide Schalenhälften boten sowohl hinsichtlich der Zahl der Streifen als auch in deren Anordnung, wie das schon LisT beobachtete, ein voneinander vollkommen abweichendes

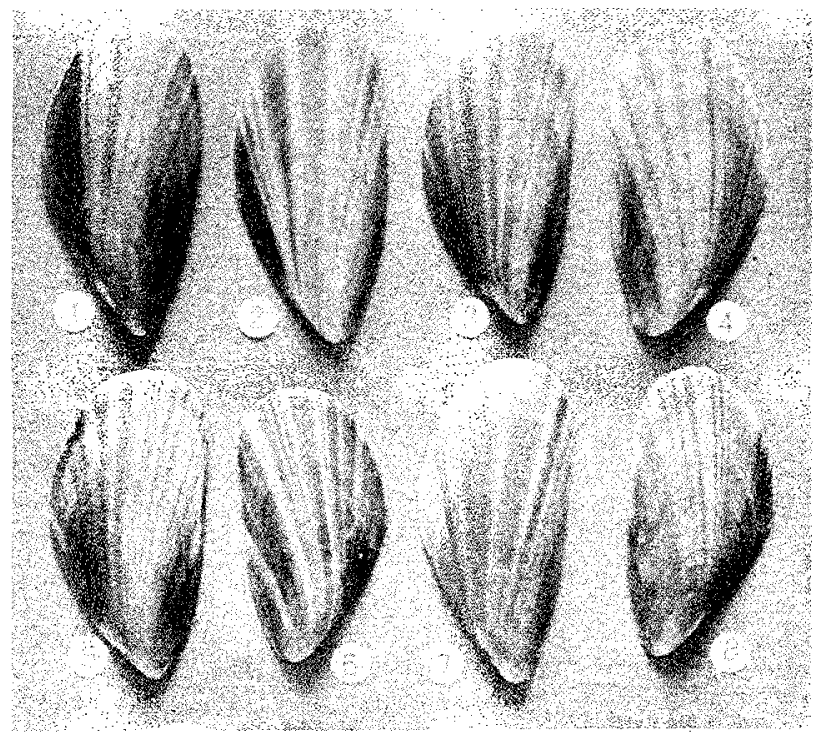

Abb. 5. Gestreifte Tiere von der Süder-Piep-Tonne. $1 \mathrm{~cm}=$ $1,32 \mathrm{~cm}$ in der Natur.

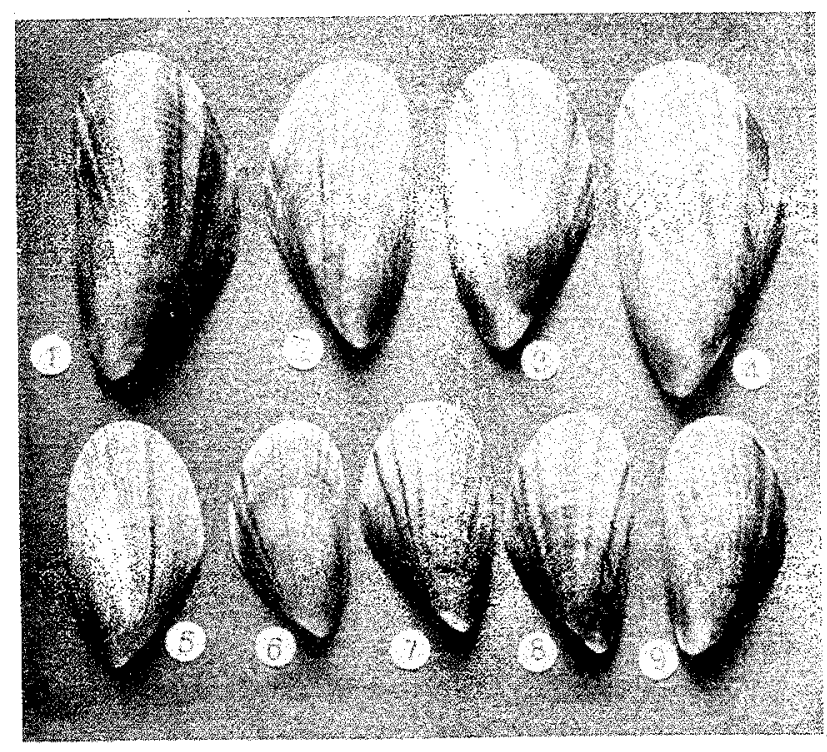

Abb. 6. Gestreifte Tiere von der Süder-Piep-Tonne. $1 \mathrm{~cm}=$ $1,32 \mathrm{~cm}$ in der Natur. Bild. Gestreifte Tiere kamen also nicht nur unter den giftigen Muscheln, sondern auch anderswo vor. Während aber in Helgoland solche Tiere hauptsächlich unter den mittelgroßen und kleinen Muscheln zu finden waren, waren unter den Süder-Pieper Muscheln eben die größten Exemplare am stärksten gestreift, wogegen die Schale der ganz winzigen Tiere oft vollkommen farblos war und keine Streifung zeigte. An Abb. 8 sind links die aus Helgoland von der schwarzen Spitzen Tonne, in der Mitte die aus der Nähe von Wyk stammenden, rechts die giftigen Muscheln von derSüder-PiepTonne dargestellt. Die mitphotographierten Erbsenkörner bezeichnen unterhalb der Abbildung die Größe der Tiere. Das Bild zeigt von jedem der drei Orte je 3 aus der Hauptmasse der Muscheln ausgewählte charakteristische Exemplare von verschiedener Größe. Dementsprechend sind die Helgoländer Exemplare schon in ganz geringer Größe meistens von gelblich-brauner Farbe gewesen und die Streifung war erkennbar. An den größeren, jedoch die Erbsengröße noch weit nicht erreichenden Tieren erschien die Schale dunkelbraun und die Streifung war ausgeprägt. Bei den Tieren aus Wyk von ähnlicher Größe oder etwas größeren Exemplaren war die Schale meistens von einer lichteren Färbung, mit weniger deutlicher Streifung, dagegen war bei den giftigen Muscheln von der SüderPiep-Tonne die Schale der ganz winzigen und etwas größeren Tiere farblos oder von sehr blasser Farbe und zeigte keine Streifung. Beim Betupfen der Schale mit warmer, stark verdünnter Salzsäure ließ sich das Periostrakum ablösen. Es wurde dann sichtbar, daß die Streifen in der violetten Prismenschicht liegen und die dunkelvioletten Streifen durch Durchscheinen des gelblichbraunen Periostrakums grün erscheinen. An den so behandelten Muscheln konnte aber auch festgestellt werden, daß die Prismenschicht der Muscheln von der Süder-Piep-Tonne sowohl bei den großen als auch bei den kleinen Tieren bedeutend weniger pigmentiert als die der Helgoländer Tiere war, dagegen zeigte sich das Periostrakum bei den giftigen Tieren viel dicker als bei den Helgoländer Muscheln. 
Während die Farbabstufung der Schale bei den Süder-Pieper Tieren gewöhnlich durch die starke Pigmentierung des Periostrakums verursacht wird, ist bei den Helgoländer Muscheln die dunkelviolette Prismenschicht vorherrschend. So wird es erklärlich, daß bei ganz winzigen giftigen Tieren, wo auch das Periostrakum noch ganz blaß ist, die Muschelschale fast farblos erscheint. Die größeren giftigen Tiere sind dagegen von gelblichbrauner. Farbe und wenig gestreift, wenn die Prismenschicht schwächer pigmentiert ist, dagegen gelblich-grün und stark gestreift, wenn die Prismenschicht von mehr dunkler Färbung ist. Demgegenüber erscheint bei den Helgoländer Tieren die Pigmentierung der Prismenschicht bereits bei den kleinen Tieren ausgeprägt und so ist die Streifung auch schon an den kleinen (jungen) Exemplaren gut sichtbar. Später führt aber das allmähliche Dunklerwerden der Prismenschicht zum Verschwinden der Streifen und das Tier wird mit der Verfärbung des Periostrakums dunkel olivgrün oder schwarz und die Streifung ist nur beim Durchleuchten des Tieres erkennbar. Es scheint aber, daß bei den Süder-

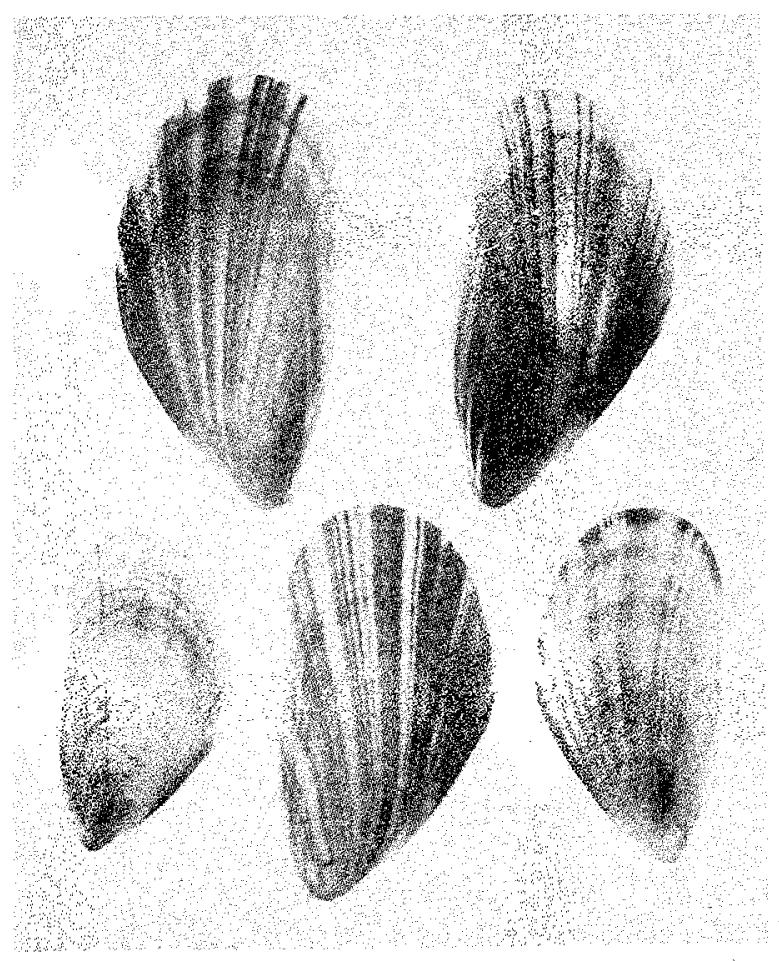

Abb. 7.

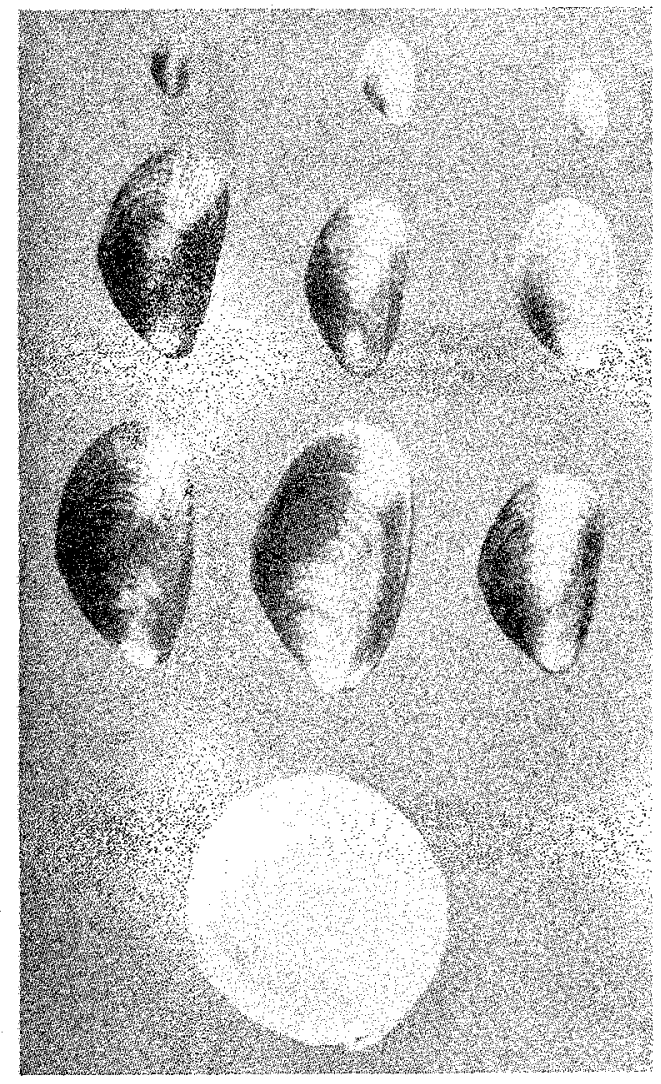

Abb. 8.

Abb. 7. Schalen von gestreiften Tieren von der Süder-Piep-Tonne in durchfallendem Licht.

Abb. 8. Sehr junge Muscheln aus Helgoland (links), aus Wyk a./Föhr (in der Mitte), und von der SüderPiep-Tonne (rechts). Zur Beurteilung der Größenverhältnisse ist unten eine grüne Erbse abgebildet.

Pieper giftigen Muscheln die Schale nicht nur pigmentärmer, sondern auch kalkärmer ist. Es darf wohl diesem Umstand zugeschrieben werden, daß an den Schalen von verhältnismäßig vielen Tieren verschiedene Mißbildungen zu beobachten waren. Allein durch die Dünne der Schale wird diese Erscheinung nicht zur Genüge begründet, da doch Tiere mit dünner Schale auch an anderen Fundorten vorkamen und Mißbildungen an diesen Tieren doch nicht in so auffallend großer Anzahl auftraten wie bei den giftigen Tieren von der SüderPiep-Tonne. Die Mißbildungen zeigten sich vorerst darin, dafs bei verhältnismäßig vielen Tieren die Wölbung der Schale unproportioniert erschien, indem, wie an Abb. 9 sichtbar, die eine Schalenhälfte gegenüber der anderen unregelmäßig flachgedrückt oder stärker gewölbt 
war. Dagegen entstanden bei anderen Muscheln (Abb. 10) am Schalenrand Ausbuchtungen und an der Oberfläche leichte Eindrückungen, wobei die Muschel eine ungewohnt breite Form annahm. Einzelne Tiere waren hauptsächlich in der Längsrichtung gewachsen und, obwohl sie den Helgoländer Museheln ähnlich sahen, nahm das Tier infolge Verdrehung der Längsachse eine mehr oder weniger entstellte Form an (Abb. 4, Fig. 2).
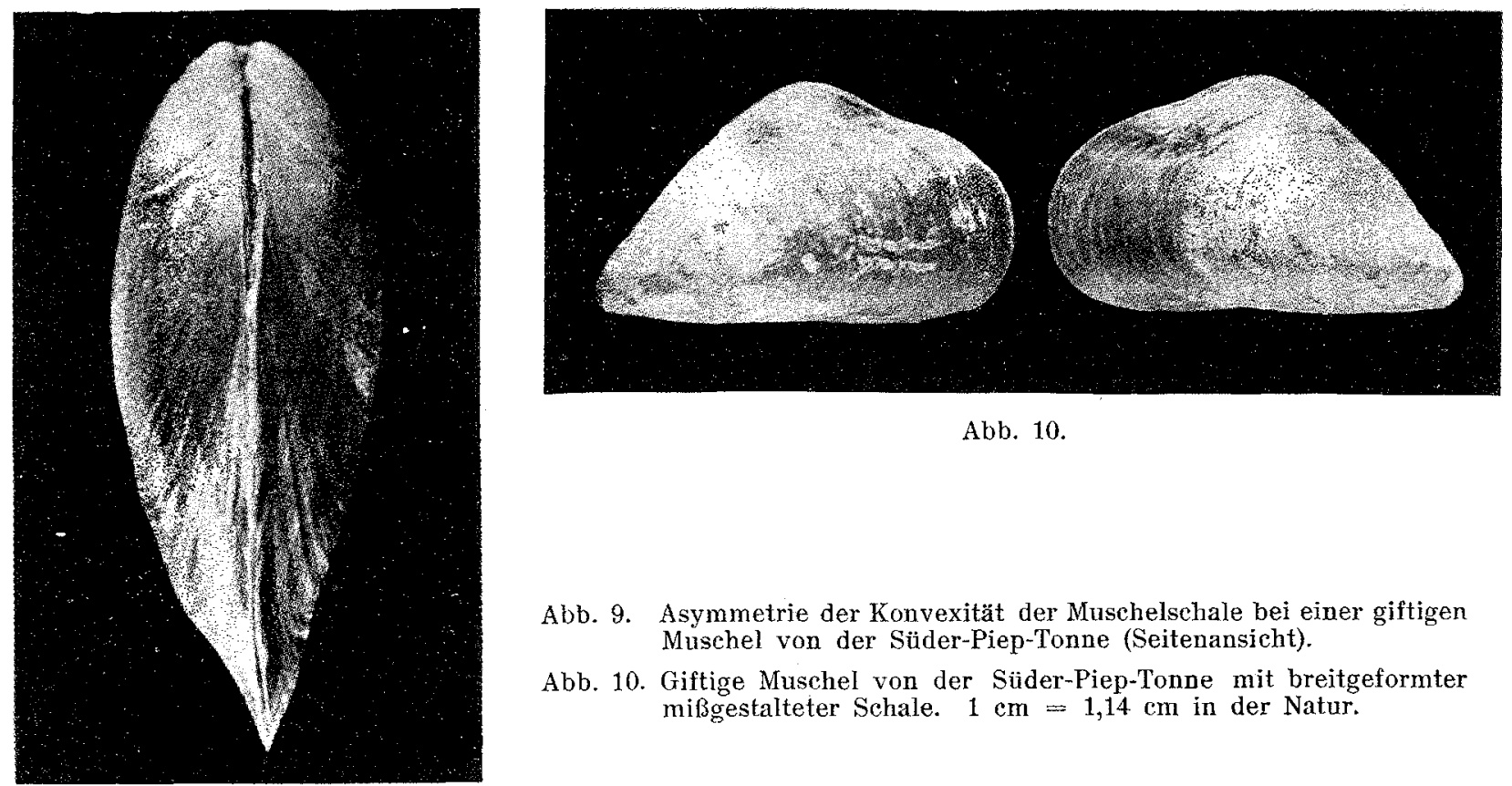

Abb. 10 .

Abb. 9. Asymmetrie der Konvexität der Muschelschale bei einer giftigen Muschel von der Süder-Piep-Tonne (Seitenansicht).

Abb. 10. Giftige Muschel von der Süder-Piep-Tonne mit breitgeformter mißgestalteter Schale. $1 \mathrm{~cm}=1,14 \mathrm{~cm}$ in der Natur.

Abb. 9.

\section{Erscheinungen an der Innenfläche der Muschelschalen.}

An der Innenfläche der Schale der Süder-Pieper giftigen Muscheln waren aber Abweichungen sichtbar, die an Muscheln anderer Lokalitäten zwar auch vorkamen, jedoch in ähnlich charakteristischer Form nur an wenigen Orten. Vor allem ist in dieser Hinsicht die kreideweiße, matte Verfärbung der Innenfläche erwähnenswert. Wie bekannt, ist die Innenfläche der Muschelschale von durchscheinendem Perlmutterglanz. Am vorderen Ende der Helgoländer Muscheln ist die Innenfläche porzellanartig, rückwärts scheint aber die violette Prismenschicht durch die dünne Perlmutterschicht durch. Die Grenze der beiden Zonen ist unscharf, der allmählich dünner werdenden Prismenschicht entsprechend verschwommen (Abb, 11, Bild 1). Dagegen ist bei den Muscheln von der SüderPiep-Tonne die Innenfläche vorn und in der Mitte kreideweif, matt, glanzlos, der Perlmutterglanz ist vollkommen verschwunden, die Oberfläche dieser Zone ist oft etwas rauh (Abb. 11, Fig. 2, 3, 5). Am hinteren Abschnitt der Muschel ist der. Perlmutterglanz in einem schmäleren oder breiteren Rand vorhanden und die beiden Stellen sind meist scharf abgegrenzt (Abb. 11, Fig. 2), jedoch nicht durch eine gerade, sondern meistens durch eine gezackte Linie und die von der kreideweißen Verfärbung frei gelassenen kleinen Stellen sind näher oder weiter vom Rande entfernt auch im Inneren der Fläche zu finden. Die kreideweiße Verfärbung der Innenfläche konnte außer an den SüderPieper Muscheln noch an den Tieren, die im Inneren der "Hackfeld“-Tonne lebten, ferner an einer großen Anzahl der im Watt bei Büsum gesammelten Muscheln festgestellt werden, $\mathrm{ab}$ und zu kam dies aber auch an einzelnen Tieren von anderen Orten vor. Eine andere pathologische Erscheinung der Schaleninnenfläche, die ebenfalls hauptsächlich an den von der Süder-Piep-Tonne stammenden Muscheln, ganz vereinzelt an Muscheln anderer Fundorte beobachtet wurde, war die rostbraune Fleckung. Allerdings trat sie auch bei den Süder-Piep-Tieren nur gelegentlich auf, während ja die kreideweiße Trübung der Perlmutterschicht bei allen Tieren dieses Fundortes beobachtet wurde. Diese Fleckung befand sich meistens innerhalb der kalkweißen Verfärbung, man fand aber auch Tiere, wo die 
Flecken an einer sonst ganz unversehrten Stelle der Perlmutterschicht vorkamen. Die rostbraune Fleckung ist im allgemeinen an beiden Schalenhälften anzutreffen, meist aber ungleich stark. Abb. 12 zeigt davon zwei Beispiele, bei denen die Fleckung eine recht ausgedehnte Form angenommen hat. Die charakteristische Stelle der Fleckung ist der Wirbel, oft jedoch ist dieselbe von hier aus nach vorn verschoben. Die Farbabstufung kann sich vom blassen Rötlichgelb bis zum dunklen Rostbraun erstrecken und die Oberfläche erscheint meistens stark marmoriert. Die Fläche wird oft durch eine bis zur Prismenschicht reichende und zuweilen auch in dieselbe eindringende Längsspalte durchfurcht. In Fällen, wo die Fleckung nicht so groß ist, zeigt sich an der Perlmutterschicht nur eine Verfärbung, bei starker Fleckung (Fig. 2, Abb. 12) treten aber scharf begrenzte, durch weiße oder graue Linien getrennte Erhebungen von ungleichmäßiger, ovaler Form und unebener, oft rauher Oberfläche auf. Bei einzelnen Muscheln fehlt in der Mitte der rostbraunen Stelle (Abb. 13) an einer scharf abgegrenzten Stelle die Perlmutterschicht völlig, dort kommt dann die violette Prismenschicht nach oben zu liegen. Diese Abweichung findet man sogar bei den Süder-Pieper Muscheln verhältnismäßig selten. Dieselbe kommt vermutlich dadurch zustande, daß die in der Mitte der rostbraunen Oberfläche vorhandene, oben erwähnte rauhe Erhebung abgestoßen oder aufgelöst wird. Während die rotbraune Verfärbung zumeist an beiden Schalenhälften auftritt, - es kam jedoch auch eine sich auf eine Schalenhälfte beschränkende braune Verfärbung vor, - konnte ich das fleckenweise Fehlen der Perlmutterschicht nur an einer Seite beobachten. Die Herstellung eines Querschliffes durch die veränderte Schalenzone führte zur Feststellung daß die rostbraune Verfärbung an der Grenze der Perlmutterund der Prismenschicht beginnt und sich von dort aus über die freie Oberfläche der Perlmutterschicht ausbreitet. Anfangs stellt das Gebiet im Schliff annähernd ein Dreieck dar, dessen Basis an der Grenze der Perlmutter- und Prismenschicht liegt, später breitet sich die Verfärbung gegen die Oberfläche zu flach aus und zugleich wird die Perlmutterschicht an Kalksalzen ärmer. Sobald der Kalkmangel des Gebietes zunimmt, hebt sich die Perlmutterschicht $\mathrm{ab}$ und schließlich wird der veränderte Teil abgestoßen oder aufgelöst, wodurch

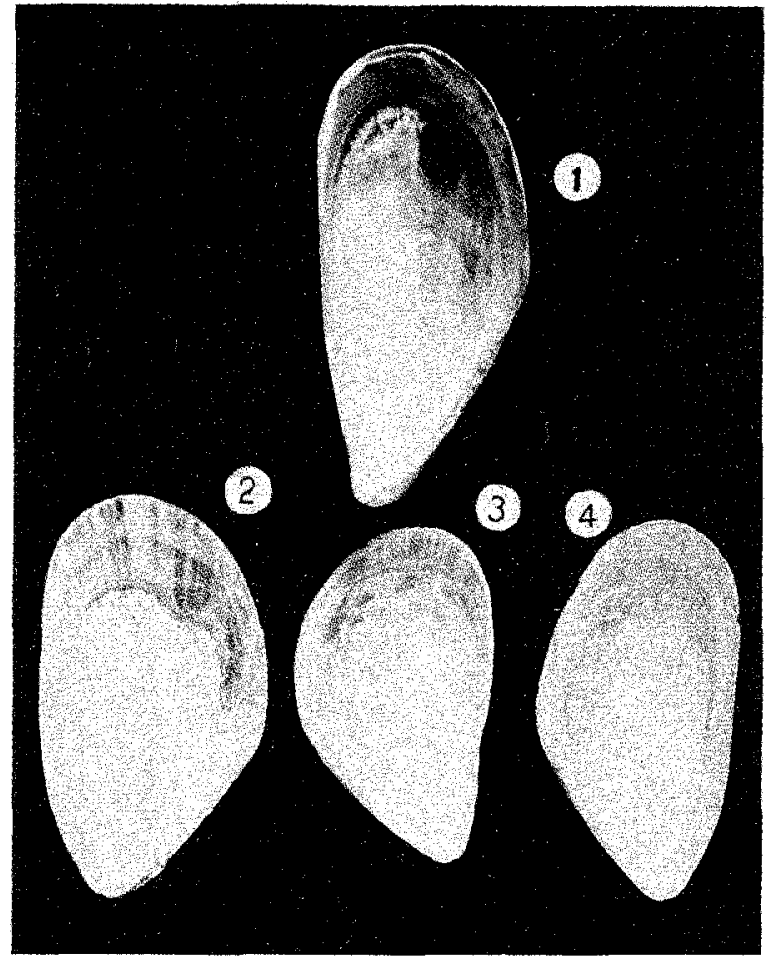

Abb. 11. Kreideweiße Verfärbung der Inuenfläche von Schalen giftiger Muscheln von der SüderPiep-Tonne (Fig. 2-4). Figur 1 zeigt den Perlmutterglanz der Innenfäche der Schale eines Tieres aus Helgoland. $1 \mathrm{~cm}=1,14 \mathrm{~cm}$ in der Natur. an der Perlmutterschicht eine Lücke entsteht, ohne daß an der Prismenschicht einezsichtbare pathologische Veränderung entstünde. Bei histologischer Untersuchung der dekalzinierten Muschelschale zeigt sich, daß die Vorwölbung des an Kalksalzen ârmer gewordenen Schalengebietes durch das Anschwellen des Conchyolins herbeigeführt wird. Abb. 14 zeigt diese Veränderung. Es ist der Querschnitt der gegen die Innenfläche zu sich ausrundenden, anschwellenden Perlmutterschicht sichtbar, die rostbraun verfärbt ist. Die Prismenschicht ist jedoch entfernt und die Innenfläche der Perlmutterschicht liegt nach oben. Am Bilde kann beobachtet werden, daß die feine fibrilläre Struktur der Perlmutterschicht nur an einem Teil des gegen die Prismenschicht zu liegenden Randes vorhanden ist, an anderen Stellen löste sich die feine fibrilläre Strukur auf, die Fibrillen zerbröckelten, die interfibrillären Spalten haben sich erweitert und es entstand an der Grenze der unversehrten und der veränderten Teile an der linken Seite des Schalengebietes (obere linke Ecke des Bildes) eine breite Spalte. Auffallend ist die stark färbbare dicke Fibrille, welche dieses Gebiet durchquert. Pilzfäden waren mikrospisch nicht nachweishar. 


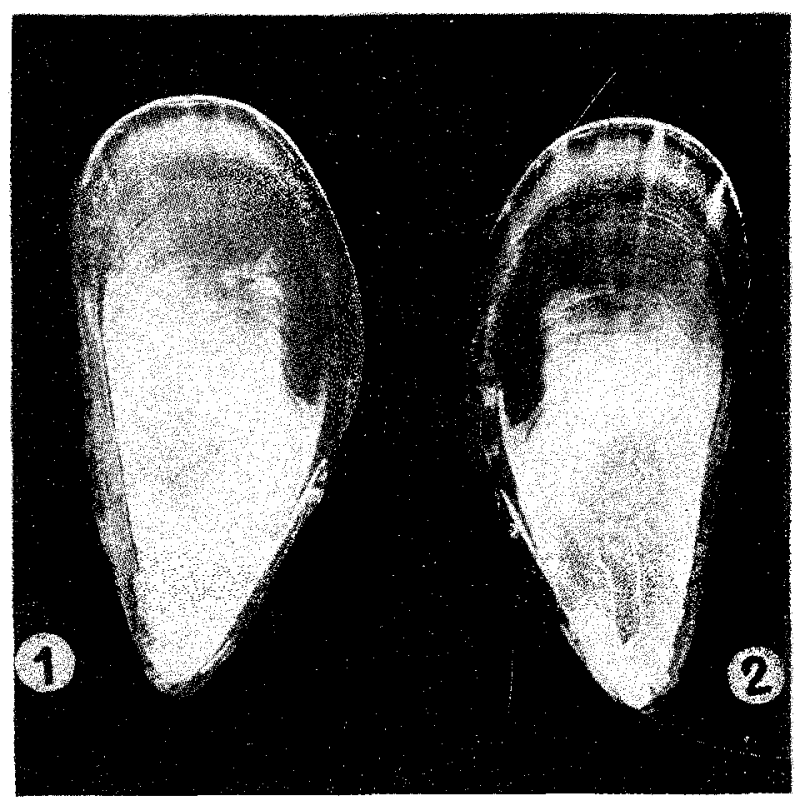

Abb. 12. Starke rostbraune Fleckung der Innenflache an Schalen einer giftigen Muschel von der SüderPiep-Tonne. $1 \mathrm{~cm}=0,82$ in der Natur.

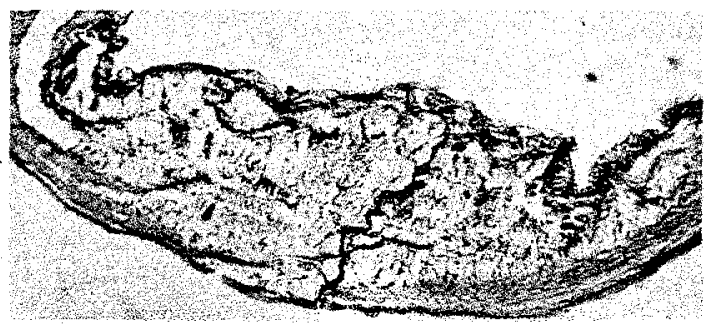

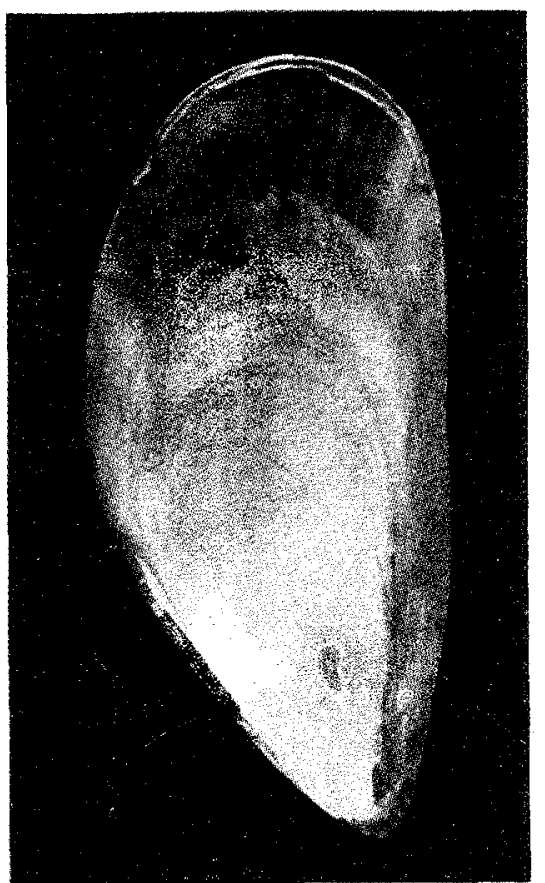

Abb. 13. Lücke in der Perlmutterschicht einer Muschel von der SüderPiep-Tlonne, zugleich rostbraune Fecken an der Innenfläche der Muschel.

Abb. 14. Mikroskopisches Querschnittsbild des rostbraunen Fleckes der entkalkten Schale einer giftigen Muschel von der Süder-PiepTonne. Nur die von der Prismenschicht abgehobene Perlmutterschicht ist sichtbar. Die Innenfläche der Perlmutterschicht liegt nach oben. (Hầmatoxylin-Eosinfärbung, Zeißapochromat 10 , Okular $8 \times$ ).

\section{Eigensehaften und histologisches Bild der Weichteile.}

Bei den von verschiedenen Fundorten stammenden Tieren habe ich naturgemäß nicht nur die Muschelschale sondern auch die Weichteile untersucht. Zwischen den Muscheln von der Süder-Piep-Tonne und Tieren von anderen Fundorten ergaben sich auch in dieser Beziehung Unterschiede. An den übrigen Orten zeigte der Mantel wohl verschiedene Farbabstufungen, doch schien er im allgemeinen mittelmäßig dick zu sein und war nur bei den Tieren der Eider-Tonne und der im Inneren der "Hackfeld“-Tonne lebenden Tieren zuweilen dünn. Dagegen war der Mantel beim größten Teil der Muscheln von der SüderPiep-Tonne gräulich-weiß, häutchenartig und erwies sich als sehr dünn. Bei den SüderPieper-Tieren war auch das Verhalten des Kristallstiels auffallend. Während nämlich bei den Tieren der meisten Fundorte der Kristallstiel fast in allen untersuchten Exemplaren auffindbar war und nur bei fast der Hälfte der im Inneren der "Hackfeld"-Tonne und bei den am Watt bei Büsum zur Ebbezeit gesammelten Muscheln fehlte, konnte bei den Süder-Pieper Muscheln der Kristallstiel, von einigen Ausnahmen abgesehen, fast niemals entdeckt werden.

Die Muscheln von der Süder-Piep-Tonne habe ich auch einer histologischen Untersuchung unterzogen und besonders den Mantel und die Leber untersucht, wobei ich auch den Magen- und Darminhalt genau beobachtete. Bei Untersuchung des Mantels ist die auffallendste Erscheinung das vollständige Fehlen der. fettartigen Substanzen und des 
Glykogens. Zu diesem Zwecke nahm ich an in Alkohol und Formalin separat fixierten Tieren die Sudan-, Nilblausulfat- und BEsT'sche Karmin-Färbung vor, Fett und Glykogen konnten aber sowohl im Mantel als auch in der Leber nur ab und zu nachgewiesen werden. Es zeigte sich die Anzahl der mit diesen Stoffen ausgefüllten Langer'schen Bläschen im allgemeinen sehr gering. Von diesem Gesichtspunkt aus habe ich auch an den von verschiedenen Fundorten stammenden Tieren Untersuchungen ausgeführt und, obzwar an diesen Orten die fettartigen Stoffe und Glykogen in schwankendem Grade nachweisbar waren, fehlten sie nirgends ganz. Ich möchte bemerken, daß ich bei den von verschiedenen Orten stammenden Tieren auch die Geschlechtsdrüsen untersuchte, ich versuchte vor allem festzustellen, ob zwischen den erwähnten Eigenarten der Muschelschale, der Giftwirkung der Muscheln und der Geschlechtstätigkeit irgendein Zusammenhang besteht und ob diese Eigenschaften bei dem einen oder anderen Geschlecht öfter vorkommen. $\mathrm{Zu}$ diesem $\mathrm{Zwecke}$ habe ich von den Weichteilen der zur Bereitung der Extrakte benutzten Tiere Material zu histologischen Untersuchungen aufbewahrt und suchte über den Zustand der Geschlechtsdrüsen auf histologischem Wege ein Bild zu gewinnen. Diese Untersuchungen zeigten eindeutig, daß weder der Zustand der Schale der Muscheln, noch die Giftwirkung derselben mit den Geschlechtern in Zusammenhang gebracht werden kann. Sowohl die Dünne, die Zerbrechlichkeit und die Streifung der Schale, als auch die

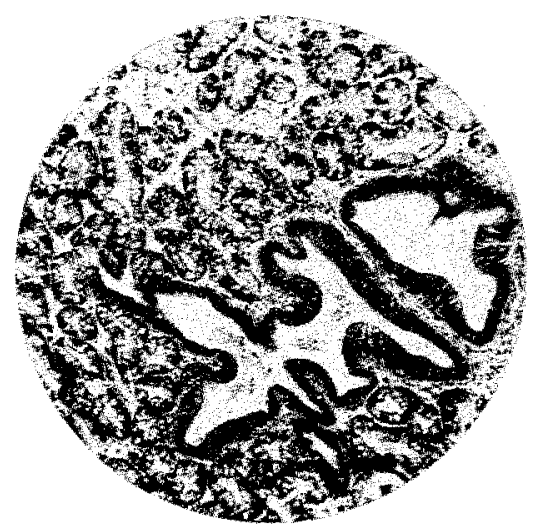

Abb. 15. Mikroskopisches Bild der Leber einer giftigen Muschel von der Süder-PiepTonne. Weite Magenleberkanäle nit wenig Detritus. (Hämatoxylin-Eosinfärbung, Zeißapochromat 10, Okular $8 \times$.)

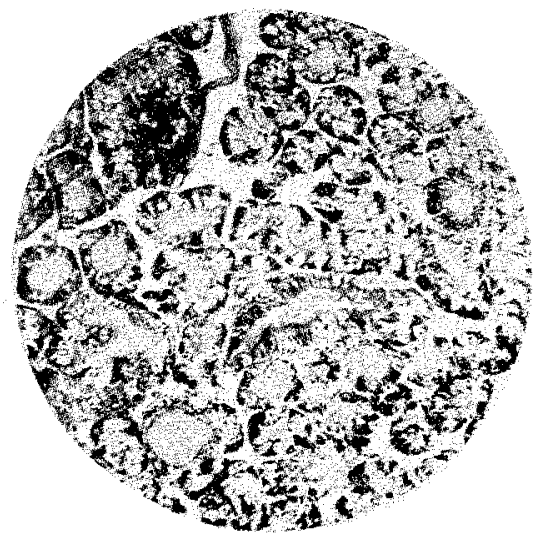

Abb. 16. Mikroskopisches Bild einer giftigen Muschel ron der Süder-Piep-Tonne. Mittelweite, meistens mit homogenen Massen gefüllte Leberkanäle. (Hämatoxylin - Eosinfärbung, Zeißapochromat 10 , Okular $8 \times$.)

Giftwirkung der Muscheln kommen bei Männchen und Weibchen ungefähr in gleicher Zahl vor. Die giftige Dosis der aus bestimmt geschlechtsunreifen Exemplaren (Tiere von ähnlicher Größe wurden histologisch kontrolliert) von ganz winzigen Süder-Pieper Muscheln nach THESEN hergestellten Extrakte betrug 0,01-0,02 cem. Es stimmte also mit der Dosis der vollentwickelten Tiere überein, was ebenfalls den Beweis liefert, daf die Giftwirkung von der Tätigkeit der Geschlechtsdrüsen unabhängig war. Hiervon abgesehen waren bei der histologischen Untersuchung der giftigen Süder-Pieper Muscheln weder reife Eier noch Samenzellen in den Geschlechtsdrüsen der größten Tiere nachweisbar, d. h. die Tiere waren auch in dieser Hinsicht den durch WOLFF untersuchten Muscheln aus Wilhelmshaven ähnlich und sie zeigten dennoch an beiden Orten eine starke Giftwirkung. Ebenso wenig aber ist die Giftwirkung an das Vorhandensein unreifer oder reifender Geschlechtsdrüsen gebunden, wie sie sie die Tiere in Zeiten außerhalb ihrer Laichperiode aufweisen, denn ich konnte in meinen Untersuchungen in Neapel nachweisen, daß auch reife Eier enthaltende Weibchen Giftwirkungen zeigen können. Bei einem laichreifen Männchen von der Eidertonne und zwei weiteren, laichreifen männlichen Tieren von der Innenfläche der "Hackfeld"-Tonne konnte ebenfalls Giftwirkung nachgewiesen werden. Da im Sinne der obigen Ausführungen für den Zusammenhang zwischen der Funktion der Geschlechtsdrüsen und der Giftwirkung kein Anhaltspunkt vorhanden ist, habe ich von Untersuchungen in dieser Richtung abgesehen. 
Bei den histologischen Untersuchungen achtete ich besonders auf die Leber, da nach einzelnen Forschern der Sitz der Giftbildung die Leber sein soll. Die Untersuchungen wurden an mit Cocain oder Magnesiumsulfat narkotisierten und in BouinLösung oder in Formalin, bzw. Alkohol fixierten Tieren ausgeführt und die Präparate mit Haematoxylin-Eosin, Sudan III., Nilblausulfat oder nach vaN GIEson, bzw. Giemsa oder BEST gefärbt. Diese Untersuchungen zeigten klar, daß die Leber der Muschel infolge ihres Arbeitsrhythmus eine wechselnde histologische Struktur aufweist, deren feinere cytologische Erscheinungen in hohem Grade von der Phase der Nahrungsaufnahme, bzw. der Verdauung des Tieres abhängen. Dementsprechend änderte sich das histologische Bild der Leber je nach den einzelnen Tieren verhältnismäßig stark und es bot nicht nur die Breite der Leberkanäle, sondern auch der Leberblindsäckchen, ferner das Verhältnis der die Gänge aufbauenden verschiedenartigen Zellarten und der Inhalt der Körnerzellen ein recht wechselreiches Bild. In manchen Tieren waren zwischen den breiten, wenig Detritus enthaltenden Magenleberkanälen auch mittelbreite, oder enge, gänzlich leere Kanäle zu finden. Die Zahl der sich dunkel färbenden Ersatzzellen war von mittlerer Größe. In dem zwischen den Gängen vorhandenen Bindegewebe sind zahlreiche zellige Elemente sichtbar (Abb. 15). Bei anderen Tieren waren dagegen neben den verhältnismäßig engen Magenleberkanälen

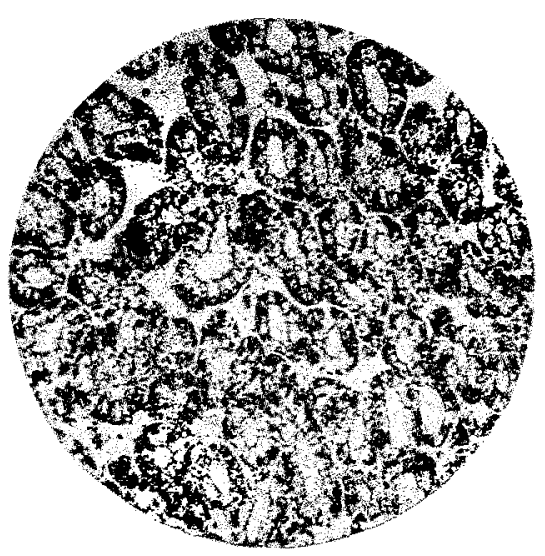

Abb. 17. Mikroskopisches Bild der Leber einer giftigen Muschel ron der Süder-PiepTonne. Mittelweite, leere Leberkanüle, reichlich Vakuolen in den Körnerzellen. (Sudan III, Hämatoxyliniz̈rbung. Zeifapoehromat 10 , Okular $8, X$.)

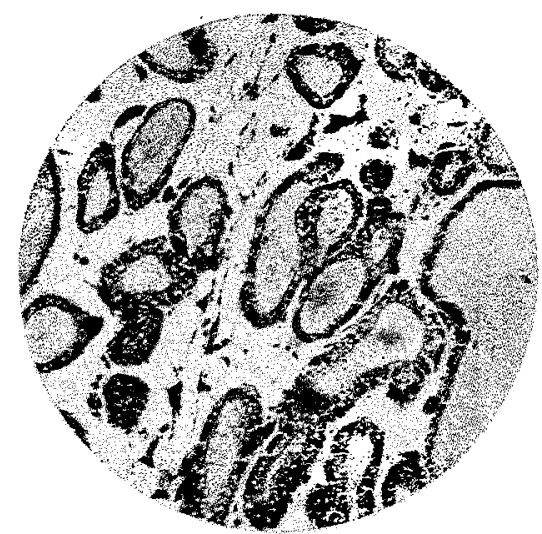

Abb. 18. Mikroskopisches Bild der Leber einer giftigen Muschel von der Siider-PiepTonne. Weite, an mehreren Stellen mit niedrigem Epithel überzogene und mit schaumigen Massen gefüllte Leberkanäle. (Hämatoxylin-Eosinfärbung, Zeißapochromat 20, Okular $8 \times$.)

die Leberkanäle und Leberblindsäckchen mit einem homogenen Stoff ausgefüllt, die Ersatzzellen ließen sich besonders dunkel färben und bildeten hie und da größere Gruppen, wobei das zwischen den Gängen befindliche Bindegewebe sich als ziemlich zellarm erwies (Abb. 16.) Bei anderen Tieren sah man in den die Leberkanäle und Leberblindsäckchen bedeckenden Körnerzellen viel kleine und größere Vakuolen, die keine fettartigen Stoffe enthielten. Diese Zellen zeigten infolgedessen eine ausgesprochen schaumige Struktur (Abb. 17.) Schließlich waren bei einigen Tieren die Leberkanäle stark erweitert, mit einem homogenen oder schwammigen Stoff ausgefüllt, mit niedrigem Epithel bedeckt und zwischen denselben war lockeres Bindegewebe zu finden (Abb. 18). Aehnliche Veränderungen kamen an den verschiedensten Fundorten sowohl unter den giftigen als auch unter den normalen Tieren vor, sie können offenbar durch die dynamische Struktur der Leber erklärt werden. Sie dürften deshalb, wenigstens bis zu einer gewissen Grenze, nicht als pathologische Erscheinung aufgefaßt werden, sondern sie sind der Funktion der Leber oder einer Ernährungsphase des Tieres zuzuschreiben. Ein ausschließlich bei den giftigen Tieren wahrnehmbares histologisches Bild konnte nicht nachgewiesen werden. In dieser Hinsicht wäre bloß der an Abb. 17 dargestellte Schnitt erwähnenswert. Hier ist nämlich das verhältnismäßig recht oftmalige Vorkommen der Vakuolenzellen und deren große Anzahl, ferner das fast stetige Fehlen von Lipoidstoffen und des Glykogens aus Körnerzellen auffällig. Ich möchte jedoch bemerken, daß das negative Ausfallen der histochemischen Reaktion nicht unbedingt das Fehlen der Lipoide beweist. Dabei kam 
sowohl die größere Anzahl der Vakuolenzellen als auch der Mangel an den bereits erwähnten Stoffen oder das Fehlen derselben auch bei vielen von zahlreichen anderen Fundorten stammenden ungiftigen Muscheln vor. So können diese histologischen Erscheinungen in sich ebenfalls nicht als spezifisch betrachtet, sondern nur mit anderen Symptomen gemeinsam als Begleiterscheinungen der Giftwirkung angesehen werden. Schließlich zeigten daher die bisherigen an der Leber von giftigen Muscheln vorgenommenen Untersuchungen keine bezeichnenden histologischen Abweichungen, dies dürfte aber nicht ausschließen, daß eine eingehende Untersuchung der Funktionsbilder des Lebergewebes derartige Abweichungen dennoch zum Vorschein bringen könnte.

An Schnitten läBt sich zugleich auch der Inhalt der Leber und des Darmkanals am besten untersuchen. Den Mageninhalt der Muschel unterzog ich zur vorherigen Orientierung in nativen Präparaten einer Beobachtung, zu einem definitiven Bild gelangte ich aber erst - besonders hinsichtlich des Magen- und Darminhaltes von giftigen Muscheln - durch histologische Präparate. Ich habe mir auf diese Weise bei diesen Tieren auch über den Zustand des Kristallstiels Klarheit verschafft. Der Magen der SüderPieper Muscheln zeigte sich manchmal ganz leer, doch war er oft mit Detritus angefüllt in welchem viele ganze oder zerbrochene Diatomeen-Panzer zu finden waren (Abb. 19). Es ist auffallend, daß der Kristallstiel auch diesen Tieren fehlte. An Abb. 20 ist ein

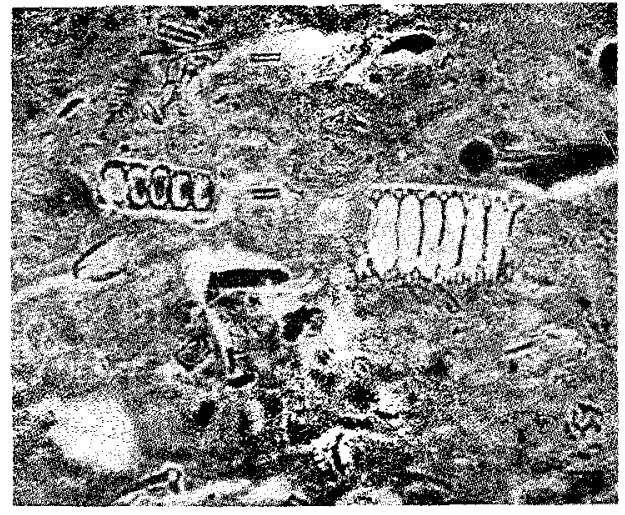

Abb. 19.

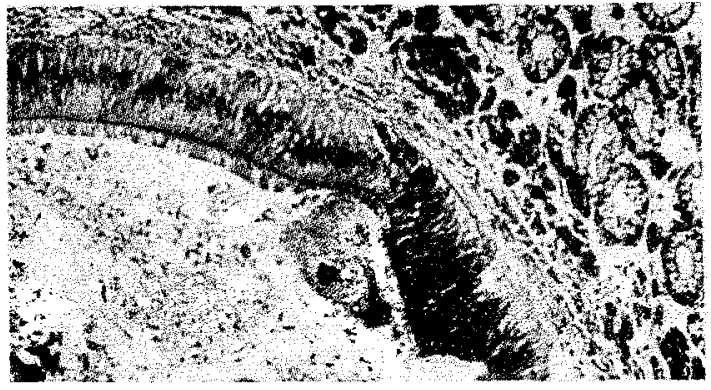

Abb. 20.

Abb. 19. Mikroskopisches Bild des Mageninhalts eines giftigen Tieres von der Süder-Piep-Tonne. (Giemsafärbung, Zeißapochromat 20 , Okular $8 \times$.)

Abb. 20. Mikroskopisches Bild des Kristallstielsackes einer giftigen Muschel von der Süder-Piep-Tonne mit anstoßendem Lebergewebe. (Giemsafärbung.) Vergrößerung: Zeißapochromat 20, Okular $8 \times$, die Aufnahme nachträglich vergrößert.

Teil des Kristallstielsackes einer solchen giftigen Muschel mit dem benachbarten Lebergewebe zu sehen, mit viel Detritus und einem Infusor; das Fehlen des Kristallstiels ist ebenfalls augenfällig. Bei den giftigen Tieren war der Darminhalt dem Mageninhalt ähnlich, indem auch im Detritus Diatomeen-Panzer oder dessen Bruchstücke zu finden waren. Peridineen waren weder im Magen noch im Darminhalt nachweisbar und das an Abb. 20 sichtbare Infusor fand sich sonst nirgends wieder.

\section{Deutung der äußeren Eigenschaften.}

Beim Ueberblick über die Eigenschaften der giftigen Süder-Pieper Muscheln gelangt man zur Feststellung, daß für diese Tiere die relative Niedrigkeit des Mittelwertes des Längen-Dicken-Quotienten, die blasse Färbung der Muschelschale oder deren starke Streifung, ferner die Dünne, die sehr hochgradige Leichtigkeit, die oftmalige Schalendeformierung, die glänzende, derbe Oberhaut, die kreideweiße Trübung und rostbraune Verfärbung der Innenfläche, die Häutchenartigkeit des Mantels, der mangelhafte Besitz an fettartigen Stoffen und Glykogen und das Fehlen des Kristallstiels am bezeichnendsten waren. Es wurde schon öfter betont, daß keine der oben erwähnten Abweichungen als ein ausschlieflich für die giftigen Muscheln in Betracht kommendes, spezifisches Merkmal aufgefaßt werden kann, sondern diese Eigenschaften dürfen nur wegen ihres gemeinsamen 
Vorkommens und infolge ihrer Ausbreitung auf den großen Teil oder auf die Gesamtheit der Muscheln als charakteristische Besonderheiten der Süder-Pieper Muscheln bezeichnet werden. Ein Teil dieser Merkmale wurde schon anläßlich der Wilhelmshavener Vergiftungen beschrieben und so ist es notwendig, zu untersuchen, wie diese Eigenschaften zustandekommen und welchen Zustand der Muschel sie im allgemeinen bezeichnen. Die Niedrigkeit der Längen-Dicken-Quotienten, die breite Form der Muschelschale hält KoBELT, aber vor allem LOHMEYER für wichtige morphologische Merkmale an den giftigen Muscheln, die auf Wuchsformen von Muscheln aus dem Mittelmeer hinweisen, und deshalb wird es von ihnen für wahrscheinlich gehalten, daß auch die Wilhelmshavener Muscheln durch Kriegsschiffe vom Mittelmeer nach Wilhelmshaven eingeschleppt worden sind. Die Längen-DickenQuotienten von Exemplaren von Mytilus galloprovincialis aus Terranova und Taranto, ferner von Mytilus minimus aus Neapel habe ich durch Messungen an 100, 80, bzw. an 100 Tieren noch im Jahre 1936 auch selbst bestimmt (Siehe Tab. 3) und fand diese tatsächlich im Verhältnis zu den Helgoländer Tieren wesentlich niedriger. Diese Tiere waren aber alle gut entwickelte Exemplare mit dicker Schale (Abb. 21), von regelmäßig breiter Form, nicht so wie bei den Süder-Pieper Muscheln, wo der Längen-Dicken-Quotient stark schwankte und nur der Mittelwert ge-

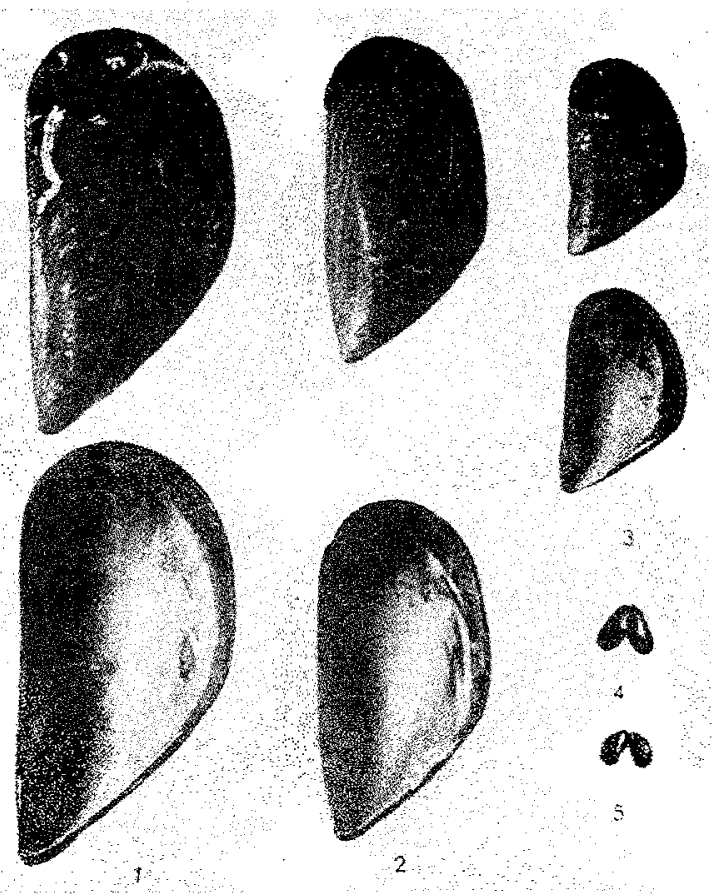

Abb. 21. Mytilus galloprovincialis aus Terranova (Fig. 1) und Taranto (Fig. 2). Mytilus minimus (Fig. 3-5) aus der Mergellina Bucht Neapels. $1 \mathrm{~cm}=1,82 \mathrm{~cm}$ in der Natur. ringer als der Durchschnittswert der Nordsee-Tiere war, weil dort neben der länglichen Form verhältnismäßig viele sehr breite, auch die Muscheln von Taranto übertreffende Formen zu finden waren. Somit wird es erklärlich, daß die Maße der durch $H$. CAspers aus Varna mir zur Verfügung gestellten 25 Muschelschalen einen den Süder-Pieper Muscheln recht nahe kommenden Wert ergaben, obwohl die Form dieser Muscheln von jener der Tiere von der Süder-PiepTonne offensichtlich abwich (Abb.22). Der Längen-Dicken-Quotient der Tiere von der Süder-Piep-Tonne kann mit jenem der Muscheln aus dem Mittelländischen und Schwarzen Meer ohne weiteres gar nicht verglichen werden. Während bei letzteren der niedrige Quotient die für sämtliche Tiere charakteristische breite Form bezeichnet, weist derselbe bei den Muscheln von der Süder-Piep-Tonne nur darauf hin, daß unter den für die Nordsee-Tiere charakteristischen länglichen Mytilus-Formen verhältnismäBig sehr viele Muscheln von breiter Form vorkommen. Wie BoETTGER sagt, sind „.. die Schalen von Mytilus zu plastisch, zu sehr auf jede kleinste Beeinflussung reagierend" und so können die Formänderungen der Süder-Pieper Muscheln nicht nur als eine Reaktion auf äußere Einflüsse aufgefaßt werden. Havinga, HaAs, Hentschel, BoetTGer und andere haben ausführlich auf jene hydrologischen Faktoren hingewiesen, die nicht nur das Längenwachstum der Muschelschale, sondern auch ihre Dicke bedeutend beeinflussen. Das tiefe, ruhige Wasser, das seichte, stark bewegte Wasser, das felsige oder sandige Ufer, der niedrige oder hohe Salzgehalt und dabei die Zeit und die Verhältnisse eines etwaigen Trockenliegens, sind Faktoren, welche die Ausgestaltung der Muschelschale beeinflussen. HAvinga bemerkt außerdem, daß die breite Form auf das langsame Wachstum der Muschel hindeutet. Es ist wohl verständlich, daß, wenn die Muscheln eine stark überlagernde Gemeinschaft bilden, die unterhalb liegenden, unter ungünstigeren Lebensbedingungen lebenden Tiere weniger Nahrung bekommen können und, in der Entwicklung zurückgeblieben, eine breitere Form annehmen. Wesentlich war auch diese Erscheinung bei den Tieren im Inneren der "Hackfeld" Tonne wahrnehmbar, wo der Längen-Dicken-Quotient bedeutend niedriger war, als bei den außerhalb anhaftenden Tieren und der überwiegende Teil der Muschein 
im Gegensatz zu den außerhalb sitzenden Tieren eine breite Form zeigte. Dies ist offenbar darauf zurückzuführen, daß die im Inneren der Tonne zusammengedrängten, sich unter ungünstigen Strömungsverhältnissen befindenden Tiere wegen des langsameren Wachstums die überwiegend kurze Form annahmen. Die Untersuchungen, welche ich an Tieren von den Tonnen in der Nähe der Küsten von Schleswig-Holstein vornahm, ergaben, daß die den Tonnen anhaftènden Tiere nicht unter günstigen Bedingungen leben. Es ist hierauf zurückzuführen, daß sich unter denselben verhältnismäßig viele in der Entwicklung zurückgebliebene Muscheln von kurzer, breiter Form befinden. Diese Erscheinung läßt sich ohne weitere Schwierigkeiten erklären. Wie HAvINGA ausführlich erörtert, gelangen die in der Nähe der Oberfläche lebenden Muscheln zu bedeutend weniger Nahrung als die am Wassergrund, weil das Oberflächenwasser an Detritus viel ärmer ist als das Bodenwasser. Dabei wird der Nahrungsstrom der Muscheln durch die übermäßige Bewegung der dem Wellengang stark ausgesetzten Tonnen auch nicht vorteilhaft beeinflußt, weiter werden die Muscheln sich dort reizbarer als gewöhnlich verhalten, sich rasch schließen, wodurch ihre Ernährung noch unvollkommener wird. Dazu befindet sich noch ein bedeutender Teil der an einer engen Stelle zusammengedrängten Muscheln in einer unvorteilhaften Lage unterhalb der anderen und es ist selbstverständlich, daß bei diesen Muscheln die ganze Entwicklung und so auch die Gestaltung der Schale noch unvollkommener sein wird Solche Tiere weichen von den normalen Muscheln derart ab, daß sie allgemein für giftig gelten und so hat sich unter den Fischern die Ansicht verbreitet, daß es gefährlich sei, die den Tonnen anhaftenden Muscheln zu essen. Die Muscheln von der Süder-Piep-Tonne stellen ein interessantes Beispiel dafür dar, da $B$ diese Beobachtungen nicht allen Grund entbehren, sie liefern aber gleichzeitig einen bestimmten Beweis dafür, daß die Formabweichungen der Giftmuscheln vor allem durch die mangelhafte Entwickiung der Muscheln und ihr langsames Wachstum infolge ungünstiger Lebensverhältnisse $\mathrm{zu}$ erklären sind. Zwischen den Muscheln von der Süder-Piep-Tonne, von Wyk auf Föhr und von der Eider Tonne besteht nur ein stufenweiser Unterschied, der in der progressiven Verschlechterung der hydrologischen und der Entwicklung der Muscheln beeinflussenden übrigen Umstände seine Erklärung finden

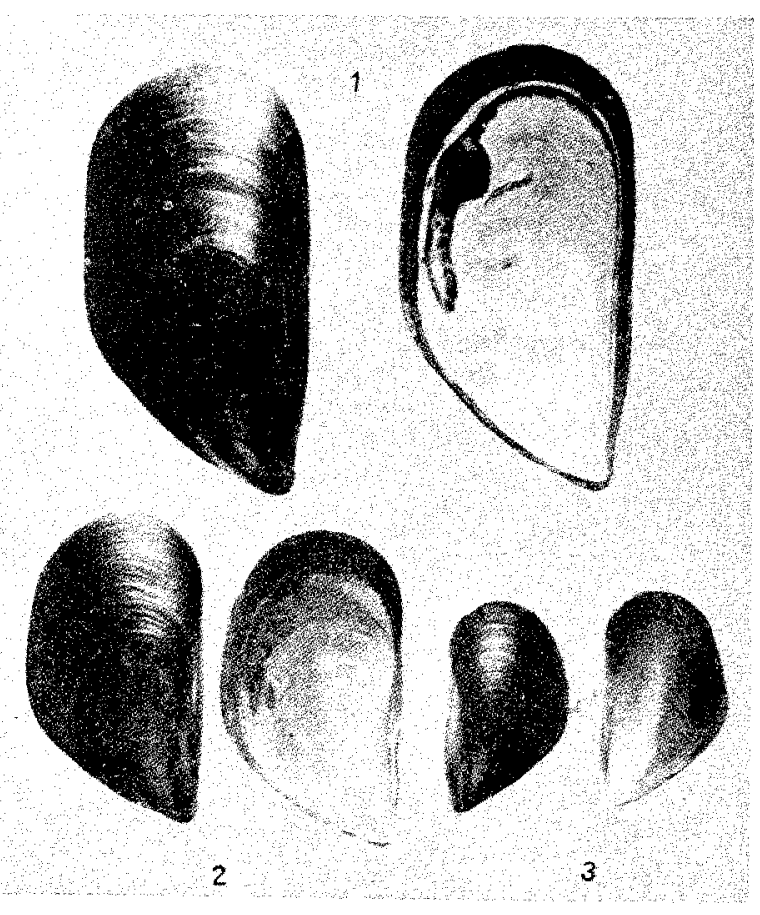

Abb. 22. Miesmuscheln aus Varna. Maßstab: $1 \mathrm{~cm}=$ $1,50 \mathrm{~cm}$ in der Natur.

kann. Aus welchem Grunde der Meeresteil von Süder-Piep in dieser Beziehung ungünstiger ist als die benachbarten Gebiete, werden wir noch später besprechen.

Die Lebensumstände der Muscheln bedingen naturgemäß nicht nur das Längenwachstum, sondern auch den ganzen Aufbau der Schale. HAvinga erörtert, daß die in ruhigen, tiefen Gewässern lebenden Muscheln eine papierdünne Schale besitzen, wogegen die der Brandung ausgesetzten Tiere von dicker Schale sind. BOETTGER weist im Zusammenhang hiermit darauf hin, daß unter gleichen Lebensverhältnissen ,bei Zunahme der mechanischen Kräfte der Wasserbewegung eine Verstärkung mit einer Verkleinerung der Schale parallel geht. Ob diese Veränderung eine reine Abwehrreaktion auf die stärkere mechanische Beanspruchung darstellt oder ob sie zum Teil oder ganz eine Folge erhöhten Stoffumsatzes durch die stärkere Durchflutung ist, bleibt zu untersuchen." Soviel steht allerdings fest, $\mathrm{da} B$ unter obigen Verhältnissen eine derartige Ausgestaltung der Muschelschale als eine Reaktion der äußeren Umstände anzusehen und nicht der ungünstigen Entwicklung zuzuschreiben ist. Die Sache verhält sich aber anders, wenn man Tiere mit so dünnen Schalen dort vorfindet, wo sie einer starken Wasserbewegung ausgesetzt sind, wie z. B. an den Tonnen, wo eben die stärkeren Schalen den äußeren Umständen angepaßt erscheinen würden, wie das bei einem großen Teil der Tiere an den Helgoländer Tonnen tatsächlich 
gefunden werden konnte. Die dünne Schale der giftigen Tiere kann bei den der starken Wasserströmung ausgesetzten, am äußeren Rand des Wattes liegenden Tonne ${ }^{\circ}{ }^{a}$ anhaftenden Muscheln nicht als eine den Milieuverhältnissen angepaßte Art der Schalenbildung angesehen werden und ist gewiß ebenso durch das mangelhafte Wachstum der Muschel zu erklären, wie auch die an einem großen Teil dieser Muschel wahrnehmbare auffallend kurze und breite Schalenform. Störungen in der Schalenbildung mögen auch die Ursache der verhältnismäßig kleinen Schalenform, der Pigment- und Kalkarmut der Muschelschale gewesen sein, was jene gelblich-braune oder blaß-grüngelbe, stark gestreifte, außerordentlich leichte, oft deformierte Muschelschalenform zustande brachte, von welcher einzelne Exemplare an den verschiedenen Fundorten wohl anzutreffen waren, doch nirgends in so großer Anzahl und so einheitlich wie bei den Süder-Pieper Muscheln. Die in den früheren Beschreibungen besonders hervorgehobene Streifung der giftigen Tiere ist ganz ähnlich zu beurteilen. Diese Erscheinung ist keineswegs ein Anzeichen für jugendliche Exemplare, sondern das Zeichen der Pigmentarmut der Prismenschicht. Bei den giftigen Tieren trat diese eben infolge der schwachen Pigmentierung der Prismenschicht bei so vielen Tieren auf. „Die Anlage für die Streifung ist unzweifelhaft bei allen Muscheln vorhanden“, sagt VIRCHOw. Wenn die Schalen mit starkem Licht durchleuchtet werden, kann die Streifung an den dunklen, ja sogar an den schwarzen

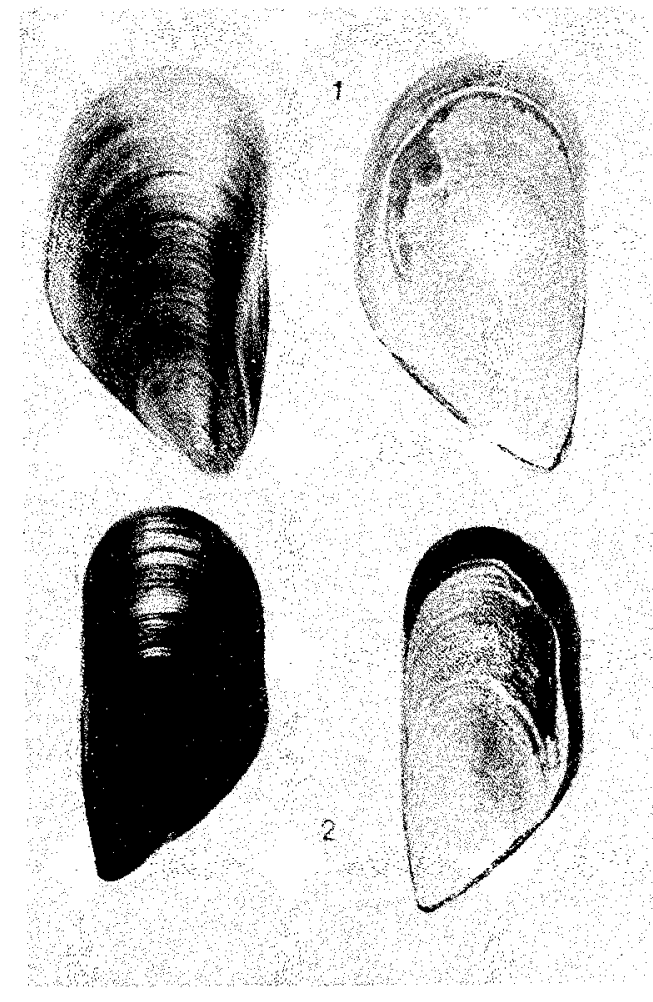

Abb. 23. Hellbraune Muscheln mit gekriimmtem Wirbel (Fig. 1) und schwarze Muschel mit wenig gekrümmtem Rand (Fig. 2) aus Varna. $1 \mathrm{~cm}=1,42 \mathrm{~cm}$ in der Natur. Schalen tatsächlich entdeckt werden. Wie bereits erörtert, ist bei den gut entwickelten dunklen Tieren die Streifung nur an ganz jungen Exemplaren sichtbar, da dieselbe in der pigmentreichen Prismenschicht durch die dunkle Farbe verdeckt wird. Anders verhält es sich aber bei den unvollkommen entwickelten Tieren, wo die kleinen Muscheln so farblos sind, daf auch die Streifen kaum zur Ausbildung kommen, dagegen wird die sehr langsam dunkler werdende Prismenschicht nie so pigmentreich, daß die Streifung schon im auffallenden Licht erkennbar sein würde. LiST, der sich mit der Schalenstreifung und den Farbvariationen der Mytiliden aus Neapel befaßte, stellte fest, daß ,im allgemeinen die beschriebenen Farbvarietäten von Mytilus galloprovincialis sehr selten sind, und gelangte zur interessanten Feststellung, daß einzelne, in Aushöhlungen des Seeufers lebende Exemplare von Mytilus minimus ganz farblos waren und ein gelbes Höhlenexemplar im Aquarium nach 2 Monaten dunkler geworden ist; daher war die Farblosigkeit der Schale dem Mangel an Pigment zuzuschreiben. Ich selbst habe in Neapel unter mehreren hundert Exemplaren von Mytilus galloprovincialis und Mytilus minimus kein einziges gestreiftes Tier gefunden und so dürften auch nach meinen eigenen Beobachtungen die gestreiften Tiere im Mittelmeer bedeutend seltener se $\mathrm{n}$ als in der Nordsee. Demgeg nüuber fand ich unter den von H. CASPERs aus Varna gesandten 25 größeren und kleineren pechschwarzen $\mathrm{Mu}$ scheln 4 Stück mit blasser Schale und bei 2 Exemplaren war auch die Streifung erkennbar. Es ist interessant, daß unter den Muscheln aus Varna bei 7 Exemplaren Deformierungen der Schale vorkamen, doch während diese bei den schwarzen Muscheln in kleinen Scharten am Rand auftraten (Abb. 23, Bild 2) bestanden sie bei den blaß-braunen Exemplaren in einer ungewöhnlich hochgradigen Erhebung und Verkrümmung der Wirbel. Die blassen Muscheln besaßen außerdem eine entstellte Form, d. h. sie waren auch unvollkommen entwickelt. Schließlich sind die blassen und gestreiften Mytiliden im Mittelländischen Meer, wo Salzgehalts- und Temperaturschwankungen nur in geringem Grade vorkommen, im allgemeinen seltener, wogegen sie in der Nordsee, wo der Salzgehalt des Wassers niedriger ist und die Temperatur stärker schwankt, viel häufiger sind; soweit man aus der kleinen Mustersendung Schlüsse ziehen 
kann, gehören nun auch die blaßbraunen Muscheln im Schwarzen Meer nicht zu den großen Seltenheiten, wo der Salzgehalt ebenfalls niedrig ist. Der Salzgehalt des Meeres, der Wechsel der hydrologischen Faktoren beeinflussen, wie bekannt, weitgehend das Wachstum der Muscheln und so kann im Mittelmeer die Seltenheit der Tiere mit blasser, dünner, gestreifter Schale eben auf das ungestörte Wachstum der Muscheln zurückgeführt werden. Dagegen waren diese Tiere gewiß aus erwähntem Grunde an den SchleswigHolsteiner Küsten verhältnismäßig häufig und es entwickelten sich als Folge der wechselnden, und für das Gedeihen der Muscheln nicht allzu günstigen Faktoren pigmentarme, blaß oder stark gestreifte Exemplare, an welchen die ungünstigen Entwicklungsumstände auch in der verhältnismäßig häufigen Deformierung der Schale zum Ausdruck kamen. Auch die giftigen Süder-Pieper Muscheln sind nichts anderes als ein Haufen (eine Gemeinschaft) von solchen schlecht entwickelten Tieren, die „in Masse einen anderen Anblick gewähren“ als die ungiftigen (VIRCHOW), an welchen aber dieselben, auf eine verringerte Wachtumsenergie deutenden Anzeichen zu finden sind, wie, wenn auch in geringerer Anzahl und weniger ausgeprägt, so doch gut erkennbar, an den Tieren der iubrigen Fundorte von Schleswig-Holstein.

\section{Deutung der Erscheinungen an der Innenfläche der Muschelschalen.}

An den Muscheln von der Süder-Piep-Tonne waren aber auch einige Veränderungen zu verzeichnen, welche mit dem mangelhaften bzw. aberranten Wachstum nicht in Zusammenhang gebracht werden können. So wäre vor allem die kreideweiße Verfärbung zu betrachten. Diese Veränderung tritt nach KüHNELT's Untersuchmngen dann auf, wenn die Muschel unter anaeroben Verhältnissen lebt. Unter diesen Umständen decken z. B. die länger trocken liegenden, geschlossenen Muscheln durch Spaltung der Reservestoffe, hauptsächlich des Glykogens ihren Energiebedarf. Bei diesem Vorgang entwickelt sich eine bedeutende Menge von $\mathrm{CO}_{\text {, }}$, welche sich in der Schalenflüssigkeit löst. Wenn dieselbe eine gewisse Konzentration erreicht, wird sie die Perlmutterschicht umso mehr angreifen, als diese Schicht bei Mytilus aus Aragonit besteht, der bekanntlich in Kohlensäure-haltigem Wasser relativ leicht löslich ist. Die kreideweiße Verfärbung ist daher nichts anderes als eine durch Kohlensäure verursachte Aetzung. Daß es sich tatsächlich so verhält, kann leicht bewiesen werden, wenn man die Schalen von Mytilus in verdünnte Säure enthaltendes Wasser legt. Auch am lebenden Tier kann das gezeigt werden, wenn die Muschel mit Draht umwickelt, am Oeffnen ihrer Schale verhindert und zwecks vollständiger luftdichter Verschließung in eine Kittmasse eingebettet wird. In $24-48$ Stunden wird sowohl bei den Tieren mit dunkler, dicker Schale

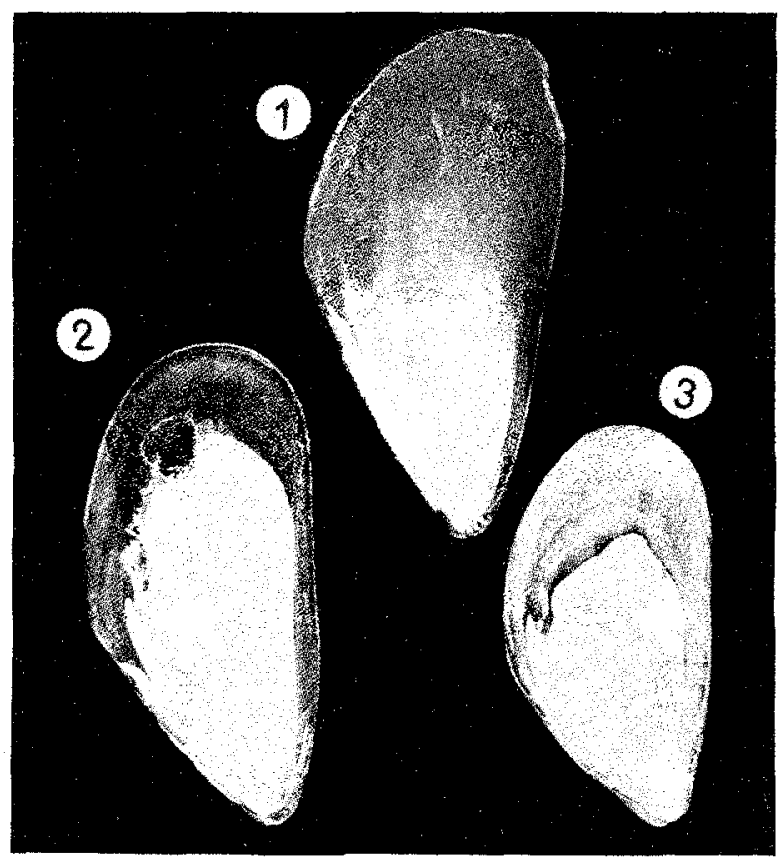

Abb. 24. Innenfläche mit kreideweißer Verfarbung von Muscheln, welche mit Draht umwunden in ihrem Öfnen gehemmt wurden (Fig. 2 u. 3). Figur 1 zeigt den Perlmutterglanz der Innenfläche eines Helgoländer Kontrolltieres. Natürliche Größe. (Abb. 24, Fig. 2), als auch bei den dünnschaligen blassen Tieren (Fig. 3), die kreideweiße Verfärbung in charakteristischer Form auftreten, während an den im Seewasser gehaltenen Kontrolltieren keine Spur einer Verfärbung zu sehen sein wird. Der Auftritt der kreideweißen Verfärbung bei den giftigen Muscheln deutet also auf eine Störung in den Oxydationsverhältnissen hin und zeigt das Ansteigen des Kohlensäuregehaltes der Schalenflüssigkeit an. Die Möglichkeit, daß die kalkweiße Verfärbung der Muscheln nach dem Einsammeln der Tiere während 
des Transportes ins Institut entstanden wäre, darf ausgeschlossen werden, weil die Muscheln sofort nach der Erbeutung ebenso in mit Seewasser gefüllte Gefäße gelegt wurden, wie die von anderen Fundorten stammenden Muscheln, bei welchen diese kreideweiße Verfärbung bei ähnlich langer Dauer des Transportes nicht wahrgenommen werden konnte. Das Ansteigen des Kohlensäuregehaltes der Schalenflüssigkeit ist ein Zeichen der Zunahme der $\mathrm{CO}_{2}$-Produktion oder ein Ergebnis der Erschwerung der $\mathrm{CO}_{2}$-Abgabe; allerdings können diese beiden Vorgänge nicht voneinander getrennt werden. Eine Zunahme der Kohlensäure-Produktion entsteht dann, wenn die Muschel unter anaeroben Verhältnissen lebt und ihren Energiebedarf durch Spaltung des Glykogens deckt. Die CO.2-Abgabe wird nach SchL.LPER's Untersuchungen hauptsächlich durch den niedrigen Salzgehalt des Wassers und infolge der Temperatur erschwert. Ob bei den Süder-Pieper Muscheln die gesteigerte $\mathrm{CO}_{2}$-Produktion oder die Erschwerung der Abgabe derselben die Hauptrolle spielte, kann auf Grund des bisher angeführten nicht beurteilt werden. Es steht aber fest, daß die Aetzung der Innenfläche durch den $\mathrm{CO}_{2}$-Gehalt der Schalenflüssigkeit herbeigeführt wurde.

Dafür, daß die Süder-Pieper Muscheln tatsächlich unter dauernd ungünstigen Ver!ı̈̈ltnissen gelebt haben müssen, sprach auch ein anderer Umstand. Der Kristallstiel fehlte fast vollständig. Nach Untersuchungen von RAY hängt die rhythmische Erneuerung des Kristallstiels von der Intensität der Nahrungsaufnahme und vom Nährwert der zugefürten Nahrung ab. Im Magen der giftigen Muscheln war zwar reichlich Detritus und Fragmente von Diatomeen-Panzer vorhanden, aber ein Kristallstiel konnte nicht entdeckt werden. Die Untersuchungen von Berkeley zeigten demgegenüber, daß der Kristallstiel auch in Gegenwart von Nahrungsstoffen verschwindet, wenn sich die Muschel unter schlechten Oxydations- oder sogar unter anaeroben Verhältnissen befindet. Wir müssen deshalb auch bei den Süder-Pieper Muscheln an diese Erscheinung denken. Bei den Süder-Pieper Muscheln war überdies der histologisch nachweisbare Mangel an Lipoiden und Glykogen zu beobachten. Es ist wohl wahr, dał die Ergebnisse der histochemischen Untersuchungen in dieser Hinsicht nicht in jeder Beziehung verläßlich sind, aber beim überwiegenden Teil der giftigen Tiere deutete die Häutchenartigkeit des Mantels schon an und für sich auf die Armut an Reservestoffen hin. Die Reservestoffe können aus verschiedenen Gründen verbraucht worden sein, oder sie bildeten sich von vornherein spärlich. Aus dem Glykogenschwund allein können keinerlei bestimmte Feststellungen gemacht werden. Dennoch müssen wir in Anbetracht des Umstandes, daß zur annähernd gleichen Zeit, als die Süder-Pieper Muscheln gesammelt wurden, an Tieren von anderen Tonnen längs der Schleswig-Holsteiner Küste diese Erscheinung so einheitlich nicht beobachtet wurde, im Hinblick auf alle auf Anoxybiose deutenden Zeichen daran denken, dal3 das Glykogen während der anoxybiotischen Atmung verbraucht worden ist. Wie erwähnt, waren in der Leber der giftigen Muscheln die fettartigen Stoffe und Glykogen nicht enthaltenden vacuolisierten Körnerzellen in verhältnismäßig vielen Tieren in großer Ausdehnung anzutreffen. Der Grund dieser Erscheinung ist unbekannt und solange die dynamische Struktur der normalen Mytilus-Leber in ihren Einzelheiten nicht klargestellt ist, können aus der großen Anzahl der vacuolen Körnerzellen naturgemäß ebenfalls keine bestimmte Schliusse gezogen werden. Hier möchte ich nur kurz auf die Untersuchungen von CoLlip hinweisen, nach welchem die Muschel Venus die Fähigkeit besitzt, die Reaktion ihrer Gewebesäfte derart zu regulieren, daß sie die entstehende Kohlensäure zu Calciumcarbonat umbildet "mit Hilfe des Kalkes der Schale und wohl auch der Leber", ferner auf die Beobachtungen von ScHLIEPER, wonach die Muscheln unter anaeroben Verhältnissen (unter Luftabschluß) das aus der Spaltung des Glykogens frei werdende $\mathrm{CO}_{2}$ mit Hilfe ihrer in der Leber und der Schale vorhandenen Kalkreserven als Bicarbonat binden. Wir wissen jedoch nicht, durch welche histologischen Anzeichen dieser Vorgang angezeigt wird und ob derselbe mit morphologisch nachweisbaren Veränderungen überhaupt verbunden ist. Es ist jedoch nicht ausgeschlossen, daß eben die oben erwähnten in großer Anzahl vorhandenen, von fettartigen Stoffen und Glykogen freien vacuolen Zellen damit im Zusammenhang stehen. Für alle Fälle kann aus der Aetzung der Schalen-Innenfläche und dem Fehlen des Kristallstiels geschlossen werden, daß die Muscheln von der SüderPiep-Tonne unter schlechten Oxydationsverhältnissen mit gesteigerter Kohlensäureproduktion oder behinderter $\mathrm{CO}_{2}$-Abgabe lebten und der histochemisch nachweisbare Glykogenschwund dieser ohnehin mangelhaft entwickelten, daher an Reservestoffen ärmeren Tiere zum Teil mit diesem Vorgang in Beziehung steht.

Die rostbraune Fleckung der Schalen-Innenfläche sowie die Bildung von kleinen Lücken an der Perlmuttersehicht fand sich am häufigsten ebenfalls bei den giftigen 
Muscheln von der Süder-Piep-Tonne. Zur Erklärung dieser Veränderung besitzen wir noch keine sicheren Anhaltspunkte. Der Vorgang nimmt an der Grenze der Prismenund Perlmutterschicht seinen Anfang und beschränkt sich ausschlieflich auf die Perlmutterschicht. Dabei scheint die Tatsache eine Rolle zu spielen, daß die Perlmutterschicht aus durch kohlensäurehaltiges Wasser leichter angreifbarem Aragonit besteht, wogegen die Prismenschicht sich aus sehr schwer löslichem Kalkspat bildet. Was aber eigentlich die beschriebene Beschädigung der Perlmutterschicht herbeiführt, dafür fehlen uns noch sichere, grundlegende Feststellungen. Durch den Fleck verlaufen oft kleine Spalten. Es ist möglich, daß solche primären Spalten in der Perlmutterschicht den Weg für die an Kohlensäure angereicherte Schalenflüssigkeit ins Innere der Perlmutterschicht der unter schlechten Oxydationsverhältnissen lebenden Muscheln freimachen. Es scheint dabei gleichfalls nicht ausgeschlossen zu sein, daß sich diese Spalten sekundär in der bereits angegriffenen Perlmutterschicht bilden. Ich war bemüht diese Erscheinung auf dem Versuchswege zu ergründen und schlug deswegen an der einen Schalenhälfte von Muscheln aus Helgoland mit Hilfe eines Locheisens eine kleine Oeffnung, durch welche ich mit einer dünnen Spitzschere auch in den Mantel einen kleinen Ausschnitt machte, wobei die Wirbelgegend vorsichtig mit einem kleinen Hammer geklopft wurde, in der Voraussetzung, daß an der mehr verletzbaren Perlmutterschicht Risse entstehen würden. Hiernach habe ich die Muscheln, um das Oeffnen ihrer Schalen zu verhindern, mit Draht umwickelt und für 12 Tage in bei $100^{\circ} \mathrm{C}$ ausgekochtes, d. h. in sauerstoffarmes Wasser gelegt. Durch die an einer Schalenhälfte geschlagene Oeffnung konnte sich aus der in sehr ungünstige Oxydationsverhältnisse versetzten Muschel das $\mathrm{CO}_{2}$ einerseits entfernen, andererseits waren die ins Wasser gelegten Muscheln viel längere Zeit am Leben zu erhalten als die aufs Trockene gelegten, mit Draht umwickelten Tiere. Abb. 25. führt von diesen Versuchen die Schale je eines Tieres vor. An Fig. 1 ist eine durchlochte Schalenhälfte, in Fig. 2. die andere Schalenhälfte eines zweiten Tieres zu sehen mit der charakteristischen Veränderung an einer Längsspalte in der PerImutterschicht. Die ausgeführten Versuche konnten aber die Frage trotzdem nicht klarlegen, ob die rostbraune Verfärbung bei allen Tieren in so hohem Grad auftritt, wie es das Bild darstellt. Die Veränderungen bleiben nämlich bei

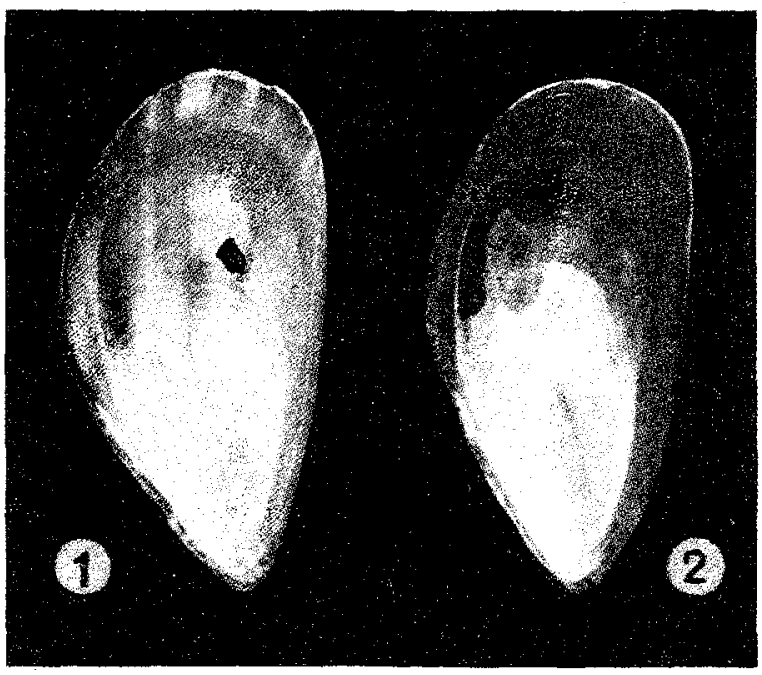
Wiederholung der Versuche oft aus. Dagegen stellte sich bei Anfertigung von

Schliffen aus den Helgoländer Kontrolltieren heraus, daß in der Wirbelgegend, an der Grenze der Prismen- und Perlmutterschicht, die primäre Form der Veränderung ohne Vorhandensein einer Spalte vorkommt. Es ist deshalb möglich, daB es sich in meinen Versuchen einfach darum handelte, daß eine bereits vorhandene Veränderung infolge der Verschlechterung der Oxydationsverhältnisse und durch das Ansteigen der Aetzwirkung der Kohlensäure bloß in ihrer Ausdehnung zunahm. Ebenso wäre zu deuten, daß diese Veränderung unter den Muscheln sämtlicher Fundorte am häufigsten und in ausgeprägtester Form bei den giftigen Muscheln der Süder-Piep-Tonne zustandekam, bei welchen ja aus der kreideweißen Verfärbung der Schalen-Innenfläche zu vermuten ist, daß die Oxydationsverhältnisse dort am schlechtesten gewesen sind und die fehlerhafte Ausbildung sowie die Dünne der Muschelschale der weiteren Ausbreitung des Vorganges günstige Bedingungen bot. Es scheint aber, daß der Auslösungsfaktor des Vorganges in anderen, bisher unbekannten aetiologischen Umständen $\mathrm{zu}$ suchen ist und vielleicht mit auch an anderen Muscheln wahrnehmbaren und durch Mikroorganismen bewirkten Schalenerkrankungen in Zusammenhang gebracht werden kann. 


\section{Versuche über die Sedimentation von Muscheln.}

\section{Die Bedeutung der Versuche für die vorliegenden Probleme.}

Das Besprochene über die Muscheln von der Süder-Piep-Tonne kann schließlich darin zusammengefaßt werden, daß diese Muscheln fehlerhaft entwickelte Tiere waren, welche unter ungünstigen Oxydationsverhältnissen lebten. Das Entstehen der Giftwirkung wird aber an und für sich durch keinen der beiden Faktoren erklärlich. An anderen Fundorten waren unter mangelhaft entwickelten Tieren verhältnismäßig sehr wenig giftige anzutreffen und an vielen trocken liegenden, oder aus anderen Gründen unter schlechten Oxydationsverhältnissen lebenden Muscheln war eine Giftwirkung überhaupt nicht nachweisbar. Nach meinen in Neapel vorgenommenen Untersuchungen wird das Entstehen der Giftwirkung durch die schlechten Oxydationsverhältnisse zusammen mit der ungünstigen Ernährungsweise, in Neapel z. B. in Gemeinschaft mit der überwiegend bakteriellen Nahrung gefördert. Bei den Süder-Pieper Muscheln kann von einer einseitigen bakteriellen Nahrung nicht die Rede sein, da doch die Muscheln nicht in einer geschlossenen Bucht von verunreinigtem Wasser lebten. Das Zustandekommen der Giftwirkung mußte daher durch andere, die Nahrungsaufnahme ungünstig beeinflussende Faktoren unterstïtzt werden. Die Ernährung der Muscheln hängt bei entsprechender Tätigkeit der Verdauungsorgane von der ungestörten Wasserströmung der Mantelhöhle $a b$, was wieder durch die erforderliche Intensität und Koordinierung der Flimmerzellenbewegung bedingt wird. Wie bekannt, sind in der Mantelhöhle der Muscheln zweierlei Wasserströmungen zu unterscheiden; die sogen. Atemströmung, die berufen ist, den Sauerstoff des Wassers den Kiemen zuzuführen und die gebildete Kohlensäure zu entfernen, wobei die als Sieb funktionierenden Kiemen die Nahrungsteilchen des Wassers aufhalten, ferner die Wandströmung, welche an der Kiemen-Oberfläche die durchfiltrierte, in Schleim eingebettete Nahrung zur Mundöffnung zu befördern hat und außerdem die überflüssigen Nahrungspartikelchen und die Abfallstoffe vom Mantel entfernt. Die beiden Strömungen sind voneinander unabhängig, beide sind aber eine Folge der Flimmerzellenbewegung. Treten daher in der Funktion der Flimmerzellenbewegung Störungen auf, so gestaltet sich sowohl die Atmung, als auch die Nahrungsaufnahme unvollkommen und aus dem gegenseitigen Aufeinanderwirken der beiden Funktionen entsteht ein richtiger "Circulus vitiosus", welcher sämtliche Lebensfunktionen der Muscheln beeinflußt. Demgemäß wirken sich sämtliche Faktoren, welche die Arbeit der Flimmerzellen beeinträchtigen, zugleich auf den ganzen Stoffwechsel der Muschel aus. So ist die durch die Flimmerzellen bewirkte Wasserströmung ein wertvolles biologisches Reagenz zum Studium des Einflusses der versehiedenen äußeren Faktoren auf die Lebensfunktion der Muschel. Die Wasserströmung der Muscheln kann am leichtesten in der Weise untersucht werden, daß man dem Seewasser in dem geschlossenen Gefäß, in welchem sich die Muschel befindet, einen schwer sedimentierenden Stoff zugibt und die Schnelligkeit und Gleichmäßigkeit der Wasserreinigung beobachtet. Die Muschel treibt nämlich mit Hilfe der Wasserströmung die im Wasser suspendierten fremden Stoffe der Mantelhöhle zu, wo diese zum Teil als Nahrungsstoffe verbraucht, zum Teil aber mit Schleim umhüllt wieder ins Wasser befördert werden, wo diese infolge ihres Gewichtes sich auf den Grund senken, d. h. das Wasser wird mit Hilfe der Wasserströmung der Muscheln gereinigt. Wenn die Temperatur des Wassers oder andere Faktoren unguinstig sind, wird die Wasserströmung der Muschel langsam oder ungleichmäßig, eventuell kann auch die Reinigung des Wassers unterbleiben, woraus mit Selbstverständlichkeit folgt, daß auch die Sauerstoffaufnahme nicht günstig sein kann und die Nahrungsaufnahme zum Teil oder ganz aufhört, da doch die langsame Wasserströmung nicht ebenso günstige Verhältnisse schaffen kann, als das bei raschem Wasseraustausch der Fall ist. Welche veränderten hydrologischen Faktoren weitgehende Störungen in den Oxydationsverhältnissen und in der Nahrungsaufnahme der Süder-Pieper Muscheln auszulösen vermochte, suchte ich so zu erforschen, daß ich die Wasserreinigungswirkung der von verschiedenen Fundorten stammenden Muscheln unter verschiedenen hydrologischen Verhältnissen und gleichzeitig auch die Nahrungsaufnahme untersuchte.

\section{Die Methodik.}

Ich habe anläßlich meiner Untersuchungen in 'lihany und Neapel hinsichtlich der Wasserreinigungswirkung der Muscheln bereits jene Schwierigkeiten erörtert, welche bei den im Simne des Obigen sich ergeben können. Die Muschel als lebender Organismus reagiert durch Aenderung ihrer Lebensfunktionen auf die verschiedensten äußeren 
Einwirkungen und das aus seinem natürlichen Milieu in fremde Verhältnisse versetzte Versuchstier wird von den physiologischen Lebenserscheinungen weitgehend abweichende Lebensfunktionen zeigen. Deshalb soll man die frisch gefangenen Tiere sich den Versuchsverhältnissen anpassen lassen und sich in Vorversuchen orientieren, ob die Tiere sich zur Ausführung der geplanten Versuche überhaupt eignen. Aber es kann auch in den derart vorbereiteten Versuchen nur der Mittelwert der Ergebnisse einer gröferen Anzahl von Versuchen berücksichtigt werden und es sind ausschließlich die Resultate der Versuche an Tieren mit identischem Gewicht miteinander zu vergleichen. In dieser Hinsicht ist besonders jene Feststellung von O. Kestner und R. PlaUt zu berücksichtigen, daß das RuBnER'sche Prinzip auch betreffs der Muscheln gültig ist, d. h., daß bei gleicher Temperatur der Stoffwechsel in geradem Verhältnis zu der Körperoberfläche ansteigt. Aber bei den von mir untersuchten Muscheln ändert sich nicht nur das Gewicht derselben stark, sondern es war auch das Verhältnis der Muschelschale zu den Weichteilen sehr schwankend. So kann man sich über das tatsächliche Gewicht der Weichteile und über die Körperoberfläche nur dann orientieren, wenn die Tiere nach Beendigung des Versuches getötet werden und das Gewicht der Weichteile bestimmt wird und nur jene Versuche berücksichtigt werden, bei welchen das Gewicht der Weichteile annähernd gleich ist und zwischen der Flächen-Ausdehnung der Muschelschalen große Abweichungen nicht vorhanden sind. Daher stellte ich die Versuche in folgender Weise an. $\mathrm{Zu}$ den Versuchen benutzte ich ein Tag vorher außerhalb des Helgoländer Hafens geschöpftes Seewasser, dessen Salzgehalt bestimmt und mit Zugabe von destilliertem Wasser auf den erforderlichen Grad eingestellt wurde. Zur Untersuchung der Sedimentierung setzte ich dem Wasser pro Liter $1 \mathrm{~g}$ Bolus alba oder 20-40 Tropfen chinesischer Tusche oder Detritus von Meeresalgen zu. Die letzteren wurden in der Weise vorbereitet, daß ich die frisch eingesammelten Meeresalgen mit Quarzsand und etwas Wasser zu einem feinen Brei zerrieb. Dies wurde dann in ein kegelförmiges Glas gegossen und mit Seewasser verdünnt. Nach viertelstündiger Sedimentierung habe ich die Emulsion vom Quarzsand abgegossen und im Verhältnis 1:10 der Versuchsflüssigkeit beigemengt. Die dem Seewasser zugegebene Substanz habe ich einige Minuten lang in einem großen Glas geschüttelt, dann in erforderlicher Menge halbliter- oder literweise in gleichgroße Gläser $(25 \mathrm{~cm}$ hoch, $13,3 \mathrm{~cm}$ Durchmesser, oder $20 \times 9,5 \mathrm{~cm}$, oder $11,5 \times 8,2 \mathrm{~cm})$ verteilt und ließ die Versuchsgefässe bis zum nächsten Morgen auf meinem Tisch im Laboratorium stehen. Die Temperatur der Flüssigkeit stellte sich auf diesem Platze in der Regel auf $20^{\circ} \mathrm{C}$ ein. Senkte sich die Temperatur unter diesen Grad, so wurden die Gefässe auf Bretter über die Heizkörper gestellt und die Temperatur der Versuchsflüssigkeit wieder genau auf $20^{\circ} \mathrm{C}$ eingestellt. Dann habe ich in sämtliche auf einen erschütterungsfreien Platz gestellten Versuchsgefässe bis zum Boden Luftzuleitungsröhren eingeführt und eine Viertelstunde lang durch die Flüssigkeit mit starker Strömung Luft durchblasen lassen. Mit Hilfe der einströmenden Luft wurde das Wasser in steter Bewegung gehalten und das nötige Vermengen des zu sedimentierenden Stoffes bewirkt. Nach einer Viertelstunde stellte ich die Luftzuleitung ein und setzte je ein Versuchstier in die Flüssigkeit. Zwei Tage zuvor habe ich die Schale der Versuchstiere gründlich gereinigt und sämtliche Tiere von gleichem Gewicht und gleichem Schalenaufbau mit dunkler dicker Schale oder blasser, gestreifter Schale auf 24 Stunden bei $20^{\circ} \mathrm{C}$ in je ein derartiges, mit den Versuchsgefässen gleich großes Gefäß untergebracht, durch dessen Wasser ich vorher eine halbe Stunde lang Luft durchströmen ließ. Zu jedem einzelnen Versuch habe ich 20 Stück solcher Tiere vorbereitet und mit diesen am Nachmittag vor dem Versuch in einer mit Algendetritus vermengten Flüssigkeit Vorversuche unternommen. Aus diesen Tieren wählte ich 14-16 Exemplare aus, bei welchen in der Wasserreinigungswirkung keine wesentlichen Unterschiede $\mathrm{zu}$ verzeichnen waren. Die Hauptversuche wurden am darauffolgenden Morgen durchgeführt. Nach Beendigung derselben habe ich die Tiere getötet und nur die Ergebnisse jener Versuche berücksichtigt, bei welchen das Gewicht der Weichteile keine bedeutende Abweichung zeigte. Die Trübung der Flüssigkeit wurde mit dem Pulfrich'schen Photometer (Zerss) in nachstehender Weise bestimmt. Die Untersuchungsflüssigkeit übertrug ich aus dem Versuchsgefäß mit einer $50 \mathrm{~cm}$-Pipette in die Absorptionsröhre des Photometers. Die Absorptionsröhre hatte eine Schichtdicke von $250 \mathrm{~cm}$. Nach Beendigung der Bestimmung ließ ich die Flïssigkeit vorsichtig ins Versuchsglas zurück. Die Bestimmung nahm ich in jedem Falle mit Hilfe von zwei Spektralfiltern vor $u$. $z w$. von den mit S 43, S 53 und S 72 bezeichneten Spektralfiltern mit jenem, welcher der Farbe der Versuchsflüssigkeit am besten entsprach und habe beide Angaben gesondert notiert. Die Messungen wurden stündlich und, wenn die Reinigung des Wassers schon in der erster halben Stunde ver- 
hältnismäßig rasch vor sich ging, halbstündig vorgenommen. In Fällen, wo die Wasserreinigung nur sehr langsam in Gang gesetzt wurde und der Versuch sich bis 24 Stunden oder noch länger hinauszog, stellte ich in den ersten 10-12 Stunden keine Messungen an und trachtete im allgemeinen die Versuchsflüssigkeit, wenn es nicht unbedingt nötig war, nicht anzurühren. Die Berechnung der Resultate erfolgte in nachstehender Weise. Mit sämtlichen Versuchen wurde paralell je ein Kontrollversuch ohne Muscheln ausgeführt, in welchem die durch die spontane Sedimentierung bewirkte Abnahme der Wassertrübung gleichzeitig mit den Muschelversuchen beobachtet wurde. Hiernach habe ich auf Grund der Formel $\mathrm{W}=\frac{\mathrm{Ev}_{\mathrm{V}} \mathrm{En}}{\mathrm{Ev}} \times 100(\mathrm{~W}=$ Wirkungsgrad, d. h. Wasserreinigungswirkung der Muschel, $\mathrm{Ev}=$ Extinction der Kontrollösung, d. h. negativer Wert des Logarithmus der Durchlässigkeit, En = Extinction der die Muschel enthaltenden Flüssigkeit) die Wirkung jedes Spektralfilters gesondert berechnet und als Endresultat den Mittelwert der beiden Ergebnisse angenommen. (Beispiel: S 53 Filter Wirkung ${ }_{1}$ :30, S 72 Filter Wirkung ${ }_{2}$ : 26, Endresultat Wirkung: 28.) Zur Berechnung der Ergebnisse benutzte ich die Tabelle der Zeiss Anleitung Mess. 430/d/v. Die Wirkung bedeutet daher in meinen Versuchen, um wieviel die Trübung der Versuchsflüssigkeit infolge der Wasserreinigungswirkung der Muscheln abnahm, d. h. W=100 bedeutet die vollständige Wasserreinigung, $W=0$ bedeutet das vollständige Fehlen der Wasserreinigungswirkung der Muschel. $W=50$ zeigt an, daß die Trübung des Wassers infolge Reinigungswirkung der Muschel zur Hälfte, $W=75$ daß dieselbe drei Viertel usw. abnahm. Tragen wir die Resultate der Messungen in ein Koordinatensystem ein, in welchem an der senkrechten Linie der Wirkungsgrad, an der waagrechten Linie der Zeitpunkt der Ablesung stündlich oder halbstündlich vermerkt wird, so zeigt die nach den Messungswerten entworfene Kurve die durch die Wasserreinigungswirkung der Muschel herbeigeführte Abnahme der Trübung unmittelbar, ohne Vergleich mit einer Kontrollkurve. Dieses Verfahren ist weit übersichtlicher, als das zu meinen in Neapel ausgeführten Versuchen verwendete Nephelometer-Verfahren. Das Zeiss'sche Pulfrich-Photometer hat sich in meinen Versuchen als ein vorzüglich brauchbarer, einfach und rasch $\mathrm{zu}$ behandelnder Apparat bewäbrt.

\section{Die Ergebnisse von Versuchen mit Normaltieren.}

Durch die in obiger Weise eingeleiteten Versuche wollte ich mich vor allem darüber orientieren, welchen Wert die Wasserreinigungswirkung der Helgoländer Muscheln im allgemeinen ergibt, um zur Beurteilung der Wasserreinigungswirkung der giftigen Tiere über bestimmte Kontrollwerte zu verfügen, wobei zu betonen ist, daß die erhaltenen $\operatorname{Re}-$ sultate nur relative Werte sind, welche die Wasserreinigungswirkung der Muscheln eines bestimmten Fundortes $\mathrm{zu}$ einer bestimmten Jahreszeit und unter gewissen Versuchsbedingungen anzeigen, ohne daß hierbei dieselben Werte z. B. für eine andere Jahreszeit maßgebend sein würden. $\mathrm{Zu}$ den in der Zeit vom 6.-10. Dezember ausgeführten Versuchen benutzte ich die am 3. Dezember gesammelten Muscheln mit dunkel-olivbrauner, dicker Schale, deren Weichteilgewicht auf Grund der ersten vergleichenden Messungen nach meiner Schätzung etwa um $5 \mathrm{~g}$ gewesen sein durfte. (Tiere mit einem Gesamtgewicht von $18,5-19,5 \mathrm{~g})$. Den Salzgehalt der Versuchsflüssigkeit babe ich mit Rücksicht darauf, daß nach REICHARD's Untersuchungen der Jahres-Mittelwert des Salzgehaltes bei Helgoland 32,1 beträgt, auf diesen Wert eingestellt. Die Schichthöhe der Versuchsflüssigkeit stellte ich durch Hebung oder Senkung eines mit der Öffnung nach unten gerichteten Zylinders von $3 \mathrm{~cm}$ Durchmesser in jedem Gefäß auf $10 \mathrm{~cm}$ ein und benutzte zu diesen Untersuchungen je ein halbes Liter Seewasser mit 0,5 g Bolus alba-Gehalt. Die Temperatur der Flüssigkeit wurde in bereits beschriebener Weise auf $20^{\circ} \mathrm{C}$ gehalten. Gleiche Versuche habe ich in dem sich im Kellergeschoß befindlichen Kulturraum angestellt, wo die Versuchsflüssigkeiten bis Ende Dezember mit einer Schwankung von kaum 1-2 Zehntelgraden die Temperatur von $10^{\circ} \mathrm{C}$ beibehielten. Aehnliche Versuche bei $20^{\circ} \mathrm{C}$ mit Tieren von $2,5 \mathrm{~g}$ Weichteil- und $10,5 \mathrm{~g}$ Körpergewicht, ferner von $0,5 \mathrm{~g}$ Weichteil- und 1,5 g Körpergewicht ausgeführt. Die Ergebnisse sämtlicher Versuche stellt Abb. 26 zusammenfassend dar. Die fortlaufende Linie (— (.........) Linie zeigt die Ergebnisse des Versuches bei $10^{\circ} \mathrm{C}$ an. Die Zahlen über den Linien geben die Größe der Tiere an. An der waagrechten Linie des Koordinatensystems ist die Zeit der Ablesungen in Stunden und Minuten vermerkt. Die Ablesungen wurden auch hier halbstündig vorgenommen u. zw. von den 16 Versuchstieren abwechselnd bei je 8 Tieren in den ersten 15 Minuten die Resultate der Tiere $\mathrm{Nr} .1-8$, in den weiteren 15 Minuten von Nr. 9-16, doch habe ich bei Bestimmung der Mittelwerte nur die Werte von 
jenen 10 Tieren berücksichtigt, bei wèlchen nach dem nachträglichen Wiegen das Gewicht der Weichteile keine wesentliche Abweichung zeigte. Auf Grund der Kurven gelangt man zur Feststellung, daß bei $20^{\circ} \mathrm{C}$ die Miesmuschel von $5 \mathrm{~g}$ Weichteilgewicht $1 / 2$ Liter Wasser in 3 Stunden vollkommen reinigte und daß dieser Wert bei der Muschel von 2,5 $\mathrm{g}$ Weichteilgewicht nur um 30 Minuten, bei $0,5 \mathrm{~g}$ Weichteilgewicht um 60 Minuten ansteigt. Während jedoch die Kurven der Tiere von $5 \mathrm{~g}$ und 2,5 $\mathrm{g}$ beinahe gemeinsam verlaufen und die zwei größeren Tiere mehr als $4 / 5$ der Trübung des Wassers schon im Laufe einer Stunde reinigten, verläuft bei der. Muschel von $0,5 \mathrm{~g}$ die Kurve wesentlich abweichend und das Tier hat im Laufe einer Stunde die Trübung des Wassers auch nicht zur Hälfte vollkommen gereinigt. Bedenkt man aber, daß diese Muschel zehnmal bzw. fünfmal kleiner ist als die beiden anderen, so kann mit Bestimmtheit gefolgert werden, daB die Reinigung des Wassers hier relativ viel rascher vor sich ging, als bei den vorigen. Im Anschluß an meine Untersuchungen in Neapel habe ich aber bereits angedeutet, daß bei Untersuchungen im geschlossenen Gefäß die kleinen Muscheln sich nicht unter denselben Versuchsverhältnissen befinden wie die großen. Da den kleinen Tieren verhältnismäßig mehr Sauerstoff zur Verfügung steht und sich weniger $\mathrm{CO}_{2}$ bildet, ist auch der Kohlensäuregehalt der Versuchsflüssigkeit geringer. Auf die Besprechung dieser Verhältnisse werden wir noch bei Erörterung der mit Luftzuleitung angestellten Versuche zurückkommen. Die Ergebnisse obiger Versuche eignen sich für alle Fälle zur Bestimmung des Durchschnittwertes der Wasserreinigungswirkung von Muscheln von 5, 2,5 und $0,5 \mathrm{~g}$ Gewicht auf ein halbes Liter Wasser bei $20^{\circ} \mathrm{C}$ Temperatur bezogen und es können auf dieser Grundlage hinsichtlich der Wasserreinigungswirkung der giftigen Muscheln Vergleiche angestellt werden.

Der beschriebene Versuch bietet auch dafür einen Stützpunkt, daß die Wasserreinigungswirkung bei $10^{\circ} \mathrm{C}$ um ein bedeutendes langsamer ist als bei $20^{\circ} \mathrm{C}$. Auf Grund des bekannten Gesetzes von STOKES kann - nachdem das spezifische Gewicht und die Viscosität der Flüssigkeit von der Temperatur abhängen, festgestellt werden, das die Sedimentierung im wärmeren Wasser rascher vor sich geht. Dies spielt jedoch bei Obigem keine Rolle, da

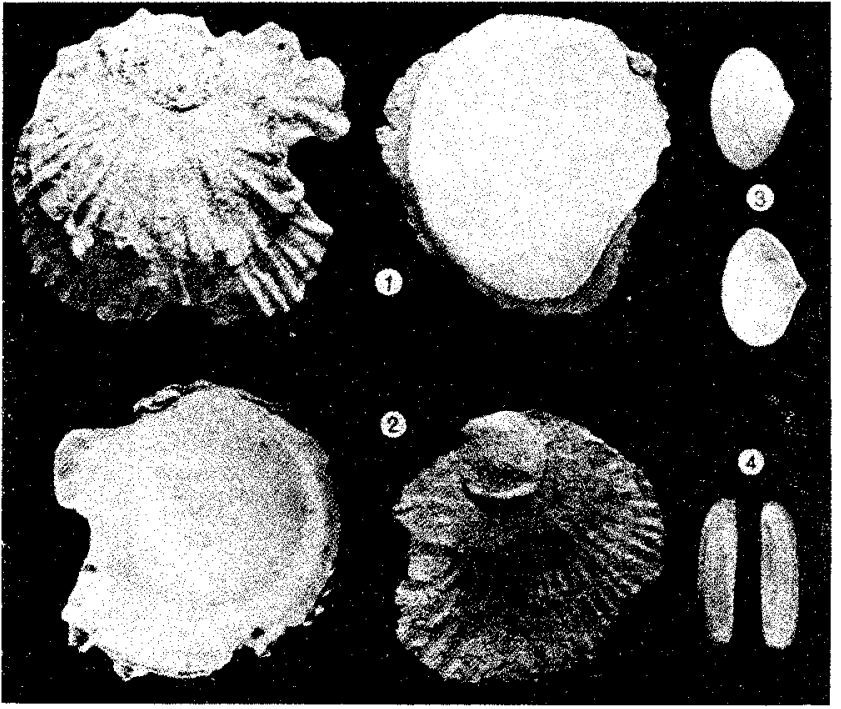

Abb. 27. Ostrea edulis aus der Osterschelde (Fig. 1 u. 2). Spisula solida (Fig. 3), Cultellus pellucidus (Fig. 4) aus der Gegend von Helgoland. die graphisch dargestellten Werte mit Kontrollversuchen verglichene, d. h. relative Werte darstellen, die also nicht den Sedimentierungsgrad anzeigen, sondern die Wasserreinigungsfähigkeit der Muschel im Verhältnis zu einer gewissen Sedimentierungs-Geschwindigkeit bestimmen. Aehnlich wären auch die bei verschiedenem Salzgehalt des Wassers ausgeführten Versuche zu beurteilen. Die Wasserreinigung der Muscheln wird durch die Tätigkeit der Flimmerzellen bedingt. Die Verlangsamung der Wasserreinigungswirkung im kalten Wasser steht offenbar mit dem Nachlassen der Flimmerzellenfunktion im Zusammenhang. GALTSOFF machte bei den amerikanischen Austern die Feststellung, daß die Tätigkeit der Flimmerzellen zwischen $25^{\circ}$ und $30^{\circ} \mathrm{C}$ am stärksten ist und im Winter die Strömungsfunktion nur dann einsetzt, wenn die Temperatur des Wassers $8^{\circ} \mathrm{C}$ erreicht. Der Zusammenhang der Tätigkeit der bewimperten Epithelzellen mit der Wassertemperatur ist vom Gesichtspunkte der Nahrungsaufnahme von großer Bedeutung. So fand ich, daß zur eingehenden Erforschung der Frage umso eher weitere Versuche nötig sind, als in der Entfaltung der Giftwirkung die Ernährungsweise entscheidend ist oder zumindest eine sehr wichtige Rolle spielt. Deshalb suchte ich die an Mytilus gemachten Wahrnehmungen mit dem ähnlichen Verhalten anderer Muscheln zu vergleichen und führte Versuche mit Austern aus. Herr Professor Havinga war so freundlich, der Biologischen Anstalt junge holländische Austern zur Verfügung zu stellen. Die Tiere trafen dort am 21. Januar ein und lebten 2 Wochen lang in Aquarien 
mit einer. Wassertemperatur von $8,5-9^{\circ} \mathrm{C}$. Das volle Durchschnittsgewicht der Tiere aus der Osterschelde (Jerseke) (Abb. 27 Fig. 1 u. 2) betrug 18--26 g, das Gewicht der Schale schwankte stärker und machte durchschnittlich $13-22 \mathrm{~g}$ aus, wogegen das Weichteilgewicht verhältnismäßig in geringerem Grade schwankte und abgesehen von wenigen Ausnahmen sich im allgemeinen zwischen 2,2-2,8 g bewegte. Außer diesen Tieren lagen uns nur wenige Exemplare wesentlich größerer oder kleinerer Austern vor. Dem Wasser des Aquariums wurde eine Algenkultur zugegeben und es konnte an einigen untersuchten Tieren festgestellt werden, daf die Austern am 3. Februar in Wasser von $8,5^{\circ} \mathrm{C}$ Temperatur reichlich Nahrung aufgenommen hatten. Mit den Austern habe ich am 4. Februar bei $20^{\circ} \mathrm{C}$ und Wassertemperaturen von $15^{\circ} \mathrm{C}$ und $10^{\circ} \mathrm{C}$, ähnlich wie mit den Mytilas, Versuche angestellt. Die Wassertemperatur von $15^{\prime \prime} \mathrm{C}$ und $10^{\circ} \mathrm{C}$ wurde in einem kühlen Institutsraum bzw. im Kühlschrank erreicht. Die übrigen Versuchsver-

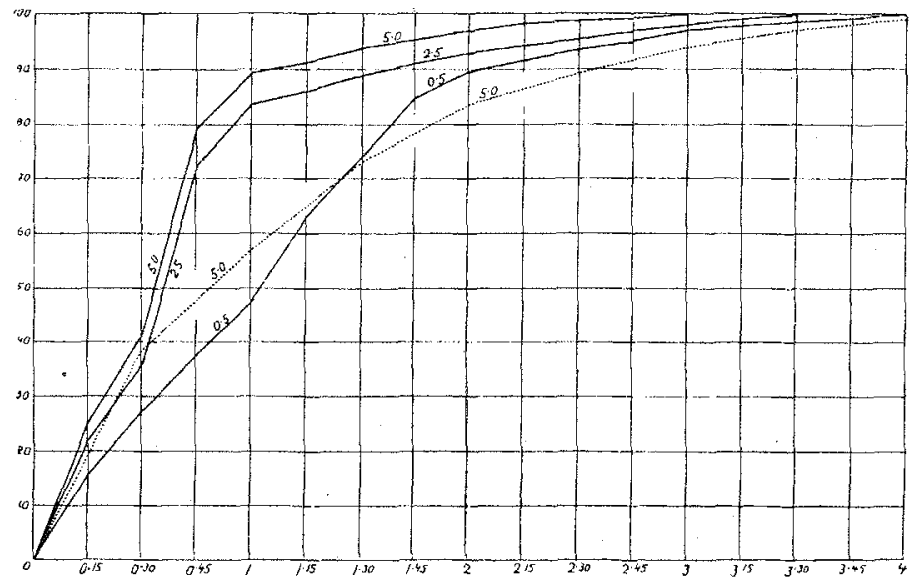

Abb. 26. Wasserreinigungswirkung Helgoländer Miesmuscheln von rerschiedenem Gewicht in mit Bolus alba gemischtem Meerwasser (Salzgeh.: $32,1^{\circ}, 0$ ). _ : Versuche bei $20^{\circ} \mathrm{C}$. …....... Versuch bei $10^{\circ} \mathrm{C}$. Die Zahlen über den Linien geben den Mittelwert des Weichteilgewichtes der Tiere an.

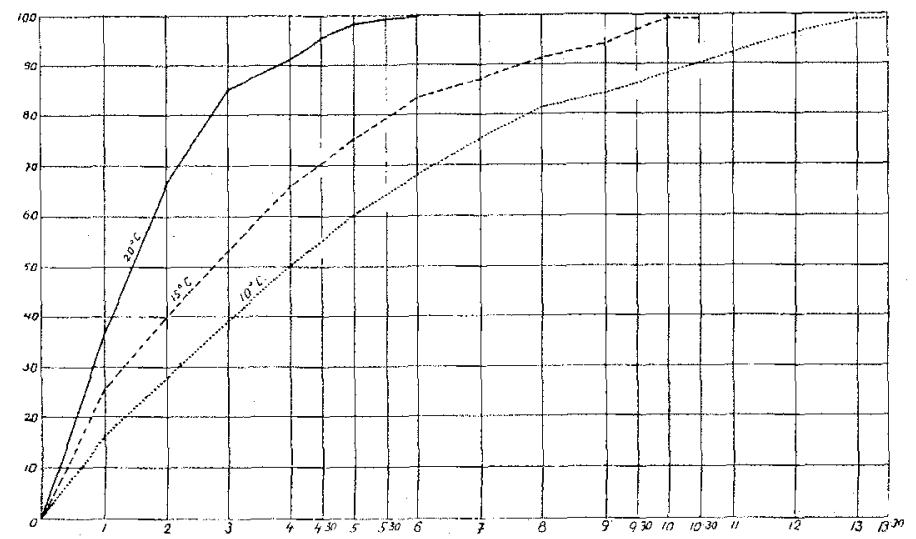

Abb. 28. Wasserreinigunoswirkung der Austern in mit Bolus alba genischtem Meerwasser von $32,1 \%$ bei versch. Temperaturen.

$$
\text { : bei } 10^{\circ} \mathrm{C} \text {. }
$$

hältnisse stimmten vollkommen mit jenen der bei Abb. 26 angeführten äberein und das Gewicht der Weichteile habe ich auch hier nach Abtöten der Austern bestimmt, allerdings mit dem Unterschied, daß die mit Nummern bezeichneten Tiere inzwischen vor dem Abtöten einige Tage hindurch auch noch zu anderen ähnlichen Versuchen verwendet wurden. Abb. 28 veranschaulicht den Einfluß der Temperatur auf die Wasserreinigungswirkung der Austern. Es sind hier die Resultate der Tiere um etwa 2,5 $\mathrm{g}$ Weichteilgewicht angeführt. Man gelangt danach zu der Feststellung, daß Austern dieser Größenordnung das Wasser bei $20^{\circ} \mathrm{C}$ in 6 Stunden, bei $15^{\circ} \mathrm{C}$ in 10 Stunden, bei $10^{\circ} \mathrm{C}$ in 13 Stunden reinigen. Auf der Tabelle bezwecken die iber Wirkungsgrad 98 eingetragenenWerte nur die Feststellung, ob die Wirkung auf 100 ansteigt oder ob der Wert 98 innerhalb der Fehlergrenze die vollständige Reinigung des Wassers bezeichnet. Daher zeigte sich die Temperatur von $20^{\circ} \mathrm{C}$ sogar bei jenen Austern, die bereits 2 Wochen vorher im Wasser von $8,5^{\circ} \mathrm{C}$ lebten, d. $h$. sich der niedrigeren Temperatur anpaßst haben, für die Wasserreinigungswirkung viel günstiger. Bei diesen Tieren nahm die Trübung des Wassers schon in nicht ganz $1^{1 / 2}$ Stunden um die Hälfte ab, wogegen dieselbe Wirkung bei $10^{\circ}$ erst in 4 Stunden eintrat.

Um diese Erscheinung auch an anderen Tieren zu untersuchen, habe ich mit 8 bezw. 16 Exemplaren der am 25. Januar von der Loreley-Bank gefischten Spisula solida Linn. (Abb. 27 Fig. 3), ferner mit aus dem nordwestlich von Helgoland etwa 4 Seemeilen entfernt liegenden, $29 \mathrm{~m}$ tiefen grauen Schlick am 28. Januar gefischten Exemplaren von Cultellus pellucidus Pennant (Abb. 27, Fig. 4) in nachstehender Weise Untersuchungen vorgenommen. Tiere von $2,2-2,3 \mathrm{~g}$ mit $0,5 \mathrm{~g}$ Weichteilgewicht, ferner von $0,8-0,9 \mathrm{~g}$ ebenfalls mit $0,5 \mathrm{~g}$ Weichteilgewicht und aus dem Helgoländer Versuchsteich stammende 
dunkelschalige Muscheln von $1,6 \mathrm{~g}$ mit $0,5 \mathrm{~g}$ Weichteilgewicht habe ich in ein Versuchsgefäß untergebracht, an dessen Boden für die Spisula aus sandigem Schlamm, für die Cultellus aus dem mit ihnen zusammen herausgehobenem Schlamm eine ungefähr $5 \mathrm{~cm}$ hohe Schicht gebildet wurde. Die beiden zuerst erwähnten Muscheln vergruben sich alsbald in den Sand, bzw. Schlamm. Die Miesmuschel legte ich auf ein auf den Schlamm gestelltes Uhrgläschen. Nach 24 stündigem Abstehenlassen habe ich das Wasser mit Hilfe einer Pipette abgesaugt und mit dem vorher gesondert mit Luft durchströmten und mit Bolus alba vermengtem Wasser Versuche unternommen. Von den sich bei der Vorbereitung bewährten Tieren wurde das Wasser erneut abgesaugt und ich füllte das Gefäß mit frischer Versuchsflüssigkeit wieder an, wobei ich das Gefäß der bei $10^{\circ} \mathrm{C}$ auszuführenden Versuche in den Kühlschrank stellte. Die Versuchsergebnisse sind auf Abb. 29 vermerkt. Die Kurven stimmen mit meinen Untersuchungen in Neapel insofern überein, als die Wasserreinigungswirkung der Siphoniaten bedeutend rascher ist als die der Mytiliden. Während nämlich die beiden Siphoniaten das Wasser in 2 Stunden 30 Minuten, bzw. 3 Stunden reinigten, erfolgte das bei den Mytiliden in voller Uebereinstimmung mit den Daten des bei Abb. 26 angeführten Versuches erst in 4 Stunden. Noch auffallender ist aber die Erscheinung, daß, während in den Untersuchungen mit Spisula und Cultellus zwischen den Versuchen bei $20^{\circ} \mathrm{C}$ und $10^{\circ} \mathrm{C}$ kein wesentlicher Unterschied besteht, bei den Mytiliden in dieser Richtung bedeutende Differenzen zu vermerken sind. Im tiefen Wasser der offenen See, wo eine wesentliche Erwärmung des Wassers in der Regel nicht auftritt, haben sich dort lebende Spisula- und $\mathrm{Cul}$ tellusmuscheln augenscheinlich an die niedrige Temperatur des Wassers angepaßt. Es scheint dagegen ein derartiges Anpassungsvermögen bei den an den Ufern lebenden Mytilus nicht vorhanden zu sein. Bei dieser Muschel stellen auch bei jüngeren Tieren, und sogar zur Winterzeit $20^{\circ} \mathrm{C}$ die günstigste Temperatur für die Strömungsfunktion dar, wenn auch der Unterschied nicht so groß ist, wie bei den Austern, wo die Wasserreinigungswirkung bei $10^{\circ} \mathrm{C}$ um das Doppelte sehlechter wird als bei $20^{\circ} \mathrm{C}$. Von diesem Gesichtspunkt aus konnten die untersuchten Tiere in 3 Gruppen eingeteilt werden $\mathrm{u}$. zw. bildeten die Muscheln Spisula und Cultellus das eine Extrem, das andere die Austern und zwischen den beiden steht die Miesmuschel, bei welcher die durch die Flimmerzellen bewirkte Strömungsfunktion
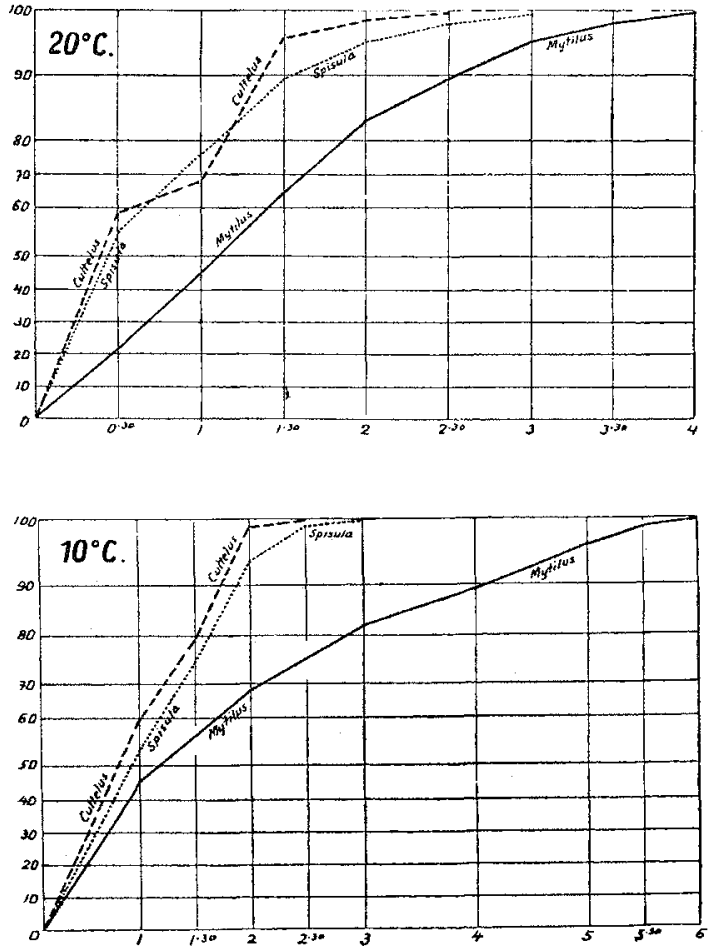

Abb. 29. Wasserreinigungswirkung von Cultellus pellucidus, Spisula solida und Mytilus edulis von gleichem Weichteilgewicht in mit Bolus alba gemischtem Meerwasser (Salzgehalt $32,1 \%$. Die obere Figur zeigt Versuchsergebnisse bei $29^{\circ} \mathrm{C}$, die untere bei $10^{\circ} \mathrm{C}$. Die mit verschiedenen Muscheln unternommenen Versuche sind mit den Namen der betreffenden Tiere bezeichnet. bei Senkung der Temperatur deutlich nachläßt.

Wie erwähnt, sind im geschlossenen Gefäß die großen und kleinen Tiere nicht unter denselben Versuchsbedingungen, da bei verschiedenem $\mathrm{O}_{2}$-Bedarf ihnen die gleiche Sauerstoffmenge zur Verfügung steht. Um das zu umgehen und um die Wasserreinigungswirkung unter sauerstoffreichen und sauerstoffarmen Verhältnissen zu untersuchen, habe ich die Versuche in der Weise wiederholt, daß ich ins Versuchsgefäß eines jeden Tieres mit Hilfe einer $3 \mathrm{~mm}$ weiten Röhre aus der Luftzuleitung des Institutes von 0,5 Atmosphaeren Ueberdruck langsam Luft einströmen ließ. Naturgemäß wurden die Versuchsbedingungen infolge der ständigen Wasserbewegung modifiziert, da hierdurch einerseits die spontane Sedimentierung verhindert wurde, andererseits trieb die verstärkte Wasserbewegung die suspendierten Stoffe den Muscheln zu und beeinflußte dadurch die Wasserreinigungswirkung derselben günstig. Die sich ergebenden Resultate sind folglich auch nur relative Vergleichswerte. Die in einem halben Liter mit 20 Tropfen chinesischer Tusche vermengtem Seewasser bei $20^{\circ} \mathrm{C}$ und bei $10^{\circ} \mathrm{C}$ in dieser Richtung ausgeführten Versuche 
sind zusammen mit den Kontrollversuchen ohne Luftzuleitung in Abb. 30 dargestellt. Die Versuche mit Luftzuleitung sind hier durch eine fortlaufende Linie, die ohne Luftzuleitung durch eine gestrichelte Linie dargestellt. Die Zahlen über den Linien zeigen den Mittelwert der Weichteilgewichte der Versuchstiere in $\mathrm{g}$ an. Sowohl hier als auch an mehreren späteren Abbildungen ist die Einteilung nicht vollkommen gleich, damit an den Stellen, wo mehrere Kurven zu nahe beieinander verlaufen, das Bild klarer hervortritt. Die Kurven lassen die Folgerung zu, daß, falls durch die Versuchsflüssigkeit ständig Luft gepumpt wird, bei $20^{\circ} \mathrm{C}$ die Reinigung des Wassers viel schneller vor sich geht als ohne Luftzufuhr, dagegen besteht bei $10^{\circ} \mathrm{C}$ bei den $5 \mathrm{~g}$ schweren Tieren in dieser Hinsicht kein Unterschied und auch bei den $0,5 \mathrm{~g}$ schweren Tieren ist der Unterschied nur gering, es macht im ganzen 30 Minuten aus. Während also bei $20^{\circ} \mathrm{C}$ das reichliche Vorhandensein von Sauerstoff die Störungsfunktion fördert, besteht bei $10^{\circ} \mathrm{C}$ eine solche
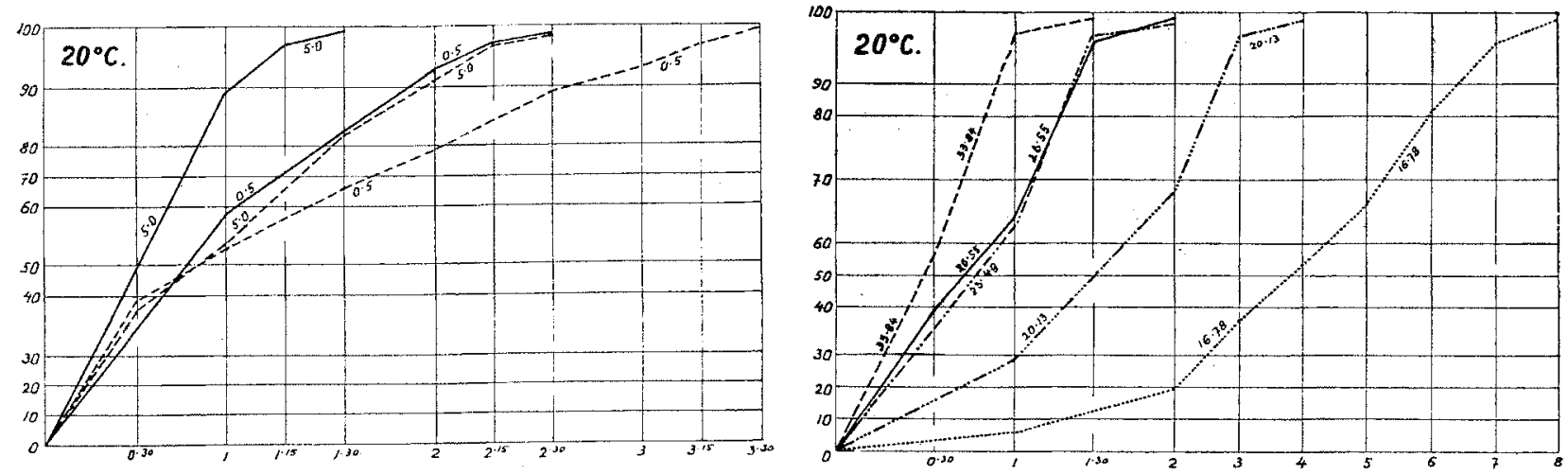

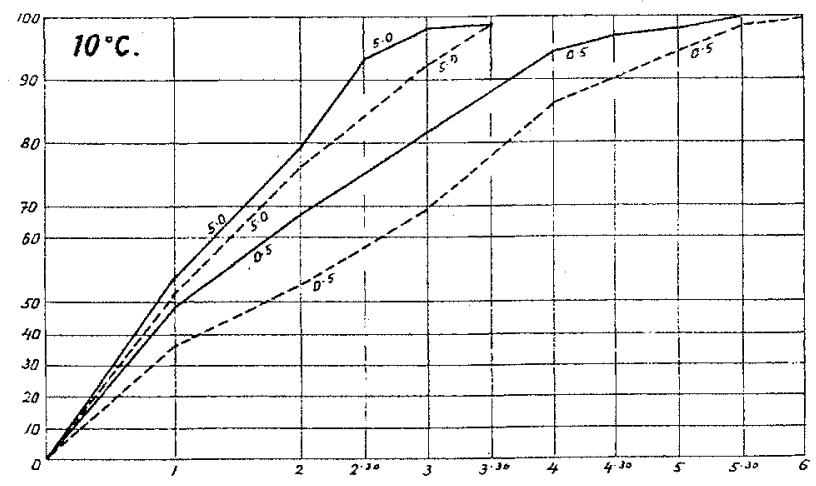

Abb. 30 .

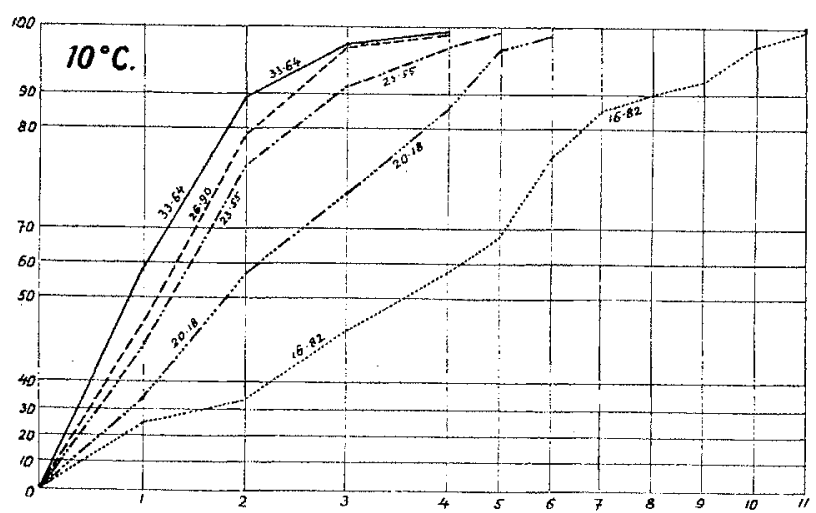

Abb. 31.

Abb. 30. Wasserreinigungswirkung von Miesmuscheln mit verschiedenem Gewicht in mit chinesischer Tusche gemischtem Meerwasser (Salzgeh. 32,1\%), ____ : Versuche bei ständiger Luftdurchströmung, -..... Versuche ohne Luftdurchströmung. Die obere Figur zeigt Versuchsergebnisse bei $20^{\circ} \mathrm{C}$, die untere bei $10^{\circ} \mathrm{C}$. Die Zahlen über den Linien geben den Mittelwert des Weichteilgewichtes der Tiere an.

Abb. 31. Wasserreinigungswirkung von Miesmuscheln mit einem Weichteildurchschnittsgewicht von $6,5 \mathrm{~g}$ in mit chinesischer Tusche gemischtem Meerwasser von verschiedenem Salzgehalt und bei verschiedenen Temperaturen. Die obere Figur zeigt Versuchergebnisse bei $20^{\circ} \mathrm{C}$, die untere bei $10^{\circ} \mathrm{C}$. Die Zahlen über den Linien geben den Salzgehalt pro Mille an.

Differenz nicht oder nur in sehr geringem Grade. Aus der Kurve ist ferner zu ersehen, daß sich in der Dauer der Wassereinigungswirkung der kleinen und großen Tiere bei Gegenwart von reichlichem Sauerstoff verhältnismäßig größere Differenzen zeigen als in der sauerstoffärmeren Versuchsflüssigkeit. Während nämlich bei Luftzufuhr die Zeitdauer der Wasserreinigungswirkung des $5 \mathrm{~g}$ schweren Tieres (1 Stunde $30 \mathrm{Min}$.) nur etwas mehr als die Hälfte der Zeitdauer des $0,5 \mathrm{~g}$ schweren Tieres (2 Stunden $30 \mathrm{Min}$.) betrug, macht der Wert bei den ohne Luftdurchströmung vorgenommenen Versuchen bei $5 \mathrm{~g}$ schweren Tieren (2 Stunden 30 Minuten) fast drei Viertel der Zeit (3 Stunden 30 Minuten) der 0,5 g schweren Tiere aus. Es werden sich also bei $20^{\circ} \mathrm{C}$ in den Versuchen ohne Luftzufuhr die kleinen Tiere unter günstigeren Versuchsverhältnissen befinden als die größeren, weil 
ihnen mehr Sauerstoff zur Verfügung steht. Bei ständiger Durchlüftung der Flüssigkeit dagegen wird die Dauer der Wasserreinigungswirkung des größeren Tieres verhältnismäßig mehr verkürzt und die Strömungstätigkeit rascher als die des kleinen Tieres, weil es seinen Sauerstoffbedarf ebenso gut befriedigen kann wie das kleine Tier. Nachdem aber in den Versuchen mit Luftdurchströmung die Differenz zwischen der Dauer der Wasserreinigungswirkung der Tiere von $5 \mathrm{~g}$ und $0,5 \mathrm{~g}$ Weichteilgewicht noch immer gering ist, da doch das zehnfach kleinere Tier während der doppelten Zeit das Wasser ebenso reinigt wie das viel größere, kann festgestellt werden, daß die Strömungstätigkeit der kleineren Tiere bedeutend rascher ist als die der großen. Diese Erscheinung dürfte wahrscheinlich in der lebhafteren Tätigkeit der Flimmerzellen ihre Erklärung finden.

Die Lebensfunktionen der Muscheln werden aber nicht nur durch den Sauerstoffgehalt und die Temperatur des Wassers, sondern neben anderen Faktoren auch durch den Salzgehalt wesentlich beeinflußt. Zur Untersuchung der Frage habe ich in $1 / 2$ Liter, mit 15 Tropfen chin. Tusche vermengtem und dest. Wasser auf verschiedenen Salzgehalt eingestellten Seewasser bei einer Schichthöhe von $6,8 \mathrm{~cm}$ Versuche vorgenommen. $\mathrm{Zu}$ diesen benutzte ich durchschnittlich $24-25,5 \mathrm{~g}$ schwere Tiere von durchschnittlich $6,5 \mathrm{~g}$ Weichteilgewicht. Die Bestimmung des Salzgehaltes wurde auf Grund der KNUDSEN' schen hydrographischen Tabelle mit dem Araeometer vorgenommen und nach Verdünnung des Seewassers mit dest. Wasser auf die Hälfte, ein Drittel, ein Viertel usw. habe ich den Salzgehalt nochmals bestimmt. Der Versuch ist an Abb. 31 veranschaulicht. Die über die Linien geschriebenen Zahlen zeigen den verschiedenen Salzgehalt an, wobei auch die Linien der in Flüssigkeiten von verschiedenem Salzgehalt ausgeführten Versuche verschiedenartig, fortlaufend gestrichelt, punktiert usw. gezogen sind. Von den Kurven kann abgelesen werden, daß im Seewasser von verschiedenem Salzgehalt in der Wasserreinigungswirkung der Mytilus verhältnismäßig große Differenzen bestehen.
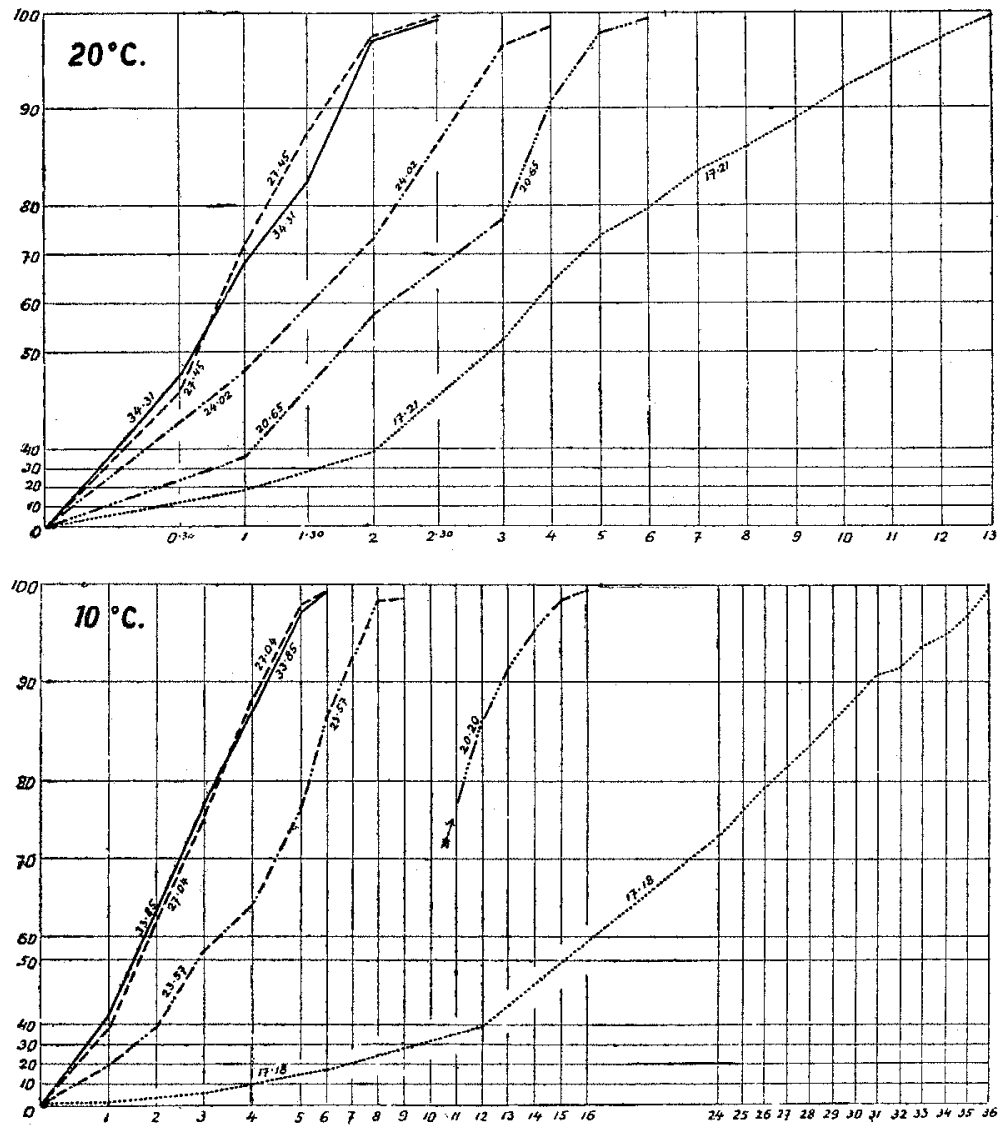

Abb. 32. Wasserreinigungswirkung von Miesmuschel mit einem Weichteilgewicht von $0,6 \mathrm{~g}$ in mit chinesischer Tusche gemischtem Meerwasser von verschiedenem Salzgehalt und bei verschiedenen Temperaturen. Die obere Figur zeigt Versuchsergebnisse bei $20^{\circ} \mathrm{C}$, die untere bei $10^{\circ} \mathrm{C}$. Die Zahlen über den Linien geben den Salzgehalt pro Mille an.

So ist z. B. bei $20^{\circ} \mathrm{C}$ und

einem Salzgehalt von $33,84 \%$ bei der angewandten Versuchsmethodik die Reinigung des Wassers schon in 1 Stunde 30 Minuten eine vollständige gewesen, wogegen im Seewasser von 16,78\% Salzgehalt diese Erscheinung erst in 8 Stunden eintrat, d. h. daß mehr als die fünffache Zeit dazu nötig war. Bei $10^{\circ} \mathrm{C}$ geht die Wasserreinigungswirkung im Seewasser mit 33,64\% Salzgehalt viel langsamer vor sich und kommt jenem mit $26,90 \%$ Salzgehalt gleich. Aus der Kurve ist auch zu ersehen, daß bei $10^{\circ} \mathrm{C}$ zwischen den Versuchswerten der beiden extremen Salzgehalte die Differenz gering ist, es macht aber trotzdem fast das Dreifache des Wertes von 33,64\% aus. Diese Versuche habe ich auch an 2-2,4 g schweren Tieren mit $0,6 \mathrm{~g}$ Weichteilgewicht wiederholt. Dieselben sind in Abb. 32 dargestellt. Wo an der Skizze die Linien der senkrechten Einteilung unter- 
brochen sind, wurde im entsprechenden Zeitpunkt die Trübung der Versuchsflüssigkeit nicht bestimmt. Bei den Versuchen im Seewasser von $10^{\circ} \mathrm{C}$ und $20,20 \%$ Salzgehalt wurden die Bestimmungen erst nach 11 Stunden begonnen. Im Seewasser mit 17,18\% Salzgehalt sind Bestimmungen von 12 bis 24 Stunden nicht vorgenommen worden. Es ist auf Grund der Kurven feststellbar, daß bei kleineren Tieren bei Senkung des Salzgehaltes die Wasserreinigungswirkung bei $20^{\circ} \mathrm{C}$ im großen und ganzen ebenso abnimmt wie bei den zehnfach größeren Tieren, wogegen bei $10^{\circ} \mathrm{C}$ die Verschlechterung der Wasserreinigungswirkung jene der großen Tiere weit übersteigt. Wenn auch der Wert von $33,85^{\circ}, 00$ schon selbst einen recht langsamen Vorgang (6 Stunden) anzeigt, stellt der Wert von 17,18 die sechsfache Verlangsamung der Wasserreinigungswirkung (36 Stunden) dar. Folglich ging bei den kleinen Muscheln von gleicher Größe die Wasserreinigungswirkung im Falle der Senkung der. Wassertemperatur um $10^{\circ} \mathrm{C}$ und des Salzgehaltes um $50^{\%} \%$ von 2. Stunden 30 Minuten auf 36 Stunden zurück.
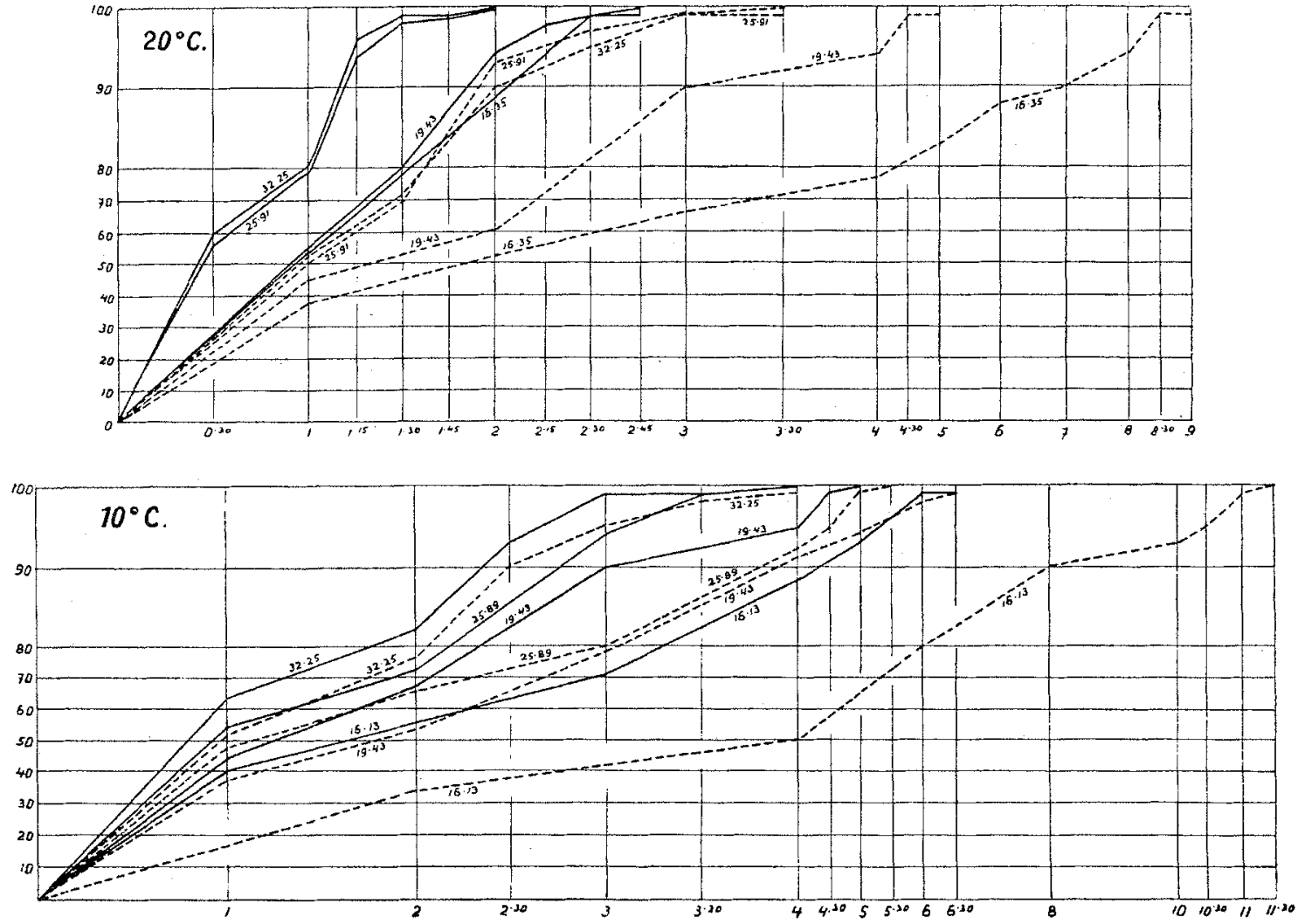

Abb. 33. Wasserreinigungswirkung von Miesmuscheln mit einem Weichteildurchschnittsgewicht von $2,5 \mathrm{~g}$ in mit chinesischer Tusche gemischtem Meerwasser von verschiedenem Salzgehalt und bei verschiedenen Temperaturen, bei ständiger Durchströmung mit Luft und ohne Luftdurchströmung. - : Versuche bei ständiger Luftdurchströmung, ... . . . : Versuche ohne Luftdurchströmung. Die Zablen über den Linien geben den Salzgehalt pro Mille an. Die obere Figur zeigt Versuchsergebnisse bei $20^{\circ} \mathrm{C}$, die untere bei $10^{\circ} \mathrm{C}$.

Mit Rücksicht darauf, daß nach den auf Abb. 30 angeführten Versuchen die Wasserreinigungswirkung der Muscheln auch durch den Sauerstoffgehalt der Versuchsflüssigkeit wesentlich beeinträchtigt wird, habe ich die vorherigen Versuche auch bei ständiger Luftdurchströmung wiederholt. Die Ergebnisse derselben sind in Abb. 33 dargestellt. Die Versuche wurden an $10,5-10,9 \mathrm{~g}$ schweren, dunkelfarbigen Helgoländer Muscheln mit einem Weichteilgewicht von etwa $2,5 \mathrm{~g}$ in mit 20 Tropfen chin. Tusche vermengtem Seewasser von $10 \mathrm{~cm}$ Schichtenhöhe ausgeführt. An der Skizze bedeuten die fortlaufenden Linien die mit Luftdurchströmung, die gestrichelten Linien die ohne dieselbe vorgenommenen Versuche. Die Zahlen über den Linien geben auch hier den jeweiligen Salzgehalt an. Die Kurven zeigen, daß bei reichlich vorhandenem Sauerstoff bei $20^{\circ} \mathrm{C}$ in den Versuchen mit Seewasser von verschiedenem Salzgehalt hinsichtlich der Dauer der Wasserreinigungswirkung die Differenz gering ist. Es macht maximal 45 Minuten aus. Die Kurven der 
Versuche von $32,25 \%$ und 25,91 beziehungsweise von $19,43 \%$ und $16,35 \%$ verlaufen fast gemeinsam. Dagegen entfernen sich die Kurven der bei $10^{\circ} \mathrm{C}$ mit verschiedenem Salzgehalt ausgeführten Versuche geradeso voneinander, wie in den Versuchen ohne Luftdurchströmung. Die Differenz der Versuchszeit der beiden extremen Salzgehalte ist bereits viel größer: 3 Stunden, obwohl sogar dieser Wert noch bedeutend geringer ist als in den Versuchen ohne Luftdurchströmung, wo derselbe $7 \frac{1}{2}$ Stunden betrug. Schließlich gelangt man zum Schlusse, daß3 bei $20^{\circ} \mathrm{C}$ das reichliche Vorhandensein von Sauerstoff die die Strömungsfunktion behindernde Wirkung des niedrigen Salzgehaltes größtenteils aufhebt, doch vermag auch reichliches Vorhandensein von $0_{2}$ bei $10^{\circ} \mathrm{C}$ die die Strömungsfunktion verlangsamende Wirkung des niedrigen Salzgehaltes nur teilweise auszugleichen. Es sei bemerkt, daß die Tusche bei Untersuchungen der Tiere in der Leber oder im Darmkanal einer jeden Muschel aufzufinden war, wodurch bestätigt wird, daß die Nahrungsaufnahme im Wasser mit niedrigem Salzgehalt nicht aufhörte.

Um festzustellen, ob sich diese Erscheinung nur auf die Miesmuscheln bezieht, oder auch bei anderen Muschelgattungen vorkommt, habe ich die Versuche an Austern von durchschnittlich $\quad 2,2 \mathrm{~g}$ Weichteilgewicht (18 bis 22 g volles Gewicht)wiederholt. Abb. 34 stellt die Versuchsergebnisse dar. Die Methodik der Versuche zeigte gegenüber den mit Miesmuscheln vorgenommenen Untersuchungen nur insofern eine Abweichung, als bej $10^{\circ} \mathrm{C}$ die Ablesung der Versuchswerte mit Rücksicht auf die zu den Versuchen erforderliche lange Zeit erst nach 11 Stunden begann. Bei $20^{\circ} \mathrm{C}$ wurde im Versuch mit $20,42 \%$ Salzgehalt vor 12 Stunden, bei $10^{\circ} \mathrm{C}$ im Versuch mit $23,26 \%$ Salzgehalt vor 14 Stunden keine Ablesung vorgenommen. Die Kurven zeigen, daß die Strömungsfunktion der Austern schon bei geringerer Senkung des Salzgehaltes sich in viel
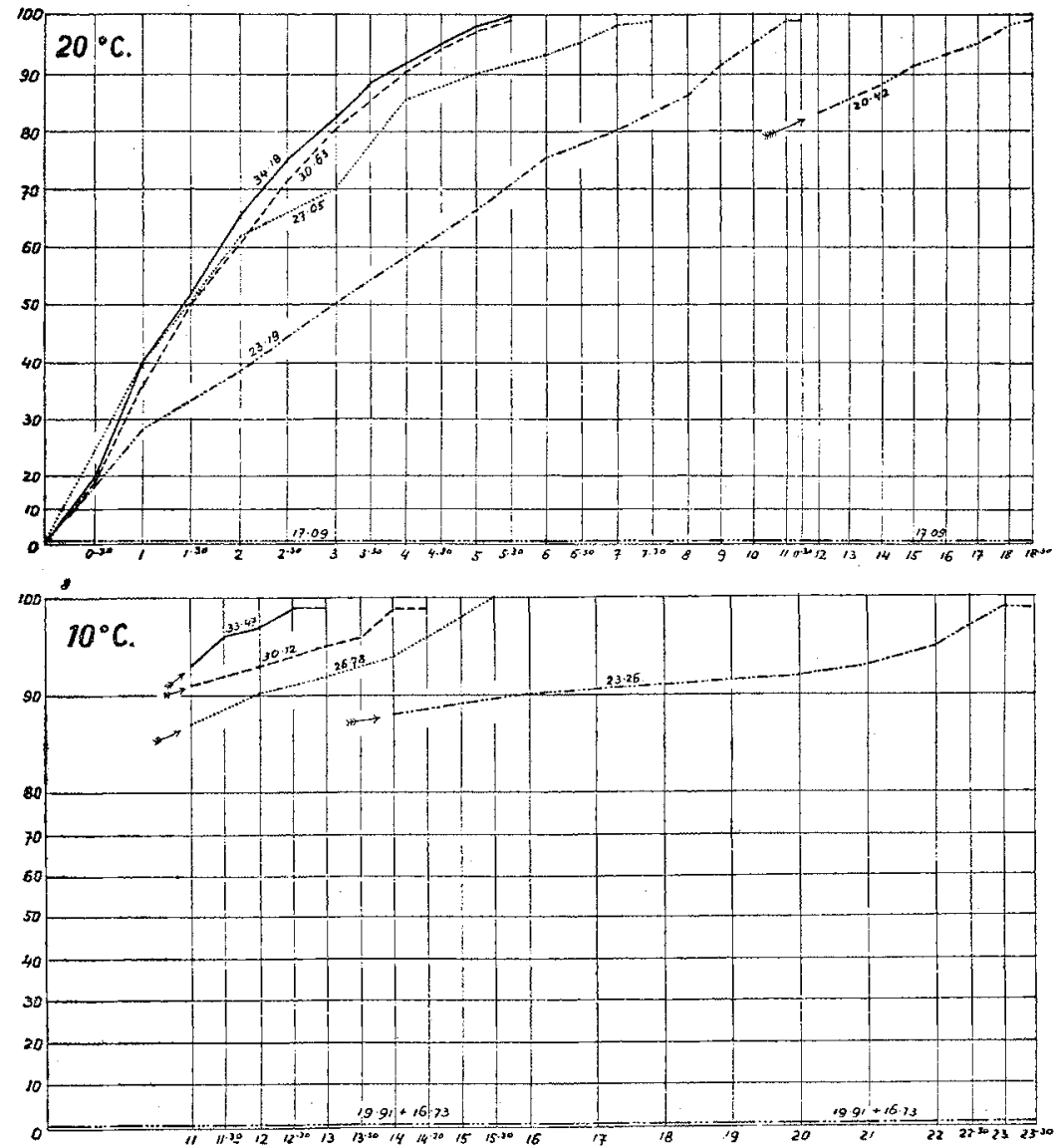

Abb. 34. Wasserreinigungswirkung von Austern mit einem mittleren Weichteilgewicht von $2,2 \mathrm{~g}$ in mit chinesischer Tusche gemischtem Meerwasser von verschiedenem Salzgehalt und bei verschiedenen Temperaturen. Die obere Figur zeigt Versuchsergebnisse bei $20^{\circ} \mathrm{C}$, die antere bei $10^{\circ} \mathrm{C}$. Die Zahlen über den Linien geben den Salzgehalt pro Mille an. Die vor den Linien gelegenen Pfeile geben den Zeitpunkt des Beginnes der Bestimmungen an.

Miesmuscheln verschlechtert und daß bei $10^{\circ} \mathrm{C}$ und einem Salzgehalt von $17,09 \%$, bei $10^{\circ} \mathrm{C}$ und einem Salzgehalt von $19,91 \%$ und $16,73 \%$ die Muschel sich schloß und eine Wasserströmung überhaupt nicht entstand. Dementsprechend sind die Austern besonders im Wasser von niedrigerer Temperatur gegen die Senkung des Salzgehaltes viel empfindlicher als die Miesmuscheln und unter dem Salzgehalt von $20 \%$ bleibt die Wasserreinigungswirkung vollkommen aus. Den Versuch wiederholte ich in gleicher Weise bei ständiger Luftdurchströmung an Tieren mit 2,4 g Weichteilgewicht (volles Gewicht 20-24 g), wie das an Abb. 35 angeführt ist. Bei $20^{\circ} \mathrm{C}$ habe ich die Trübung der Flüssigkeit von $19,42 \%$ Salzgehalt, bei $10^{\circ} \mathrm{C}$ und $23,67 \%$ Salzgehalt nicht vor 12 Stunden bestimmt. Es geht aus den Kurven hervor, daß, falls die Versuchsflüssigkeit bei $20^{\circ} \mathrm{C}$ reichlich 
Sauerstoff enthält, die Wasserreinigungswirkung der Austern im Seewasser auch noch in einem Salzgehalt verhältnismäßig rasch vor sich geht, in welchem ohne Luftzuleitung die Muschel ihre Strömungsfunktion einstellt. Bei $10^{\circ}$ ist die Wasserreinigungswirkung auch bei Vorhandensein von reichlichem $0_{2}$ verhältnismäßig langsam, dieselbe erreicht im Seewasser von 16,18\% Salzgehalt 12 Stunden, wobei zu beachten ist, daß in den Versuchen ohne Luftdurchströmung bei den Austern bei einer Temperatur von $10^{\circ} \mathrm{C}$ und dem Salzgehalt von $20 \%$ die Wasserreinigungswirkung bereits ausblieb, d. h. die behindernde Wirkung des niedrigen Salzgehaltes wird durch den reichlichen Sauerstoff zum Teil doch aufgehoben. Es handelt sich in der Tat nur um eine teilweise Wirkung, denn in den nach den Versuchen untersuchten Tieren konnte nachgewiesen werden, daß im Seewasser von
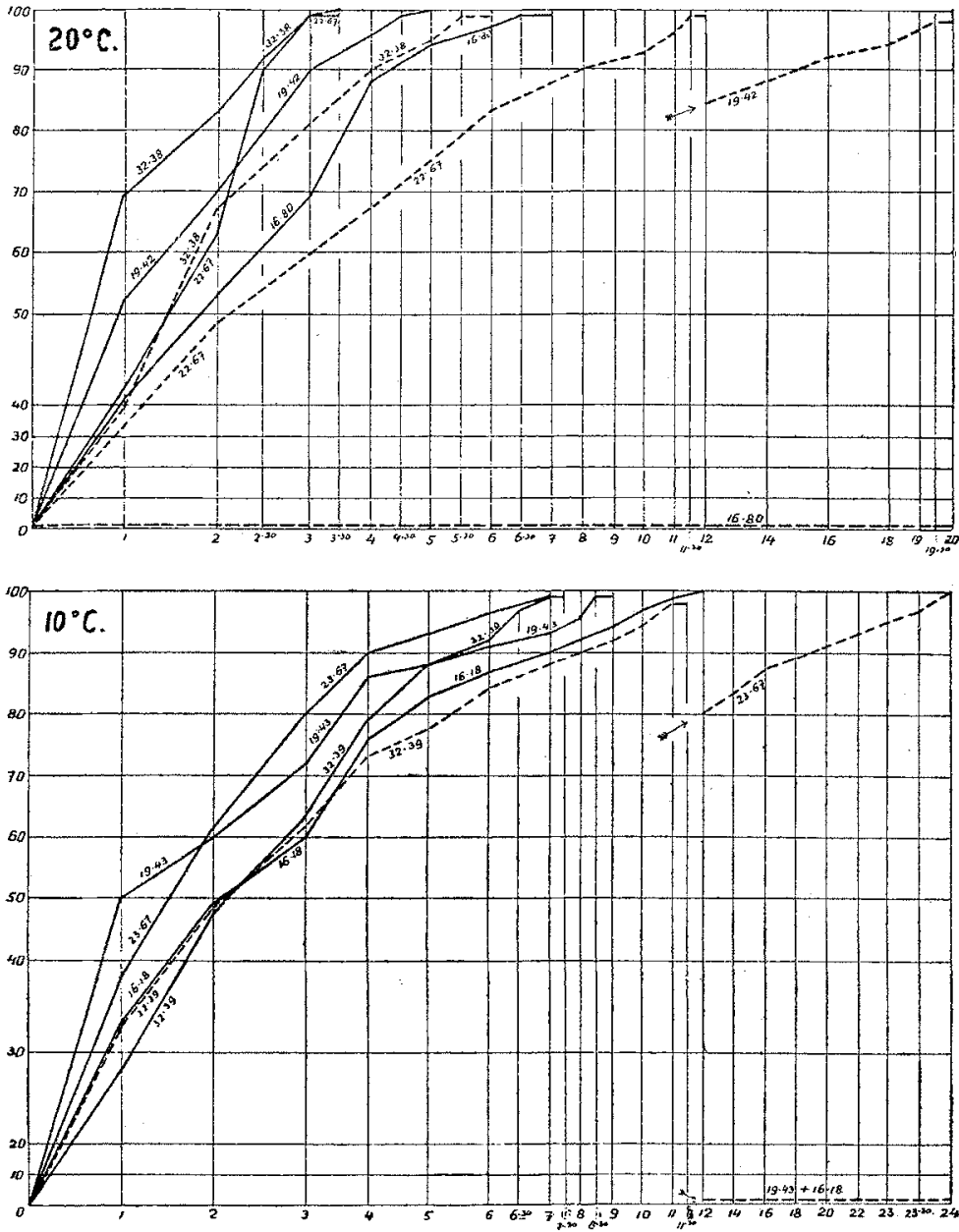

Abb. 35. Wasserreinigungswirkung von Austern mit einem Weichteildurchschnittsgewicht von $2,4 \mathrm{~g}$ in mit chinesischer Tusche gemischtem Meerwasser von verschiedenem Salzgehalt und bei verschiedenen Temperaturen bei ständiger Luftdurchströmung und ohne Luftdurchströmung. - Versuche bei ständiger Luftdurchströmung, ......... Versuche ohne Luftdurchströmung. Die Zahlen über den Linien geben den Salzgehalt pro Mille an. Die obere Figur zeigt Versuchsergebnisse bei $20^{\circ} \mathrm{C}$, die untere bei $10^{\circ} \mathrm{C}$. $19,43 \%$ und weniger Salzgehalt die Tuschekörnchen auch bei reichlichem $0_{2}$ nicht in den Darmkanal gelangten, obwohl sich diese Tiere im Aquarienwasser von $8,5^{\circ} \mathrm{C}$ und $28,5^{\circ} \%$ Salzgehalt gut ernährten und in sämtlichen Versuchen mit Luftdurchströmung bei $20^{\circ} \mathrm{C}$ Tusche reichlich aufgenommen hatten.

Die beschriebenen Untersuchungen habe ich auch mit größeren Wassermengen und mit Algendetritus wiederholt und nahm Versuche bei $15^{\circ} \mathrm{C}$ separat vor. Nachdem die Ergebnisse dieser Versuche im Wesentlichen mit den angeführten Untersuchungen übereinstimmten, habe ich von der Erörterung derselben der Kürze wegen abgesehen. Beim Ueberblick über sämtliche Versuchsergebnisse kann festgestellt werden, daß die Senkung der Temperatur die Geschwindigkeit der Strömungsfunktion der Miesmuscheln in hohem Grade beeinflußt und daß in dieser Beziehung die Temperatur von $20^{\circ} \mathrm{C}$ viel günstiger ist, als eine niedrigere Temperatur. Enthält das Wasser reichlich Sauerstoff, so wird die Wasserreinigungswirkung bei höherer Temperatur wesentlich beschleunigt, wogegen bei niedrigerer Temperatur das Nachlassen der Wasserreinigungswirkung auch durch das Vorhandensein von reichlicher Sauerstoffmenge nicht ganz verhindert werden kann. Die Senkung des Salzgehaltes des Seewassers beeinträchtigt ähnlich der Wassertemperatur die Geschwindigkeit der Wasserreinigungswirkung und obwohl bei den Miesmuscheln die Wasserreinigungswirkung gegenüber den Austern auch bei einem Salzgehalt von $16 \%$ ungestört weiter vor sich geht, bewirkt die Salzgehaltsenkung eine hochgradige Verlangsamung derselben. Enthält das Wasser reichlich Sauerstoff, so wird bei höherer Temperatur die behindernde Wirkung des niedrigeren Salzgehaltes ausbleiben, dagegen vermag bei niedrigerer Temperatur sogar die Gegenwart einer reichlichen Sauerstoffmenge dem Ein- 
fluß des niedrigeren Salzgehaltes nur teilweise entgegenzuarbeiten. Die Wasserreinigungswirkung der ganz kleinen Tiere ist im allgemeinen verhältnismäßig geschwinder als die von größeren Tieren, dagegen zeigt sich bei denselben bei niedrigerer Temperatur die Wasserströmung-behindernde Wirkung des niedrigen Salzgehaltes bedeutend stärker als bei den großen Tieren. Da nun die Wasserströmung dem Gasstoffwechsel und der Nahrungsaufnahme der Muschel dient, ist es klar, daß die Verlangsamung derselben diese lebenswichtigen Funktionen mit beeinträchtigt. Wenn die Wasserströmung allzusehr nachläßt, oder unregelmäßig wird, können im Gasstoffwechsel und in der Nahrungsaufnahme weitgehende Störungen entstehen. Nach meinen Untersuchungen in Neapel tragen zur Entwicklung der Giftwirkung einerseits die schlechten Oxydationsverhältnisse, andererseits die ungünstige Ernährung bei und so dürfte die Vermutung richtig sein, daß, falls infolge Senkung oder Schwankung der Wassertemperatur oder auch des Salzgehaltes, noch dazu im sauerstoffarmen Wasser, Störungen in der Ernährung eintreten, die diese Entwicklung der Giftwirkung begünstigen. Es ist deshalb zu beachten, daß die Strömungsfunktion der jungen Tiere durch die niedrige Temperatur in Gemeinschaft mit dem niedrigen Salzgehalt verlangsamt wird. Es wird daher unter diesen Verhältnissen eine sich ungünstig ernährende, fehlerhaft entwickelte Muschelgeneration von unvollkommenem Gasstoffwechsel entstehen, bei welcher als Folge der unterwertigen Lebensfunktionen die zur Entwicklung der Giftwirkung erforderlichen Ernährungs- und Oxydationsstörungen besonders leicht auftreten können.

\section{Die Ergebnisse von Versuchen mit mangelhaft entwickelten Tieren.}

Es war zur Beurteilung der Frage nötig, zwischen den Feststellungen an den Helgoländer gut entwickelten Tieren mit dunkler, dicker Schale, und dem Verhalten der mangelhaft entwickelten Miesmuscheln vom Bewuchs der Seezeichen von der Westküste Schleswig-Holsteins einen Vergleich anzustellen. Zu diesem Zwecke wollte ich vor allem die Geschwindigkeit der Wasserreinigswirkung der Muscheln vergleichen und habe aus diesem Grund die an Abb. 26 angeführten Versuche unter strenger Berücksichtigung der

Abb. 36. Vergleich der Wasserreinigungswirkung von den von den äußeren bzw. înneren Teilen der „Hackfeld"Tonne stammenden Miesmuscheln und Helgoländer Miesmuscheln mit gleichem Gewicht in mit Bolus alba gemischtem Meerwasser (Salzgeh. 32,1\% $\%$ ), bei $20^{\circ} \mathrm{C}$..... Versuche mit von der äußeren Tonnenfläche stammenden Tieren, ............... Versuche mit von der inneren Tonnenfläche stammtenden Tieren. Helgoland (Kontroll).

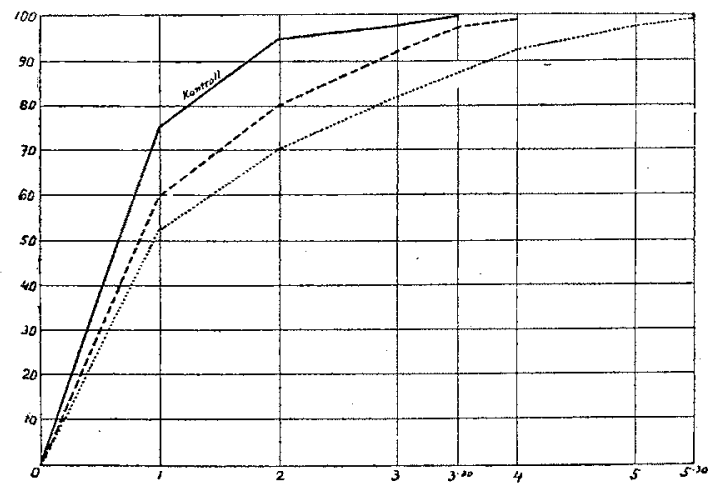

dort bekanntgegebenen Methodik mit Muscheln von verschiedenen Fundorten der SchleswigHolsteiner Küsten wiederholt. Die großen Differenzen, die sich zwischen den Schalen und den Weichteilen der unvollkommen entwickelten Tiere zeigten, machten beï den Untersuchungen große Schwierigkeiten, so daß die mit 14-16 Tieren begonnene Versuchsreihe mehrmals ganz auber acht gelassen werden mußte, da es sich nach Präparation der Tiere herausstellte, daß die Weichteile von anscheinend gleichen Tieren beträchtliche Gewichtsdifferenzen aufwiesen. Ich suchte den Schwierigkeiten in der Weise zu entgegnen, daß ich mit Algendetritus an zwei auf einander folgenden Tagen Versuche vornahm und die Tiere nur auf Grund dieser Versuche zum Hauptversuch auswählte. Andererseits habe ich den Hauptversuch mit mehr Tieren begonnen, damit nach Untersuchung derselben wenigstens 8 Muscheln zurückblieben, bei welchen das Gewicht der Weichteile keine bedeutende Abweichung aufweist. Die somit vorgenommenen Versuche zeigten, daß die Wasserreinigungswirkung der Schleswig-Holsteiner dünnschaligen und gestreiften Tiere bei $20^{\circ} \mathrm{C}$ im allgemeinen jener der Helgoländer Miesmuscheln ähnlich war. Unter den an Abb. 26 angeführten Verhältnissen betrug sie bei Tieren von $5 \mathrm{~g}$ Weichteilgewicht etwa 3 Stunden, bei Tieren von der halben Größe etwa $3^{1 / 2}-4$ Stunden. In dieser Hinsicht sah ich nur an von zwei Stellen stammenden Tieren Abweichungen u. zw. bei den 
Muscheln aus dem Inneren der „Hackfeld“-Tonne und bei den giftigen Tieren von der Süder-Piep-Tonne. Mit den Tieren der "Hackfeld"-Tonne stellte ich in zwei Gruppen Versuche an und zwar einzeln mit den außerhalb anhaftenden Tieren von $2,3 \mathrm{~g}$ Weichteilgewicht und 9,7 bis $9,8 \mathrm{~g}$ vollem Gewicht, ferner mit den im Inneren der Tonne

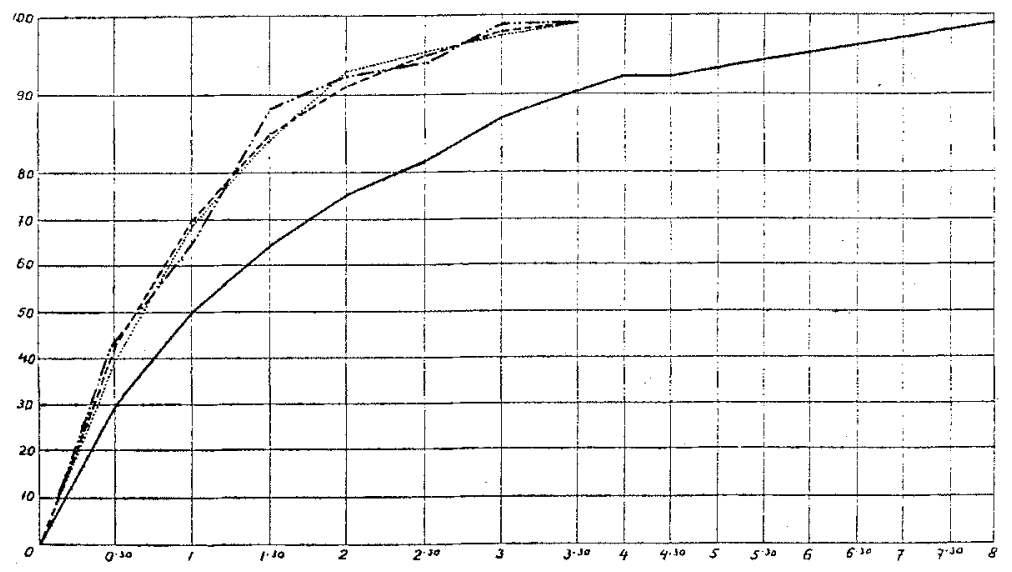

Abb. 37. Vergleich derWasserreinigungswirkung von giftigen Muscheln von der Süder-Piep-Tonne mit einem Weichteilgewicht von $2,2 \mathrm{~g}$ und von verschiedenen Orten stammenden nicht giftigen Muscheln mit gleichem Gewicht in mit Bolus alba gemischtem Meerwasser (Salzgeh. $32,1^{\circ} / 00$ ), bei $20^{\circ} \mathrm{C}$ - Versuche mit giftigen Tieren von der SüderPiep-Tonne, ...... Tersuche mit Tieren aus Helgoland. -......... Versuche mit Tieren aus Wyk, Versuche mit Tieren ron der Eidertonne. sitzenden Muscheln von 2,3 g Weichteilgewicht und 9,3 bis $10,2 \mathrm{~g}$ vollem Gewicht. Mit Helgoländer Tieren von ähnlichem Weichteilgewicht wurden Kontrollversuche ausgeführt. Abb. 36 stellt die Versuche dar, u. zw. sind die Untersuchungen mit den Helgoländer Tieren durch eine fortlaufende Linie, jene mit den Tieren der Außenfläche der Tonne durch eine gestrichelte Linie und die mit den Muscheln vom Inneren den Tonne durch eine punktierte Linie bezeichnet. Auf Grund der Kurven gelangt man zur Feststellung, daß in den Kontrollversuchen mit den Helgoländer Muscheln die vollständige Reinigung des Wassers in $3^{1 / 2}$ Stunden vor sich ging und die Wasserreinigungswirkung der außen anhaftenden Tiere kaum etwas hinter jener der Helgo-
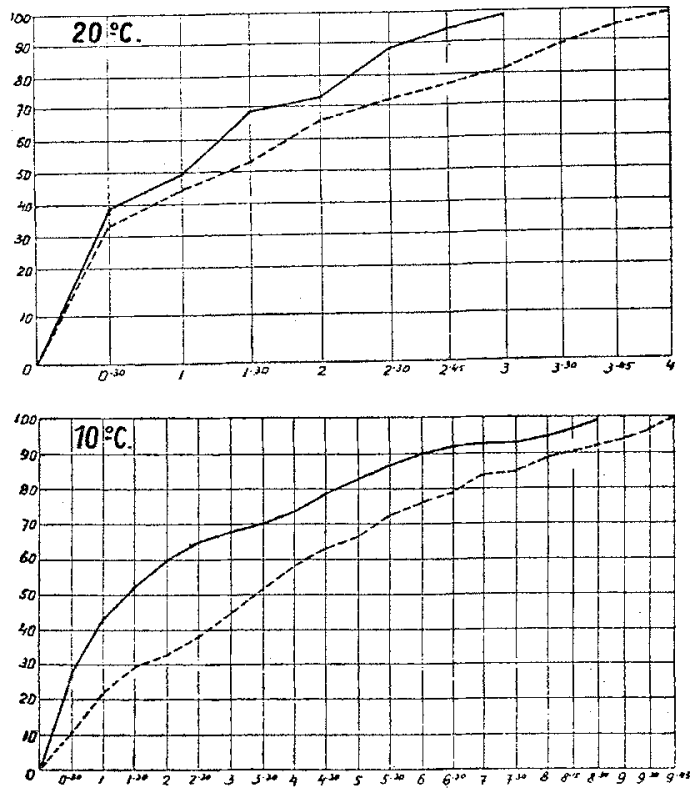

Abb. 38. Wasserreinigungswirkung von Miesmuscheln aus Wyk auf Föhr mit einem Weichteildurchschnittsgewicht von $2 \mathrm{~g}$ in mit chinesischer Tusche gemischtem Meerwasser (Salzgeh. 32,1\%o), bei verschiedenen Temperaturen, bei ständiger Durchströmung mit Luft und ohne Luftdurchströmung. —_ Versuche mit ständiger Luftdurchströmung, ......: Versuche ohne Luftdurchströmung. Die obere Figur zeigt Versuchsergebnisse bei $20^{\circ} \mathrm{C}$, die untere bei $10^{\circ} \mathrm{C}$. länder Tiere zurückblieb. Dagegen erwies sich die Wasserreinigungswirkung der innerhalb sitzenden Muscheln als bedeutend langsamer und zeigte eine Differenz von 2 Stunden gegenüber den Helgoländer und anderthalb Stunden gegenüber den sich an der Außenfläche der Tonne befindlichen Tieren. Der Umstand, daß die Tiere von der unmittelbaren Wasserströmung abgeschlossen an einer Stelle zusammengedrängt lebten, übte auf eine wichtige Lebenserscheinung der Muscheln einen weitgehenden EinfluB aus. So zeigen die an der "Hackfeld "-Tonne lebenden Muscheln mit Gewibheit, daß sogar die Lebensfunktionen von Tieren desselben Fundorts abweichen können, wenn die biologischen Verhältnisse verschiedenartig sind.

Aehnlich den Tieren der "Hackfeld“Tonne habe ich auch mit den Giftmuscheln von der Süder-Piep-Tonne Versuche angestellt, welche an Abb. 37 dargestellt sind. Die fortlaufende Linie deutet die Versuche mit 8,2 bis $9,2 \mathrm{~g}$ schweren Tieren von $2,2 \mathrm{~g}$ Weichteilgewicht bei $20^{\circ} \mathrm{C}$ an. Die verschiedenen gestrichelten Linien bezeichnen die Versuche mit den Tieren von Helgoland (volles Gewicht 9,2 bis $10,4 \mathrm{~g}$ ), Wyk (volles Gewicht 8,8 bis $9,8 \mathrm{~g}$ ) und der Eider Tonne (volles Gewicht 8,4 bis $9,2 \mathrm{~g}$ ), alle mit einem Weichteilgewicht von etwa 2,2 g. Die Auswahl der Tiere erfolgte auch hier nach zahlreichen vorangehenden Messungen und zwei aufeinanderfolgenden Vorversuchen. Die Kurven zeigen, daß die giftigen Tiere zur 
Reinigung des Wassers mehr als die doppelte Zeit brauchen, während die Wasserreinigungswirkung der Helgoländer und der von den beiden anderen Fundorten stammenden Tiere übereinstimmend $3 \frac{1}{2}$ Stunden ausmacht. Das bedeutet, daß die Strömungsfunktion dieser Muscheln viel langsamer ist als die der anderen und bei $20^{\circ} \mathrm{C}$ einen derart niedrigen Wert zeigt, daß ich einen solchen bei den Miesmuscheln von ähnlichem Gewicht von keinem einzigen anderen Fundort bekam.

Wie angeführt, konnten in Bezug auf die Geschwindigkeit der Wasserreinigungswirkung der von verschiedenen Schleswig-Holsteiner Tonnen stammenden Tiere bei $20^{\circ} \mathrm{C}$ im - Verhältnis zu den Helgoländer Muscheln im allgemeinen keine wesentlichen Abweichungen verzeichnet werden. Dagegen gelangte ich nach Wiederholung der Versuche bei $10^{\circ} \mathrm{C}$ zum Ergebnis, daß sowohl bei den Tieren von Wyk als bei jenen der Eider- und der "Hackfeld"-Tonne die Lage bei niedrigerer Temperatur eine ganz andere ist, besonders wenn man bei $10^{\circ} \mathrm{C}$ sowohl mit als auch ohne Luftdurchströmung gleichzeitig Versuche unternimmt. Als Beispiel dieser Versuche sind jene mit den Tieren aus Wyk an Abb. 38 veranschaulicht. Die bei ständiger Luftdurchströmung ausgeführten Versuche sind durch fortlaufende Linien, die ohne Luftdurchströmung mittels gestrichelter Linien angedeutet. Es sind die Versuchsergebnisse der Tiere von gestreifter, dünner Schale oder blasser Farbe von durchschnitttlich $2 \mathrm{~g}$ Weichteilgewicht (volles Gewicht 8,2-8,8g) dargestellt. Vor allem fällt uns bei Betrachtung der Kurven auf, daß bei $20^{\circ} \mathrm{C}$ auch die Luftdurchströmung in geringem Grade die Wasserreinigungswirkung beschleunigt, nicht so wie bei den Helgoländer Muscheln, wo bei Gegenwart von reichlichem Sauerstoff die Reinigungsdauer des Wassers fast auf die Hälfte herabsank. Bei $10^{\circ} \mathrm{C}$ kann demgegenüber festgestellt werden, daß die Wasserreinigungswirkung der Muscheln in den Versuchen ohne Luftdurchströmung im Verhältnis zu den Helgoländer Tieren sehr langsam vor sich geht, da das Tier, welches bei $20^{\circ} \mathrm{C}$ das Wasser in 4 Stunden reinigte,
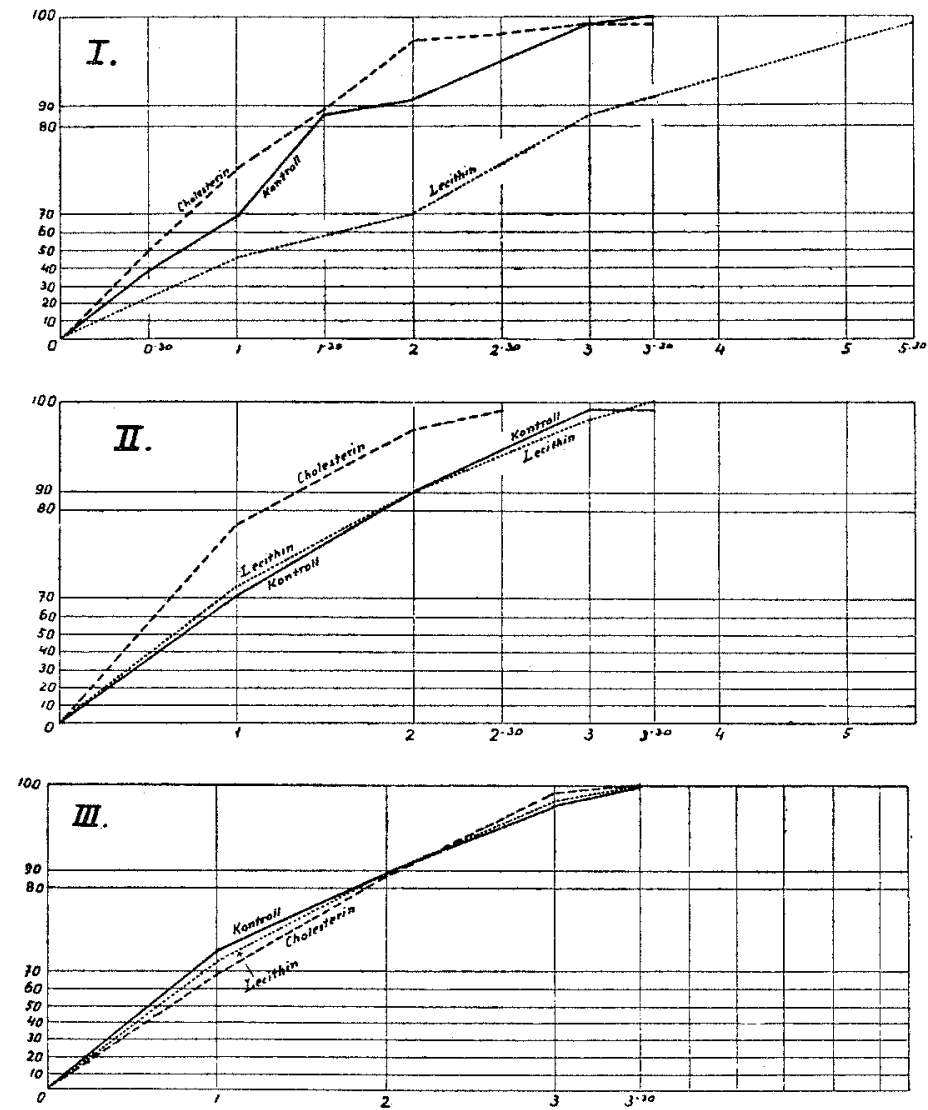

Abb. 39. Wasserreinigungswirkung von Helgoländer Miesmuscheln mit einem Weichteildurchschnittsgewicht von $2,3 \mathrm{~g}$ in einer mit Tusche gemischten Cholesterinbzw. Lecithinsuspension im Meerwasser (Salzgehalt $32,1 \%$ ), bei $20^{\circ} \mathrm{C}$ I. Versuche in Cholesterin- bzw. Lecithinsuspension II. Versuch nach 10 Minuten in mit chinesischer Tusche gemischtem Meerwasser III. Versuch nach 24 Stunden in mit chinesischer Tusche gemischtem Meerwasser: -....... Cholesterin: Versuche mit cholesterinisierten Tieren. ……....... Lecithin : Versuche mit lecithinisierten Tieren.
Kontrolle: Versuche mit Kontrolltieren. diese Wirkung erst in 9 Stunden 45 Minuten, also erst in fast 2,5-mal soviel Zeit zustandebrachte. Den Kurven entsprechend konnte auf die Strömungsfunktion der Muscheln auch das reichliche Vorhandensein von $\mathrm{O}_{2}$ keinen größeren Einfluß ausüben, weil dies trotz der günstigen Strömungsverhältnisse nur in verhältnismäßig geringem Maße die Zeit der Wasserreinigung verkürzte. Die Untersuchungen an den Tieren der Eider- und der „Hackfeld“-Tonne ergaben im Wesentlichen ähnliche Resultate und so habe ich von der Besprechung derselben abgesehen. Diese Untersuchungen zeigen also, daf bei $20^{\circ} \mathrm{C}$ zwischen der Wasserreinigungswirkung der Helgoländer und der mangelhaft entwickelten Küstenmuscheln große Abweichungen nicht zu finden waren, bei $10^{\circ} \mathrm{C}$ die Strömungsfunktion bei letzteren aber bedeutend langsamer 
gewesen ist. Die Wasserreinigungswirkung wurde sogar durch den reichlichen Sauerstoff nur verhältnismäßig wenig gefördert. Schließlich bestand bei einer vom Gesichtspunkte der Wasserströmung günstigen Temperatur in der Wasserreinigungswirkung der gut und schwach entwickelten Tiere scheinbar kein Unterschied, bei einer niedrigeren Temperatur kam es aber zum Vorschein, daß die zuletzt erwähnten Tiere den ungünstigen Verhältnissen sich nicht so anzupassen vermögen, wie die Helgoländer Tiere. Dabei wurde die Geschwindigkeit der Wasserreinigungswirkung bei den mangelhaft entwickelten Muscheln durch den reichlichen Sauerstoff sowohl bei $20^{\circ} \mathrm{C}$ als auch bei $10^{\circ} \mathrm{C}$ nur wenig gefördert. Das heißt, daß die Tätigkeit der die Wasserströmung bewirkenden Flimmerzellen von beschränkter Intensität ist.

Es gelang mir durch eine weitere Versuchsreihe nachzuweisen, daß die Sache sich tatsächlich so verhält. Diese Untersuchungen sollten die Wirkung des Cholesterins auf
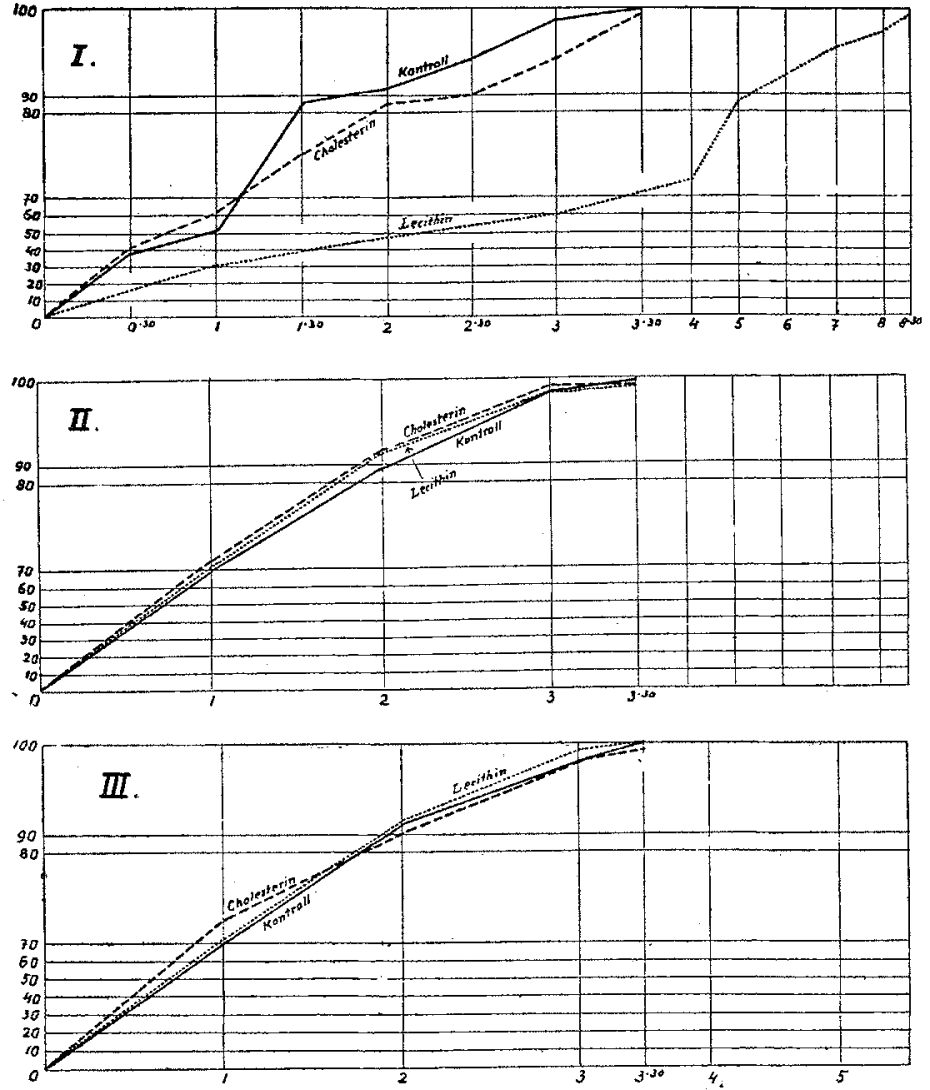

4bb. 40. Wasserreinigungswirkung von Miesmuscheln aus Wyk auf Föhr mit einem Weichteildurchschnittsgewicht von 2,3 $\mathrm{g}$ in einer mit Tusche gemischten Cholesterin- bezw. Lecithinsuspension in Meerwasser (Salzgeh. 32,1\%0), bei $20^{\circ}$ C. I. Versuch in Cholesterin- bezw. in Lecithinsuspension. II. Versuch nach 10 Minuten in mit chinesischer Tusche gemischtem Meerwasser. III. Versuch nach 24 Stunden in mit chinesischer Tusche gemischtem Meerwasser. ...... Cholesterin : Versuche nit cholesterinisierten Tieren, …............ Lecithin: Versuche mit Iecithinisierten Tieren, mit Kontrolltieren. die Zelloxydationsvorgänge und die antagonistische Wirkung dieses Stoffes und des Lecithins im Zusammenhang mit der Funktion der Flimmerzellen der Muscheln erforschen. Doch würde die Erörterung der Einzelheiten dieser Versuche sich über den Rahmen dieser Arbeit erstrecken und so will ich mich mit der Erwähnung jener beiden Versuche begnügen, welche im Hinblick auf die Wasserströmungsverhältnisse der Tiere aus Helgoland und Wyk zu interessanten Vergleichen Veranlassung boten. Die Versuche sind an Abb. 39 und 40 veranschaulicht $u$. $z w$. sind an der ersteren die Versuche mit den Helgoländer, an der zweiten jene mit den Wyker Muscheln von gestreifter, dünner, zerbrechlicher Schale dargestellt. In den Versuchen wurde folgendermaßen vorgegangen: Tiere von 2,3 g Weichteilgewicht wurden in $1 / 2$ Liter $0,01 \%$-ige nach DEGKwITz bereitete Cholesterin-Suspension gesetzt, zu deren Herstellung Seewasser von $32,1 \%$ Salzgehalt verwendet und welchem nachträglich 20 Tropfen chinesische Tusche zugegeben und die Temperatur der Flüssigkeit auf $20^{\circ} \mathrm{C}$ eingestellt wurde. In derselben Weise bereitete ich von dem MERck' schen Lecithin eine $0,01 \%$-ige Suspension und nahm in dieser Flüssigkeit mit 10 anderen Tieren Versuche vor. Schließlich habe ich zu gleicher Zeit mit 10 Tieren ohne Cholesterin und Lecithin Kontrollversuche angestellt. Die Versuche s. Abb. 39, I. In Fällen, wo das Wasser vollständig gereinigt wurde, habe ich die Tiere sofort in ein Aquarium mit reiner Wasserzuleitung umgelegt und nach Verlauf von 10 Minuten eine neue Versuchsreihe eingeleitet (Abb. 39, II), wo die Flüssigkeiten bereits weder Cholesterin noch Lecithin, sondern ausschließlich Tusche enthielten. Nach Reinigung des Wassers brachte ich die Tiere wieder in ein Aquarium mit reinem Wasser und stellte nach 24 Stunden in mit chin. Tusche vermengtem Seewasser (ohne Cholesterin und Lecithin) noch eine dritte Versuchsreihe an (Abb. 39, III). Aus den Daten der Helgoländer Tiere 
auf Abb. 39 geht hervor, daß in den Versuchen mit Cholesterin und in den Kontrollversuchen die Geschwindigkeit der Wasserreinigungswirkung der Muscheln ungefähr die gleiche ist, wogegen dies in den Versuchen mit Lecithin als bedeutend langsamer erscheint. Gegenüber 3 Stunden 30 Minuten der beiden ersten Versuche dauerte es dort 5 Stunden 30 Minuten. In dem nach 10 Minuten wiederholten Versuch zeigten dagegen auffallenderweise jene Tiere, die in Cholesterin-Suspension gewesen sind, eine beschleunigte Wasserreinigungswirkung (2 Stunden 3 Minuten). Die Wasserreinigungswirkung der Tiere des Lecithin-Versuches stimmte indessen mit jener der Kontrollversuche überein. Nach 24 Stunden ergaben die Versuche sämtlicher drei Tiergruppen gleiche Resultate. Wie Abb. 40 zeigt, übertraf dagegen in der Lecithin-haltigen Flüssigkeit das Nachlassen der Wasserreinigungswirkung der Tiere aus Wyk sogar das der Helgoländer Tiere um ein Bedeutendes (8 Stunden 30 Minuten), wogegen in Versuchsreihe II die die Wasserströmung beschleunigende Wirkung des Cholesterins bei den Tieren aus Wyk vollständig ausblieb. Die eingehende biologische Erklärung der Versuche mit Cholesterin und Lecithin geht über den Rahmen dieser Abhandlung, auch sind meine Untersuchungen noch nicht beendet und erfordern weitere Versuche. Es dürfte aber auch so als wahrscheinlich anzunehmen sein, daß sowohl die außergewöhnlich starke, die Tätigkeit der Flimmerzellen behindernde Lecithinwirkung, als auch das Ausbleiben der beschleunigenden Wirkung des Cholesterins eine minderwertige Funktionsbereitschaft der Flimmerzellen voraussetzt, demzufolge die Flimmerzellen der Leeithinwirkung nur in beschränktem Maße entgegenzuarbeiten vermögen, wogegen die Cholesterin-Nachwirkung eben infolge der beschränkten Reaktionsbereitschaft der Zelltätigkeit schon nicht mehr imstande ist, die Arbeitsleistung der Flimmerzellen zu steigern.

An den giftigen Muscheln von der Süder-Piep-Tonne konnten die vorausgehend erwähnten Versuche ebenso wenig ausgeführt werden wie die bei niedrigerer Temperatur mit Luftdurchströmung vorgenommenen Untersuchungen, weil ich eben $\mathrm{zu}$ den verschiedenen Versuchen so viele Tiere verwendete, daß zu diesen nur noch-sehr wenig zur Verfügung standen und diese Muscheln schon bei $10^{\circ} \mathrm{C}$ eine derartig langsame und außerordentlich abweichende Resultate zeigende Wasserreinigungswirkung aufwiesen, weshalb keinerlei bestimmte Feststellungen gemacht werden konnten. Als Beispiel möchte ich nur anführen, daß bei $10^{\circ} \mathrm{C}$ ohne Luftdurchströmung unter 6 Muscheln von etwa $2,2 \mathrm{~g}$ Weichteilgewicht bei 4 Tieren die Reinigung des Wassers sogar nach 36 Stunden kaum die natürliche Sedimentierung übertraf. Auch bei den beiden übrigen Tieren wurden während dieser Zeit nicht einmal $60 \%$ der Wirkung erreicht. Die Erscheinung kann mit der bei den Muscheln sich schon bei $20^{\circ} \mathrm{C}$ zeigenden außerordentlich langsamen Strömungstätigkeit in Zusammenhang gebracht werden.

\section{Versuche zum Hervorrufen des Giftigwerdens der Muscheln.}

Nach diesen Versuchen mit den von den Tonnen längs der Küsten von SchleswigHolstein stammenden, mangelhaft entwickelten, dünnschaligen Tieren gelangt man zur Feststellung, daß bei diesen nicht nur der Schalenaufbau von den gut entwickelten Tieren von starker, dunkler Schale abwich, sondern es bestanden auch hinsichtlich der Strömungsfunktion bedeutende Differenzen. Diese Abweichungen waren wohl bei dem überwiegenden Teil der Tiere nur von geringerem Ausmaß und traten hauptsächlich bei gesteigerter Beanspruchung der die Strömungsfunktion aufrechterhaltenden Flimmerzellen auf. Bei Tieren aus dem Innern der "Hackfeld"-Tonne und noch mehr bei den giftigen Tieren von der Süder-Piep-Tonne handelt es sich jedoch um so hochgradige Abweichungen, daß dieselben sogar bei günstigen Temperatur- und Salzgehaltsverhältnissen schon das wesentliche Nachlassen der Strömungsfunktion verursachten. Wie in Bezug auf die Formabweichung zwischen den normalen Helgoländer Muscheln und den giftigen Tieren von der Süder-Piep-Tonne eine nur durch mehrfache Uebergänge überbrückte, stufenweise ansteigende Differenz bestand, konnten auch die Strömungen in der zur Nahrungsaufnahme und zum Gasstoffwechsel der Muscheln dienenden Strömungsfunktion auf die progressiv erfolgte Aenderung einzelner physiologischen Lebensfunktionen der normalen Nordseemuscheln zurückgeführt werden. Auf Grund des Gesagten ergibt sich die Frage, in welcher Beziehung die mangelhafte Entwicklung und die Aenderung in den Verhältnissen der Strömungsfunktion zur Entstehung der Giftwirkung stehen kann. Ich war bemüht, die Frage auf dem Versuchswege zu klären. Den Ausgangspunkt bildete meine in Neapel gemachte Feststellung, daß die Entstehung der Giftwirkung einerseits durch die schlechten Oxydationsverhältnisse, 
andererseits durch die mangelhafte Einährung begünstigt wird. Da sowohl die Sauerstoffaufnahme als auch die Emährung unter Einfluß der Strömungsfunktion steht, liegt es auf der Hand, daß die sich auf die Strömungsfunktion ungünstig auswirkenden Faktoren beide erwähnten Lebensfunktionen nachteilig beeinflussen und somit zugleich die Entstehung der Giftwirkung fördern. Wie erwähnt, wird die Verlangsamung der Strömungstätigkeit durch die niedrige Temperatur, den geringen Salzgehalt des Wassers und durch den Mangel an Sauerstoff hervorgerufen. Die nachteilige Wirkung des geringen Salzgehaltes bei niedriger Temperatur vermag auch das reichliche Vorhandensein ron Sauerstoff nicht auszugleichen. Die ersten Versuche führte ich in der Weise aus, daf ich je 5 gut entwickeite, dunkelschalige Helgoländer Tiere von etwa 2,5 $\mathrm{g}$ Weichteilgewicht bei 6 " $\mathrm{C}$ in Seewasser von $12^{\prime \prime}$ Salzgehalt hielt, welches vorher sterilisiert worden war, wodurch der Sauerstoff aus dem Wasser vertrieben wurde. Dann setzte ich dem Wasser eine Bakterienemulsion zu. In dieser Versuchsflüssigkeit ging der größte Teil der Tiere in 6-8 Stunden ein und die zurückgebliebenen haben die dem Wasser zugesetzte Tusche nicht aufgenommen, d. h. die Tiere haben sich nicht eruährt und sie zeigten keine Giftwirkung. Um die Tiere weiter am Leben zu erhalten, unterließ ich die rorherige Sterilisierung des Wassers und habe dann, nachdem auch das nicht zum Ziel führte, jeden zweiten Tag die Versuchsflüssigkeit mit Luft durchströmt. Ueberdies habe ich, um die übermäßige Vermehrung der Bakterien zu verhindern, die aus Bakterium coli communis aus Paracoli-Stamm und aus dem Micrococcus catarhalis zusammengesetzte und mit Algendetritus vermengte Emulsion bei $62^{\circ} \mathrm{C}$ getötet. In dieser Versuchsflüssigkeit blieben die Tiere volle 2 Monate am Leben, aber sie zeigten keine Giftwirkung, obwohl in den Kontrollversuchen die Tiere die dem Wasser zugesetzte Tusche aufnahmen und so auch die Bakterienemulsion in den Darmkanal gelangt sein mufte. Weiterhin suchte ich die Beobachtungen bei Senkung des Salzgehaltes und niedrigerer Temperatur fortzuführen, diesen wurden aber bald Schranken gesetzt, da die Tiere bei Salzgehaltserniedrigung über eine gewisse Grenze hinaus eingingen oder zumindest keine Nahrung aufnahmen, meistens geschlossen da lagen und ihre Strömungsfunktion einsteilten. Diese Lntersuchungen haben gezeigt, dafs der Wechsel der hydrologischen Faktoren und der Ernährungsverhältnisse bis zu einer gewissen Grenze bei normalen, gut entwickelten Tieren die Giftwirkung nicht auslösen und daß das Tier sich den nachteiligen Terhältnissen einigermaßen anpassen kann. Sind dagegen die Lebensumstände der Muschel zu ungünstig, so geht das Tier ein oder es ernährt sich zum mindesten nicht und die Giftwirkung kamn wieder nicht zustandekommen. Die Untersuchungen an den längs der Schleswig-Holsteiner Küsten aufgef undenen, mangelhaft entwickelten Tieren zeigten aber, daB bei diesen schon eine geringfügige Senkung der Wassertemperatur eine bedeutende Verlangsamung der Strömungsfunktion zur Folge hat, außerdem ist bei diesen Tieren auch die Funktion der Flimmerzellen unvollkommener als bei den gut entwickelten, dunklen Tieren. Es darf daher mit Recht angenommen werden, daß bei diesen Tieren schon eine geringfügige, die Lebensfunktionen der Muscheln nicht ummittelbar bedrohende Aenderung in den hỵdrologischen Faktoren Störungen herrorrufen kann, die zur Entfaltung der Giftwirkung genügen. Lit Rücksicht darauf habe ich mit den von der Eider-Tonne am 23. Dezember gesammelten Nuscheln von dïnner, zerbrechlicher, gestreifter Schale, ferner mit den ron Wyk-Tonne 6 stammenden, am 3. Januar gesammelten Tieren von dünner, zerbrechlicher, gestreifter oder sehr blasser, kaum gestreifter Schale Versuche vorgenommen. Es wurcle eine Versuchsreihe angestellt, in welcher die Versuche bei $8^{\circ} \%, 12^{\circ} / 0,16^{\prime \prime} / 0$, $18^{\prime \prime} \%$, Salzgehalt und bei $4^{\prime \prime} \mathrm{C}, 6^{\prime \prime} \mathrm{C}, 10^{\circ} \mathrm{C}, 15^{\circ} \mathrm{C}$ Wassertemperatur in sterilisiertem, bzw. unverändert gelassenem, jedoch mit Luft nicht durchströmten, bezw. zweitägig 5 Minuten lang durchströmten Seewasser aufeinander folgten. In einer weiteren Versuchsreihe wurde den Tieren keine besondere Nahrung gegeben, in einer anderen dem Wasser täglich eine Emulsion ron lebenden Bakterien zugegeben, in einer weiteren eine Emulsion von bei $62^{\circ} \mathrm{C}$ getöteten Bakterien und schlieblich in einer letzten eine mit Algentritus vermengten Bakterienemulsion. Die Versuche zeigten vor allem, daß die mangelhaft entwickelten Tiere viel rascher eingehen als die dunkelschaligen, gut entwickelten Helgoländer Muscheln. Bei $4^{\circ} \mathrm{C}$ und bei einem Salzgehalt von $8 \%$, in nicht von Luft durchströmtem Wasser, oder in reichlich Bakterien enthaltendem Wasser konnten die Muscheln über 2-3 Wochen hinaus nicht am Leben erhalten werden und sie nahmen keine Nahrung zu sich. Die Nahrungsaufnahme unterblieb auch dann, wenn im Wasser Algendetritus nicht vorhanden war. Bei der Untersuchnng von 3 Tieren - zu Kontrollzwecken - die 4 Tage hindurch dem Seewasser täglich zugegebene chinesische Tusche und Emulsion von lebenden oder getöteten Bakterien bekamen, stellte sich heraus, daß in keinem der Tiere Tusche in den Verdauungsorganen aufzufinden war. Wo die Tiere am Leben geblieben waren, stellte ich aus diesen nach THESEN Extrakte 
her und prüfte sie nachträglich auf Giftwirkung. Diese Untersuchungen ergaben, daf bei $10^{\circ} \mathrm{C}$ und höherer Temperatur die Muscheln, bei einem Salzgehalt von $20 \%$ des ständig mit Luft durchströmten Seewassers und, falls dem Wasser Algendetritus und Bakterienemulsion nicht beigemengt wurden, nicht giftig wurden, auch nicht, wenn das Wasser nur Algendetritus enthielt. $5 \mathrm{ccm}$ des aus 5 Tieren gemeinsam hergestellten Extraktes, der Maus intraperitoneal injiziert, löste die Giftwirkung nicht aus. Wenn aber das Seewasser von $6^{0}$ Temperatur und $12 \%$ Salzgehalt alle zwei Tage mit Luft durchströmt wurde und dabei Bakterienemulsion und Algendetritus enthielt, sind die Muscheln im Laufe von 6 Wochen giftig geworden und der gemeinsam aus 5 Tieren der Eider-Tonne bereitete Extrakt tötete in einer Dosis von $0,04 \mathrm{ccm}$ im Laufe von 10 Minuten unter typischen Vergiftungserscheinungen die etwa $20 \mathrm{~g}$ schwere Maus. In einer anderen Versuchsreihe, wo von 5 Tieren aus Wyk Extrakte einzeln hergestellt wurden, stellte sich die Giftdosis bei 2 Tieren auf $0,06 \mathrm{ccm}$, bei einem Tier auf $0,04 \mathrm{ccm}$ und bei weiteren 2 Tieren auf $0,02 \mathrm{ccm}$, dieselbe blieb daher nur wenig hinter der Giftdosis der von der Süder-Piep-Tonne stammenden Tiere zurück. In dem gleichen, jedoch nur 3 Wochen lang anhaltendem Versuch entstand keine Giftwirkung. Die Möglichkeit, daß die Tiere aus Wyk und von der Eider-Tonne von vornherein giftig gewesen wären, habe ich im voraus als ausgeschlossen angesehen, da doch nach Tabelle 5 von je 40 solchen Tieren nur bei einem, bzw. nur bei zweien eine Giftwirkung festgestellt werden konnte. Aber auch bei diesen sank die Giftdosis nicht unter $1 \mathrm{ccm}$. In den übrigen, unter anderen Versuchsbedingungen mit ähnlichen Tieren ausgeführten oder kürzer andauernden Versuchen vermochte ich mit dem Muschelextrakt von keiner einzigen, je 5 Tiere zählende Gruppe, eine Giftwirkung hervorzurufen. Es erscheint deshalb ganz ausgeschlossen, daß gerade die Tiere der drei unter denselben Bedingungen ausgeführten Versuche von vornherein giftig gewesen wären und zwar mit einer Giftdosis, wie das ausschließlich bei den Muscheln von der Süder-Piep-Tonne festgestellt worden war. In den angeführten Versuchen konnte daher die Entstehung der Giftwirkung ausschließlich den Versuchsfaktoren zugeschrieben werden. Der Ablauf der von Erfolg begleiteten Versuche war folgender. Je 5 Exemplare der Tiere der Tonne F bei Wyk auf Föhr und von der Eider-Tonne 2, mit 14-16 g, bzw. 16-18 g Gewicht, von dünner, zerbrechlicher, mehr breiter, gestreifter oder blasser, weniger gestreifter Schale wurden in einen $25 \mathrm{~cm}$ hohen Glascylinder von $13,5 \mathrm{~cm}$ Durchmesser mit 2,5 Liter friseh geschöpftem, jedoch unter SEITz-Filter filtriertem Seewasser gelegt, dessen Salzgehalt durch Verdünnung mit dest. Wasser auf $12 \%$ eingestellt wurde. Das mit einem Glasdeckel zugedeckte Gefäß stellte ich in den Kühlschrank, wo die Temperatur des Wassers im allgemeinen, abgesehen von einer Schwankung von $1-2$ Zehntelgraden, $6{ }^{\circ} \mathrm{C}$ zeigte. (An fiinf Tagen erhöhte sich die Temperatur des Wassers infolge eines Regulierungsfehlers zeitweise auf $8^{\circ}$ C.) Den Versuch habe ich am 18. Januar begonnen und nach 6 Wochen unterbrochen. In die Versuchsflüssigkeit ließ ich vom dritten Tag an bis zur letzten Woche mittels einer Luftzuleitungsröhre jeden zweiten Tag (an den Tagen, wo keine Bakterienemulsion zugesetzt wurde) 5 Minuten lang Luft einströmen. Alle zwei Tage gab ich der Versuchsflüissigkeit ein Gemisch von Bakterienemulsion und Algendetritus zu. Die Bakterienemulsion bereitete ich aus dem vom Wasser des Helgoländer Hafens gezüchteten Bakterium coli communis, ferner aus einem in Milchzucker nicht gährenden Paracoli-Stamm und aus einem aus Augensekret gezüchteten Stamm von Micrococcus catarrhalis. Die Bakterien wählte ich unter Berücksichtigung der Untersuchungen von C. R. BAYER und meiner eigenen Beobachtungen, nach welchen die Gram negativ Bakterien zu den am leichtesten verdaulichen Bakterien gehören. Die Bakterienemulsion habe ich aus einer Agar-Agar Kultur hergestellt und ich setzte je 2,5 Liter Versuchsflüssigkeit $40 \mathrm{ccm}$ einer insgesamt 50 Milliarden Keime enthaltenden Emulsion zu (vorerst mit der HeLBER-GLEEN Kammer bestimmt, in den weiteren mit Standard-Lösungen verglichen). Die Bakterienemulsion habe ich 2 Stunden hindurch im Wasserbad von $63^{\prime \prime C}$ abgetötet und derselben $10 \mathrm{~cm}$ einer Algendetritus-Suspension beigemengt. Der Algendetritus wurde durch Verreibung mit Quarzsand und nach Setzung des Quarzsandes in einem kegelförmigen Glasgefäß durch Abgiessen der Flüssigkeit gewonnen. Vor Zusetzung der Bakterienemulsion habe ich von der Versuchsflüssigkeit ebensoviel abgesaugt. Um die ungestörte Wasserreinigungswirkung der Muscheln genauer zu kontrollieren, setzte ich dem Wasser an den Tagen, an denen keine Bakterienemulsion beigemengt wurde, 3 Tropfen chin. Tusche zu und habe die Reinigung des.Wassers kontrolliert. Sämtliche Versuche, wo die Wasserreinigungswirkung zweimal hintereinander aufhörte, wurden unterbrochen. Die Tiere wurden, um sie später eventuell zu verwenden, wieder ins Aquarium mit Wasserzuleitung gelegt. In der letzten Versuchswoche habe ich die Durchströmung von Luft ganz unterlassen. 12 Stunden vor 
Beendigung der Versuche wurden der Versuchsflüssigkeit 20 Tropfen chinesischer Tusche beigemengt und ein Teil des Eingeweidesackes der zur Bereitung von Extrakten verwendeten Tiere für histologische Untersuchungen aufbewahrt. Es stellte sich bei der Untersuchung der Tiere heraus, daß unter 15 giftig gewordenen Muscheln $(10$ von Wyk und $\check{5}$ von der Eider-Tonne) die kreideweiße Verfärbung der Schalen-Innenfläche bei 9 Tieren sehr deutlich, bei 6 Tieren in geringerem Maße zu erkenmen war. Im allgemeinen besaßen die Tiere einen dünnen, grau-weißen Mantel. Der Kristallstiel fehlte bei sämtlichen 15 Tieren. Bei der histologischen Untersuchung konnten die Tuschekörnchen in der Leber und im Darm überall entdeckt werden. Im Lebergewebe waren die bei den giftigen Tieren beschriebenen, als physiologisch anzusehenden, wechselnden Gewebeerscheinungen zu beobachten. Es fiel aber auch hier die verhältnismäßig große Anzahl der die Lipoide und Glykogen nicht enthaltenden vacuolisierten Körnerzellen auf. Reife Eier waren in keinem Tier zu sehen.

Die erfolgreichen Versuche bestätigen also mit Sicherheit, daß fehlerhaft oder schwach entwickelte Tiere, falls sie unter ungünstigen Oxydationsverhältnissen bei niedriger Temperatur und geringem Salzgehalt Nahrung von überwiegend bakteriellem Ursprung erhalten, giftig werden. Nach meinen Untersuchungen in Neapel verdauen die Mluscheln die Bakterien nur dann, wenn die Oxyclationsverhältnisse nicht zu ungünstig sind und wenn ihnen keine andere Nahrung zur Verfügung steht. Bakterien können daher für die Muscheln nicht als günstige Nahrung betrachtet werden und dies scheint auch die Ursache zu sein, weshalb dieselben in kaltem Wasser mit niedrigem Salzgehalt die Bakterien nur mit dem Algendetritus zusammen aufnahmen. Die ungünstige Ernährung ist also eine Voraussetzung für das Giftigwerden der Muscheln, denn wenn die Tiere keine oder nur Algendetritus-Nahrung bekommen, werden sie nicht giftig. Die Ernährung durch Bakterien scheint aber nur eine Form jener Ernährungsverhältnisse zu sein, die zur Entwicklung des Muschelgiftes führen. Hierauf lassen auch die Beobachtungen von amerikanischen Forschern schliessen, daf3 die sich mit Gonyaulax ernährenden Muscheln giftig werden. HAvisia erörtert im Zusammenhang mit der Ernährung der Viesmuscheln, daß die Schwebstoffe des Bodenwassers die Nahrung der Wusche!n bieten und daß es von den örtlichen Verhältnissen abhängt, welche der beiden für die Muscheln von größerer Bedeutung ist. Gewißs stellt sich in dieser Richtung überall der Gleichgewichtszustand her und der Stoffwechsel der Muschel wird sich demselben anpassen. Wenn nun infolge außerordentlicher Vermehrung der Peridineen die Lage sich plötzlich ändert, kann das für die Ernährungsverhältnisse der Muscheln nicht gleichgültig sein und diese Lage kann mit Recht als eine ebenso einseitige Ernährung angesehen werden, als wenn die Muscheln im stark verunreinigtem Wasser überwiegend bakterielle Nahrung erhalten. Die durch Gonyaulax hervorgerufene Giftwirkung ist dementsprechend nur eine Form der Entstehung des Muschelgiftes, wobei nicht ein spezielles Gift von Gonyaulax, sondern die ungünstige Nahrung die Hauptrolle spielt. Ueberdies ist $\mathrm{zu}$ beachten, daß bei rascher Vermehrung der Peridineen auch in den hydrologischen Verhältnissen, im Sauerstoff- und Kohlensäuregehalt des Wassers weitführende Aenderungen eintreten können. Alle diese Faktoren üben auf die Entstehung des Muschelgiftes einen bedeutenden Einfluß aus. Es ist auf Grund meiner Untersuchungen klar, daß unter solchen Umständen die Muscheln giftig werden, wird aber das Muschelgift als spezifisches GonyaulaxGift aufgefalist, so würde es ganz unverständlich sein, wie die Muscheln in unserem Versuch giftig geworden sind. Die Giftwirkung in meinen Versuchen kann ausschließlich damit erklärt werden, daß bei mangelhaft entwickelten von empfindlicherem Stoffwechsel unter ungünstigen Oxydationsverhältnissen im Zusammenhang mit den ungünstigen Lebensumständen und der nachteiligen Ernährung jene Stoffwechselbedingungen entstanden, welche die Entstehung des Muschelgiftes herbeiführten.

Zugleich mit den Miesmuscheln suchte ich auch mit den Austern eine Versuchsreihe anzustellen. Diese zeigte aber im Einklang mit den Versuchen im Seewasser von verschiedener Temperatur und Salzgehalt, daßi die Austern unter ungünstigen Lebensverhältnissen ihre Wasserreinigungswirkung einstellen, ihre Schalen schliefen und falls sie sich einige Tage unter solchen Umständen befanden, bald eingehen. Natürlich können aus der geringen Anzahl von Versuchen weitführende Folgerungen nicht gøzogen werden, doch liegt der Gedanke auf der Hand, daß bei den Austern das Entstehen der Giftwirkung als eine auferordentlich seltene Erscheinung zu betrachten ist, weil die Art Ostrea edulis unter den zur Entwicklung der Giftwirkung erforderlichen ungünstigen Verhältnissen nicht am Leben bleibt und schon eingeht, bevor sich noch eine größere Giftmenge bilden kann. Es ist möglich, daß die große Seltenheit der Austernvergiftungen in Europa auf diesen Umstand zurückzuführen ist. 


\section{E. Beziehungen zwischen dem Giftigwerden der Muscheln und den Verhältnissen des Lebensraumes.}

Auf Grund der Daten der experimentellen Untersuchungen wird die Frage aufgeworfen, warum an den Schleswig-Holsteiner Küsten einzelne, in geringerem Grade giftige Muschelexemplare gefunden werden konnten und weshalb die Muscheln von der SüderPiep-Tonne eine hochgradige Giftwirkung erreichten. Sowohl meine Untersuchungen hinsichtlich der Giftwirkung von Muscheln von verschiedenen Fundorten, als auch meine Versuche mit diesen Tieren zeigten, daß vor allem die in der Entwicklung zurückgebliebenen Tiere giftig werden und wenn wir auch die Feststellung von KobeLT (am Ende des vorigen Jahrhunderts), daß nur die Tiere mit dünner, zerbrechlicher Schale giftig sein können, nicht annehmen, gelangt man dennoch zum Schlusse, daß das Muschelgift sich in erster Linie in Tieren von einem für die Störung empfindlichen Stoffwechsel entwickelt. Es darf folglich eine Erklärung für die giftigen Muscheln der verschiedenen Fundorte nur dann gesucht werden, wenn vorerst entschieden ist, aus welchem Grunde an diesen Orten so viele mangelhaft entwickelte Tiere von zerbrechlicher, dünner, deformierter Schale vorkamen. Auf Grund der Untersuchungen von HagmeIER sind uns die im Wattenmeer herrschenden, wechselnden biologischen Verhältnisse bekannt und es wird aus seinen Beschreibungen klar, daß dieselben für die Entwicklung der Muscheln nicht immer vorteilhaft sind. Wie aber Havinga erörtert ,gibt es Stellen, wo die jungen Tiere sich häufig niederlassen, ohne geeignete Lebensverhältnisse zu finden“. „Der Instinkt der jungen Tiere ist also in dieser Hinsicht nicht unfehlbar." Folglich ist es sehr leicht möglich, daß oft dort Muschelkolonien entstehen, wo die Muscheln einer sehr starken Temperatur- und Salzgehaltschwankung, einer zu starken Wasserbewegung ausgesetzt sind oder wo die Nahrungsverhältnisse sich aus anderen Gründen ungünstig gestalten. Ueberdies können die Tonnen, wie bereits erwähnt, wegen der Anhäufung und Uebereinanderlagerung der Tiere, der relativen Nahrungstoffarmut des Oberflächenwassers auch sonst nicht als vorteilhafte Ansiedlungsorte für die Muscheln angesehen werden. So wird es ohne weiteren Schwierigkeiten erklärlich, daß hier schlechter entwickelte Tiere anzutreffen waren als um Helgoland, wo das Meer nicht zufriert und die. Muscheln sich im allgemeinen unter beständigeren hydrologischen Verhältnissen befinden als am Rande des Wattes. Viel schwieriger ist aber zu erklären, warum die Verhältnisse an Tonne F. bei Süder-Piep ungünsig waren, so daß die Tiere in ihrer Gesamtmenge, viel stärker als an den übrigen Fundorten, Zeichen der mangelhaften Entwicklung aufwiesen. Diese Frage könnte nur dann entschieden werden, wenn die hydrologischen Verhältnisse von Süder-Piep für das ganze Jahr 1938 bekannt sein würden. Doch hat nach der Mitteilung der Staatlichen Forschungsstelle Westküste Husum bei Tonne $F$ eine derartige Aufnahme nicht stattgefunden. Von dort wurden mir freundlicherweise ausführliche, hydrographische Messungen, die bei Süder-Piep am 6. Oktober 1937 vorgenommen wurden, zur Verfügung gestellt. Nach diesen Messungen war der Sinkstoffgehalt sehr schwankend. Er zeigte mit seinem ersten Maximum eine dem Maximum des Ebbstromes, mit seinem zweiten Maximum eine dem Flutstrom folgende Schwankung. Das Maximum des Sinkstoffgehaltes betrug unter der Oberfläche 230 Litermilligramm (lmg) bzw. $192 \mathrm{lmg}$, dessen Minimum betrug hingegen 15 bzw. $31 \mathrm{lmg}$. Dieselben Werte zeigten über dem Grund 800 und $330 \mathrm{lmg}$, hzw. 22 und $65 \mathrm{lmg}$, d. h. über dem Grund war ein wesentlich größerer Sinkstoffgehalt feststellbar. Der Salzgehalt war auch recht schwankend, er wies Werte zwischen $27,1 \%$ und $24,3 \%$ unter der Oberfläche auf, morgens um $9 \mathrm{Uhr}$ einmal sogar bloß 21.4\%. In der Nähe von Tonne F bestimmte außerdem H. SсHACH im Rahmen der bakteriologischen Forschungen der Helgoländer Biologischen Anstalt am 6. Juli 1938 die Keimzahl des Wassers und fand, daß diese an der Oberfläche 7000, in der Tiefe 16000 betrug, d. h. es war verhältnismäßig hoch. Dabei wurde ein Salzgehalt von $28 \%$ beobachtet. Da lie Messungen aber nicht in unmittelbarer Nähe der Tonne F, an der sich die giftigen Muscheln befanden, gemacht worden sind, können sie über die in ihrer unmittelbarsten Nähe herrschenden Verhältnissse doch kein genaues Bild geben. Diese Tonne liegt efwa am Rande der nordwärts dringenden Elbströmung und gleichzeitig im Einfluß einer west-östlich gerichteten Wattströmung, also in einem Gebiet sehr wechselnder hydrographischer Verhältnisse. Es ist möglich, daß diese in der mangelhaften Entwicklung der Muscheln eine gewisse Rolle spielen. Genauere hydro graphische Messungen müßten vorgenommen werden, um diese Frage endgültig zu klärenDie angeführten Momente erklären indessen nur die mangelhafte Entwicklung der Muscheln und nicht ihre Giftwirkung. Nach meinen Untersuchungen ist zu letzterer auch 
die Mitwirkung anderer Faktoren nötig. Welche diese außerordentlichen Ursachen an den Tonnen bei Süder-Piep und an einzelnen Tonnen bei Schleswig-Holstein gewesen sind, ist noch schwieriger zu beurteilen, eben weil uns genaue hydrologische Daten für den Zeitpunkt des Sammelns nicht zur Verfügung stehen. Hier können nämlich nur Daten von Ort und Stelle aus der dem Einsammeln der Tiere unmittelbar vorangehender Zeit verwertet werden, zumal, wie bekannt, die Giftwirkung in 6 Wochen auch in unseren Versuchen zur Entwicklung kam und dazu z. B. in Wilhelmshaven sogar eine kürzere Zeit genügte. An den Muscheln vor der Süder-Piep-Tonne waren jedoch Symptome wahrnehmbar, die allein schon auf eine hydrologische Erscheinung schließen lassen, welche in der Entwicklung der Giftwirkung eine bedeutende Rolle spielte. Die kreideweiße Verfärbung der Sehaleninnenfläche, der mit Nahrungsstoffen angefüllte Magen, das gleichzeitige Fehlen des Kristallstiels und der Glykogenschwund deuten an, daß die Muscheln unter anoxybiotischen Verhältnissen lebten. Wie aber HAGMEIER feststellt: „kann das ständig bewegte und täglich zweimal erneuerte Wasser sich nicht in dem $\mathrm{Maße}$ mit $\mathrm{CO}_{2}$ anreichern und den Sauerstoff verlieren, daß dies für den Organismus schädlich wird" und so ist zur Beurteilung der anoxybiotischen Verhältnisse nur folgende Erklärung möglich. Nach Mitteilung der Forschungsstelle Westküste, Husum; setzte nach der am 9. Dezember 1938 eingetretenen starken Abkühlung und Sturm am 15.-16. das Einfrieren des Wattwassers ein, am 17. fror auch die Umgebung von Tonne $\mathrm{F} z u$, die Tiere bei Süder-Piep gerieten folglich ins Eiswasser. Der Frost tötet in der freien Natur die Miesmuscheln nicht unbedingt. HAGMEIER fand im Jahre 1922 die in die Eisscholle eingefrorenen und gegen Helgoland (Düne) getriebenen Tiere zum Teil noch am Leben. Dagegen ist nach den Untersuchungen von Schlieper die Abgabe von $\mathrm{CO}_{2}$ und daher die Atmung umso schwieriger, je niedriger der Salzgehalt und die Temperatur des Wassers ist. Die an den Muscheln beobachteten Zeichen der Anoxybiose können nur mit der Abkühlung und dem Zufrieren des Wassers in Zusammenhang gebracht werden. Die bei den Muscheln eingetretene Abnahme der Vitalität zeigt sich also auch an der geringeren Tätigkeit der Flimmerzellen und an dem raschen Eingehen der Tiere unter ungünstigen Versuchsbedingungen. Daß dabei im Magen der Muscheln von der Süder-Piep-Tonne Nahrungsstoffe auffindbar waren, obwohl in meinen Versuchen die Tiere unter $6^{\circ} \mathrm{C}$ keine Nahrung zu sich nahmen, spricht nicht gegen obige Feststellung, da es, wie Havinga berichtet, im Winter "schwierig ist, die Muscheln im Laboratorium zur Nahrungsaufnahme zu bringen. In der Natur findet man aber auch im Winter, daß ein leerer Magen sehr bald wieder gefüllt ist, wenn die Temperatur des Wassers nur etwas über $0^{\circ} \mathrm{C}$ ist." Es scheint eben, daß die bei niedriger Temperatur ohne Kristallstiel, unter anoxybiotischen Verhältnissen vor sich gehende Ernährung bei der Entstehung des Muschelgiftes eine Rolle spielt. Laut BERKELEY soll der Kristallstiel eben unter anoxybiotischen Verhältnissen verschwinden und zugleich spaltet das Tier sein Glykogen. Unter Versuchsverhältnissen im Laboratorium nimmt das Tier in dieser Zeit Nahrung kaum oder äberhaupt nicht auf. Die Süder-Pieper Tiere bestätigen mit Gewißheit die Richtigkeit der Beobachtungen von Havinga, d. h., daß die Lage in der freien Natur eine andere ist als im Versuch und, daß das Tier auch bei etwa $0^{\circ} \mathrm{C}$ Nahrung aufnimmt. Diese unregelmäßige Ernährungsweise mag die unmittelbare Ursache der Auslösung der Giftwirkung gewesen sein und zwar entstand die Giftigkeit vor allem bei sämtlichen Tieren an der Süder-Piep-Tonne, weniger bei den Tieren von anderen irgendwie ungünstig liegenden oder unter Eis gératenen Tonnen. Die anoxybiotische Ernährung stellt daher neben der einseitigen bakteriellen oder einseitig aus Peridineen bestehenden Nahrung eine dritte nachteilige Ernährungsweise dar, bei welcher das Muschelgift entsteht. Offenbar ist der zur Entwicklung des Giftes führende ordnungswidrige Stoffwechsel weder an die Bakterien noch an die Peridineen gebunden, sondern derselbe hängt mit irgend einem unregelmäßigen Vorgang in der Nahrungsverarbeitung zusammen. Worin das besteht, wird nur dann zu erfahren sein, wenn die Verdauungsvorgänge der Muscheln in allen Einzelheiten geklärt sein werden. Es ist nicht ausgeschlossen, daß bei den ungünstigen Ernährungsverhältnissen anoxybiotischen Charakters die unvollkommen entwickelten Tiere von minderwertigem Stoffwechsel Histamin abgeben und das Muschelgift diesem oder einem ähnlichen Stoff entspricht. Schon im Anschluß an die RICHET'schen Versuche habe ich auf den interessanten Zusammenhang hingewiesen, welcher zwischen der durch MuscheleiweiB ausgelösten anaphylaktischen Reaktion und der durch das Gift hervorgerufenen Ueberempfindlichkeit besteht. Ich habe angedeutet, daß einzelne Forscher bei Entwicklung des anaphylaktischen Erscheinungen dem Histamin eine entscheidende Rolle zuschreiben. Histamin ist im Salzsäure-Extrakt eines jeden Organes vorhanden. Die Herstellung des Muschelgift-Extraktes erfolgt in saurem Medium in Gegen- 
wart von Salzsäure und es ist sehr leicht möglich, daß die Verfahren von WolfF, Salkowsky, BRIEGER, THESEN schlieBlich den Histamingehalt nachweisen. Das Histamin ist in normalen Geweben oder zumindest in gewissen Zellen vorhanden, der Salzsäure-Extrakt des Muschelkörpers wird daher unter allen Umständen Histamin aufweisen und dieser Stoff bleibt auch nach Behandlung mit Alkohol in Lösung. Stellt daher das Muschelgift Histamin oder damit verwandte chemische Verbindungen dar, dann besteht der Unterschied zwischen den giftigen und ungiftigen Tieren nur in der Quantität und Form des Histamins. Die zur Herstellung des Muschelgiftes dienenden Verfahren weisen demnach nur quantitative Differenzen auf, wodurch verständlich wird, daß von diesem Gesichtspunkt aus von den ungiftigen Tieren biș zu den giftigen alle Uebergänge angetroffen werden. Man kann sich schließlich nicht wundern, daß, falls aus den Tieren Extrakte einzeln hergestellt werden, je nach Entwicklungs- und Ernährungsgrad der Muschel im Giftgehalt der Extrakte Abreichungen bestehen.

Diese Tatsachen bedeuten vorderhand natürlich nur theoretische Möglichkeiten, welche vor allem ausführliche chemische Untersuchungen erfordern. Auf Grund der in dieser Arbeit angeführten kann aber soviel dennoch festgestellt werden, daß das Muschelgift ein Produkt des pathologischen Stoffwechsels der unter ungünstigen Oxydationsbedingungen stehenden und sich ungünstig ernährenden Muschel ist. Der Stoffwechsel der Muscheln ist im allgemeinen recht träge und es bedarf keiner weiteren Erklärung, daf ein extremer Wechsel der hydrologischen Faktoren (z. B. das massenhafte Auftreten von Gonyaulax) mitspielen muß, damit der erforderliche pathologische Grad im Stoffwechsel der normal entwickelten Muschel zur Bildung oder Anhäufung des Giftes erreicht wird. Nach meinen Versuchen sind jedoch auch die Verhältnisse der Wasserreinigungswirkung, so auch die Atmung und die Nahrungsaufnahme der mangelhaft entwickelten Tiere von einem niedrigeren Wert als bei den normalen Tieren. So kann bei jenen schon ein weniger bedeutender Wechsel in den hydrologischen Faktoren ausreichen, um den Stolfwechsel pathologisch zu gestalten und das Gift somit in den Geweben der Muschel anzuhäufen. Ist diese Erklärung richtig, so erscheint es klar, weshalb am Mittelmeer die Muschelvergiftung so außerordentlich selten ist und warum sie verhältnismäßig öfter in den Buchten der Nordsee vorkommt. Während nämlich am Mittelmeer der hohe Salzgehalt und die weniger schwankende Wassertemperatur, die im allgemeinen beständigen hydrologischen Faktoren das Gedeihen der Muscheln sichern, sind an der Nord- und Ostsee die hydrologischen Verhältnisse für die Entwicklung der Muscheln nicht immer und nicht überall günstig. Da, wie beschrieben, jedoch gut entwickelte Tiere nur unter ganz auBerordentlichen Verhältnissen giftig werden, können dagegen bei den in der Entwicklung zurückgebliebenen Muscheln in ihrem nicht vollwertigen Stoffwechsel auch geringfügige Ernährungs- oder Atmungsstörungen zur Entwicklung oder Anhäufung des Giftes führen. Daher entstehen in den normal entwickelten Tieren in den verumreinigten Buchten des Mittelländischen Meeres höchstens Vergiftungen mit dem menschlichen Organismus unzureichenden Giftspuren (z. B. in den Muscheln der Bucht von Mergellina). Doch können an der Nord- und Ostsee, als Folge der ungünstigen hydrologischen Verhältnisse oder im Falle der Verunreinigung des Wassers die mangelhaft entwickelten Muscheln sehr giftig werden. Theoretisch betrachtet erscheint daher die Entstehung des Muschelgiftes in keinem der Meere und in keinem einzigen normal entwickelten Tier als ausgeschlossen, aber es kann in Meeren wie z. B. im Mittelmeer nur unter ganz auferordentlichen hydrologischen Verhältnissen zustandekommen. Dagegen köunen die Muscheln in jenen Meeresgebieten, wo die Lebensbedingungen für sie ungünstiger sind (an einzelnen Teilen der Nord- und Ostsee) schon infolge von geringfügigen hydrologischen Aenderungen in hohem Grade giftig werden. Daß die Muschelvergiftungen trotzdem auch an der Nord- und Ostsee verhältnismäßig sehr selten sind, wird gewiß darauf zurückzuführen sein, daß dort die schlecht entwickelten kleinen Muscheln von niemanden gegessen werden, umso weniger, da, wie bereits erwähnt, viele Fischer die den Tonnen anhaftenden Miesmuscheh mit dünner Schale schon von vornherein für giftig halten. Doch mit Rücksicht darauf, daß der hohe Vitamin- und Glykogengehalt der Muscheln eine bisher noch nicht in vollem Maße ausgenützte Lebensmittelquelle von stets zunehmender Bedeutung darstellt und die, im Gegensatz zu den Austern, weniger anspruchsvolle Miesmuschel auch in der Nordsee verbreitet ist und in Zukunft vielleicht noch mehr heimisch gemacht werden kann, ist die Klärung der Frage, wie häufig die giftigen Muscheln an den verschiedenen Fundorten vorkommen und welche hydrologischen Faktoren das Entstehen der Giftwirkung begünstigen, nicht nur von theoretischem, sondern auch vom praktischen Gesichtspunkt aus von .großer Wichtigkeit. 
Die Klärung der obigen Verhältnisse ist von besonderer praktischer Bedeutung, denn die sich so ergebenden Erfahrungen sind wichtig für die Schaffung von Muschelkulturen. Es kann jedenfalls auf Grund des Gesagten ohne jede besondere Untersuchung festgestellt werden, daf die Tiere dẹ natürlichen Muschelbänke der Nord- und Ostsee nur in jenem Falle dem allgemeinen Verbrauch überlassen werden dürfen, wenn die hydrologischen Verhältnisse dieser Orte unter ständiger Kontrolle stehen und unter den Tieren schlecht entwickelte Exemplare nur in geringer Zahl zu finden sind. Die Erfordernisse, die an natürliche Muschelbänke gestellt werden müssen, sind jedoch in Wirklichkeit kaum durchführbar. Einmal ist die ständige, systematische hydrologische Untersuchung der natürlichen Fundorte mit großen Schwierigkeiten verbunden und die Spesen dieser Kontrolle sind mit der Rentabilität der Muschelbank nicht in Einklang zu bringen. Ferner muß es in Betracht gezogen werden, daß die Muscheln bei ihrem Ansiedeln nicht immer die für ihre Entwicklung günstigen Orte wählen. Sie siedeln sich oftmals an Orten an, wo sie zur Zeit der Ebbe durch längere Zeit trocken liegen oder wo sie größeren Verunreinigungen ausgesetzt sind. Auch häufen sie sich dergestalt übereinander, daß die tiefliegenden Tiere in ihrer Entwickelung stark gehemmt werden. So kommt es, daß unter den Tieren der natürlichen Muschelbänke - besonders in Meeresteilen mit veränderlichen hydrologischen Verhältnissen - schlecht entwickelte Tiere in größerer ZahI vorkommen. Eine sichere Vermeidung der Muschelvergiftungen ist deshalb nur auf dem Wege zu erreichen, den die Biologische Anstalt auf Helgoland und die zuständigen anderen Dienststellen zur Zeit anstreben: das ist die Einrichtung von Betrieben für Muschelkulturen im Wattenmeer. Hierdurch wird es ermöglicht, bei dem Festlegen der Orte für künstliche Muschelbänke, Meeresteile mit optimalen und ständig kontrollierbaren hydrologischen Verhältnissen auszuwählen, und „die Saat-Muscheln in einer solchen Dichte auszustreuen, daß sie sich gut entwickeln und "fett" werden; das liegt schon im Interesse des Muschelzüchters" (HAGMeIER). Bei wohl angelegten Muschelkulturen fehlen also die beiden Hauptbedingungen des Giftigwerdens der Muscheln: die schlechten hydrologischen Verhältnisse und die fehlerhafte Entwickelung der Tiere. HaGMeIER's Feststellung, wonach ,auf den stets unter Wasser liegenden und sorgfältig gepflegten Kulturbänken keine Gefahr vorhanden ist, daß daselbst giftige Muscheln rorkommen", ist deshalb gewiß richtig. Würden zum Verbrauch nur Tiere von künstlich angelegten Muschelbänken gelangen, so wäre die Muschelvergiftung mit voller Sicherheit vermeidbar. Die große Vitaminmenge des Muschelkörpers ist heute eine noch wenig beanspruchte Vitaminquelle, deren Bedeutung für Volksernährungszwecke sehr groß ist. Das Anlegen von Muschelkulturen, - als einzige sichere Waffe zur Vermeidung der Gefahren beim Muschelverbrauch - ist deshalb ein Unternehmen von großem praktischem und wirtschaftlichem Werte.

\section{Zusammenfassung.}

Miesmuscheln, die im Winter 1938 von dem Bewuchs der Seezeichen an der Westküste von Schleswig-Holstein gesammelt wurden, wiesen bedeutende Unterschiede der Form, Farbe, Decke und Innenfläche der Muschelschalen auf. In der Nähe Helgolands waren besonders dunkle Tiere mit dicken Schalen zu finden, an anderen Orten war ein kleinerer oder größerer Teil der Tiere blaß grüngelb oder hellbraun, stark gestreift, mit dünnen, zerbrechlichen, oft deformierten Schalen, an deren Innenfläche manchmal kreideweiße Verfärbungen oder rostbraune Flecke sich zeigten. Tierexperimente konnten nachweisen, daß unter Muscheln mit den letztgenannten Veränderungen, auch falls sie von in offenem Meeresgebiete liegenden Seezeichen stammten, vereinzelte giftige Exemplare zu finden waren. Die Schalenveränderungen zeigten sich besonders einheitlich bei Tieren von der Süder-Piep-Tonne, und diese wirkten auch stark giftig. Die Veränderungen der Muschelschalen konnten teilweise auf eine fehlerhafte Entwicklung der Muscheln, auf ungünstige Lebensvehältnisse, besonders auf ungünstige Oxydationsverhältnisse zurückgeführt werden. Somit ergibt sich der Gedanke eines Zusammenhanges dieser ungiustigen biologischer Faktoren und der Giftwirkung der Muscheln. Zur Klärung dieser Frage konnte die Wasserreinigungswirkung der Muscheln, als Maß der Funktion der Flimmerepithelzellen, die die Wasserströmungen der Muscheln herrorrufen, als wertvolles biologisches Reagens herangezogen werden. So konnte festgestellt werden, daß die Wasserreinigungswirkung der jungen Tiere durch niedrige Temperatur in Gemeinschaft mit niedrigem Salzgehalt verlangsamt 
wird und daher unter diesen Verhältnissen eine sich ungenügend ernährende, fehlerhaft entwickelte Muschelgeneration von unvollkommenem Gasstoffwechsel entsteht, bei welcher als Folge der minderwertigen Lebensfunktionen die zur Entwicklung der Giftwirkung erforderlichen Ernährungs- und Oxydationsstörungen besonders leicht auftreten können. Auf Grund dieser Feststellungen konnte experimentell nachgewiesen werden, daß fehlerhaft oder schwach entwickelte Tiere giftig werden, wenn sie unter ungünstigen Oxydationsverhältnissen bei niedriger Temperatur und geringem Salzgehalt Nahrung von überwiegend bakteriellem Ursprung erhalten. Die bakterielle Ernährung scheint aber nur eine Form jener Ernährungsverhältnisse zu sein, die zur Entwickelung des Muschelgiftes führen, wie dies Beobachtungen von amerikanischen Forsehern zeigen, wonach sich mit Gonyaulax ernährende Muscheln giftig werden. Unsere Feststellungen können somit in dem Satz zusammengefaßt werden, daß das Muschelgift ein Produkt des pathologischen Stoffwechsels der sich unter ungünstigen Oxydationsbedingungen ungünstig ernährenden Muschel ist.

\section{Schrifttum.}

1. ÁBRAHAM, A.: Âllati mérgek és mérges állatok, (Magyar Gyógyszerésztud. Társ. Értesitö, 1933).

2. Atlas für Salzgehalt, Temperatur und Dichte der Nord-Ostsee. (Dtsch. Seewarte, 1927.)

3. BAIER, C. R.: Studien zur Hydrobakteriologie stehender Binnengewässer. (Arch. Hydrobiol. 1936. Bd. 29.)

4. BANDr, I.: Italienische Austernzüchtung und Darmkrankheiten. (Zbl. f. Bakt. I. Abt. 1912. Bd. 61.)

5. BERkEXEY: (Ref.: Bericht. ü. d. ges. Phys. 1924. Bd. 23).

6. - : (Ref.: Bericht. ü. d. ges. Phys. 1934. Bd. 78).

7. Bethe, BergmanN u. a.: Handbuch der normalen und pathologischen Physiologie. 1927. Bd. 3.

8. BRtEGER, L.: Ueber basische Produkte in der Miesmuschel. (Dtsch. Med. Wschr., 1885.)

9. - : Zur Kenntnis des Tetanins und des Mytilotoxins. (Virchows Arch. 1888. T. 112.)

10. - : Beitrag zur Kenntnis der Zusammensetzung des Mytilotoxins nebst eiper Uebersicht der bisher in ihren Haupteigenschaften bekannten Ptomaine, Toxine und Leukomaine. (Virchows Arch. 1889. T. 115.)

11. BoETTGER: Die Standartmodifikationen der mediterranen Miesmuschel, Mytilus galloprovincialis Lam. im Golf von Neapel. 1930. (Zoolog. Anz. 1930. Bd. 91.)

12. BRuce, J. R.: The Respiratory Exchange of the Mussel (Mytilus edulis L.). (Biochm. J. 1926. Bd. 20.)

13. BuchoLZ: Ueber Gesundheitsstörungen nach dem Genuß von Austern und Muscheln und ihre Verhütung. (Mitt. Dtsch. Seefisch.-Ver. 1912. Bd. 28.)

14. DeGkwITZ: Lipoide und Ionen.

15. DodGson: Report on Mussel Purification. (Fishery Invest. Series II. 1928. Vo I. X. No. 1.)

16. DotTerweich, H. und ElsSNER: Die Mobilisierung des Schalenkalkes für die Reaktionsregulation der Muscheln. (Biol. Zbl. 1938. Bd. 45.)

17. Entz, G.: Méreg az állatországban. (Term. Tud. Kö̀l. 1893. Bd. 25.)

18. FAtck, F. A.: lst die Miesmuschel des Kieler Hafens giftig. (Schr. d. Nation. Verein. Schlesw. - Holst. 1883. T. 6.)

19. Faust, E.: Darstellung und Nachweis tierischer Gifte (in Abderhalden's Handb. d. biolog. Arbeitsmeth. Abt. 4. T. 7).

20. Frank, J. P.: System einer vollständigen medicinischen Polizen. (1786-1790.)

21. Gage, St., Gorham, Fr.: (Ref.: Zbl. f. Bakt. 1. Abt. 1926. Bd. 83).

22. Galtsoff, P. S.: The effect of Temperature on the mechanical activity of the gills of the Oyster (Ostrea virginica Gm.). (Journal of General Physiolog. 1928. Bd. 11.)

23. GarÁ YY, V.: Az Adriai tenger betegsége. (A tenger. 1929. Bd. 19.)

24. Geiger, I. C., Ward, W. E., Jacobson, M. A.: (Ref.: Zbl. f. Bakt. 1. Abt. 1926. Bd. 83).

25. Gellhorn : Allgemeine Physiologie der Flimmer- und GeiBelbewegung (in Bethe Bergmann's Handb. d. norm. u. path. Phys. 1925. Bd. 8).

26. HAAS, F.: Lamellibranchiata (in Grimpe und Wagler's Tierwelt der Nord- und Ostsee. Bd. 9).

27. HAAS, F.: Bivalvia (in Bronn's Klassen Ord. Tierreich).

28. HAGMEIER, A.: Züchtung verschiedener wirbelloser Meerestiere (in Abderhalden's Handb. d. biolog. Arbeitsmeth. Abt. 9. T. 5).

29. - : Die Besiedlung des Felsstrandes und der Klippen von Helgoland. Teil I. Der Lebensraum. (Wiss. Meeresunters. N. F. Abt. Helg. 1930. Bd. 15.)

30. - Wissenschaftliche Forschung und praktische Wirtschaft auf den fiskalischen Austernbänken. (Nordelbingen, 1931. Bd. 15.)

30a. - : Die intensive Nutzung des nordfriesischen Wattenmeeres durch Austern- und Muschelkultur (Ztschr. f. Fiseh. u. d. Hilfswiss. 1941. Bd. 39, Nr. 2).

31. Hagmerer, A., und KäNDLER, R.: Neue Untersuchungen im nordfriesischen Wattenmeer und auf den fiskalischen Austernbänken. (Wiss. Meeresunters. N. F. Abt. Helgoland. 1925-1927. Bd. 16.)

32. HaRanghy, L.: Édesvizi kagylóìn és a Lithoglyphus naticoides Fer, mint a szabad vizek öntisztulási képességének tényezöi. (M. Tud.. Akad. Matemat. Természettud. Ért. 1936. Bd. 54.)

33. - : A Mytilus minimus Poli és az Ostrea plicata Chemn. mérgezö hatásának összefüggése a kagylók életviszonyailval. (Magyar Tud. Akad. Matemat. és Természettud. Ert., 1937. Bd. 56.)

34. - : A kagylók jelentösége a táplálkozásban és a kagylóevéssel összefüggö betegségek. (Tenger, 1937. Bd. 28.)

35. - : Experimentelle Beiträge zur Kenntnis der Wasserreinigungs- und Wasserklärungswirkung der Seemuscheln. (Pubbl. Staz. Zool. Napoli. 1938.)

36. - : A kagylómérgezésröll. (Magyar Path. Társ, Munkálatai, 1939.) 
37. HARANGHY, L.: Rapporto tra l'azione tossica dei laemilibranchi e il, pabulum degli stessi, nonché le condi zionidi ossigenazione degli ambienti. (Bollet. di pesca di piscicoltura e di idrobiologia 1940. Bd. 16.)

38. Havinga, B.: Marine Mollusken, Flora en Fauna der Zuiderzee (1922).

39. - - Krebse und Weichtiere (in Lübbert's und Ehrenbaum's Handbuch der Seefischerei Nordeuropas, Bd. 3).

40. - : Austern und Muschelkaltur. (Ibidem, Bd. 7.)

41. HEATH, H.: (Ref.: Zool. Bericht. 1929. Bd. 21).

42. HeNTSCHEI, E.: Grundzïge der Hydrobiologie. 1923.

43. Hock, R.: Ueber Muschelvergiftung. (Tierärtzl. Rdsch. 1930.)

44. HusemanN, Th.: Vergiftung und Bazillenübertragung durch Austern und deren medizinal-polizeiliche Bedeutung. (Wiener Med. Bl. 1897.)

45. JoRdAn, H.: Vergleichende Physiologie wirbelloser Tiere. (Jena.)

46. JordaN, E. O.: (Ref.: Zbl. f. Bakt. l. Abt., 1925, Bd. 80).

47. Kathleen, M., White, B., Sc.: Mytilus. (L. M. B. C. Memoirs on Typical British Marine Plants et Animals., 1937.)

48. KeluhwaY: (Ref.: Bericht. ï. d. ges. Phys. 1936. Bd. 90).

49. Kentzher, Gy.: Elméleti és gyakorlati Serologia. (1913.)

50. KNudsen, M.: Hydrographische Tabellen.

51. KOBELT: Die Wilhelmshavener Giftmuschel. (Jb. Dtsch. malak. Ges. 1886. T. 13.)

52. Koford, Ch. A.: Dinoflagellata of the San Diego Region. IV. The Genus Gonilaulax. (Publ. Zool. Univ. Californ. Bd. 8.)

53. Kolle, K.: Meereskundliche chemische Untersuchngen mit Hilfe des Zeisschen. Pulfrich Photometers. I. Mitteilung. (Annalen d. Hydrogr. und Maritimen Meteorolog. 1931). (II. Mitteilung). (Ibidem 1933.)

54. KÜHNELT: Beziehungen zwischen Kalkstoffwechsel und Atmung bei Mollusken der Meeresküste. (Zoolog. Anzeig. 1938. Bd. 124.)

55. Lindemann, E.: Peridineae (in Engler's: Die Natürlichen Pflanzenfamilien. Bd. 2).

56. - : Massensterben von Fischen inf. einer Hochproduktion von Panzergeißlingen. (KI. Mitt. d. P. Landesanstalt. f. Wasserhyg. Jahrg. 2.)

57. Lindner, G.: Ueber giftige Miesmuscheln. (Zbl. f. Bakt. 1. Abt. 1888. Bd. 3.)

58. - : Ueber giftige Miesmuschel namentlich über den mikroskopischen Befund. ece. (Ber. Ver. Naturk. Cassel. 1889. Bd. 34-35.)

59. Linke, O.: Biologie und Praxis an der ostfriesischen Küste. (Der Biologe, 1938. Bd. 7.)

60. LiNser, H.: Lichtabsorptionsmessungen an natürlichen und Gebrauchwassern. (Bot. Zeitschr. 1931. Bd. 53.)

61. List, T.: Die Mytiliden des Golfes von Neapel. (Fauna Flora Neapel. 1902 Mon. 27.)

62. LoHmeyer, C.: Die Wilhelmshavener Giftmuschel. (Berl. klin. Wochenschr. 1886.)

63. Meyer, H. A., und MöBIUs, K.: Prosobranchia und Lamellibranchia der Kieler Bucht. (Fauna der Kieler Bucht. 1872. Bd. 2.)

64. MgYer, K. F.: (Ref.: Zool. Bericht. 1929. Bd. 21).

65. Meunier, A.. Le Microplancton de la Mer Flamande. (Mussée R. Hist. Nat. de Belgique. 1919. Bd. 8.)

66. MǗlter, H.: (Ref.: Bericht. ü. d. ges. Phys. 1935. Bd. 86).

67. NELson, T. C.: On the Feeding Habits of Oysters. (Proc. Soc. exp. Biol. Med. 1923. Bd. 21.)

68. Oppenheimer, C.: Handbuch der Biochemie des Menschen und der Tiere. (1934. 2. Aufl.)

69. PAwlowsky: Gifttiere und ihre Giftigkeit. (1927.)

70. PERKINS, E. R.; The Story of an Oyster (New Jersy Oyster. Inwest. Laborat.).

71. Peterson, G. G. J. and Boysen-Jensen, P.: Valuation of the Sea animal Life of the Sea Bottom its Food and Quantity. (Rep. Danish. biol. Stat. 1911. Bd. 20.)

72. Preisz, H.: Az infectio es immunitâs tanának elemei. (1936.)

73. Prinzmetal, Sommer, Leale: The pharmacological action of "mussel poison". (Journal. of. Pharm. 1932. Bd. 46.)

74. ReICHARD, A. C.: (Wiss. Meeresunters. Abt. Helgoland. 1910. Bd. 10)

75. Richet, CH.: De l'anaphylaxie en général et de l'anaphylaxie par la mytilocongestine en particulier. (Ann. Pasteur, 1907. Bd. 21.)

76. - : Anaphylaxie par la mytilocongestine. (C. R. Soc. Biol. Paris 1907 T. 62.)

77. SalKowskY, E.: Zur Kenntnis des Giftes der Miesmuschel. (Virchows. Arch. 1885. T. 102.)

78. SAVAGE, R. E.: The Food of the Oyster. (Fish. Invest. Serie. 2., 1925. Bd. 8.)

79. Schiller, D. J.: Dinoflagellatae (in Rabenhorst's Kryptogamen-Flora von Deutschland, Oesterreich und Schweiz. Bd. 10. T. 2).

80. SCHLIEPER, C.: Die biologische Bedeutung der Salzkonzentration der Gewässer. (Naturw. Berlin, 1928. Bd.16.)

81. - : Ueber die Einwirkung niederer Salzkonzentrationen auf marine Organismen. (Z. vergl. Physiol. 1929. Bd. 9.)

82. - : Ueber das Eindringen mariner Tiere in das Süßwasser. (Biolog. Zbl. 1931. Bd. 51.)

83. SchmotMANN, C.: Miesmuschelvergiftungen in Wilhemshaven im Herbst 1887. (Z. f. Medizinalbeamte. 1887.)

84. Schröpfr, E.: Lamellibranchiaten der Nordsee. (Wiss. Meeresunters., 1911. Abt. Kiel. Bd. 12.)

85. SOMmer, H. : (Ref.: Bericht ü. d. ges. Phys. 1933. Bd. 72).

86. Sommer, H., MeYer, K. F., Whedon, W. F., Kofold, C. A. : (Abstracts of Communications Intern. Mikrobiol. Kongr, 2. London 1936. Zit. nach Lindemann).

87. SPÄRCK, R.: On the Food Problem in Relation to marine Zoogeography (Physiological papers. Krogh Festschr.). 88. - : Studies on the Biology of the Oyster. (Rep. Danish. biol. Stat. 1927. Bd. 33.)

89. Stenta, M.: Zur Kenntnis der Strömungen im Mantelraume der Lamellibranchiaten. (Arb. zool. Inst. Wien. 1902. Bd. 14.)

90. STohlnR: Gewichtsverhältnisse bei gewissen marinen Evertebraten. (Zool. Anz. 1930. Bd. 91.)

91. THESEN, J.: Studien über die paralytische Form von Vergiftung durch Muscheln. (Mytilus edulis.) (Arch. f. experim. Pathol. u. Pharmakol. 1902. T. 47.)

92. Thiele, J.: Handbuch der systematischen Weichtierkunde. 1934.

93. Thiele, J. und Reichensperger: Bivalvia (in Kükenthal's Handbuch der Zool.).

94. VIrchow, R.: Ueber die Vergiftung durch Miesmuscheln in Wilhelmshaven. (Berl. klin. Wochenschr. 1885.) 
95. VIrchow, Lohneyer, Schulze und MARTexs: Beitrige zur Kenntnis der giftigen Miesmuscheln. (Virchows Arch. 1886. T. 104.)

96. WALlengrex, H.: Zur Biologie der Muscheln. I. Wasserströmungen; II. Nahrungsanfuahme. (Lumds Unirersitets Arsshift. N. F. Afd. 2." 1905 . Bd. 1.)

97. Whedox, W. F., Kofold, C. A.: Dinoflagellata of the San Franciseo region usw. (Publ. Zool. Cnir. Californ. 19:6. Bd. 41.)

98. Whedos, W. F.: Spawning Habits of the Mussels Mytilus califomianus Conrad. (Publ. Zool. Univ. Cilitorn. 1936. Bd. +1 .)

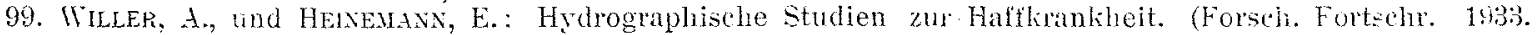
Jahrg. 9.)

100. - - : Sedimentitionsvorgänge in Gewässern. (Phys. okon. Ges. Kionigsbero 1936. Bd. (69.)

101. Wistersten, H.: Handbuch der vergleichenden physiologie.

10:. WolfF, M.: Die Lokalisation des Giftes in den Hiesnuscheln. (Virchows Arch. 188t;. T. 103.)

103. - : Die Ausdehnung des Gebietes der giftigen Miesmuschelu und der sonstigen giftigen Seetiere in Willelmsiaven. (Virchows Arch, 1886 . T. 104.)

104. -- Lebel dis ernente Torkommen del giftigen Niesmuschel in Wilhelmshaven. (Virchous Arh. 185. T. 110.)

105. Foxis: Structure and thysiology of the Organs of Feeding and Digention in Ostrea edulis. (J. Marin. biol. Ass. 1926. Bid, 14.) 